$$
\begin{gathered}
\text { Universidade de São Paulo } \\
\text { Instituto de Física de São Carlos }
\end{gathered}
$$

João Batista Florindo

\title{
Descritores fractais aplicados à análise de texturas
}





\section{João Batista Florindo}

\section{Descritores fractais aplicados à análise de texturas}

Tese apresentada ao Programa de PósGraduação em Física do Instituto de Física de São Carlos da Universidade de São Paulo, para obtenção do título de Doutor em Ciências.

Área de Concentração: Física Aplicada Opção: Física Computacional

Orientador: Prof. Dr. Odemir Martinez Bruno

Versão Corrigida

(versão original disponível na Unidade que aloja o Programa)

São Carlos 
AUTORIZO A REPRODUÇÃO E DIVULGAÇÃO TOTAL OU PARCIAL DESTE TRABALHO, POR QUALQUER MEIO CONVENCIONAL OU ELETRÔNICO, PARA FINS DE ESTUDO E PESQUISA, DESDE QUE CITADA A FONTE. com os dados fornecidos pelo(a) autor(a)

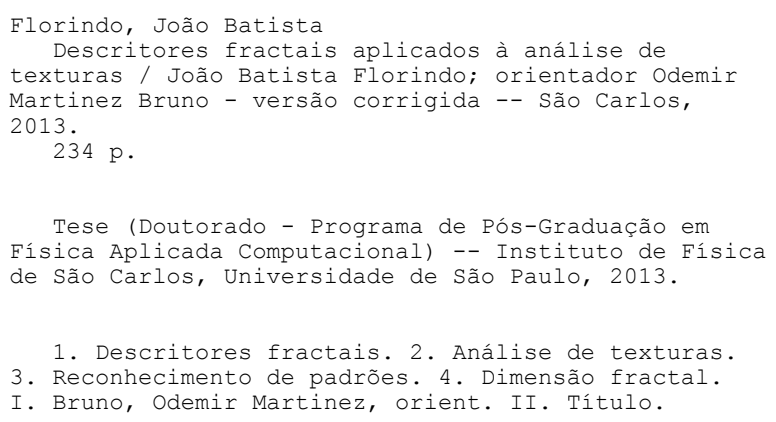






\section{AGRADECIMENTOS}

A Deus, por ter me permitido chegar até aqui.

A minha esposa Rosileide, pelo apoio e compreensão em todos os sentidos, em cada etapa deste doutorado.

A meu filho João Vítor, por ter me ensinado tanto com sua inocência.

A meu pai e minha mãe (in memoriam), por terem me educado com os valores mais importantes.

A meu orientador Odemir, por me ajudar a crescer como pesquisador e profissional.

A meus colegas de grupo, por tantos momentos agradáveis que passamos juntos e pelas dicas que compartilhamos.

A meus amigos de república, pelo companheirismo.

Aos professores e pesquisadores que colaboraram neste projeto.

À Universidade de São Paulo e, em particular, ao Instituto de Física de São Carlos (IFSC), por toda estrutura que permitiu a realização desta pesquisa.

À Biblioteca do IFSC, pela adequação desta tese a seu devido formato.

Ao Conselho Nacional de Desenvolvimento Científico e Tecnológico (CNPq), pelo apoio financeiro. 

Se verdadeiramente vale a pena fazer uma coisa, vale a pena fazê-la a todo o custo.

G. K. Chesterton 



\section{RESUMO}

FLORINDO, J. B. Descritores fractais aplicados à análise de texturas. 2013. 234 p. Tese (Doutorado em Ciências) - Instituto de Física de São Carlos, Universidade de São Paulo, São Carlos, 2013.

Este projeto descreve o desenvolvimento, estudo e aplicação de descritores fractais em análise de texturas. Nos últimos anos, a literatura vem apresentando a geometria fractal como uma ferramenta poderosa para a análise de imagens, com aplicações em variados campos da ciência. A maior parte destes trabalhos faz uso direto da dimensão fractal como um descritor do objeto representado na imagem. Entretanto, em função da complexidade de muitos problemas nesta área, algumas soluções foram propostas para melhorar essa análise, usando não apenas o valor da dimensão fractal, mas um conjunto de medidas que pudessem ser extraídas pela geometria fractal e que descrevessem as texturas com maior riqueza e precisão. Entre essas técnicas, destacam-se a metodologia de multifractais, de dimensão fractal multiescala e, mais recentemente, os descritores fractais. Esta última técnica tem se mostrado eficiente na solução de problemas relacionados à discriminação de imagens de texturas e formas, uma vez que os descritores gerados fornecem uma representação direta do padrão de complexidade (distribuição dos detalhes ao longo das escalas de observação) da imagem. Assim, essa solução permite que se tenha uma descrição rica da imagem estudada pela análise da distribuição espacial e/ou espectral dos pixels e intensidade de cores/tons de cinza, com uma modelagem que pode se aproximar da percepção visual humana para a geração de um método automático e preciso. Ocorre, entretanto, que os trabalhos apresentados até o momento sobre descritores fractais focam em métodos de estimativa de dimensão fractal mais conhecidos como Bouligand-Minkowski e Box-counting. Este projeto visa estudar mais a fundo o conceito, generalizando para outras abordagens de dimensão fractal, bem como explorando diferentes formas de se extraírem os descritores a partir da curva logarítmica associada à dimensão. Os métodos desenvolvidos são aplicados à análise de texturas, em problemas de classificação de bases públicas, cujos resultados podem ser comparados com métodos da literatura, bem como 
à segmentação de imagens de satélite e à identificação automática de amostras obtidas em estudos de nanotecnologia. Os resultados alcançados demonstram o potencial da metodologia desenvolvida para a solução destes problemas, mostrando tratar-se de uma nova fronteira a ser usada e explorada em análise de imagens e visão computacional como um todo.

PAlavras-Chave: Descritores fractais. Análise de texturas. Reconhecimento de padrões. Dimensão fractal. 


\section{ABSTRACT}

FLORINDO, J. B. Fractal descriptors applied to texture analysis. 2013. 234 p. Tese (Doutorado em Ciências) - Instituto de Física de São Carlos, Universidade de São Paulo, São Carlos, 2013.

This project describes the development, study and application of fractal descriptors to texture analysis. Recently, the literature has shown fractal geometry as a powerful tool for image analysis, with applications to several areas of science. Most of these works use fractal dimension as a descriptor of the object depicted in the image. However, due to the complexity of many problems in this context, some solutions have been proposed to improve this analysis. These proposed methods use not only the value of fractal dimension, but a set of measures which could be extracted by fractal geometry to describe the textures with greater richness and accuracy. Among such techniques, we emphasize the multifractal methodology, multiscale fractal dimension and, more recently, fractal descriptors. This latter technique has demonstrated to be efficient in solving problems related to the discrimination of texture and shape images. This is possible as the extracted descriptors provide a direct representation of the complexity (the details distribution along the scales of observation) in the image. Thus, this solution allows for a rich description of the image studied by analyzing the spatial/spectral distribution of pixels and intensity of colors/gray-levels, with a model which can approximate the human visual perception, generating an automatic and precise method. However, the works about fractal descriptors presented in the literature focus on classical methods to estimate fractal dimension, such as Bouligand-Minkowski and Box-counting. This project aims at studying more deeply the concept, generalizing to other approaches in fractal dimension, as well as exploring different ways of extracting the key features from the logarithmic curve associated with the dimension. The developed methods are applied to texture analysis, in classification problems over public databases, whose results can be compared with literature methods, as well as to the segmentation of satellite images and automatically identifying samples obtained from studies on nanotechnology. The results demonstrate the potential of the methodology 
developed to solve such problems, showing that this is a new frontier to be explored and used in image analysis and computer vision at all.

Keywords: Fractal descriptors. Texture analysis. Pattern recognition. Fractal dimension. 


\section{LISTA DE FIGURAS}

2.1 Fractal de Julia: um exemplo clássico de fractal gerado por sistema dinâmico não-linear no plano complexo. O sistema é governado pela função $f(z)=$ $z^{2}+c$ e são exibidas as 100 primeiras iterações. Os pontos em tonalidades escuras representam a bacia de atração ao infinito. As regiões tendendo para um tom mais claro correspondem aos confinamentos. . . . . . . . . . . . . p p. 41

2.2 Exemplos de fractais de diferentes categorias. a) Geométrico. b) Não-linear. c) Probabilístico. . . . . . . . . . . . . . . . . . . . . . . . . . . p. . . . . . . .

2.3 Primeiras iterações do conjunto de Cantor: um exemplo clássico de fractal. p. 43

2.4 Três exemplos de Sistemas-L modelando plantas. Nota-se a semelhança com espécies do mundo real. . . . . . . . . . . . . . . . . . . . . . . . . . p.46

2.5 Imagens da natureza com aspecto altamente semelhante ao dos fractais matemáticos. . . . . . . . . . . . . . . . . . . . . . . . p. 47

2.6 Exemplos de estruturas geradas por IFS em duas e três dimensões e que se assemelham a cenários encontrados na natureza. . . . . . . . . . . . . . . p. p.49

3.1 Dimensão fractal por Box-counting. A forma analisada é um fractal clássico, chamado de floco de neve de Koch. Na parte superior, a forma sendo dividida em caixas de tamanhos diferentes. Abaixo, à esquerda, a tabela de valores para $\log (N(r))$ em função $\log (r)$. À direita, o gráfico $\log (N(r)) \times \log (r)$. Os logaritmos usados estão na base 2. Foram usados apenas três pontos a título de ilustração. . . . . . . . . . . . . . . . . . p. 56

3.2 Dimensão fractal por Bouligand-Minkowski. Na parte superior, a forma sendo dilatada por esferas de raios diferentes. Abaixo, à esquerda, a tabela de valores para $\log (A(r))$ em função $\log (r)$. À direita, o gráfico $\log (A(r)) \times$ $\log (r)$. Foram usados apenas três pontos a título de ilustração. 
3.3 Método de estimativa de dimensão fractal de textura por Box-counting. a) Imagem em tons de cinza. b) Grade tridimensional envolvendo a superfície de intensidade da imagem. c) Gráfico $\log (N) \times \log (r)$ do qual se extrai a dimensão. . . . . . . . . . . . . . . . . . . . p. 58

3.4 Processo de dilatação da superfície da intensidade de níveis de cinza no método de Bouligand-Minkowski. a) Imagem em tons de cinza. b) Superfície tridimensional da intensidade dos pixels. c) Estrutura de cada ponto da superfície dilatado. . . . . . . . . . . . . . . . . . . . . . . p.60

3.5 Método de estimativa de dimensão fractal por Fourier. a) Imagem em tons de cinza. b) Espectro de potência. c) Gráfico $\log (P) \times \log (f)$ do qual se extrai a dimensão fractal. . . . . . . . . . . . . . . . . . . . . . . . . . p. 61

3.6 Dimensão fractal por wavelets. Da esquerda para a direita, a imagem de textura original, a transformação aplicada (note-se que os quadrantes não foram divididos por igual como na transformada convencional) e a curva $\log (C) \times \log (r)$, em que $r$ é um índice de ordenação. . . . . . . . . . . . $\quad$ p. 62

3.7 Textura dividida em quadrados e um prisma construído tendo como base cada quadrado . . . . . . . . . . . . . . . . . . . p. 64

3.8 Dois objetos com graus de complexidade distinta e gráfico da dimensão fractal mostrando a maior dimensão do objeto mais complexo. . . . . . . . p p.71

4.1 Duas formas de aspecto totalmente distinto, mas com a mesma dimensão fractal. . . . . . . . . . . . . . . . . . . . . p. 74

4.2 Duas texturas de aspecto diferente, mas com a mesma dimensão fractal. . p.74

4.3 Curva de fractalidade de uma forma exibindo a existência de diferentes valores da dimensão fractal dependendo do intervalo de escala tomado. . . . . . . p p.75

4.4 Curva de fractalidade de uma textura exibindo a existência de diferentes valores da dimensão fractal dependendo do intervalo de escala tomado. . . p. p.75

4.5 Duas formas com dimensões fractais idênticas sendo discriminadas pelos descritores fractais. . . . . . . . . . . . . . . . . . p. 80

4.6 Duas texturas com dimensões fractais idênticas sendo discriminadas pelos descritores fractais. . . . . . . . . . . . . . . . . . . . . . . . . . p. 81 
5.1 Descritores fractais. À esquerda, duas imagens de texturas que apresentam dimensões fractais idênticas e são de difícil distinção mesmo a um ser humano. À direita, os descritores fractais das respectivas imagens separando claramente as amostras. . . . . . . . . . . . . . . . . . . . . . . p. 84

5.2 Discriminação dos descritores fractais. (a) Texturas de dois materiais diferentes. (b) Descritores de cada textura representados em um mesmo gráfico e ilustrando a separação entre as classes. . . . . . . . . . . . . . . . . . . p. 85

5.3 Curva dos descritores fractais, já com cada variável normalizada, para cada método de dimensão fractal numérica discutido neste trabalho. . . . . . . p p.87

5.4 Etapas do método multinível de descritores fractais. De cima para baixo, imagens originais, descritores de cada janela, descritores médio e de desvio, vetor contendo $i$-ésimo componente de todos os níveis de decomposição (tanto para os descritores médios $(\varphi)$ como de desvio $\psi$ ), entropia dos vetores anteriores, seleção de atributos. . . . . . . . . . . . . . . . . . . . . . p.89

5.5 Aplicação dos descritores coloridos propostos sobre 4 imagens de texturas:
(a) Imagem original;
(b) $r=1$;
(c) $r=2$;
(d) $r=4$;
(e) $r=6$.
p. 94

5.6 Diagrama ilustrando o processo de extração dos descritores fractais da imagem nanométrica por janelas. . . . . . . . . . . . . . . . . . . . . p.96

5.7 Diagrama exemplificando o poder de discriminação dos descritores fractais individuais (Fourier e Lacunaridade) e combinados. . . . . . . . . . . . . . p p. 99

5.8 Objetos fractais matemáticos usados para validação do método de dimensão fractal proposto. . . . . . . . . . . . . . . . . p. 102

6.1 Amostras de algumas imagens da base de texturas Brodatz (uma imagem por classe). . . . . . . . . . . . . . . . . . . . . . . . . p. 105

6.2 Amostras de algumas imagens da base de texturas Vistex (uma imagem por classe). . . . . . . . . . . . . . . . . . . p. 106

6.3 Amostras de algumas imagens da base de texturas Outex (uma imagem por classe). . . . . . . . . . . . . . . . . . . . p. 107

7.1 Taxas de acerto em função do número de descritores na base de Brodatz, com classificador KNN. 
7.2 Matrizes de confusão (parte 1) para os métodos comparados sobre a base de Brodatz, usando classificador KNN. (a) Multifractal 2. (b) LBP. (c) Fourier. (d) Bouligand-Minkowski. (e) Wavelike. (f) Probabilidade. . . . . . . . . . p p. 132

7.3 Matrizes de confusão (parte 2) para os métodos comparados sobre a base de Brodatz, usando classificador KNN. (a) Lacunaridade + Wavelike. (b) Browniano + Wavelike. (c) Fourier + Wavelike. . . . . . . . . . . . . . . p. 133

7.4 Taxas de acerto em função do número de descritores para a Base de Brodatz, com classificador SVM. . . . . . . . . . . . . . . . . . . . . . . . . . . . p. 142

7.5 Matrizes de confusão (parte 1) para os métodos comparados sobre a base de Brodatz, usando classificador SVM. (a) LBP. (b) GLCM. (c) Fourier. (d) Wavelike. (e) Bouligand-Minkowski. (f) Probabilidade. . . . . . . . . . . . p. 144

7.6 Matrizes de confusão (parte 2) para os métodos comparados sobre a base de Brodatz, usando classificador SVM. (a) Bouligand-Minkowski + Proba-

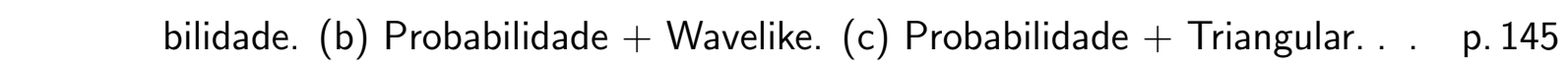

7.7 Taxas de acerto em função do número de descritores para a base de Vistex, classificada por KNN. . . . . . . . . . . . . . . . . . . . . . . . . . . . . p. 153

7.8 Matrizes de confusão (parte 1) para os métodos comparados sobre a base de Vistex, usando classificador KNN. (a) Multifractal 2. (b) LBP. (c) GLCM. (d) Wavelike. (e) Bouligand-Minkowski. (f) Fourier fractal. . . . . . . . . . p. 154

7.9 Matrizes de confusão (parte 2) para os métodos comparados sobre a base de Vistex, usando classificador KNN. (a) Blanket + Wavelike. (b) Fourier + Wavelike. (c) Variograma + Wavelike. . . . . . . . . . . . . . . . . . . p. 155

7.10 Taxas de acerto em função do número de descritores para a base de Vistex, com classificação por SVM. . . . . . . . . . . . . . . . . . . . . . . . . . . p. 163

7.11 Matrizes de confusão (parte 1) para os métodos comparados sobre a base de Vistex, usando classificador SVM. (a) LBP. (b) Multifractal 2. (c) Gabor. (d) Wavelike. (e) Bouligand-Minkowski. (f) Fourier. . . . . . . . . . . . . p. 164

7.12 Matrizes de confusão (parte 2) para os métodos comparados sobre a base de Vistex, usando classificador SVM. (a) Fourier + Wavelike. (b) Blanket + Wavelike. (c) Variograma + Wavelike. . . . . . . . . . . . . . . . . . . p. 165

7.13 Taxas de acerto em função do número de descritores para a base de Vistex, com classificador KNN. . . . . . . . . . . . . . . . . . . . . . . . . . . . p. 172 
7.14 Matrizes de confusão (parte 1) para os métodos comparados sobre a base de Vistex, usando classificador SVM. (a) Gabor cores. (b) Momentos cromáticos. \begin{tabular}{|l}
\hline (c) Razão de histogramas. (d) Bouligand-Minkowski 3D. (e) Bouligand- \\
\hline
\end{tabular}

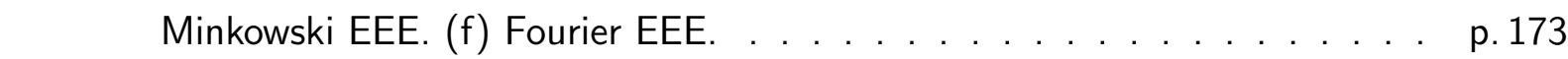

7.15 Matrizes de confusão (parte 2) para os métodos comparados sobre a base de Vistex, usando classificador SVM. (a) Bouligand-Minkowski 3D + BouligandMinkowski EEE. (b) Bouligand-Minkowski 3D + Fourier EEE. (c) Bouligand-

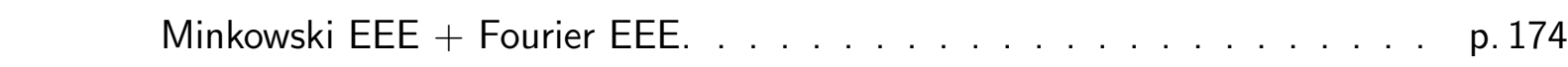

7.16 Taxas de acerto em função do número de descritores. $\quad$. . . . . . . . . . . . . p. 180

7.17 Matrizes de confusão (parte 1) para os métodos comparados sobre a base de Vistex, usando classificador SVM. (a) Gabor cores. (b) Momentos cromáticos.

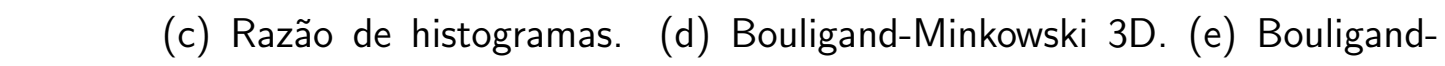

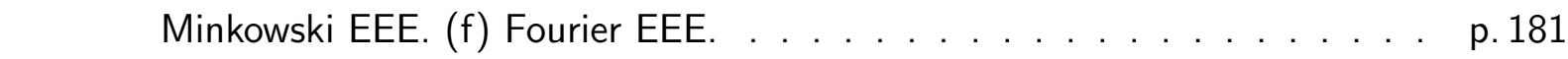

7.18 Matrizes de confusão (parte 2) para os métodos comparados sobre a base de Vistex, usando classificador SVM. (a) Bouligand-Minkowski 3D + BouligandMinkowski EEE. (b) Bouligand-Minkowski 3D + Fourier EEE. (c) Bouligand-

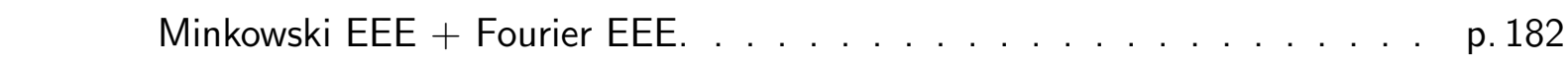

7.19 Taxas de acerto em função do número de descritores. $\quad \ldots$. . . . . . . . . . . p. 188

7.20 Matrizes de confusão (parte 1) para os métodos comparados sobre a base de Outex, usando classificador KNN. (a) Gabor cores. (b) Momentos cromáticos. (c) Razão de histogramas. (d) Bouligand-Minkowski 3D. (e) BouligandMinkowski EEE. (f) Fourier EEE. . . . . . . . . . . . . . . . . . . . . p. 189

7.21 Matrizes de confusão (parte 2) para os métodos comparados sobre a base de Outex, usando classificador KNN. (a) Bouligand-Minkowski 3D + BouligandMinkowski EEE. (b) Bouligand-Minkowski 3D + Fourier EEE. (c) BouligandMinkowski EEE + Fourier EEE. . . . . . . . . . . . . . . . . . . . p. 190

7.22 Taxas de acerto em função do número de descritores na base de Outex, com classificador SVM. . . . . . . . . . . . . . . . . . . . . . . . . . . p. 196

7.23 Matrizes de confusão (parte 1) para os métodos comparados sobre a base de Outex, usando classificador SVM. (a) Gabor cores. (b) Momentos cromáticos. (c) Razão de histogramas. (d) Bouligand-Minkowski 3D. (e) BouligandMinkowski EEE. (f) Fourier EEE. . . . . . . . . . . . . . . . . . . . . . . p. 197 
7.24 Matrizes de confusão (parte 2) para os métodos comparados sobre a base de Outex, usando classificador SVM. (a) Bouligand-Minkowski 3D + BouligandMinkowski EEE. (b) Bouligand-Minkowski 3D + Fourier EEE. (c) BouligandMinkowski EEE + Fourier EEE. . . . . . . . . . . . . . . . . . . . . . . . p. 198

7.25 Imagens segmentadas pelos métodos comparados e resultados esperados. Da primeira à sexta linha, imagens de Buenos Aires 1, Buenos Aires 2, Sao Paulo 1, Sao Paulo 2, Nova York 1 e Nova York 2. Na primeira coluna, as imagens originais, na segunda, as imagens segmentadas por um especialista, na terceira, imagens segmentadas por matriz de co-ocorrência, na quarta, por Gabor e na quinta coluna, imagens segmentadas pelo método proposto. p. 209

7.26 Imagens de Buenos Aires, observadas sob três diferentes alturas (níveis de zoom) segmentadas pelos métodos comparados e respectivos resultados esperados. Na primeira coluna, são mostradas as imagens originais, na segunda, as imagens segmentadas por um especialista, na terceira, imagens segmentadas por matriz de co-ocorrência, na quarta, por Gabor e na quinta coluna, imagens segmentadas pelo método proposto. . . . . . . . . . . . . p. p. 210

7.27 Curvas de descritores fractais para as amostras analisadas. Linhas sólidas correspondem à amostra 1 e linhas pontilhadas, à amostra $2 . \quad$. . . . . . . . p. p. 212

7.28 Gráfico dos componentes PCA (esquerda) e CCA (direita) dos descritores. Nota-se a clara formação de duas nuvens de pontos representando cada condição de experimento. . . . . . . . . . . . . . . . . . . . . . . . . . . . p. 212

7.29 Taxa acerto em função do número de pares de janelas para o óxido de titânio.p. 213

7.30 Taxa acerto em função do número de pares de janelas para o óxido de zircônio dopado por cálcio. . . . . . . . . . . . . . . . . . . . . . . . . . . . . . . . p. 214

7.31 Taxa acerto em função do número de pares de janelas para o óxido de zircônio dopado por nióbio, aumentado 3000x. . . . . . . . . . . . . . . . . . . . . p. 214

7.32 Taxa acerto em função do número de pares de janelas para o óxido de zircônio dopado por nióbio, aumentado 8000x. . . . . . . . . . . . . . . . p. 215 


\section{LISTA DE TABELAS}

3.1 Dimensão dos objetos fractais matemáticos calculada por diferentes métodos e comparada à dimensão teórica de Hausdorff-Besicovitch. Os valores sublinhados correspondem às melhores aproximações. . . . . . . . . . . . . . . p. p9

3.2 Erro médio na estimativa da dimensão fractal pelos métodos comparados em objetos fractais submetidos a transformações geométricas. . . . . . . . . . . p. 70

3.3 Erro médio na estimativa da dimensão de objetos fractais afetados por ruído. p. 70

7.1 Breve descrição de cada métrica estatística usada na análise dos resultados. p. 121

7.2 Siglas das transformadas empregadas nos resultados. . . . . . . . . . . . . p. 121

7.3 Representação dos descritores fractais por números nas matrizes de combinação. . . . . . . . . . . . . . . . . . . . . . . . p. 122

7.4 Taxa de acerto para os descritores fractais usados de forma direta e outras medidas, na base de Brodatz, com classificador KNN. . . . . . . . . . . . p. 123

7.5 Taxa de acerto para os descritores fractais individuais na base de Brodatz, classificados por KNN. . . . . . . . . . . . . . . . . . . . . . . . . . . . . p. 124

7.6 Taxa de acerto para os descritores fractais individuais combinados na base de Brodatz, classificados por KNN. . . . . . . . . . . . . . . . . . . . . p. 124

7.7 Taxa de acerto para os descritores fractais FDA na base de Brodatz, classificados por KNN. . . . . . . . . . . . . . . . . . . . . . . . . . . . . . . . p 125

7.8 Taxa de acerto para os descritores fractais FDA combinados na base de Brodatz, classificados por KNN. . . . . . . . . . . . . . . . . . p. 125

7.9 Taxa de acerto para os descritores fractais espaço-escala na base de Brodatz, classificados por KNN. . . . . . . . . . . . . . . . . . . . . . . . . p. 126 
7.10 Taxa de acerto para os descritores fractais espaço-escala combinados na base de Brodatz, classificados por KNN. . . . . . . . . . . . . . . . . . . . . p. 126

7.11 Taxa de acerto para os descritores fractais tempo-frequência na base de Brodatz, classificados por KNN. . . . . . . . . . . . . . . . . . . . . p. 127

7.12 Taxa de acerto para os descritores fractais tempo-frequência combinados na base de Brodatz, classificados por KNN. . . . . . . . . . . . . . . . . p. 127

7.13 Taxa de acerto para os descritores fractais tempo-escala na base de Brodatz, classificados por KNN.

7.14 Taxa de acerto para os descritores fractais tempo-escala combinados na base de Brodatz, classificados por KNN. . . . . . . . . . . . . . . . . . . . . . p. 129

7.15 Taxa de acerto para os métodos da literatura na base de Brodatz, classificados por KNN. . . . . . . . . . . . . . . . . . . . . . . . . . . . . . . . . . . . . p 129

7.16 Resumo das taxas de acerto obtidas para a base de Brodatz, classificada por KNN. . . . . . . . . . . . . . . . . . . . . . p. 130

7.17 Taxa de acerto para os descritores fractais diretos na base de Brodatz, classificados por SVM. . . . . . . . . . . . . . . . . . . . . . . . . . . . . . . . . . . . . p. 134

7.18 Taxa de acerto para os descritores fractais individuais na base de Brodatz, classificados por SVM. . . . . . . . . . . . . . . . . . . . . . . . . . p. 135

7.19 Taxa de acerto para os descritores fractais individuais combinados na base de Brodatz, classificados por SVM. . . . . . . . . . . . . . . . . p. 135

7.20 Taxa de acerto para os descritores fractais FDA na base de Brodatz, classificados por SVM. . . . . . . . . . . . . . . . . . . . . . . . . . . . . . . p. 136

7.21 Taxa de acerto para os descritores fractais FDA combinados na base de Brodatz, classificados por SVM. . . . . . . . . . . . . . . . . . . . . p. 136

7.22 Taxa de acerto para os descritores fractais espaço-escala na base de Brodatz, classificados por SVM. . . . . . . . . . . . . . . . . . . . . . . . . . . . . p. 137

7.23 Taxa de acerto para os descritores fractais espaço-escala combinados na base de Brodatz, classificados por SVM. . . . . . . . . . . . . . . . . . p. 137

7.24 Taxa de acerto para os descritores fractais tempo-frequência na base de Brodatz, classificados por SVM. . . . . . . . . . . . . . . . . . . . . p. 138 
7.25 Taxa de acerto para os descritores fractais tempo-frequência combinados na base de Brodatz, classificados por SVM.

7.26 Taxa de acerto para os descritores fractais tempo-escala na base de Brodatz, classificados por SVM.

7.27 Taxa de acerto para os descritores fractais tempo-escala combinados na base de Brodatz, classificados por SVM.

7.28 Taxa de acerto para os métodos da literatura na base de Brodatz, classificados por SVM.

7.29 Resumo das taxas de acerto obtidas para a base de Brodatz, classificada por SVM. . . . . . . . . . . . . . . . . . . . . . . p. 142

7.30 Taxa de acerto para os descritores fractais em uso direto e outras medidas para a base de Vistex, com classificador KNN. . . . . . . . . . . . . . p. 146

7.31 Taxa de acerto para os descritores fractais individuais na base de Vistex, classificados por KNN. . . . . . . . . . . . . . . . . . . . . . . . . . . p. 146

7.32 Taxa de acerto para os descritores fractais individuais combinados na base de Vistex, classificados por KNN. . . . . . . . . . . . . . . . . . . . . . . p. 147

7.33 Taxa de acerto para os descritores fractais FDA na base de Vistex, classificados por KNN. . . . . . . . . . . . . . . . . . . . . . . . p. 147

7.34 Taxa de acerto para os descritores fractais FDA combinados na base de Vistex, classificados por KNN. . . . . . . . . . . . . . . . . . . . . p. 148

7.35 Taxa de acerto para os descritores fractais espaço-escala na base de Vistex, classificados por KNN. . . . . . . . . . . . . . . . . . . . . . . . . . . p. 148

7.36 Taxa de acerto para os descritores fractais espaço-escala combinados na base de Vistex, classificados por KNN. . . . . . . . . . . . . . . . . . . . . p. 149

7.37 Taxa de acerto para os descritores fractais tempo-frequência na base de Vistex, classificados por KNN. . . . . . . . . . . . . . . . . . . p. 149

7.38 Taxa de acerto para os descritores fractais tempo-frequência combinados na base de Vistex, classificados por KNN. . . . . . . . . . . . . . . . . . . . p. 149

7.39 Taxa de acerto para os descritores fractais tempo-escala na base de Vistex, classificados por KNN. . 
7.40 Taxa de acerto para os descritores fractais tempo-escala combinados na base de Vistex, classificados por KNN. . . . . . . . . . . . . . . . . . . . . . . p. 150

7.41 Taxa de acerto para os métodos da literatura na base de Vistex, classificados por KNN. . . . . . . . . . . . . . . . . . . . . . . . . . . . . . . . . . . . . . . . . p. 151

7.42 Resumo das taxas de acerto obtidas para a base de Vistex, classificada por KNN. . . . . . . . . . . . . . . . . . . . . . . . p. 152

7.43 Taxa de acerto para os descritores fractais em uso direto e outras medidas na base de Vistex, com classificador SVM. . . . . . . . . . . . . . . . . . p. 156

7.44 Taxa de acerto para os descritores fractais individuais na base de Vistex, classificados por SVM. . . . . . . . . . . . . . . . . . . . . p. 156

7.45 Taxa de acerto para os descritores fractais individuais combinados na base de Vistex, classificados por SVM. . . . . . . . . . . . . . . . . . . . p. 157

7.46 Taxa de acerto para os descritores fractais FDA na base de Vistex, classificados por SVM. . . . . . . . . . . . . . . . . . . . . . . . . . . . . . . . . . p. 157

7.47 Taxa de acerto para os descritores fractais FDA combinados na base de Vistex, classificados por SVM. . . . . . . . . . . . . . . . . . . . . . . . . p. 158

7.48 Taxa de acerto para os descritores fractais espaço-escala na base de Vistex, classificados por SVM. . . . . . . . . . . . . . . . . . . . p. 158

7.49 Taxa de acerto para os descritores fractais espaço-escala combinados na base de Vistex, classificados por SVM. . . . . . . . . . . . . . . . . . . . . . . $\quad$ p. 159

7.50 Taxa de acerto para os descritores fractais tempo-frequência na base de Vistex, classificados por SVM. . . . . . . . . . . . . . . . . . . . . . . . . p. 159

7.51 Taxa de acerto para os descritores fractais tempo-frequência combinados na base de Vistex, classificados por SVM. . . . . . . . . . . . . . . . . . . . p. 160

7.52 Taxa de acerto para os descritores fractais tempo-escala na base de Vistex, classificados por SVM. . . . . . . . . . . . . . . . . . . p. 160

7.53 Taxa de acerto para os descritores fractais tempo-escala combinados na base de Vistex, classificados por SVM. . . . . . . . . . . . . . . . . . . . . . . p. 161

7.54 Taxa de acerto para os métodos da literatura na base de Vistex, classificados por SVM. . . . . . . . . . . . . . . . . . . . . . . . . . . . . . . . . . . . . p 161 
7.55 Resumo das taxas de acerto obtidas para a base de Vistex, classificada por SVM. . . . . . . . . . . . . . . . . . . . . . . . p. 162

7.56 Taxa de acerto para os descritores fractais em cores em uso direto e outras medidas na base de Vistex, com classificador KNN. . . . . . . . . . . . . . p. 166

7.57 Taxa de acerto para os descritores fractais individuais na base de Vistex, classificados por KNN. . . . . . . . . . . . . . . . . . . . . . . p. 167

7.58 Taxa de acerto para os descritores fractais individuais combinados na base de Vistex, classificados por KNN. . . . . . . . . . . . . . . . . . p. 167

7.59 Taxa de acerto para os descritores fractais FDA na base de Vistex, classifi-

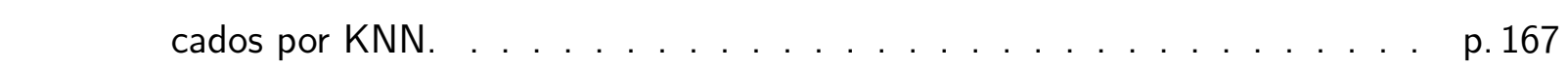

7.60 Taxa de acerto para os descritores fractais FDA combinados na base de Vistex, classificados por KNN. . . . . . . . . . . . . . . . p. 168

7.61 Taxa de acerto para os descritores fractais espaço-escala na base de Vistex, classificados por KNN. . . . . . . . . . . . . . . . . p. 168

7.62 Taxa de acerto para os descritores fractais espaço-escala combinados na base de Vistex, classificados por KNN. . . . . . . . . . . . . . . . . . . . . p. 169

7.63 Taxa de acerto para os descritores fractais tempo-frequência na base de

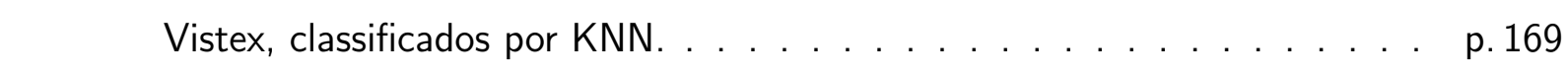

7.64 Taxa de acerto para os descritores fractais tempo-frequência combinados na base de Vistex, classificados por KNN. . . . . . . . . . . . . . . . . . . . . p. 169

7.65 Taxa de acerto para os descritores fractais tempo-escala na base de Vistex, classificados por KNN. . . . . . . . . . . . . . . . . p. 170

7.66 Taxa de acerto para os descritores fractais tempo-escala combinados na base de Vistex, classificados por KNN. . . . . . . . . . . . . . . . . . . . p. p. 170

7.67 Taxa de acerto para os métodos da literatura na base de Vistex, classificados -

7.68 Resumo das taxas de acerto obtidas para a base de Vistex, classificada por KNN. . . . . . . . . . . . . . . . . . . p. 171

7.69 Taxa de acerto para os descritores fractais em cores, sem redução de dimensionalidade, e outras medidas para a base de Vistex com SVM. 
7.70 Taxa de acerto para os descritores fractais individuais na base de Vistex, classificados por SVM. . . . . . . . . . . . . . . . . . . . . . . p. 175

7.71 Taxa de acerto para os descritores fractais individuais combinados na base de Vistex, classificados por SVM. . . . . . . . . . . . . . . . . . p. 175

7.72 Taxa de acerto para os descritores fractais FDA na base de Vistex, classificados por SVM. . . . . . . . . . . . . . . . . . . . . . p. 176

7.73 Taxa de acerto para os descritores fractais FDA combinados na base de Vistex, classificados por SVM. . . . . . . . . . . . . . . p. 176

7.74 Taxa de acerto para os descritores fractais espaço-escala na base de Vistex, classificados por SVM. . . . . . . . . . . . . . . . . p. 176

7.75 Taxa de acerto para os descritores fractais espaço-escala combinados na base de Vistex, classificados por SVM. . . . . . . . . . . . . . . . . . p. 177

7.76 Taxa de acerto para os descritores fractais tempo-frequência na base de Vistex, classificados por SVM. . . . . . . . . . . . . . . . . . . . p. 177

7.77 Taxa de acerto para os descritores fractais tempo-frequência combinados na base de Vistex, classificados por SVM. . . . . . . . . . . . . . . . . p. 177

7.78 Taxa de acerto para os descritores fractais tempo-escala na base de Vistex, classificados por SVM. . . . . . . . . . . . . . . . . . . . . . . . . . . . p. 178

7.79 Taxa de acerto para os descritores fractais tempo-escala combinados na base de Vistex, classificados por SVM. . . . . . . . . . . . . . . . . . . . . . . p. 178

7.80 Taxa de acerto para os métodos da literatura na base de Vistex, classificados por SVM. . . . . . . . . . . . . . . . . . . . . . . . . . . . . . . . . . . . . p. 178

7.81 Resumo das taxas de acerto obtidas para a base de Vistex, classificada por SVM. .

7.82 Taxa de acerto para os descritores fractais em cores usados de forma direta e outras medidas na base de Outex, com KNN. . . . . . . . . . . . . . . p. 183

7.83 Taxa de acerto para os descritores fractais individuais na base de Outex, classificados por KNN. . . . . . . . . . . . . . . . . . . . . . . . . . . . p. 183

7.84 Taxa de acerto para os descritores fractais individuais combinados na base de Outex, classificados por KNN. . . . . . . . . . . . . . . . . . . . p. 184 
7.85 Taxa de acerto para os descritores fractais FDA na base de Outex, classificados por KNN. . . . . . . . . . . . . . . . . . . . . . . . . . . . . . . . . p. 184

7.86 Taxa de acerto para os descritores fractais FDA combinados na base de Outex, classificados por KNN. . . . . . . . . . . . . . . . . . . . . . . . . p. 184

7.87 Taxa de acerto para os descritores fractais espaço-escala na base de Outex, classificados por KNN. . . . . . . . . . . . . . . . . . . . . . . . . . . p. 185

7.88 Taxa de acerto para os descritores fractais espaço-escala combinados na base de Outex, classificados por KNN. . . . . . . . . . . . . . . . . . . p. 185

7.89 Taxa de acerto para os descritores fractais tempo-frequência na base de - Outex, classificados por KNN. . . . . . . . . . . . . . . . p. 185

7.90 Taxa de acerto para os descritores fractais tempo-frequência combinados na base de Outex, classificados por KNN. . . . . . . . . . . . . . . . p. 186

7.91 Taxa de acerto para os descritores fractais tempo-escala na base de Outex, classificados por KNN. . . . . . . . . . . . . . . . . . . . . . p. 186

7.92 Taxa de acerto para os descritores fractais tempo-escala combinados na base de Outex, classificados por KNN. . . . . . . . . . . . . . . . . . . p. 186

7.93 Taxa de acerto para os métodos da literatura na base de Outex, classificados por KNN. . . . . . . . . . . . . . . . . . . . . . . . . . . . . . p. 187

7.94 Resumo das taxas de acerto obtidas para a base de Outex, classificada por KNN. . . . . . . . . . . . . . . . . . . . . . . . . . . . . . . p. 187

7.95 Taxa de acerto para os descritores fractais em cores usados no modo direto e outras medidas na base de Outex, com classificador SVM. . . . . . . . . p p. 191

7.96 Taxa de acerto para os descritores fractais individuais na base de Outex, classificados por SVM. . . . . . . . . . . . . . . . . . . . . . . . . . . . . p. 191

7.97 Taxa de acerto para os descritores fractais individuais combinados na base de Outex, classificados por SVM. . . . . . . . . . . . . . . . . . . p. 192

7.98 Taxa de acerto para os descritores fractais FDA na base de Outex, classificados por SVM. . . . . . . . . . . . . . . . . . . . . . . . . . . . . . . . p 192

7.99 Taxa de acerto para os descritores fractais FDA combinados na base de Outex, classificados por SVM. . . . . . . . . . . . . . . . . . . . p. 192 
7.100Taxa de acerto para os descritores fractais espaço-escala na base de Outex, classificados por SVM. . . . . . . . . . . . . . . . . . . . . . . . . . p. 193

7.101Taxa de acerto para os descritores fractais espaço-escala combinados na base de Outex, classificados por SVM. . . . . . . . . . . . . . . . . . . p. 193

7.102Taxa de acerto para os descritores fractais tempo-frequência na base de Outex, classificados por SVM. . . . . . . . . . . . . . . . . . p. 193

7.103Taxa de acerto para os descritores fractais tempo-frequência combinados na base de Outex, classificados por SVM. . . . . . . . . . . . . . . . . p. 194

7.104Taxa de acerto para os descritores fractais tempo-escala na base de Outex, classificados por SVM. . . . . . . . . . . . . . . . . . . . . . . . . . . . p. 194

7.105Taxa de acerto para os descritores fractais tempo-escala combinados na base de Outex, classificados por SVM. . . . . . . . . . . . . . . . . . p. 194

7.106Taxa de acerto para os métodos da literatura na base de Outex, classificados por SVM. . . . . . . . . . . . . . . . . . . . . . . . . . . . . . p. 195

7.107Resumo das taxas de acerto obtidas para a base de Outex, classificada por SVM. . . . . . . . . . . . . . . . . . . . p. 195

7.108Resultado para as texturas de Brodatz afetadas por ruído Gaussiano. . . . p. 199

7.109Resultado para as texturas de Brodatz afetadas por ruído "sal-e-pimenta". p. 200

7.110Porcentagem da queda nas taxas de acerto para cada tipo de ruído. . . . . p p. 200

7.111Resumo do tempo computacional consumido para os diferentes métodos de análise de texturas, na geração dos descritores para cada imagem. . . . . . . p. 201

7.112Dimensão dos objetos fractais comparados calculada por diferentes métodos e comparada à dimensão teórica de Hausdorff-Besicovitch. Os valores sublinhados correspondem às melhores aproximações. . . . . . . . . . . . . . . p. 202

7.113Dimensão dos fractais rotacionados de 45 graus. . . . . . . . . . . . . . . p. 202

7.114Dimensão dos fractais rotacionados de 90 graus. . . . . . . . . . . . . . . p. 203

7.115Dimensão dos fractais reduzidos horizontal e verticalmente por um fator 0.5. p. 203

7.116Dimensão dos fractais aumentados horizontal e verticalmente por um fator 2.0. . . . . . . . . . . . . . . . . . . . . . . . p. 204

7.117Dimensão dos fractais transladados horizontal e verticalmente por 10 pixels. p. 204 
7.118Dimensão dos fractais transladados horizontal e verticalmente por 20 pixels.

7.119Erro médio na estimativa da dimensão fractal pelos métodos comparados em objetos fractais submetidos a transformações geométricas. . . . . . . . . . p. p. 205

7.120Dimensão fractal de objetos afetados por ruído pontual. . . . . . . . . . . p. 206

7.121Erro médio na estimativa da dimensão de objetos fractais afetados por ruído. p. 206

7.122Tempo computacional médio de cada método para cada objeto fractal. . . p. 206

7.123Comparação entre as taxas de acerto do método de segmentação proposto e outros métodos clássicos. Os melhores resultados estão sublinhados. . . . p. 208

7.124Comparação entre as taxas de acerto do método de segmentação proposto e outros métodos clássicos para mapas de Buenos Aires sob diferentes níveis de aproximação. Os melhores resultados estão sublinhados. . . . . . . . . p p. 208

8.1 Atividades realizadas e contribuições geradas por este trabalho de doutorado. p. 219 



\section{SUMÁRIO}

\begin{tabular}{lll}
\hline 1 & Introdução & p. 35
\end{tabular}

1.1 Descrição e Motivação . . . . . . . . . . . . . . . . . . . . . . p. 35

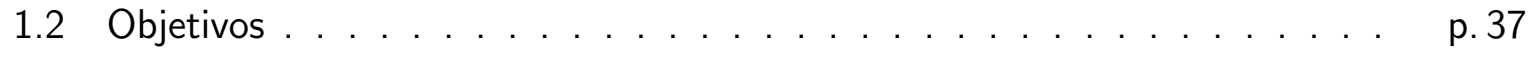

1.3 Organização $\ldots \ldots \ldots \ldots \ldots \ldots$. . . . . . . . . . . . . . . . . . . . . . . . . .

$\begin{array}{llr}2 & \text { Geometria Fractal } & \text { p. } 39\end{array}$

2.1 Introdução aos Fractais $\ldots \ldots \ldots$. . . . . . . . . . . . . . . . . . 39

2.2 Tipos de Fractais . . . . . . . . . . . . . . . . . . . . . . . . p. 42

2.3 Propriedades dos Fractais . . . . . . . . . . . . . . . . . . p. p 43

2.4 Geometria Fractal na Natureza $\ldots \ldots \ldots$. . . . . . . . . . . . . 44

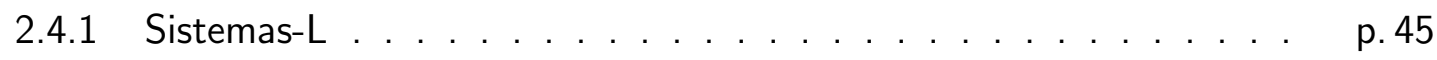

2.4 .2 Sistema de funções iteradas . . . . . . . . . . . . . . . . p. 47

2.5 Geometria Fractal em Análise de Imagens . . . . . . . . . . . . . p. p. 50

3 Dimensão Fractal p. 53

3.1 Definição . . . . . . . . . . . . . . . . . . . . . . p. p . p3

3.2 Dimensão Fractal: Analítica $\times$ Numérica . . . . . . . . . . . . . . . p. 54

3.3 Dimensão Fractal de Formas . . . . . . . . . . . . . . . . . . . . . . . . p. 55

3.3 .1 Dimensão por Box-counting . . . . . . . . . . . . . . . . . p. 55

3.3 .2 Dimensão por Bouligand-Minkowski . . . . . . . . . . . . . . p. 55

3.4 Dimensão Fractal Volumétrica . . . . . . . . . . . . . . . . . . . p. p. 57 
3.4 .1 Box-counting . . . . . . . . . . . . . . . . p. 58

3.4 .2 Dimensão por Bouligand-Minkowski . . . . . . . . . . . . . . . . . p p. 59

3.4 .3 Dimensão por Fourier . . . . . . . . . . . . . . . . . . . . . . . . . . p. 59

3.4 .4 Dimensão por Wavelets . . . . . . . . . . . . . . . . . p. 61

3.4 .5 Dimensão de Probabilidade . . . . . . . . . . . . . . . . . . . . . p. 62

3.4 .6 Dimensão por Prismas Triangulares . . . . . . . . . . . . . . . . . p. 63

3.4 .7 Variograma . . . . . . . . . . . . . . . . . . . . . p. 64

3.4 .8 Variação . . . . . . . . . . . . . . . . . . . . . p. 65

3.4 .9 Blanket . . . . . . . . . . . . . . . . . . . . . p. 66

3.4 .10 Browniano . . . . . . . . . . . . . . . . . p. 66

3.4.11 Lacunaridade . . . . . . . . . . . . . . . . . . . . . . . . . . . . p. 67

3.4 .12 Dimensão de Curvas Fechadas por Fourier . . . . . . . . . . . . p. 68

3.5 Comparativo entre Métodos Numéricos de Dimensão Fractal . . . . . . . . p p. 69

3.6 Complexidade $\ldots \ldots \ldots \ldots$. . . . . . . . . . . . . . . . . . . . . p. 70

$\begin{array}{lll}4 \text { Medidas Fractais } & \text { p. } 73\end{array}$

4.1 Dimensão Escalar versus Medidas Vetoriais . . . . . . . . . . . . . . . . . . p p.73

4.2 Multifractais $\ldots \ldots \ldots \ldots \ldots$. . . . . . . . . . . . . . . . . . . . . . . . . .

4.3 Dimensão Fractal Multiescala $\ldots \ldots \ldots$. . . . . . . . . . . . . . . . . . .

4.4 Descritores fractais $\ldots \ldots \ldots \ldots$. . . . . . . . . . . . . . . . . . . . . . 78

5 Metodologia Desenvolvida $\quad$ p. 83

5.1 Descritores Fractais $\ldots \ldots \ldots$. . . . . . . . . . . . . . . . . . . . .

5.2 Descritores Multiníveis $\ldots \ldots \ldots$. . . . . . . . . . . . . . . . . . . . . . . . . . $\quad$ p. 86

5.3 Análise de Dados Funcionais . . . . . . . . . . . . . . . . . . . . . . . . . $\quad$ p. 88

5.4 Transformada Multiescala $\ldots \ldots \ldots$. . . . . . . . . . . . . . . . . . p. 91

5.4 .1 Espaço-escala $\ldots \ldots \ldots$. . . . . . . . . . . . . . . . . . . p. 91

5.4 .2 Tempo-frequência . . . . . . . . . . . . . . . . . . . . . . p. 91 
5.4 .3 Tempo-escala $\ldots \ldots \ldots \ldots \ldots$ p. 92

5.5 Descritores para Imagens Coloridas $\ldots \ldots \ldots$ p. 92

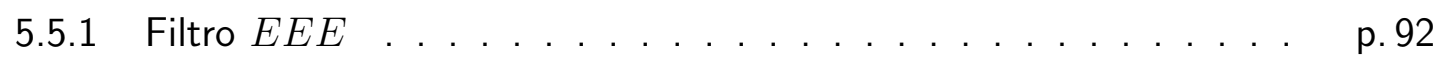

5.5 .2 Descritores volumétricos de Bouligand-Minkowski . . . . . . . . . . p. p.93

5.6 Descritores Fractais em Segmentação $\ldots \ldots$. . . . . . . . . . . . . . . 93

5.7 Descritores por Janelas . . . . . . . . . . . . . . . . . . . . p. 95

5.8 Descritores Combinados $\ldots \ldots \ldots \ldots$. . . . . . . . . . . . . . . . . . . .

5.9 Dimensão Fractal $\ldots \ldots \ldots \ldots$. . . . . . . . . . . . . . . . . . p. 98

\begin{tabular}{lll}
\hline 6 & Experimentos & p. 103
\end{tabular}

6.1 Bases de Dados $\ldots \ldots \ldots \ldots$. . . . . . . . . . . . . . . . . . . . . 104

6.1 .1 Brodatz . . . . . . . . . . . . . . . . . . . . . . . . p. 104

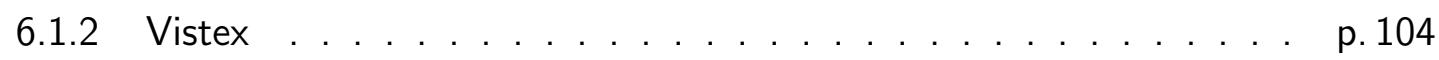

6.1 .3 Outex $\ldots \ldots \ldots \ldots \ldots$. . . . . . . . . . . . . . . . . . . . 104

6.2 Técnicas Estatísticas . . . . . . . . . . . . . . . . . . . . . . . . p. 105

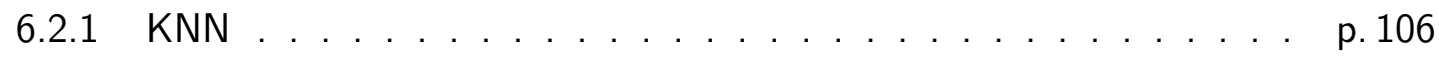

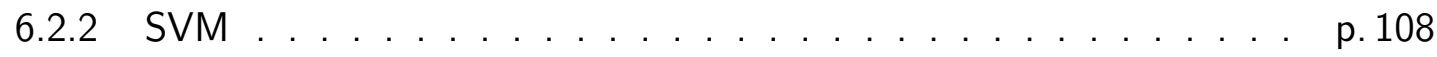

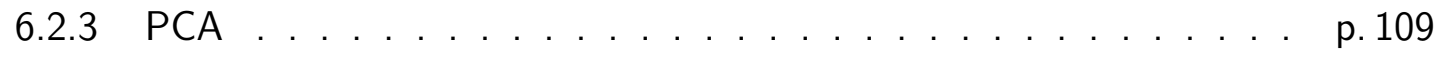

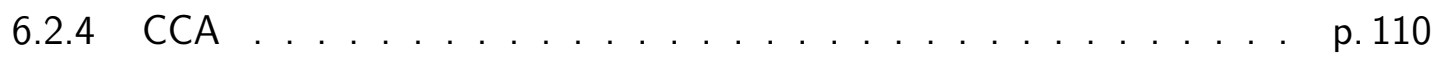

6.3 Métodos de Análise de Texturas . . . . . . . . . . . . . . . . . . . . p. 112

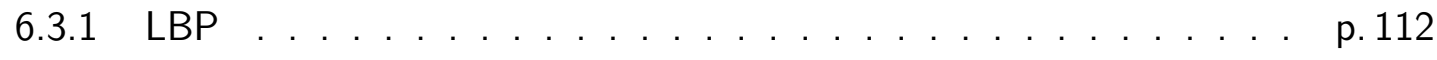

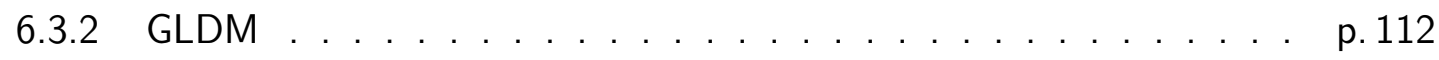

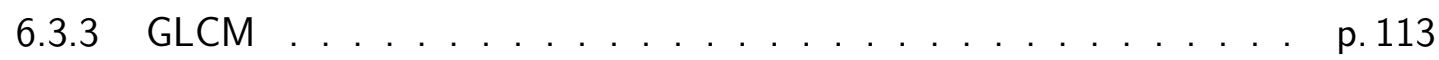

6.3 .4 Descritores de Fourier . . . . . . . . . . . . . . . . . . . . . . . p. 114

6.3 .5 Gabor-wavelets . . . . . . . . . . . . . . . . . . . . . . . p. 114

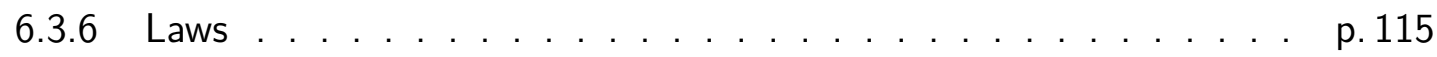

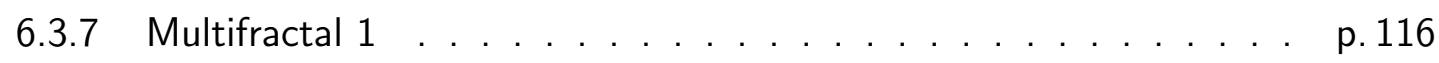




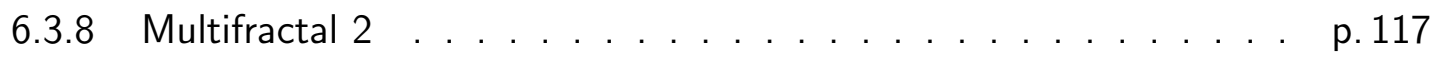

6.3 .9 Multifractal $3 \ldots \ldots \ldots \ldots$. $\ldots \ldots \ldots \ldots$

6.3 .10 Histograma de Cores . . . . . . . . . . . . . . . . . . . . . . . p. 118

6.3 .11 Momentos Cromáticos . . . . . . . . . . . . . . . . . . . . . . . . p. 119

6.3 .12 Gabor em Cores . . . . . . . . . . . . . . . . . . . . . p. 120

\begin{tabular}{lll}
\hline 7 & Resultados & p. 121
\end{tabular}

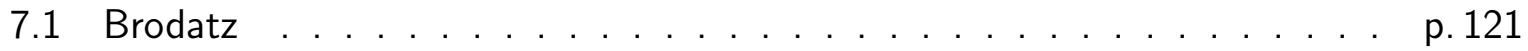

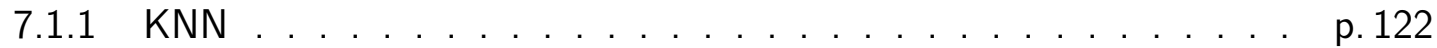

7.1.1.1 Outros Métodos . . . . . . . . . . . . . . . . . . . . p. 128

7.1.1.2 Resumo dos Resultados . . . . . . . . . . . . . . . . . p. 129

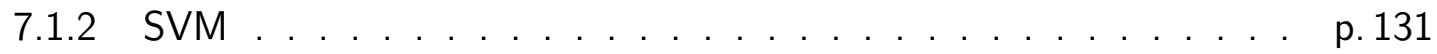

7.1.2.1 Outros Métodos . . . . . . . . . . . . . . . . . . . p. 140

7.1.2.2 Resumo dos Resultados . . . . . . . . . . . . . . . . p. 140

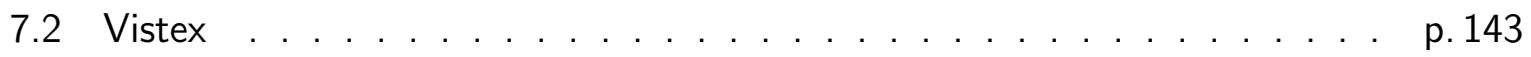

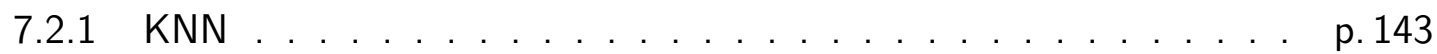

7.2 .1 .1 Outros Métodos . . . . . . . . . . . . . . . . . . . p. 151

7.2.1.2 Resumo dos Resultados . . . . . . . . . . . . . . . p. 151

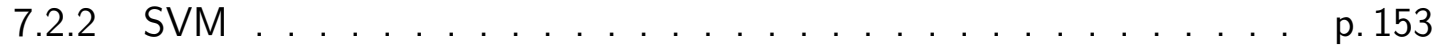

7.2 .2 .1 Outros Métodos . . . . . . . . . . . . . . . . . p. 160

7.2.2.2 Resumo dos Resultados . . . . . . . . . . . . . . . . . . p. 161

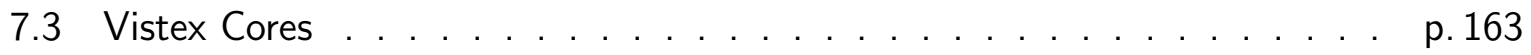

$7.3 .1 \mathrm{KNN} \ldots \ldots \ldots \ldots \ldots \ldots$

7.3.1.1 Outros Métodos . . . . . . . . . . . . . . . . p. 170

7.3.1.2 Resumo dos Resultados . . . . . . . . . . . . . . . . p. 170

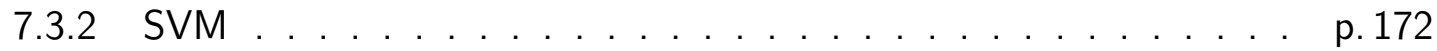

7.3.2.1 Outros Métodos . . . . . . . . . . . . . . . . . . . . . p. 178 
7.3.2.2 Resumo dos Resultados . . . . . . . . . . . . . . . . p. 179

7.4 Outex Cores $\ldots \ldots \ldots \ldots$. . . . . . . . . . . . . . . . . . . . . . . . . p. 180

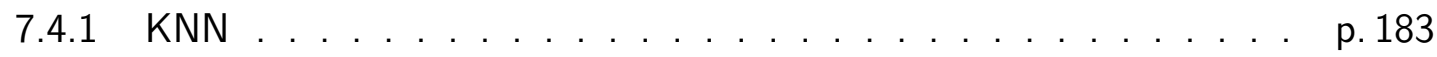

$7.4 .1 .1 \quad$ Outros Métodos . . . . . . . . . . . . . . . . . p. 186

7.4.1.2 Resumo dos Resultados . . . . . . . . . . . . . . . . p. 187

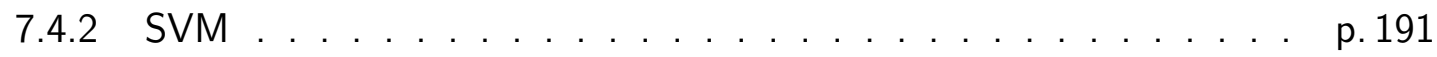

7.4.2.1 Outros Métodos . . . . . . . . . . . . . . . . . . . . . . . . p. 194

7.4.2.2 Resumo dos Resultados . . . . . . . . . . . . . . p. 195

7.5 Tolerância a Ruídos . . . . . . . . . . . . . . . . . . . . . . . . . . . p. 199

7.6 Custo Computacional . . . . . . . . . . . . . . . . . . . . . . . . p. 200

7.7 Dimensão Fractal $\ldots \ldots \ldots$. . . . . . . . . . . . . . . . . . . . . . . . . . . . . . p. 201

7.8 Segmentação . . . . . . . . . . . . . . . . . . . . . . . . . . . . . . p. 207

7.9 Análise de Imagens em Nanoescala $\ldots \ldots \ldots$. . . . . . . . . . . . . . . . 210

7.9 .1 Descritores Globais . . . . . . . . . . . . . . . . . . . . . . . . . p. 210

7.9 .2 Descritores por Janelas . . . . . . . . . . . . . . . . . . . p. 211

\begin{tabular}{lll}
\hline 8 & Conclusões & p. 217
\end{tabular}

8.1 Considerações Finais $\ldots \ldots \ldots$. . . . . . . . . . . . . . . . . . . . . . . . . p. 217

8.2 Atividades Realizadas e Contribuições Geradas . . . . . . . . . . . . . . . p. 218

8.3 Trabalhos Futuros $\ldots \ldots \ldots \ldots$. . . . . . . . . . . . . . . . . . . 220

8.4 Publicações Geradas . . . . . . . . . . . . . . . . . . . . . . . . . . . p. 220

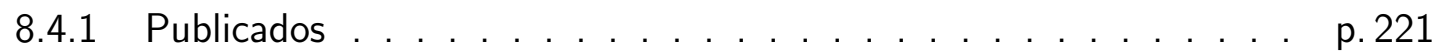

8.4 .2 Aceitos . . . . . . . . . . . . . . . . . . . . . . . . . p. 222

8.4 .3 Submetidos. . . . . . . . . . . . . . . . . . . . . . p. 222

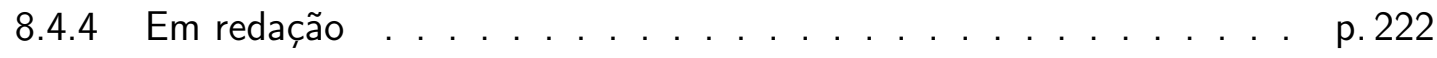

8.5 Distinções Obtidas . . . . . . . . . . . . . . . . . . . . . . . . . . . p. 223

\begin{tabular}{ll}
\hline REFERÊNCIAS & p. 225
\end{tabular} 



\section{CAPÍTULO 1}

\section{Introdução}

\subsection{Descrição e Motivação}

Nas últimas décadas, a geometria fractal (1) vem encontrando um grande número de aplicações nas mais diversas áreas da ciência. Podem ser encontrados trabalhos usando essa teoria em Física (2-4), em Ciência da Computação (5-7), em Medicina (8-10), entre muitas outras áreas.

A geometria fractal se apresenta como alternativa à geometria Euclidiana clássica, sobretudo na representação e análise de objetos encontrados na natureza (1, 11). De fato, como bem pontuado por Benoit Mandelbrot (1), uma montanha não pode ser modelada satisfatoriamente por um cone nem uma nuvem por um elipsoide, por exemplo. Por outro lado, a natureza apresenta um alto nível de complexidade e padrões que se repetem, características essas que são intrínsecas aos fractais. Assim, a geometria fractal possui uma maior flexibilidade e precisão na representação dessas estruturas que surgem naturalmente em diversas áreas do conhecimento.

Uma dessas áreas em que a teoria fractal apresenta várias aplicações é a análise de imagens (12). Esta consiste em obter informações quantitativas e qualitativas de objetos e cenários a partir de uma análise matemática da imagem digital na qual o objeto é representado. Deste modo, esse estudo permite que a descrição e identificação destes objetos torne-se menos exaustiva do que seria se feita diretamente por humanos, além de tornar esta tarefa mais rápida e precisa.

Particularmente, o presente trabalho aplica a geometria fractal para a análise de texturas, uma abordagem bastante comum dentro da análise de imagens. Texturas são imagens em tons de cinza ou coloridas, obtidas geralmente da natureza, e caracterizadas pela presença de padrões (espaciais ou estatísticos) não necessariamente periódicos (13). Tais imagens são 
obtidas e estudadas em diversas aplicações e representam um grande desafio para técnicas de análise de imagens e reconhecimento de padrões (14). As abordagens aplicadas à análise de texturas se dividem essencialmente em quatro categorias (13): espacial, estrutural, espectral e por modelos. Aqui, adota-se a última abordagem, em que a textura é associada a um modelo matemático e/ou físico e medidas de interesse são extraídas a partir desta modelagem. Dentro desta solução, a literatura apresenta vários trabalhos que demonstram a eficácia da geometria fractal na análise de texturas (5, 15-17).

A medida fractal mais usada na modelagem de texturas e imagens em geral é a dimensão fractal. Essa métrica se mostra de grande valor na descrição de objetos complexos que não podem ser representados simplesmente por parâmetros clássicos como área e perímetro. A dimensão fractal quantifica a complexidade de um objeto, isto é, o nível de detalhes que podem ser observados em diferentes partes do todo. Assim, ela mede, em termos mais práticos, a distribuição espacial e mesmo espectral de uma textura. Tal medida está diretamente ligada a atributos físicos e psico-visuais, como rugosidade, luminância e arranjo de padrões, características essas que são primordiais na descrição e discriminação de objetos (80).

Ocorre, entretanto, que em situações mais severas, como quando se tem um número elevado de imagens com alta taxa de irregularidades e similaridades, mesmo a dimensão fractal pode ser ineficiente para se obter um resultado satisfatório. Neste contexto, algumas abordagens foram desenvolvidas visando prover uma ferramenta mais robusta para a solução deste tipo de problema. É o caso dos multifractais (18), da dimensão fractal multiescala (19) e dos descritores fractais (20). Aqui, o trabalho se baseia no uso de descritores, técnica esta que demonstrou sua eficiência em diversos trabalhos (3, 8, 9, 21--29) relacionados à modelagem de texturas similares às estudadas neste projeto.

A ideia essencial dos descritores fractais é extrair um conjunto de medidas a partir da lei de potência que expressa a evolução do fractal ao longo de diferentes escalas de medida. Desta forma, estes descritores são capazes de mapear o comportamento fractal do objeto como um todo e não apenas por um valor global como a dimensão fractal. Na prática, isso permite uma descrição mais completa e precisa de características físicas e visuais do objeto. Muitas dessas características são usadas pelo sistema visual na distinção e segmentação de objetos em cenas do cotidiano (46, 47). Os descritores propostos tornam possível a automatização do processo, permitindo que os objetos sejam caracterizados com maior precisão e velocidade. 


\subsection{Objetivos}

O presente trabalho visa desenvolver e estudar novas técnicas de descritores fractais, aplicando-os à análise de texturas em tons de cinza e coloridas. Os testes de eficiência dos descritores propostos são feitos pela classificação de bases de texturas conhecidas na literatura, bem como em aplicações a imagens de microscopia eletrônica em nanotecnologia e texturas extraídas de imagens de satélites.

Entre as novas abordagens propostas, podem-se citar os descritores fractais baseados na dimensão de Fourier, Wavelets, Probabilidade, Lacunaridade, Variação, Blanket, Browniano, Box-counting, Triangular e Variograma, além de uma técnica que mescla a decomposição de escala usada na transformada wavelet com a dimensão de Bouligand-Minkowski. Ainda, são desenvolvidos descritores fractais para imagens coloridas e uma abordagem que combina descritores baseados em diferentes tipos de dimensão fractal. Outra aplicação é no desenvolvimento de novos métodos para a estimativa da dimensão fractal. Por fim, são estudadas técnicas que melhorem o uso destes descritores, como a análise de dados funcionais e transformada multiescala. Nos capítulos seguintes, faz-se um resumo de cada tópico estudado.

\subsection{Organização}

O presente trabalho está dividido em oito capítulos incluindo esta introdução, na qual se faz a contextualização do trabalho e são apresentados os objetivos propostos. No capítulo 2 , discutem-se as definições básicas de fractais e sua aplicação na análise de objetos da natureza. No capítulo seguinte é feita uma descrição teórica dos conceitos relacionados à geometria fractal que são necessários para o entendimento do restante do projeto. Assim, define-se o conceito de objeto e dimensão fractal e são apresentados métodos para o cálculo desta dimensão. No capítulo quatro, são abordadas as deficiências da dimensão fractal na análise de imagens e as propostas da literatura para sanar estes problemas. No capítulo seguinte, aborda-se o núcleo deste trabalho, que é toda a metodologia desenvolvida a partir do conceito de descritores fractais. Nele, são mostradas as diferentes possibilidades exploradas de obtenção destes descritores e de aplicações em análise de texturas. O sexto capítulo apresenta informações sobre as ferramentas empregadas nos experimentos que visam validar a metodologia proposta. $\mathrm{O}$ capítulo 7 mostra os resultados dos experimentos para os métodos propostos, bem como uma comparação com outras abordagens de análise de texturas conhecidas na literatura e ainda 
uma discussão sobre os resultados alcançados. Finalmente, o oitavo capítulo apresenta as conclusões relativas aos resultados obtidos. 


\section{CAPÍTULO 2}

\section{Geometria Fractal}

Neste capítulo, é apresentado o conceito de fractal, além da motivação para o emprego da geometria fractal na extração de características de objetos representados em imagens digitais. Fractais são estruturas complexas compostas a partir de partes simples e caracterizadas pela auto-similaridade, ou seja, cada parte é composta de outras partes semelhantes. Embora não sejam fractais em sua concepção matemática, muitas formas e cenários da natureza podem ser modelados como tal, uma vez que possuem alto nível de complexidade e aspecto auto-similar, ainda que em um intervalo limitado de escalas. Neste contexto, surgiram várias aplicações da geometria fractal em reconhecimento de padrões e visão computacional.

\subsection{Introdução aos Fractais}

Do ponto de vista matemático, um objeto fractal é definido como sendo a estrutura geométrica (conjunto de pontos) cuja dimensão de Hausdorff-Besicovitch (ver definição na Seção 3.1) excede estritamente a dimensão Euclidiana (topológica) (1). Basicamente, esta definição reafirma que um fractal deve ser um objeto auto-similar, mas também com grau infinito de complexidade.

Na prática, um fractal é uma estrutura geométrica caracterizada pela auto-similaridade infinita, isto é, cada parte é sempre uma cópia (alterada apenas por transformações geométricas simples) do objeto todo. Entretanto, esta propriedade não é suficiente para caracterizar um objeto como fractal, uma vez que até mesmo uma reta possui auto-similaridade infinita. Assim, um fractal também deve ser uma estrutura de complexidade infinita, no sentido de que em cada nível de escala sempre podem ser observados diferentes detalhes que não estão presentes em outros níveis. Outro aspecto singular dos fractais é que esta complexidade surge a partir de estruturas básicas e regras simples que vão sendo iteradas até o limite para o infinito. Este 
fato também permite que um fractal seja analisado como um sistema dinâmico não-linear, de natureza caótica.

De um modo geral, todos os fractais podem ser representados por um sistema dinâmico (30, 31) e todo sistema deste tipo pode ser perfeitamente caracterizado por um ponto inicial $x_{0}$ e uma função $f$ que é aplicada iterativamente sobre $x_{0}$, de tal forma que

$$
x_{k+1}=f\left(x_{k}\right) .
$$

De particular interesse na geometria fractal, é o caso em que a função iterada age sobre o plano complexo, isto é: $f\left(z_{k}\right): \mathbb{C} \rightarrow \mathbb{C}$. Neste caso, o conjunto de pontos $z_{k}$ formado pela iteração de $f$ sobre $z_{0}$ é chamado de órbita de $z_{0}$. Este conjunto pode apresentar dois comportamentos distintos. A órbita pode ser progressiva, quando o módulo $\left\|f^{n}\left(z_{0}\right)\right\|$ cresce indefinidamente tendendo ao infinito, ou regressiva, quando o $\operatorname{limite}_{\lim } \operatorname{lom}_{n \rightarrow \infty}\left\|f^{n}\right\|$ tende à origem do plano complexo. No caso da órbita progressiva, diz-se que o infinito é um atrator e o conjunto de pontos que possuem atrator infinito formam a chamada bacia de atração ao infinito $B_{\infty}$ :

$$
B_{\infty}=\left\{z \in \mathbb{C}: \lim _{k \rightarrow \infty}\left\|f^{k}(z)\right\|=\infty\right\} .
$$

No caso de órbitas regressivas, formam-se igualmente as bacias de atração $B_{0}$ :

$$
B_{0}=\left\{z \in \mathbb{C}: \lim _{k \rightarrow \infty}\left\|f^{k}(z)\right\|=0\right\}
$$

Uma generalização da bacia de atração é o chamado conjunto de confinamento $K$, dado por:

$$
K=\left\{z \in \mathbb{C}:\left\|f^{k}(z)\right\|<\delta, \forall k \in \mathbb{Z}, \delta>0\right\}
$$

A Figura 2.1 ilustra um exemplo bem conhecido de fractal gerado por um sistema dinâmico no plano complexo: o fractal de Julia. Este é obtido a partir da função $f(z)=z^{2}+c$, em que $c$ também é um número complexo. No caso da figura, $c=0.2+0.65 i$.

A auto-similaridade e a complexidade são características que sugerem fortemente o uso da geometria fractal na modelagem de objetos do mundo real (32). De fato, quando se observam objetos na natureza, como uma nuvem ou uma montanha, por exemplo, nota-se facilmente que o grau de detalhes presentes na estrutura, em cada nível de escala, é alto. Tal complexidade torna a modelagem Euclidiana clássica muitas vezes limitada. É perceptível, por exemplo, que uma nuvem não pode ser representada com fidelidade por um elipsoide nem uma montanha por um cone. Outro aspecto favorável ao uso da modelagem fractal é o fato de que muitas formas na natureza apresentam uma auto-similaridade intrínseca, ainda que apenas em certo 


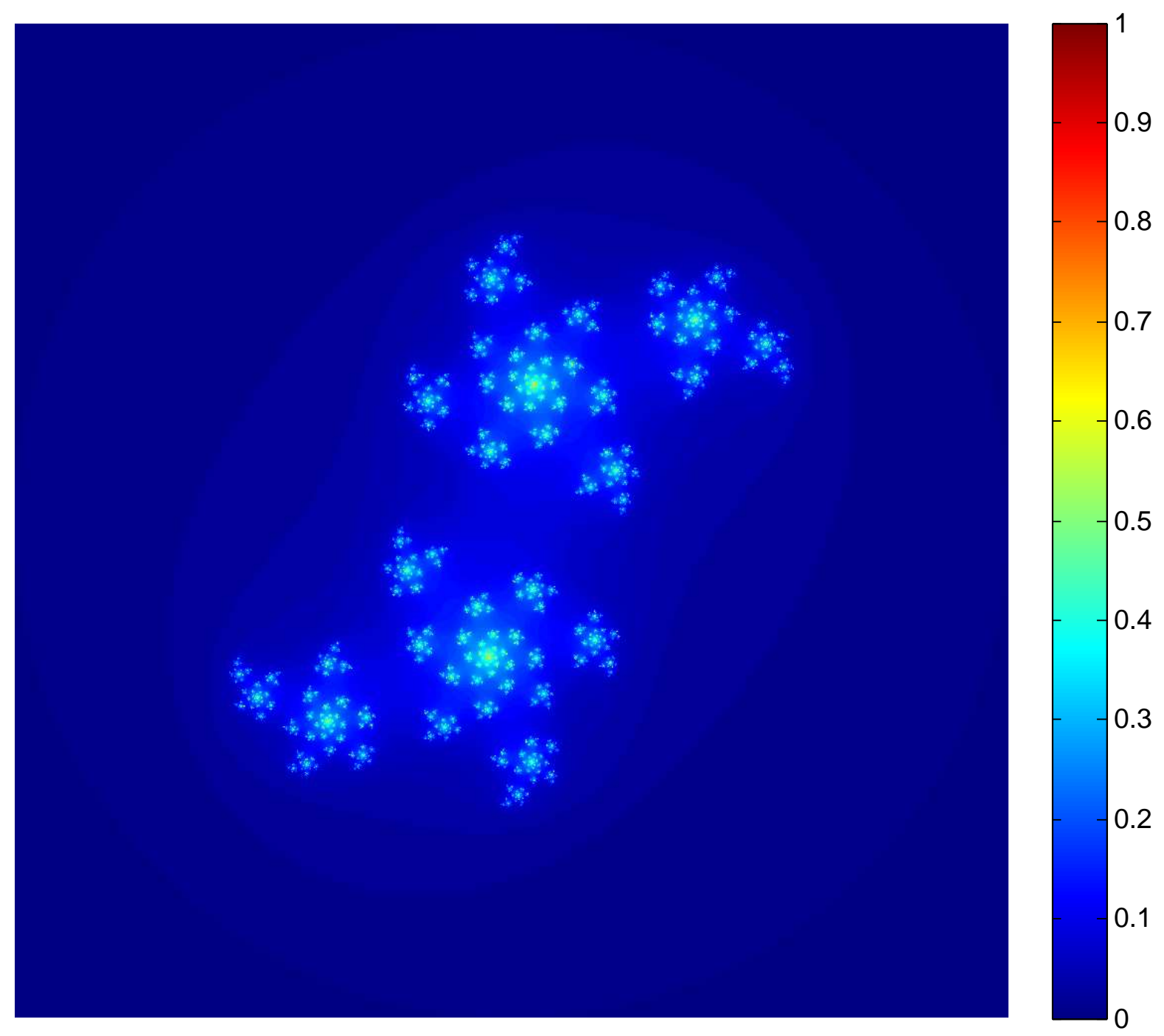

Figura 2.1 - Fractal de Julia: um exemplo clássico de fractal gerado por sistema dinâmico não-linear no plano complexo. O sistema é governado pela função $f(z)=z^{2}+c$ e são exibidas as 100 primeiras iterações. Os pontos em tonalidades escuras representam a bacia de atração ao infinito. As regiões tendendo para um tom mais claro correspondem aos confinamentos. 
intervalo de escalas. É o caso, por exemplo, da ramificação dos afluentes de um rio, da folha de uma samambaia ou da ramagem de muitas outras árvores ou ainda dos bronquíolos no pulmão humano, entre muitos outros exemplos.

A partir destas observações, a literatura vem apresentando um número crescente de aplicações da teoria fractal nos mais variados campos da ciência.

\subsection{Tipos de Fractais}

Existem basicamente três categorias de objetos fractais: os geométricos, os não-lineares e os aleatórios, também chamados de probabilísticos (33).

No primeiro grupo estão os fractais formados a partir de estruturas geométricas simples, pela aplicação de regras iterativas também simples, mas que, quando o número de passos da iteração tende ao infinito, gera um objeto de complexidade infinita como o fractal deve ser. Estes fractais costumam ser descritos por um sistema de funções iteradas, funções simples e lineares que são aplicadas iterativamente sobre um conjunto inicial. Exemplos desta categoria são a curva de Koch, o triângulo de Sierpinski, a esponja de Menger, etc.

Já os fractais não-lineares são aqueles obtidos por regras complexas representadas por funções não lineares, por exemplo, por funções de variáveis complexas. Chamados também de fractais de fuga, estes objetos são gerados em computadores de alto poder de processamento e apresentam um nível de complexidade que faz com que, embora sejam determinísticos, seja praticamente impossível fazer qualquer previsão a respeito do comportamento destas estruturas após cada iteração. Exemplos destes fractais são os conjuntos de Mandelbrot e de Julia.

A terceira categoria, chamada de fractais aleatórios, corresponde a objetos que são gerados a partir de funções de densidade de proabilidade, como a Gaussiana, e que são usados para modelar objetos da natureza, como montanhas e plantas, por exemplo. São usados também em computação gráfica para a construção de cenários artificiais que imitam o mundo real.

A Figura 2.2 ilustra um exemplo para cada categoria de fractal.

Os fractais também podem ser classificados quanto ao tipo de auto-similaridade presente. Novamente existem três categorias relacionadas a cada tipo de fractal discutido nesta seção.

O primeiro tipo é a auto-similaridade exata, quando o fractal é claramente idêntico em diferentes níveis de escala. Tal propriedade costuma ser observada nos fractais geométricos 


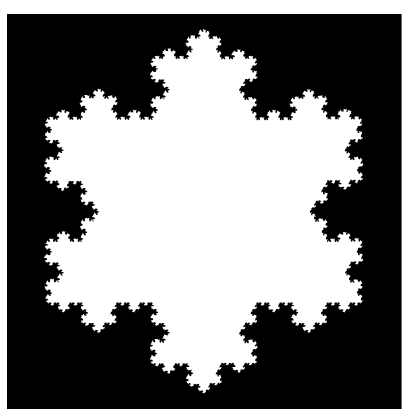

(a)

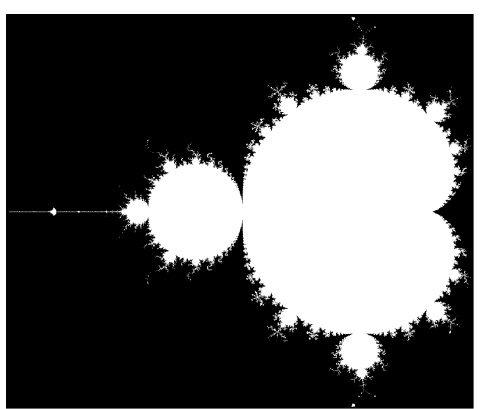

(b)

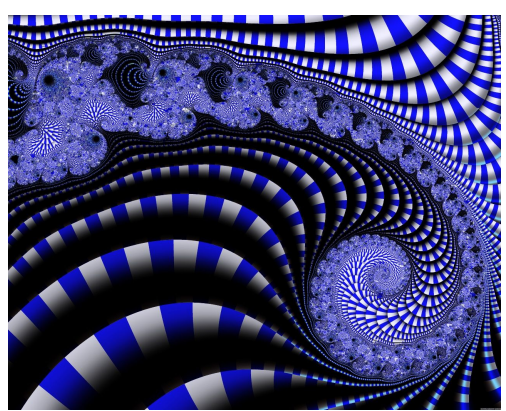

(c)

Figura 2.2 - Exemplos de fractais de diferentes categorias. Probabilístico.

a) Geométrico. b) Não-linear. c)

formados por sistemas de funções iteradas.

Já a segunda categoria é a chamada quase auto-similaridade, quando as estruturas não são exatamente iguais, mas sim semelhantes em diferentes escalas. Este tipo de característica é amplamente encontrado em fractais não-lineares.

Por fim, a auto-similaridade estatística é encontrada em fractais aleatórios e, nestes casos, a repetição de padrões em diferentes escalas é menos evidente, mantendo-se apenas algumas medidas numéricas e estatísticas específicas em diferentes escalas.

\subsection{Propriedades dos Fractais}

Para ilustrar algumas das mais relevantes propriedades de um fractal, Falconer (34) usa como exemplo o conjunto de Cantor, ilustrado na Figura 2.3. Inicialmente, parte-se do segmento de reta de comprimento unitário correspondente ao intervalo $[0,1]$. Este é, em seguida, dividido em três partes iguais. A parte que fica no meio é apagada. Este processo é repetido com cada segmento que vai sendo preservado: sempre se divide em três partes e apaga-se a parte intermediária. No limite quando este procedimento tende a um número infinito de repetições, obtém-se o fractal de Cantor.

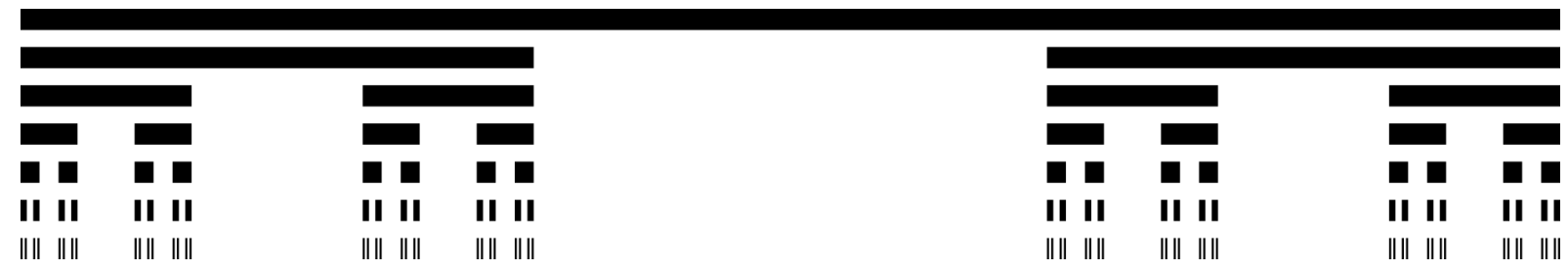

Figura 2.3 - Primeiras iterações do conjunto de Cantor: um exemplo clássico de fractal. 
As propriedades mais importantes deste e dos fractais de um modo geral são listadas a seguir.

- Dimensão Fractal: Diferentemente dos objetos Euclidianos que possuem dimensão sempre inteira, a dimensão fractal pode ser qualquer valor real não-negativo. No caso de Cantor, por exemplo, sua dimensão é $\log (2) / \log (3)$.

- Auto-similaridade: Nota-se, por exemplo, que o segmento no intervalo $[0,1 / 3]$ ou $[2 / 3,1]$ é similar geometricamente ao segmento $[0,1]$, apenas reduzido de escala por um fator de $1 / 3$.

- Estrutura fina: o fractal apresenta detalhes ricos em qualquer escala em que seja analisado.

- Definição simples: embora a estrutura seja de alta complexidade, as regras que definem o fractal são simples e diretas.

- Recursividade: os fractais costumam ser gerados por procedimentos recursivos. No caso de Cantor, esta recursão existe na repetição do ato de eliminar o terço intermediário do segmento.

- Geometria: a geometria convencional falha em descrever satisfatoriamente estes objetos, uma vez que eles não podem ser tratados como simples conjuntos de pontos nem como solução de uma determinada equação simples.

- Falta de representação local: As medidas locais de um fractal não possuem utilidade prática, já que na vizinhança existem muitos pontos com comportamento geométrico discrepante.

- As medidas Euclidianas não são capazes de descrever nenhuma característica importante do fractal. Por exemplo, o comprimento do conjunto de Cantor é zero. Outro caso clássico é o fractal chamado "floco de neve", que apresenta a aberração (do ponto de vista Euclidiano) de possuir área finita e perímetro infinito.

\subsection{Geometria Fractal na Natureza}

A seção seguinte trata de duas abordagens bem conhecidas na literatura, que modelam com grande precisão objetos do mundo real, sobretudo os naturais, por meio de sistemas que também são usados para gerar objetos fractais matemáticos. 


\subsubsection{Sistemas- L}

Como observado tão didaticamente por Benoit Mandelbrot (1) no livro que deu origem à formalização da geometria fractal tal como se conhece hoje, a geometria da natureza é inerentemente fractal. A geometria clássica (Euclidiana) não é capaz de representar toda a complexidade presente na ramificação de uma árvore, na nervura de uma folha, no formato fragmentado de uma nuvem, etc.

Entretanto, ao contrário do que se possa imaginar inicialmente, toda essa complexidade é constituída de elementos simples, seguindo regras simples e que somente após um número muito grande de passos (iterações) gera uma estrutura tão rica em detalhes. Este mecanismo está em plena conformidade com a teoria morfogênica da emergência multicelular (35), segundo a qual a natureza é composta por blocos que interagem entre si, adquirindo características complexas que não seriam possíveis a partir de uma sobreposição simples. Do ponto de vista biológico, este processo se deve ao mecanismo de multiplicação e especialização das células de um ser vivo, mecanismo este que leva, por exemplo, uma semente a gerar uma árvore tão maior e mais complexa do que a estrutura que a gerou.

Na década de 60, o botânico holandês Aristid Lindenmayer (36), observando essa característica modular e iterativa da natureza, propôs um sistema de modelagem do desenvolvimento de plantas baseado em regras de produção e substituição, derivado das gramáticas de Chomsky (37).

O método proposto, chamado hoje de Sistema-L $(36,38)$ difere da modelagem de Chomsky pelo fato de os eventos no tempo ocorrerem de forma paralela, exatamente como ocorre em uma planta, por exemplo, em que o desenvolvimento de diferentes órgãos se dá paralelamente e muitas vezes seguindo estratégias idênticas.

A ideia geral é que se parta de um organismo multicelular inicial, geralmente representado computacionalmente por uma cadeia de caracteres e de um conjunto de regras que operam sobre estes caracteres ao longo de um determinado número de passos para assim formar uma estrutura de alta complexidade, como uma samambaia, por exemplo. Desta forma, pode se dizer que estes sistemas se baseiam em dois pilares: reescrita e desenvolvimento modular.

O mecanismo de reescrita permite a criação de objetos complexos a partir de estruturas simples, por meio da substituição iterativa de partes do conjunto formado em cada passo. Quais partes e de que forma estas serão transformadas é o que é determinado pelas regras de produção definidas inicialmente. 
Já o conceito de desenvolvimento modular se refere ao uso de unidades básicas, os chamados módulos, que vão sendo transformadas em um ou mais módulos (chamados módulos sucessores), à medida que o Sistema-L vai evoluindo no tempo.

A Figura 2.4 exibe alguns exemplos de estruturas modeladas por Sistemas- $L$ e que se assemelham fortemente a plantas encontradas na natureza.
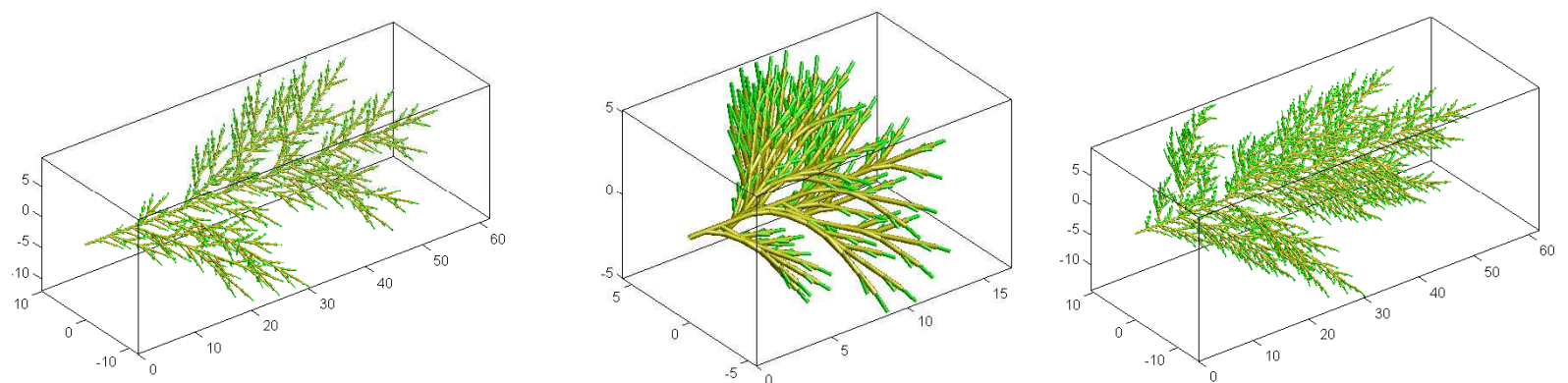

Figura 2.4 - Três exemplos de Sistemas-L modelando plantas. Nota-se a semelhança com espécies do mundo real.

Na prática, um Sistema- $\mathrm{L}$ se define por um alfabeto $V$ (espaço dos caracteres que poderão aparecer na estrutura em cada passo), um conjunto inicial de caracteres $\omega$ (organismo embrionário) e um conjunto de regras $P$ que mapeiam cada caracter em outro(s). Um exemplo de Sistema-L é o seguinte:

$$
\begin{aligned}
& L=(V, \omega, P) \\
& V=(A, B) \\
& \omega=A \\
& P=(A \rightarrow A B A, B \rightarrow B B B)
\end{aligned}
$$

Para fins práticos, os Sistemas-L também possuem representação gráfica. Para isso, cada elemento do alfabeto é substituído por instruções para o computador exibir na tela como, por exemplo, mover o cursor à frente, desenhar uma reta horizontal, mover-se $90^{\circ}$, etc. Assim, no caso do exemplo de sistema descrito anteriormente, se considerado o $A$ como "mova-se para a frente" e o $B$ como "desenhe uma reta no sentido do cursor", obtém-se exatamente o conjunto de Cantor, descrito anteriormente e um dos primeiros fractais descobertos pelos matemáticos, quando esses objetos ainda eram conhecidos por "curvas-monstros".

O fato dos sistemas- $L$ serem amplamente usados para a obtenção de fractais matemáticos na representação em computadores fornece uma informação importante: as plantas que são tão bem modeladas por este sistema guardam várias propriedades em comum com os fractais. De fato, a estratégia de composição dos objetos usada na teoria de Sistemas-L leva diretamente a um caráter fortemente auto-similar dos objetos gerados, em função da substituição de módulos 
por cópias similares em outras escalas.

O caráter inerentemente fractal dos Sistemas- $L$ associado à sua precisão na modelagem de objetos da natureza, como plantas, rios e órgãos humanos, mostrou claramente o quanto a geometria fractal é a teoria que de fato mais se aproxima da "linguagem" da natureza, linguagem esta que constrói estruturas altamente complexas a partir de blocos simples e aplicando regras geométricas básicas sobre estes blocos indefinidamente (39). Este mesmo raciocínio levou o próprio Mandelbrot a formalizar a teoria fractal, dado seu papel tão importante para a ciência, e a afirmar que a natureza não só é bem modelada por esta geometria como ela em si é fractal de fato.

A Figura 2.5exemplifica estruturas típicas da natureza com forte característica auto-similar e complexa.
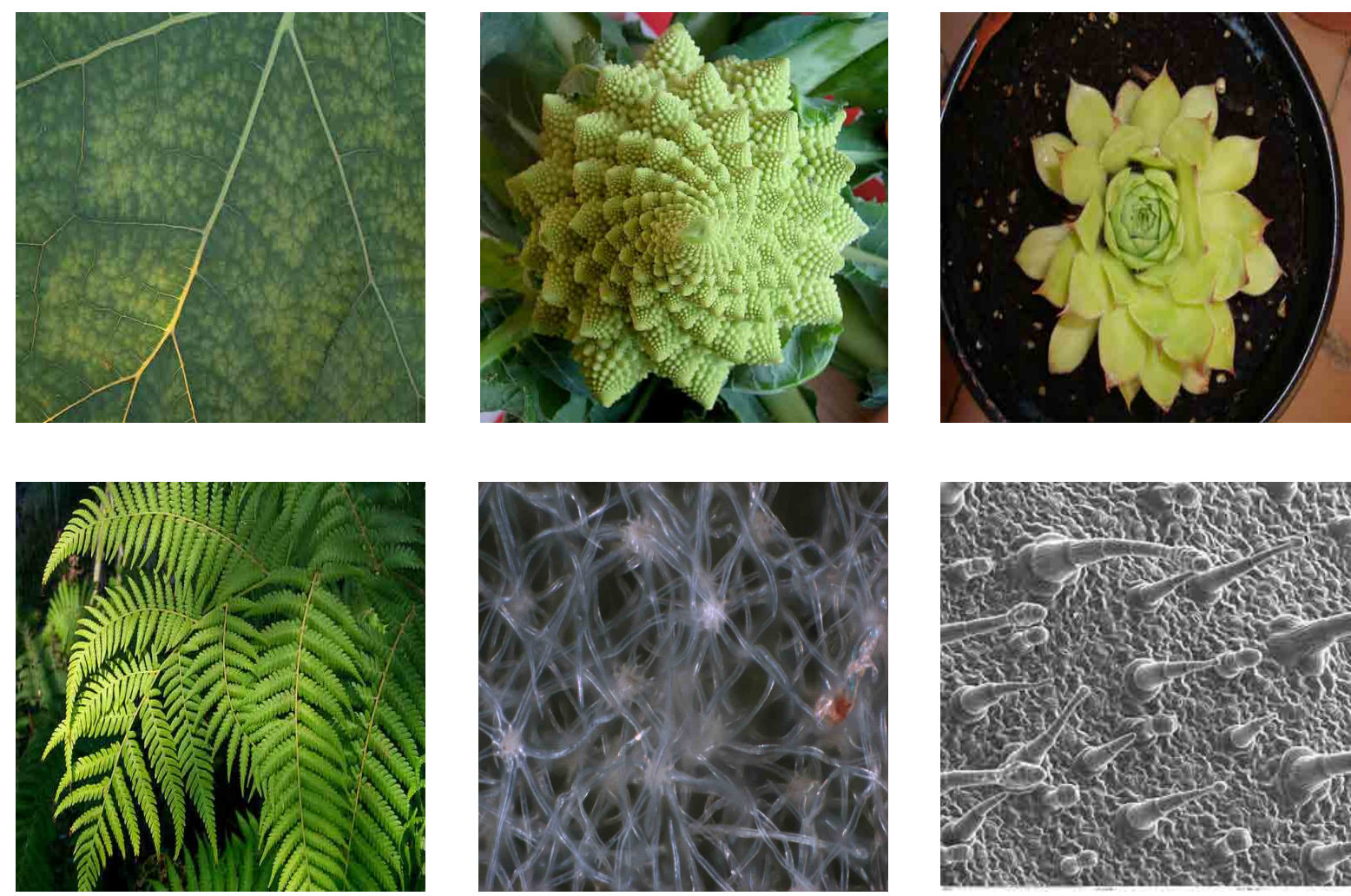

Figura 2.5 - Imagens da natureza com aspecto altamente semelhante ao dos fractais matemáticos.

\subsubsection{Sistema de funções iteradas}

Sistema de funções iteradas (sigla IFS, em Inglês) é um método amplamente empregado na literatura, tanto para a geração de fractais matemáticos, quanto de estruturas de característica 
fractal e de grande semelhança com objetos encontrados na natureza (39-41).

A estratégia consiste em se aplicar iterativamente uma transformação $\omega: X \rightarrow X$ sobre um conjunto de pontos $S \subset X$, de modo que para cada ponto $x \in S, f_{1}(x)=f(x)$, $f_{2}(x)=f\left(f_{1}(x)\right), \ldots, f_{k}(x)=f\left(f_{k-1}(x)\right)$.

Geralmente, a transformação usada é do tipo afim, que em $\Re^{2}$ pode ser definida por:

$$
\omega(\vec{x})=\omega\left(\begin{array}{l}
x_{1} \\
x_{2}
\end{array}\right)=\left(\begin{array}{ll}
a & b \\
c & d
\end{array}\right)\left(\begin{array}{l}
x_{1} \\
x_{2}
\end{array}\right)+\left(\begin{array}{l}
e \\
f
\end{array}\right),
$$

em que $a, b, c, d$, e e $f$ são parâmetros reais que, em princípio, podem variar livremente. Para toda transformação afim, pode se encontrar um valor real não-negativo $s$, chamado constante de Lipschitz, tal que:

$$
\|\omega(\vec{x})-\omega(\vec{y})\| \leq s|| \vec{x}-\vec{y} \| \text { para qualquer vetor } \vec{x} \text { e } \vec{y} \text { em } X \text {. }
$$

A transformada é chamada contrativa se $s<1$.

O chamado código IFS é dado então pela associação de $N$ transformações afins $\omega_{i}$ com $N$ probabilidades $p_{i}$, tais que:

$$
\sum_{i=1}^{N} p_{i}=1
$$

e as transformações obedeçam ao critério de contratividade média:

$$
\prod_{i=1}^{N} s_{i}^{p_{i}}<1
$$

Satisfeitas as condições, o IFS é dado então por:

$$
I F S=\left\{\omega_{n}, p_{n}: n=1,2, \ldots, N\right\}
$$

Um importante teorema apresentado por Barnsley (39) demonstra que qualquer conjunto $S \in \mathfrak{H}(X)$, em que $\mathfrak{H}(x)$ é o espaço dos subconjuntos compactos não vazios de $X$, com métrica de Hausdorff, pode ser aproximado arbitrariamente do atrator $A$ de algum IFS, isto é:

$$
h\left(S, \bigcup_{n=1}^{N} \omega_{n}(S)\right) \leq \epsilon,
$$

em que $h$ é a distância de Hausdoff definida sobre o espaço métrico $(X, d)$ :

$$
h(A, B)=\max \left\{\sup _{a \in A} \inf _{b \in B} d(a, b), \sup _{b \in B} \inf _{a \in A} d(a, b)\right\} .
$$


Os resultados obtidos por Barnsley são impressionantes, uma vez que ele consegue reproduzir estruturas da natureza como, por exemplo, uma samambaia, fazendo apenas pequenas alterações no código que poderia ser usado para gerar um triângulo de Sierpinski, ou seja, um fractal matemático. Outro aspecto importante é que se usa pouca informação (apenas o código IFS) para se obter uma estrutura tão rica quanto um fractal matemático ou uma samambaia (42). Este fato, que é a base para os métodos de compressão fractal (43), também confirma uma propriedade intríseca dos fractais que é o fato de serem gerados a partir de regras simples que propiciam uma estrutura mais complexa apenas em função da longa sequência de iterações.

Este comportamento presente no mecanismo de IFS também é notado o tempo todo na natureza. Desde o processo de divisão celular nos seres vivos ou na sedimentação do terreno que vai moldando uma montanha ao longo do tempo, pode se observar que a complexidade está na repetição, que em uma janela de tempo fixa aparenta ser completamente aleatória, mas que tende para um atrator, de forma muito semelhante ao que ocorre na execução dos códigos IFS.

A Figura 2.6 exibe alguns atratores de IFS conhecidos e que apresentam alta semelhança com cenários encontrados na natureza.
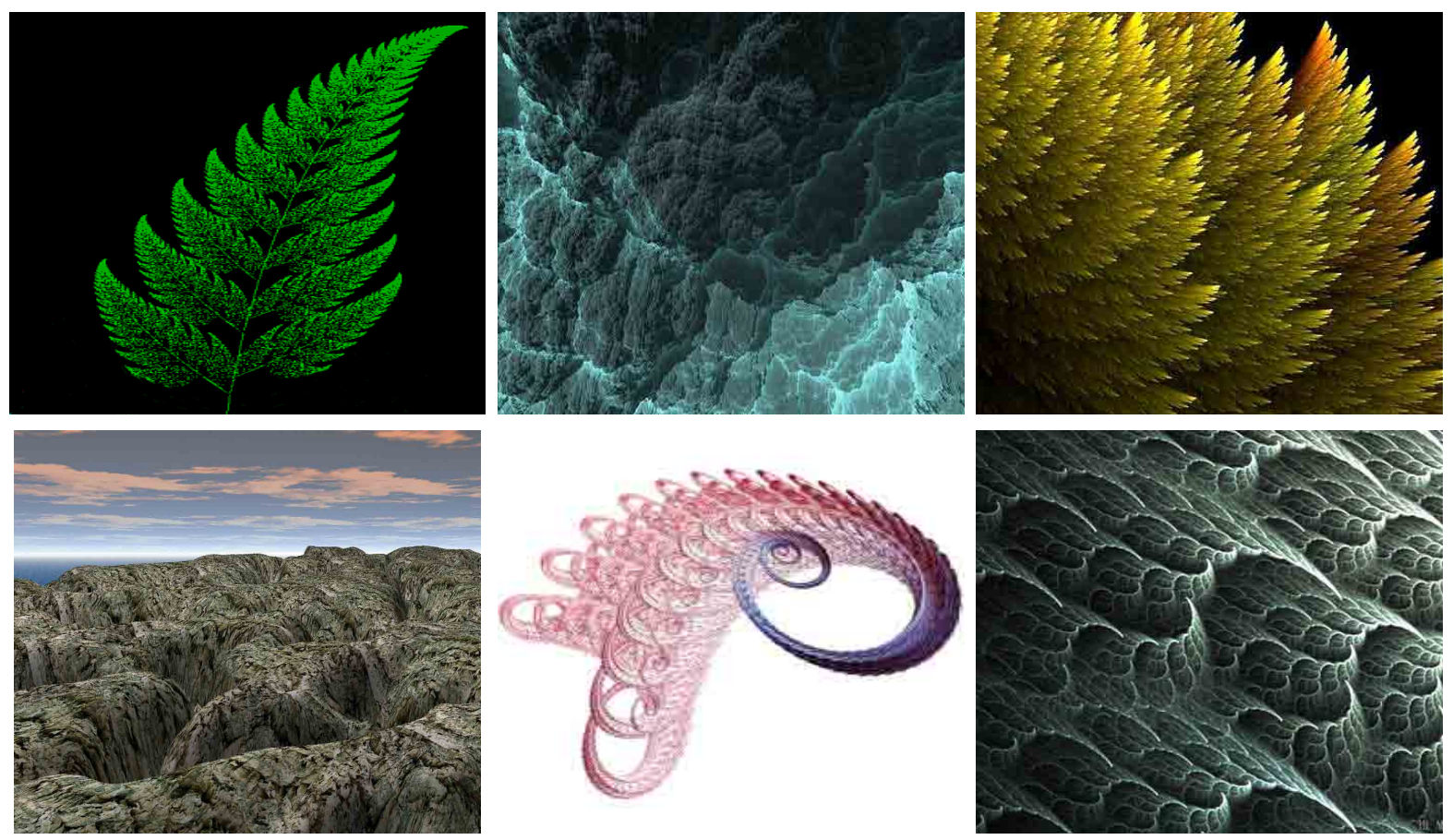

Figura 2.6 - Exemplos de estruturas geradas por IFS em duas e três dimensões e que se assemelham a cenários encontrados na natureza. 


\subsection{Geometria Fractal em Análise de Imagens}

Desde tempos remotos, o homem observa que a natureza é composta por estruturas demasiado complexas para serem representadas por figuras Euclidianas simples como círculos, retas e cilindros. A representação Euclidiana destes objetos, além de exigir um complexo processo de aproximação por partes, ainda gera um modelo do qual é difícil de se extraírem medidas relevantes que caracterizem o objeto modelado.

Um trabalho pioneiro que começou a estudar este desafio de encontrar medidas significativas para uma estrutura complexa foi apresentado por Lewis F. Richardson (44), um meteorologista inglês, em 1961. Na tentativa de medir o comprimento da ilha britânica através de um mapa, ele observou que, quando variava o comprimento da unidade de medida, o comprimento total da costa não variava linearmente como esperado, mas sim exponencialmente.

Paralelamente a isso, como visto na seção anterior, Lindenmayer propunha seu Sistema-L de modelagem de plantas (36), que reafirmava o caráter auto-similar e complexo das estruturas na natureza.

Mais tarde, Mandelbrot concluiu que esta propriedade descoberta por Richardson também surgia em objetos fractais e estava relacionada à auto-similaridade destas estruturas. Essa mesma auto-similaridade havia sido apontada nas plantas por Lindenmayer, então colega de pesquisa de Mandelbrot. A partir daí, toda a teoria fractal foi formalizada e demonstrou-se que a geometria fractal apresentava a modelagem ideal para objetos encontrados na natureza, fato este que é confirmado posteriormente pelo trabalho de Barnsley e seus colegas sobre modelagem IFS (50).

Entretanto, dada a dificuldade de se calcular manualmente a dimensão fractal de um objeto e com a popularização dos programas de computador, surgia uma nova abordagem e uma nova dúvida (45). Os objetos passavam então a ser representados computacionalmente por meio de imagens digitais, ou seja, por matrizes de pixels com valores de intensidade e cor. Mas aí surgia o questionamento se os métodos de modelagem por dimensão fractal em imagens seriam tão eficientes quanto a análise executada diretamente a partir da estrutura do objeto analisado.

Pentland (46, 47) respondeu esta pergunta por meio da análise de uma distribuição estatística dos pixels em uma imagem e da relação que esta distribuição apresenta, tanto com a distribuição das normais da superfície física representada, quanto com um movimento Browniano bidimensional, um exemplo clássico de fractal. 
Uma função aleatória $I(x)$ é dita ser Browniana fractal se obedecer à função de distribuição acumulada $F(y)$ :

$$
\operatorname{Pr}\left(\frac{I(x+\Delta x)-I(x)}{\|\Delta x\|^{H}}<y\right)=F(y),
$$

em que $\Delta x$ é um deslocamento e $H$ é o chamado coeficiente de Hurst. Note-se que $I(x)$ pode ser uma função de múltiplas dimensões. Se $I(x)$ for escalar, a dimensão fractal é dada por:

$$
D=2-H
$$

e para o caso em que $H=1 / 2$ e $F(y)$ vem da Gaussiana padronizada, tem-se o movimento Browniano clássico.

Em uma imagem real, o valor de $H$ pode ser inferido a partir da relação entre o espectro de potência $P(f)$ e a frequência $f$ :

$$
P=f^{-2 H-1}
$$

O procedimento é o mesmo usado na estimativa da dimensão fractal por Fourier, descrito na Seção 3.4 .3 .

Pentland demonstra que a grande maioria das superfícies naturais são espacialmente isotrópicas fractais, isto é, as componentes da normal da superfície em cada ponto $N=$ $\left(N_{x}, N_{y}, N_{z}\right)$ obedecem à distribuição 2.5.1 e possuem dimensão fractal idêntica. Esta propriedade é demonstrada tanto pela aplicação de propriedades típicas do movimento Browniano, quanto por experimentos feitos com linguistas, avaliando a correlação entre a dimensão fractal estimada pelo modelo Browniano e uma estimativa do quão rugosas/suaves as superfícies eram na opinião de especialistas em linguagem humana.

Pentland ainda obtém um importante resultado que afirma que uma superfície Browniana fractal espacialmente isotrópica produz uma imagem cujas intensidades dos pixels compõem uma função fractal Browniana e cuja dimensão fractal é idêntica à dimensão dos componentes da normal, dado que a superfície apresenta refletância Lambertiana, iluminação e albedo constantes.

Desta forma, a modelagem Browniana e, consequentemente, a aplicação da geometria fractal sobre a imagem extrai características fundamentais da superfície modelada.

Peleg et al.(48), entretanto, observou que a dimensão fractal da imagem (e da superfície, por consequência) varia dependendo do intervalo escolhido para análise. Esta observação dá origem aos métodos que estimam a dimensão em diferentes níveis de escala e que serão abordados mais à frente. 


\section{CAPÍTULO 3}

\section{Dimensão Fractal}

Este capítulo descreve os aspectos teóricos do conceito de dimensão fractal, cujo cálculo pode ser feito analiticamente por Hausdorff-Besicovitch. Aborda-se também a extensão do conceito para objetos que não são fractais de fato. Neste sentido, são discutidos os mais variados métodos usados para estimar numericamente a dimensão destes objetos encontrados no mundo real.

\subsection{Definição}

A dimensão fractal é uma medida da complexidade da estrutura, ou seja, quanto mais detalhes o objeto apresenta nas diferentes escalas, maior sua dimensão. Na prática, ela também mede a ocupação espacial do objeto (49, 50). Embora seja uma medida fundamental de qualquer objeto fractal, a dimensão não possui uma definição de consenso na literatura, uma vez que restrições encontradas em aplicações específicas tornaram necessária a definição de novas métricas, também chamadas de dimensão fractal, por analogia. Entretanto, a definição original, usada na própria definição de fractal, é o da dimensão de Hausdorff-Besicovitch. Esta, por sua vez, é derivada da medida de Hausdorff $\mathfrak{H}_{\delta}^{s}$. Seja o conjunto $X \subset \Re^{n}$ e $s$ e $\delta$ reais não-negativos. Assim:

$$
\mathfrak{H}_{\delta}^{s}(X)=\inf \left\{\sum\left\|U_{i}\right\|^{s} \text { sendo }\left\{U_{i}\right\} \text { uma } \delta \text {-cobertura of } X\right\}
$$

em que $\left\{U_{i}\right\}$ é uma $\delta$-cobertura de $X$ se $X \subset \bigcup_{i=1}^{\infty} U_{i}$, sendo $0<\left\|U_{i}\right\| \leq \delta$.

Partindo da definição anterior, a $s$-medida de Hausdorff $\mathfrak{H}^{s}$ é obtida por:

$$
\mathfrak{H}^{s}(X)=\lim _{\delta \rightarrow 0} \mathfrak{H}_{\delta}^{s}(X)
$$

Um resultado importante demonstrado na Teoria da Medida (51) afirma que a s-medida 
$\mathfrak{H}^{s}(X)$ vale sempre 0 para $s<d_{H}$ e $\infty$ para $s>d_{H}$. O número real não-negativo $d_{H}$ corresponde à dimensão de Hausdorff-Besicovitch ou dimensão fractal de $X$ :

$$
d_{H}(X)=\sup \left\{s \mid \mathfrak{H}^{s}(X)=0\right\}=\inf \left\{s \mid \mathfrak{H}^{s}(X)=\infty\right\}
$$

\subsection{Dimensão Fractal: Analítica $\times$ Numérica}

A literatura apresenta um grande número de trabalhos que extraem um valor da dimensão fractal para objetos do mundo real que não correspondem exatamente à definição matemática de fractal apresentada no capítulo anterior, mas que podem ter sua complexidade estimada pelo valor da dimensão (5, 15-17).

Entretanto, nestes casos, o cálculo analítico da dimensão de Hausdorff-Besicovitch é inviável, essencialmente por três motivos. O primeiro é que estes objetos não podem possuir auto-similaridade infinita, como ocorre com fractais matemáticos, uma vez que sempre vai haver a limitação macroscópica do tamanho do objeto e a microscópica do tamanho do átomo. Um segundo motivo é que a representação destes objetos em imagens digitais, para que a dimensão possa ser obtida de forma eficiente por algoritmos computacionais, esbarra nas limitações da própria representação digital, que traz consigo uma perda de resolução inerente ao processo de amostragem. Assim, estes objetos do mundo real vão possuir sempre um nível de fractalidade (auto-similaridade) limitado a um determinado intervalo de escalas, sendo comum que diferentes intervalos apresentem diferentes níveis de fractalidade e, assim, o valor da dimensão é agora apenas uma aproximação desta fractalidade global. Por fim, o método analítico exige que se conheça a regra de formação do fractal, o que geralmente não é possível no caso destes objetos da natureza.

Desta forma, para tais situações, a literatura vem apresentando uma série de novos métodos para a estimativa da dimensão. Em muitos materiais, é comum que se refira a estes métodos como sendo efetivamente novas definições de dimensão fractal (52, 53). Entretanto, aqui, procura-se sempre realçar que estes são métodos de estimativa, e não de cálculo da dimensão, em oposição ao método analítico de Hausdorff-Besicovitch. Nas próximas seções, são apresentados alguns destes métodos, aqueles que são mais relevantes para o presente estudo. 


\subsection{Dimensão Fractal de Formas}

Os métodos de estimativa da dimensão fractal foram desenvolvidos inicialmente para a análise de objetos que possam ser representados por formas bidimensionais que possam ser expressas em uma imagem por conjuntos de pixels brancos sobre um fundo preto (ou vice-versa, se assim for pré-definido). A seguir, mostra-se o mecanismo empregado para a estimativa da dimensão por dois dos métodos mais conhecidos, Box-counting e Bouligand-Minkowski.

\subsubsection{Dimensão por Box-counting}

Neste caso, a imagem binária que representa o objeto analisado é dividida em uma grade de quadrados de lado $r$. A seguir, conta-se o número $N(r)$ de quadrados que contêm parte(s) do objeto de interesse. $\mathrm{O}$ valor de $r$ é variado exponencialmente, ou seja, usa-se $r=1,2,4,8, \ldots$ até o limite das dimensões da imagem. A dimensão fractal $D$ é estimada por:

$$
D=2-\lim _{r \rightarrow 0} \frac{\log (N(r))}{\log (r)} .
$$

O limite acima é obtido ajustando-se uma reta, por mínimos quadrados, à curva $\log (N(r)) \times$ $\log (r)$. O valor do limite corresponde ao coeficiente angular $\alpha$ da reta ajustada. Como, neste caso, $\alpha$ é negativo, o seu módulo é usado na Equação 3.3.1. Assim:

$$
D=2-|\alpha|
$$

A Figura 3.1 mostra o mecanismo empregado neste método.

\subsubsection{Dimensão por Bouligand-Minkowski}

Nesta abordagem, o objeto de interesse é dilatado morfologicamente (54) por um círculo de raio $r$ e, para cada valor de $r$, calcula-se a área da estrutura dilatada, também chamada de área de dilatação $A(r)$. De modo semelhante ao que ocorria com Box-counting, a dimensão é estimada por:

$$
D=2-\lim _{r \rightarrow 0} \frac{\log (A(r))}{\log (r)}
$$



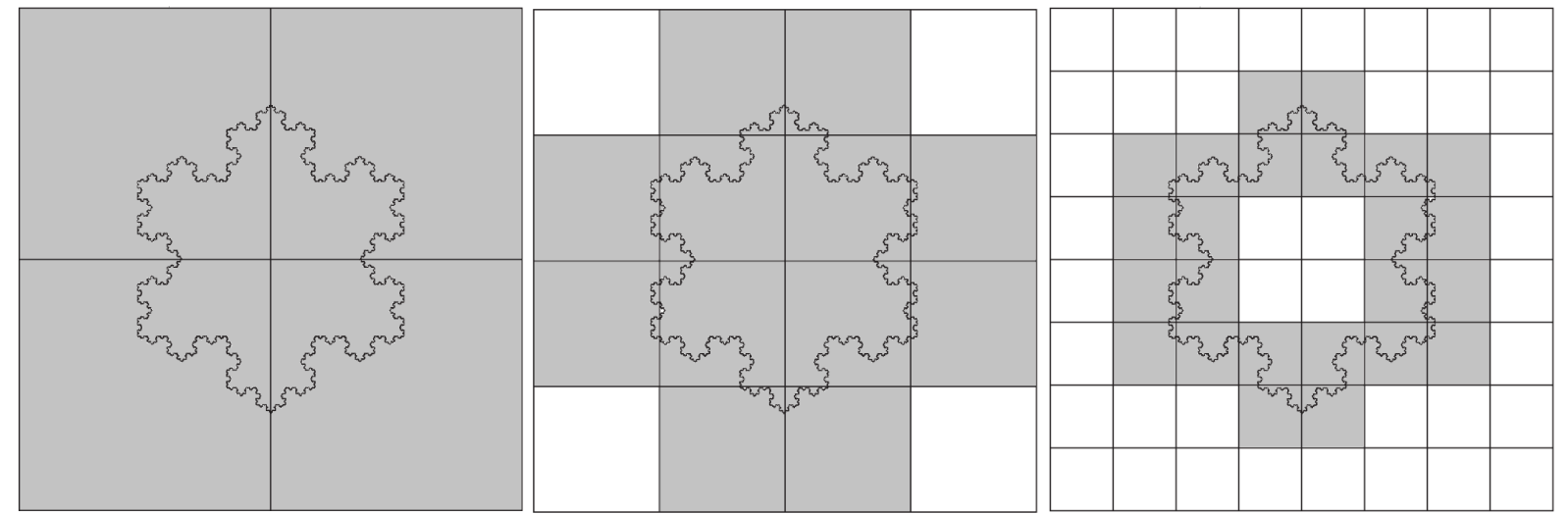

$r=4, N(r)=4$

$r=2, N(r)=12$

$r=1, A(r)=24$

\begin{tabular}{l|l}
$\log (r)$ & $\log (N(r))$ \\
\hline 0 & 4.58 \\
1 & 3.58 \\
2 & 2.00
\end{tabular}

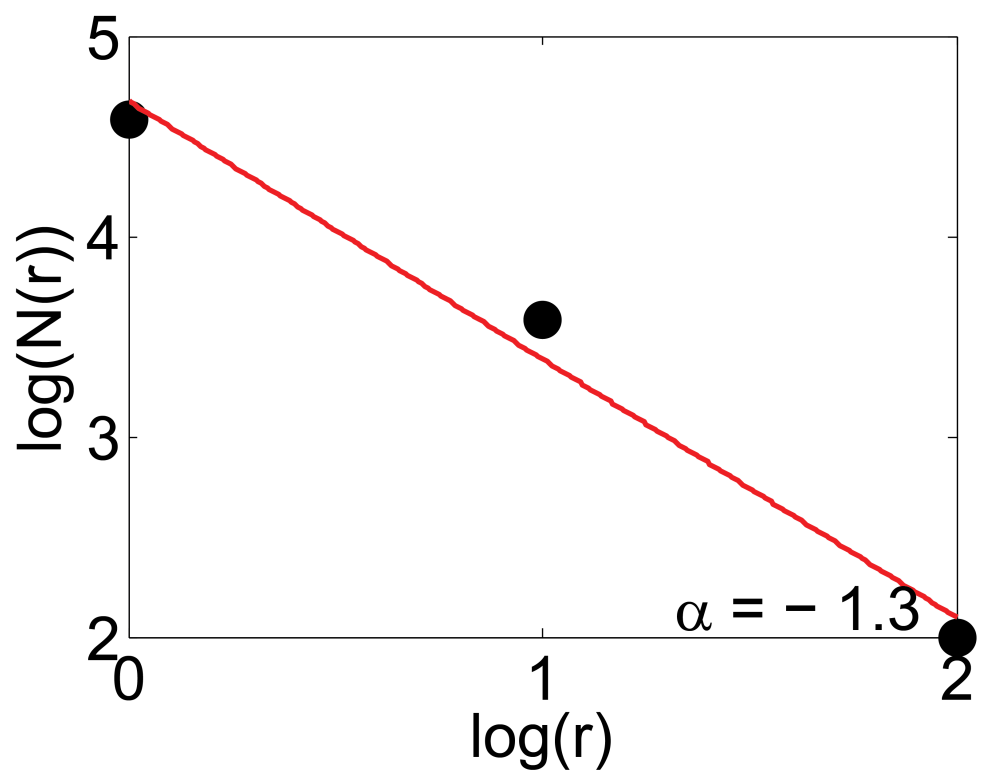

Figura 3.1 - Dimensão fractal por Box-counting. A forma analisada é um fractal clássico, chamado de floco de neve de Koch. Na parte superior, a forma sendo dividida em caixas de tamanhos diferentes. Abaixo, à esquerda, a tabela de valores para $\log (N(r))$ em função $\log (r)$. À direita, o gráfico $\log (N(r)) \times \log (r)$. Os logaritmos usados estão na base 2. Foram usados apenas três pontos a título de ilustração. 
e o limite é obtido novamente a partir do ajuste linear por mínimos quadrados da curva $\log (A(r)) \times \log (r)$.

A Figura 3.1 mostra um exemplo minimalista do funcionamento do método sobre um fractal conhecido.

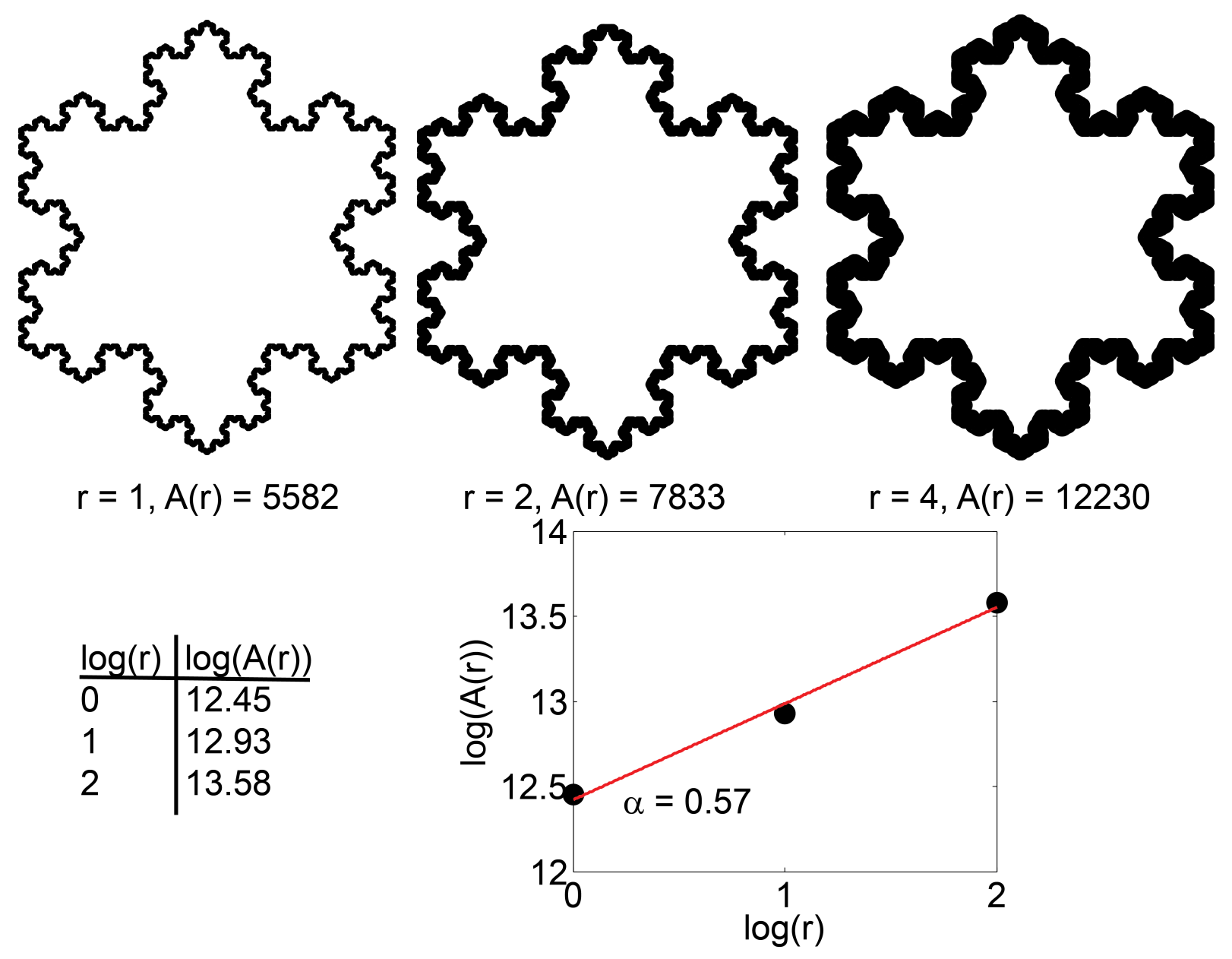

Figura 3.2 - Dimensão fractal por Bouligand-Minkowski. Na parte superior, a forma sendo dilatada por esferas de raios diferentes. Abaixo, à esquerda, a tabela de valores para $\log (A(r))$ em função $\log (r)$. À direita, o gráfico $\log (A(r)) \times \log (r)$. Foram usados apenas três pontos a título de ilustração.

\subsection{Dimensão Fractal Volumétrica}

No caso de uma textura, a dimensão é chamada de volumétrica, uma vez que a imagem em tons de cinza é representada por uma superfície e a dimensão é estimada no espaço tridimensional. A seguir, uma descrição da generalização dos métodos de Box-counting e Bouligand-Minkowski para imagens de texturas. 


\subsubsection{Box-counting}

O Box-counting aplicado sobre uma imagem de textura faz uso de uma transformação espacial da imagem original. No caso, a imagem em tons de cinza $I \in[1: M] \times[1: N] \rightarrow \Re$ é mapeada para uma superfície tridimensional $S$, sendo que cada ponto de coordenada $(x, y, z)$ corresponde a um pixel de coordenada $(x, y)$ e intensidade $z$ na imagem original, isto é:

$$
S=\{i, j, f(i, j) \mid(i, j) \in[1: M] \times[1: N]\}
$$

e

$$
f(i, j)=\{1,2, \ldots, m\} \mid f=I(i, j)
$$

sendo $m$ a intensidade de cinza máxima.

O método é então aplicado de modo similar ao caso da imagem binária, exceto que agora a grade de quadrados é substituída por uma grade tridimensional de cubos. A dimensão é obtida novamente a partir da relação entre o número de cubos $N(r)$ e o comprimento $r$ do lado destes cubos. Assim, a seguinte expressão fornece o valor da dimensão:

$$
D=3-\lim _{r \rightarrow 0} \frac{\log (N(r))}{\log (r)} .
$$

Novamente, o limite é estimado por regressão linear e a dimensão é obtida a partir do coeficiente angular $\alpha$ da reta ajustada:

$$
D=3-|\alpha|
$$

A Figura 3.3 a seguir ilustra as principais etapas do processo.

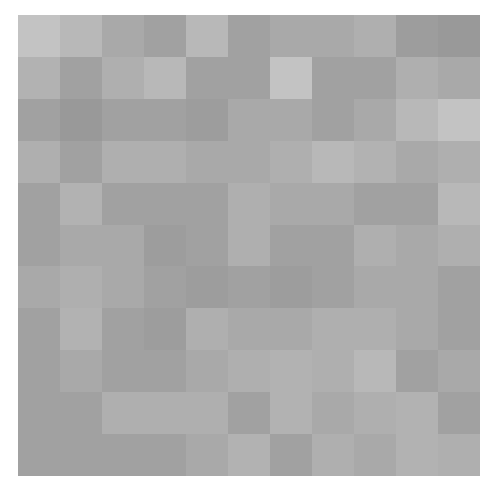

(a)

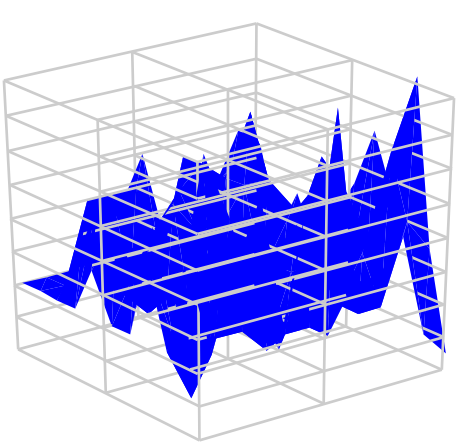

(b)

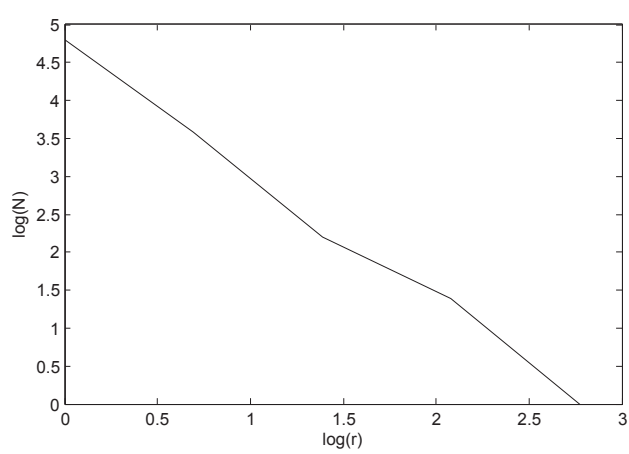

(c)

Figura 3.3 - Método de estimativa de dimensão fractal de textura por Box-counting. a) Imagem em tons de cinza. b) Grade tridimensional envolvendo a superfície de intensidade da imagem. c) Gráfico $\log (N) \times \log (r)$ do qual se extrai a dimensão. 


\subsubsection{Dimensão por Bouligand-Minkowski}

No caso do método de Bouligand-Minkowski (49), inicialmente a imagem em tons de cinza $I$ é mapeada para uma superfície $S$ do mesmo modo que no caso do método de Box-counting. A seguir, cada ponto nesta superfície é dilatado por uma esfera de raio $r$. A dimensão é fornecida pela relação logarítmica entre o volume $V(r)$ da superfície dilatada e o raio de dilatação.

A grosso modo, pode-se dizer que, neste processo, a superfície dilatada é composta pela união de esferas de raio $r$ centradas em cada ponto da superfície inicial. O volume de dilatação corresponde ao número de pontos no interior da estrutura dilatada (54). Mais formalmente, tem-se:

$$
V(r)=\cup B_{r}(s),
$$

em que $B_{r}(s)$ são as esferas de raio $r$ e centro em $s \in S$. Ainda outra forma de expressar o volume de dilatação é a seguinte:

$$
V(r)=\left\{s \in \Re^{3}\left|\exists s^{\prime} \in S:\right| s-s^{\prime} \mid \leq r\right\} .
$$

Com base na equação acima e visando a um melhor desempenho computacional, o volume de dilatação pode ser calculado usando-se a chamada transformada exata da distância, que possui algoritmos clássicos que tornam possível um cálculo bastante eficiente (55).

O processo de dilatação leva ao surgimento de regiões em que os pontos dilatados se chocam criando uma barreira, que é determinada pela ocupação espacial da superfície original. Esse ponto de choque é chamado de frente de onda, por analogia ao fenômeno físico de propagação de sinal, e é fundamental para que o método de Bouligand-Minkowski tenha acurácia na estimativa da dimensão, que acaba sendo também uma medida dessa ocupação no espaço (56). A Figura 3.4 mostra o mapeamento de uma imagem de textura para uma superfície tridimensional, seguido da dilatação de cada ponto da superfície.

\subsubsection{Dimensão por Fourier}

A dimensão fractal por Fourier (52) é obtida a partir da transformada de mesmo nome. Assim, a imagem de intensidade $I(x, y)$ é convertida para a função $\mathfrak{I}$ no espaço de frequências 


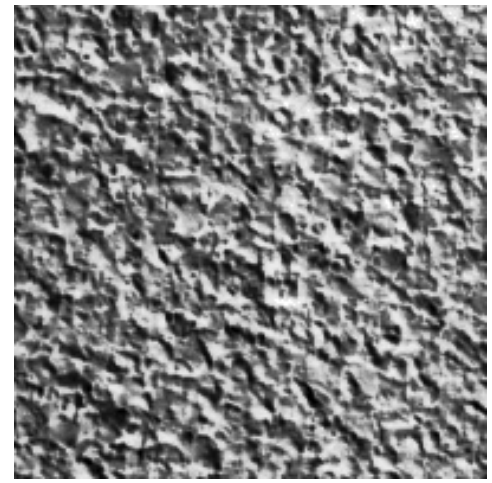

(a)

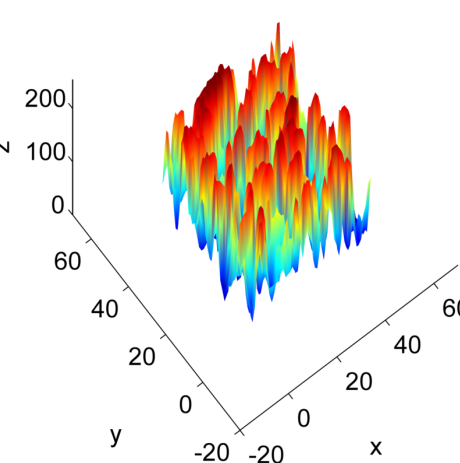

(b)

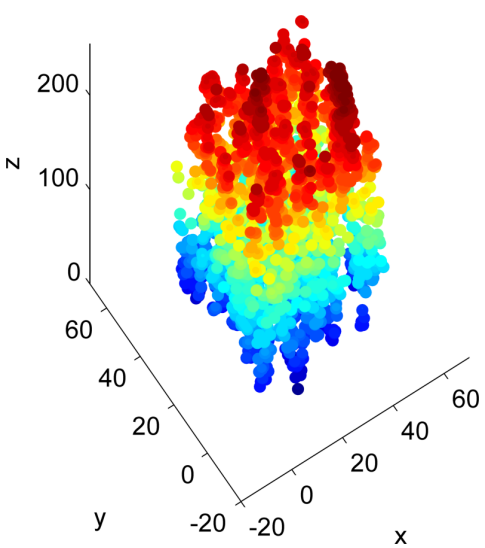

(c)

Figura 3.4 - Processo de dilatação da superfície da intensidade de níveis de cinza no método de Bouligand-Minkowski. a) Imagem em tons de cinza. b) Superfície tridimensional da intensidade dos pixels. c) Estrutura de cada ponto da superfície dilatado.

por:

$$
\mathfrak{I}(u, v)=\int_{-\infty}^{+\infty} \int_{-\infty}^{+\infty} I(x, y) e^{-j 2 \pi(u x+v y)} d x d y
$$

onde $j$ corresponde ao número imaginário e $u$ e $v$ são os componentes ortogonais da frequência $f=\sqrt{u^{2}+v^{2}}$. A transformada de Fourier gera uma saída com valores complexos que não possuem um sentido físico explícito. Assim, uma medida importante que pode ser extraída da transformada é o espectro de potência $P$, dado por:

$$
P=\sqrt{R^{2}+J^{2}}
$$

em que $R$ e $J$ representam, respectivamente, as partes real e imaginária da transformada.

A dimensão fractal é obtida a partir da relação exponencial que existe entre o espectro de potência $P$ e a frequência $f$. Assim, de modo semelhante aos métodos geométricos, pode se ajustar uma reta de aproximação à curva $\log (P) \times \log (f)$, encontrando-se então o coeficiente angular $\alpha$. A dimensão $D$ é obtida por:

$$
D=\frac{6+\alpha}{2}
$$

Na Figura 3.5, são mostrados os principais passos para a estimativa da dimensão de uma imagem de tons de cinza por espectro de Fourier. 


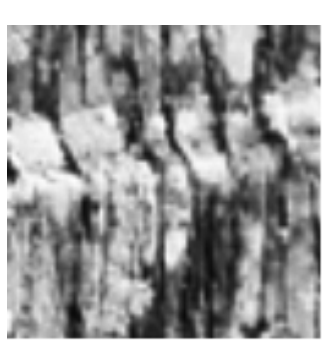

(a)

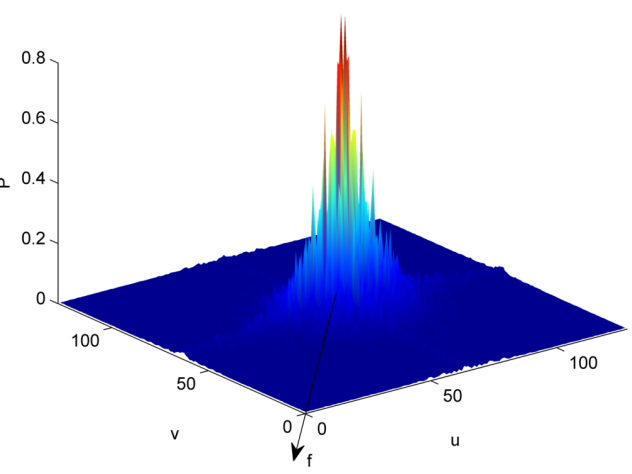

(b)

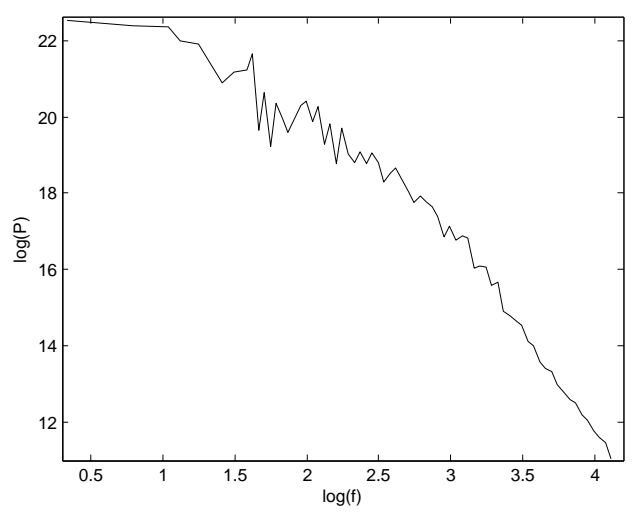

(c)

Figura 3.5 - Método de estimativa de dimensão fractal por Fourier. a) Imagem em tons de cinza. b) Espectro de potência. c) Gráfico $\log (P) \times \log (f)$ do qual se extrai a dimensão fractal.

\subsubsection{Dimensão por Wavelets}

Assim como a análise de Fourier, a transformada wavelets também possibilita o mapeamento da imagem original para o domínio das frequências. Entretanto, em vez de usar bases periódicas fixas, como Fourier, as wavelets usam bases que variam por translação e escala. Tal variação permite uma análise mais flexível, permitindo um estudo das frequências em níveis diferentes de escala, sendo que, em cada nível, é possível também se preservar a informação espacial, dentro da resolução permitida pelo nível usado. Na prática, isso fornece um mapa mais completo da distribuição espaço-frequência da imagem e, como consequência, permite um estudo mais preciso e uma análise mais rica.

Matematicamente, a transformada wavelet consiste no desenvolvimento da função original $f(x)$ em funções-base $\psi$, da seguinte maneira:

$$
f(x)=c_{i, j} \psi_{i, j}(x)
$$

sendo que $c$ são os coeficientes da transformada e $i$ e $j$ são os chamados índices de translação e escala. A função $\psi_{i, j}$ é obtida a partir da chamada função wavelet mãe $\psi$ :

$$
\psi_{i, j}(x)=2^{-i / 2} \psi\left(2^{-i} x-j\right)
$$

Por sua vez, os coeficientes podem ser calculados por:

$$
c_{i, j}=\int_{-\infty}^{+\infty} f(x) \psi_{i, j}(x) .
$$


Na prática, a transformada wavelet de uma imagem digital é feita por meio da aplicação recursiva de dois filtros de frequência, um passa-altas e um passa-baixas. Os filtros são aplicados sucessivamente gerando uma árvore de decomposição. Existem diferentes estratégias para a aplicação desta decomposição (57). Para o cálculo da dimensão fractal (8), o método usado é denominado "seleção das melhores bases". Nesta abordagem, a árvore é montada de tal forma que cada nó é decomposto em dois nós-filhos (um gerado pelo passa-baixas e outro pelo passa-altas) apenas se algum critério for satisfeito. Geralmente, este critério corresponde à minimização de alguma medida, chamada de função de custo, extraída da imagem transformada. Para a aplicação aqui estudada, a função de custo que demonstra ser mais apropriada é a entropia de Shannon (58, 59).

Quando os valores da energia $C$ em cada ponto da imagem transformada são ordenados decrescentemente, observa-se que eles seguem uma relação exponencial, de maneira semelhante aos demais casos de métodos de dimensão fractal. A dimensão $D$ é obtida por:

$$
D=3-|\alpha|,
$$

em que $\alpha$ é o coeficiente angular da reta ajustada à curva do logaritmo dos custos ordenados $\log (C)$. A Figura 3.6 ilustra o processo.
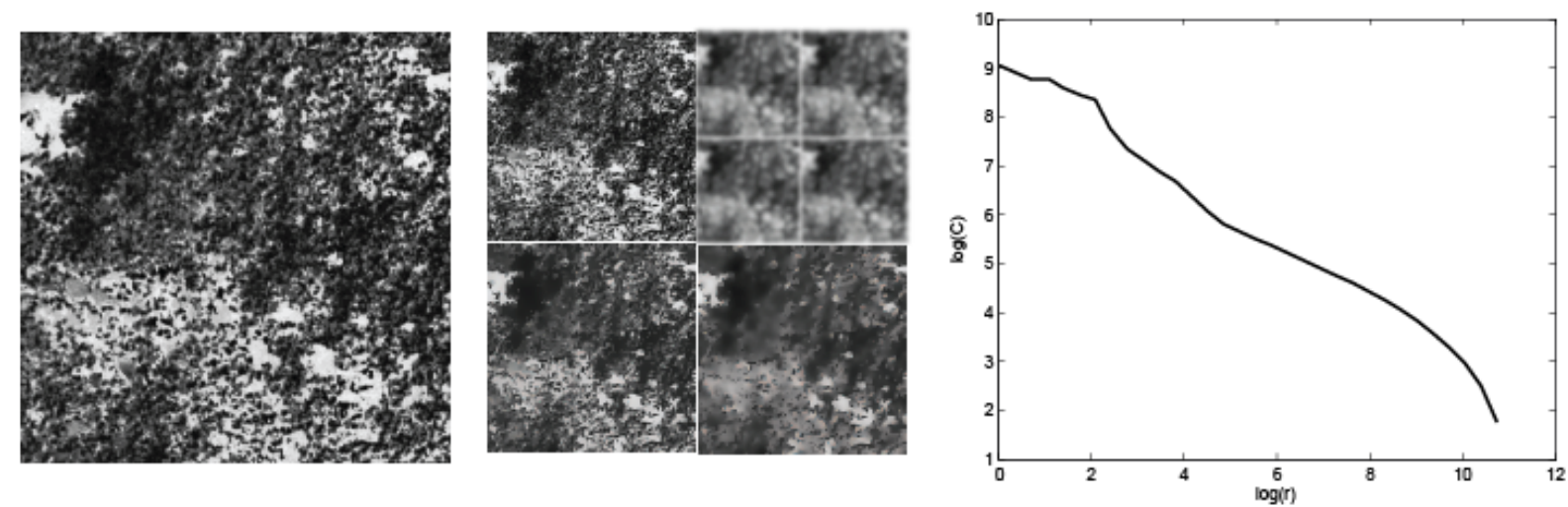

Figura 3.6 - Dimensão fractal por wavelets. Da esquerda para a direita, a imagem de textura original, a transformação aplicada (note-se que os quadrantes não foram divididos por igual como na transformada convencional) e a curva $\log (C) \times \log (r)$, em que $r$ é um índice de ordenação.

\subsubsection{Dimensão de Probabilidade}

Também conhecido por dimensão de Voss (60), este método estima a dimensão fractal pela análise da distribuição estatística de pixels dentro da imagem. 
O método usa o conceito de função de informação, que pode ser definida em qualquer situação em que exista um objeto preenchendo uma determinada região do espaço. No caso, o objeto analisado é a superfície $S$. O espaço tridimensional que contém essa superfície é dividido em uma grade de cubos de lado $\delta$. A função de informação $N_{P}$, calculada para cada valor de $\delta$, corresponde à probabilidade $p_{m}$ de $m$ pontos da superfície pertencerem (ao mesmo tempo) a um mesmo cubo da grade. Assim, a função é dada por:

$$
N_{P}(\delta)=\sum_{m=1}^{N} \frac{1}{m} p_{m}(\delta),
$$

em que $N$ é o número máximo possível de pontos dentro de um mesmo cubo.

Por fim, a dimensão fractal $D$ é estimada a partir da relação entre $N_{P}$ e $\delta$ :

$$
D=-\lim _{\delta \rightarrow 0} \frac{\ln N_{P}}{\ln \delta}
$$

Novamente, a regressão linear por mínimos quadrados pode ser aplicada para obter o valor do limite na equação.

\subsubsection{Dimensão por Prismas Triangulares}

Esta abordagem (61) realiza uma tesselação da superfície $S$ por triângulos de lado $r$ e estima a dimensão fractal a partir da relação entre a área total da tesselação e o lado do triângulo.

Inicialmente, a imagem de textura $I$ é dividida em quadrados de lado $r$, de tal forma que cada quadrado possui seus cantos nos seguintes pontos:

$$
a=I(i, j) ; b=I(i+r, j) ; c=I(i+r, j+r) ; d=I(i, j+r)
$$

sendo $(i, j)$ a coordenada do ponto tomado como inicial. Tendo este quadrado como base, constrói-se um prisma com pico $e$ :

$$
e=(a+b+c+d) / 4
$$

O prisma construído é ilustrado na Figura 3.7 .

Calcula-se então a área de cada face deste prisma pela seguinte expressão:

$$
s a=1 / 2(w+p+o) ; s b=1 / 2(x+p+q) ; s c=1 / 2(y+q+r) ; s d=1 / 2(z+o+r) .
$$




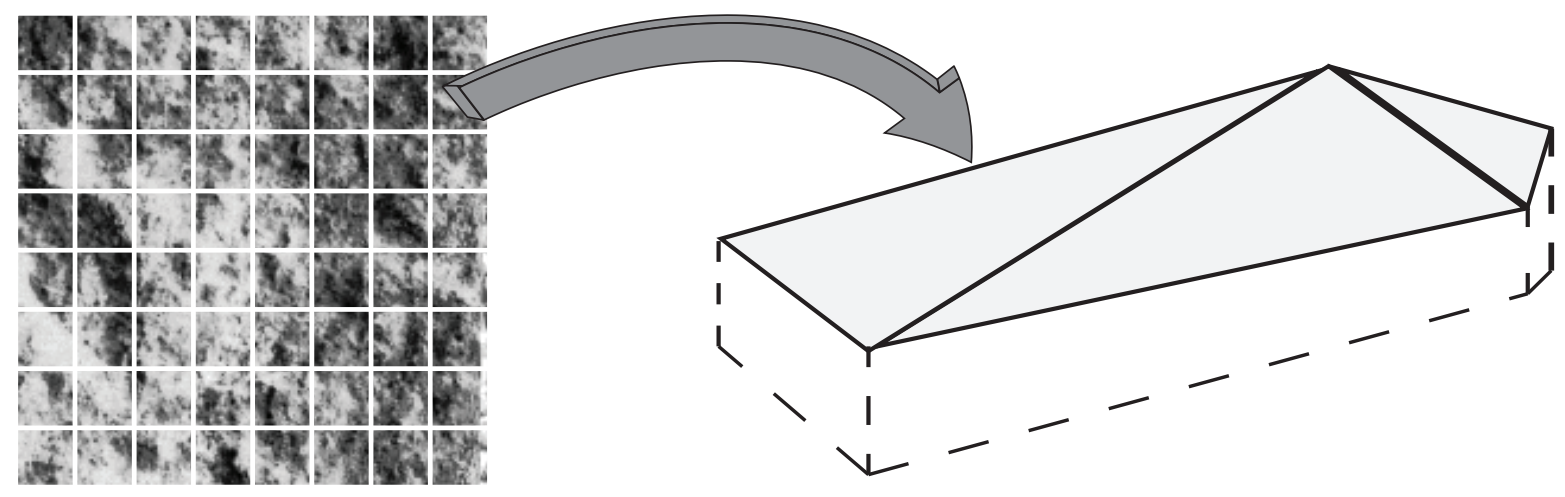

Figura 3.7 - Textura dividida em quadrados e um prisma construído tendo como base cada quadrado

sendo:

$$
\begin{gathered}
w=\sqrt{(b-a)^{2}+s^{2}} ; x=\sqrt{(c-b)^{2}+s^{2}} ; \\
y=\sqrt{(d-c)^{2}+s^{2}} ; z=\sqrt{(a-d)^{2}+s^{2}} \\
o=\sqrt{(a-e)^{2}+\left(\frac{\sqrt{2}}{2} s\right)^{2}} ; p=\sqrt{(b-e)^{2}+\left(\frac{\sqrt{2}}{2} s\right)^{2}} ; \\
q=\sqrt{(c-e)^{2}+\left(\frac{\sqrt{2}}{2} s\right)^{2}} ; r=\sqrt{(d-e)^{2}+\left(\frac{\sqrt{2}}{2} s\right)^{2}} .
\end{gathered}
$$

Por fim, a área total da superfície de cada prisma é fornecida por:

$$
\mathfrak{S}=A+B+C+D
$$

considerando:

$$
\begin{aligned}
& A=\sqrt{s a(s a-w)(s a-p)(s a-o)} ; B=\sqrt{s b(s b-x)(s b-p)(s b-q)} \\
& C=\sqrt{s c(s c-y)(s c-q)(s c-r)} ; D=\sqrt{s d(s d-z)(s d-o)(s d-r)}
\end{aligned}
$$

A área de todos os prismas $\mathfrak{S}(r)$ para cada lado $r$ é obtida pela soma das áreas individuais e a dimensão é obtida da relação $\log (r) \times \log (\mathfrak{S}(r))$, de maneira análoga aos métodos anteriores.

\subsubsection{Variograma}

Baseado nas diferenças de intensidades dos pixels vizinhos na imagem, este método (62) parte da modelagem da textura por uma distribuição Gaussiana. O método assume que uma imagem representando uma textura é produto da realização de um movimento Browniano. A dimensão é estimada a partir do parâmetro do modelo. 
Na prática, a dimensão de uma imagem em tons de cinza é dada por:

$$
D F=2-\frac{1}{2}\left(\frac{\log (\gamma(h))}{\log (h)}\right)
$$

sendo $\gamma$ a função de variabilidade Browniana:

$$
\gamma(h)=\frac{1}{2 n(h)} \sum_{i=1}^{n(h)}\left[Z_{i}-Z_{i+h}\right]^{2},
$$

em que $h$ é o passo (distância entre os pixels) considerado, $Z_{i}$ e $Z_{i+h}$ são as intensidades dos respectivos pixels e $n(h)$ é o número de pares de pixels com distância $h$.

O método de Variograma apresenta boa aceitação na literatura, gerando valores robustos para a dimensão fractal, sobretudo em dados que apresentam irregularidades severas e sobre superfícies que possuem uma tendência característica na distribuição de intensidades. Uma deficiência desta abordagem é que, para superfícies (imagens de intensidade) com dimensão elevada, o método se mostra instável.

\subsubsection{Variação}

O método de Variação (63) estima a dimensão fractal de uma imagem de textura a partir das diferenças entre as intensidades dos pixels dentro de uma janela deslizante de tamanho variável.

Para cada pixel $(i, j)$ da imagem original $I:[M \times N] \rightarrow \Re$, uma janela de lado $L=2 d+1$ é centrada e calcula-se a variação local $V(i, j)$ como sendo a diferença entre a máxima e a mínima intensidades de pixel dentro da respectiva janela. Então, todos os pixels são varridos por essa janela e a variação total $V(d)$ é calculada como sendo a média das variações locais para cada valor de $d$ :

$$
V(d) \propto \frac{1}{M N} \sum_{i=0}^{M} \sum_{j=0}^{N} V(i, j) .
$$

O valor de $d$ é então variado exponencialmente $(d=1,2,4,8, \ldots)$ e a dimensão é estimada por:

$$
D F=3-\alpha,
$$

em que $\alpha$ é o coeficiente angular de uma reta ajustada à curva $\log (d) \times \log (V(d))$. 


\subsubsection{Blanket}

Do mesmo modo que nos métodos espaciais anteriores, a dimensão de Blanket também assume a existência de uma superfície tridimensional representando a imagem em tons de cinza (53). Constroem-se então duas mantas (blanket, em Inglês) de grossura $\epsilon$, uma abaixo $\left(b_{\epsilon}\right)$ e outra acima da superfície $\left(u_{\epsilon}\right)$. Assim, tratando a imagem como uma função de níveis de cinza $g(i, j)$, pode-se definir também $u_{0}(i, j)=b_{0}(i, j)=g(i, j)$. Para $\epsilon=1,2, \ldots$, a seguinte expressão calcula as mantas:

$$
u_{\epsilon}(i, j)=\max \left\{u_{\epsilon-1}(i, j)+1, \max _{|(m, n)-(i, j)| \leq 1} u_{\epsilon-1}(m, n)\right\}
$$

e

$$
b_{\epsilon}(i, j)=\min \left\{b_{\epsilon-1}(i, j)-1, \min _{|(m, n)-(i, j)| \leq 1} b_{\epsilon-1}(m, n)\right\} .
$$

Calcula-se então o volume das mantas por:

$$
v_{\epsilon}=\sum_{i, j}\left(u_{\epsilon}(i, j)-b_{\epsilon}(i, j)\right)
$$

Finalmente, a área da superfície $\mathfrak{A}$ será dada por:

$$
\mathfrak{A}(\epsilon)=\frac{v_{\epsilon}-v_{\epsilon-1}}{2} .
$$

A dimensão fractal é então estimada a partir de:

$$
D=2-\frac{\log (\mathfrak{A}(\epsilon))}{\log (\epsilon)}
$$

\subsubsection{Browniano}

Este método explora a propriedade, já discutida por Pentland (47), de que em uma imagem de intensidade de cinza com característica fractal, a distribuição da diferença absoluta entre as intensidades de pixels a uma determinada distância apresenta o mesmo comportamento presente no movimento Browniano e assim:

$$
E \propto d^{H}
$$


em que $d$ é a distância entre os pixels, $H$ é o coeficiente de Hurst e $E$ é dado pela seguinte expressão:

$$
E=\frac{\sum_{x=0}^{M-1} \sum_{y=0}^{N-1} \sum_{u=0}^{M-1} \sum_{v=0}^{N-1}[I(u, v)-I(x, y)]^{2}}{P},
$$

em que $I(x, y)$ e $I(u, v)$ são dois pixels na imagem, enquanto que $M$ e $N$ são as dimensões da região de interesse e $P$ é o número de pares de pixels na região. A distância $d$ é expressa por:

$$
d=\sqrt{(u-x)^{2}+(v-y)^{2}} .
$$

A dimensão fractal $D$ é dada por:

$$
D=3-H \text {. }
$$

\subsubsection{Lacunaridade}

Por fim, uma medida de fractalidade importante é a Lacunaridade (64). Esta não é empregada para estimar a dimensão fractal como as técnicas anteriores, mas se apresenta como uma alternativa ao conceito de dimensão de Hausdorff-Besicovitch.

A Lacunaridade foi proposta com o objetivo de ser uma medida complementar à dimensão fractal e que permitisse resolver um problema da teoria fractal original. $O$ fato é que dois objetos totalmente distintos podem apresentar o mesmo valor para a dimensão fractal. Observou-se então que nestes casos, os objetos apresentavam a mesma lei de distribuição de pontos, mas diferiam severamente na distribuição do espaço vazio deixado pela estrutura.

Assim, a Lacunaridade se propõe a, em vez de medir a distribuição do objeto no espaço como faz a dimensão fractal, medir a distribuição dos espaços vazios, formando assim uma medida complementar e igualmente rica para a compreensão da estrutura geométrica do objeto.

O método mais comumente usado para o cálculo da Lacunaridade é baseado na técnica chamada gliding-box. Nesta, a superfície $S$ da textura é imersa em uma grade tridimensional de cubos de lado $r$ e calcula-se então a distribuição de massa $Q(s, r)$ :

$$
Q(s, r)=\frac{n(s, r)}{N(r)}
$$

em que $n(s, r)$ é o número de cubos contendo exatamente $s$ pontos da superfície e $N(r)$ é o número total de cubos de lado $r$. Na prática $Q(s, r)$ constitui uma distribuição de probabilidades. 
Assim, da estatística básica, pode-se obter o primeiro e segundo momentos $Z_{1}$ e $Z_{2}$ :

$$
Z_{1}(r)=\sum_{s=1}^{s_{\max }} s Q(s, r)
$$

$\mathrm{e}$

$$
Z_{2}(r)=\sum_{s=1}^{s_{\max }} s^{2} Q(s, r) .
$$

A partir dos momentos, obtém-se o quociente de momentos $\Lambda(r)$ :

$$
\Lambda(r)=Z_{1}(r) / Z_{2}(r)
$$

A Lacunaridade é então obtida da derivada da relação $\log$ - $\log$ a seguir:

$$
\lambda=\frac{d \log (\Lambda(r))}{d \log (r)} .
$$

De novo, computacionalmente, o método mais simples para este cálculo é a partir do ajuste linear da curva $\log (\Lambda(r)) \times \log (r)$, tomando-se o coeficiente angular da reta ajustada.

\subsubsection{Dimensão de Curvas Fechadas por Fourier}

Este método, proposto em (27), aplica a transformada de Fourier para estimar a dimensão fractal de contornos bidimensionais. Seja $C$ um contorno fechado em $\Re^{2}$. Inicialmente, esta estrutura é parametrizada por uma variável $t$, possibilitando sua descrição por uma função complexa $I$ :

$$
I(t)=x(t)+i y(t)
$$

em que $x$ e $y$ são as coordenadas de cada ponto em $C$ e $i$ é o número imaginário. A seguir, calcula-se a série de Fourier unidimensional $\mathfrak{I}$ :

$$
\mathfrak{I}=\int_{-\infty}^{+\infty} I(t) e^{-2 \pi i t u} d t
$$

em que $u$ é a frequência.

Em seguida, obtém-se o espectro de potência $P$ de $I$ :

$$
P=\sum_{k=1}^{n}\left|\mathfrak{I}_{k}\right|^{2},
$$

em que $n$ é o número de componentes da transformada.

Por fim, constrói-se a curva em escala log-log do espectro em função da frequência $\log (u) \times$ 
$\log (P)$. Como esperado pela teoria (52), esta curva apresenta um comportamento similar ao linear. Baseado nisso, uma reta é ajustada, por mínimos quadrados (65), à curva e a dimensão $D$ é obtida a partir do coeficiente angular $\alpha$ por:

$$
D=-\frac{3}{4} \alpha+\frac{1}{4}
$$

sendo que os coeficientes são obtidos empiricamente.

\subsection{Comparativo entre Métodos Numéricos de Dimensão Fractal}

Em (27), os autores apresentam um comparativo entre vários métodos de estimativa numérica da dimensão de fractais matemáticos clássicos cuja medida analítica é conhecida.

A Tabela 3.1 mostra as dimensões estimadas para cada método. O método de Fourier em contornos fechados proposto naquele trabalho mostrou-se eficiente, obtendo o valor mais próximo da dimensão analítica em $60 \%$ dos casos. Esta precisão é particularmente interessante considerando-se um método simples e de custo computacional significativamente menor do que seus concorrentes.

Tabela 3.1 - Dimensão dos objetos fractais matemáticos calculada por diferentes métodos e comparada à dimensão teórica de Hausdorff-Besicovitch. Os valores sublinhados correspondem às melhores aproximações.

\begin{tabular}{cccccc}
\hline Fractal & Box-counting & Bouligand-Minkowski & Fourier & Proposto & Hausdorff \\
\hline Dragon & 1.4414 & 1.4524 & 1.3689 & $\underline{1.5760}$ & 1.5236 \\
Fibonacci & 1.3044 & 1.3453 & 1.2669 & $\underline{1.2499}$ & 1.2465 \\
Gosper & $\underline{1.1284}$ & 1.1217 & 1.0685 & 1.1213 & 1.1292 \\
Julia1 & $\underline{1.0905}$ & 1.0538 & 1.1283 & 1.1485 & 1.0812 \\
Julia2 & 1.1465 & 1.1972 & 1.2146 & $\underline{1.2509}$ & 1.2683 \\
Julia 3 & 0.9677 & 1.0166 & 1.0680 & $\underline{1.0076}$ & 1.0043 \\
Koch & 1.2479 & 1.2497 & 1.1080 & $\underline{1.2722}$ & 1.2619 \\
Rabbit & 1.2724 & $\underline{1.3643}$ & 1.2197 & 1.3586 & 1.3934 \\
Terdragon & 1.1871 & 1.0949 & 1.1162 & $\underline{1.2313}$ & 1.2619 \\
Vicsek & 1.3757 & $\underline{1.4356}$ & 1.3308 & 1.5436 & 1.4650 \\
\hline
\end{tabular}

Aquele trabalho ainda analisa o comportamento de cada método quando o objeto fractal é afetado por transformações geométricas e ruído aleatório. As Tabelas 3.2 e 3.3 mostram o erro quadrático médio de cada abordagem e o método de Fourier em contorno obteve vantagem em relação a outras soluções da literatura. Mais resultados deste experimento podem ser encontrados na Seção 7.7 . 
Tabela 3.2 - Erro médio na estimativa da dimensão fractal pelos métodos comparados em objetos fractais submetidos a transformações geométricas.

\begin{tabular}{cc}
\hline Método & Erro Médio Quadrático \\
\hline Box-counting & 0.2340 \\
Bouligand-Minkowski & 0.2249 \\
Fourier & 0.3610 \\
Proposto & $\underline{0.1269}$ \\
\hline
\end{tabular}

Tabela 3.3 - Erro médio na estimativa da dimensão de objetos fractais afetados por ruído.

\begin{tabular}{cc}
\hline Método & Erro Médio Quadrático \\
\hline Box-counting & 0.2307 \\
Bouligand-Minkowski & 0.2244 \\
Fourier & 0.3667 \\
Proposto & $\underline{0.2228}$ \\
\hline
\end{tabular}

\subsection{Complexidade}

Uma das medidas mais importantes de um objeto e, por consequência, da imagem que o representa, é a complexidade. Embora não exista uma definição consensual na literatura, a complexidade pode ser explicada como sendo a medida do quão irregular é o objeto. $\mathrm{Na}$ análise de formas, a complexidade estima o nível de ocupação do espaço. Já para texturas, a complexidade mede a distribuição dos pixels dentro da imagem.

Embora o conceito original de dimensão fractal (Hausdorff-Besicovitch) não possa ser aplicado a objetos do mundo real, que não são fractais no sentido estrito, a literatura reporta um grande número de estudos nos quais métodos de estimativa (aproximada) da dimensão são usados para medir estes objetos. O primeiro estudo deste tipo conhecido é empreendido por Richardson (126), quando, em um trabalho investigando relações entre a geografia de um país e a probabilidade de estes entrarem em guerra, acaba descobrindo uma lei exponencial entre a medida do comprimento da costa britância e o comprimento da unidade de medida empregada. Richardson observou que o expoente envolvido era particular de cada costa analisada e trazia uma informação importante a respeito da irregularidade da mesma. Mais tarde, Mandelbrot cita este estudo em (44) e chama esse expoente de dimensão fractal (1). Embora esta nomenclatura tenha gerado polêmica, sobretudo pelo fato da medida de dimensão ser tomada apenas em um intervalo (pequeno na maioria das vezes) (127, 128), hoje o uso do nome "dimensão fractal" para estas medidas é amplamente aceito, como se vê em inúmeros trabalhos nas mais variadas áreas de aplicação (32, 52, 69, 124).

Dada sua natureza, a dimensão fractal também tornou-se uma medida de complexidade consolidada na literatura. Para ilustrar a capacidade da dimensão em medir este atributo, tome-se um exemplo em que a dimensão de Bouligand-Minkowski é estimada para duas figuras geométricas simples, mas que apresentam padrões de complexidade distintos. 
Tome-se então, por exemplo, um hexágono e um triângulo, na Figura 3.8, baseada em (82). No método de Bouligand-Minkowski, a dimensão e, consequentemente, a complexidade é estimada pela área de dilatação dos pontos da forma. À medida que a estrutura vai sendo dilatada, nota-se que o maior número de quinas no hexágono faz com que a área de dilatação cresça mais rapidamente. Esta velocidade de crescimento é diretamente relacionada à dimensão fractal. Assim, a estrutura com mais cantos possui maior dimensão e, consequentemente, maior complexidade, como era de se esperar intuitivamente. Esta relação entre complexidade e dimensão é demonstrada no gráfico da derivada de $\log (A(r))$ em função de $r$, representada por $d u / d t$ para fins de simplificação. Este gráfico é exibido na parte inferior da Figura 3.8. A derivada corresponde ao valor instantâneo da dimensão fractal quando o raio é variado e confirma a maior dimensão do hexágono.
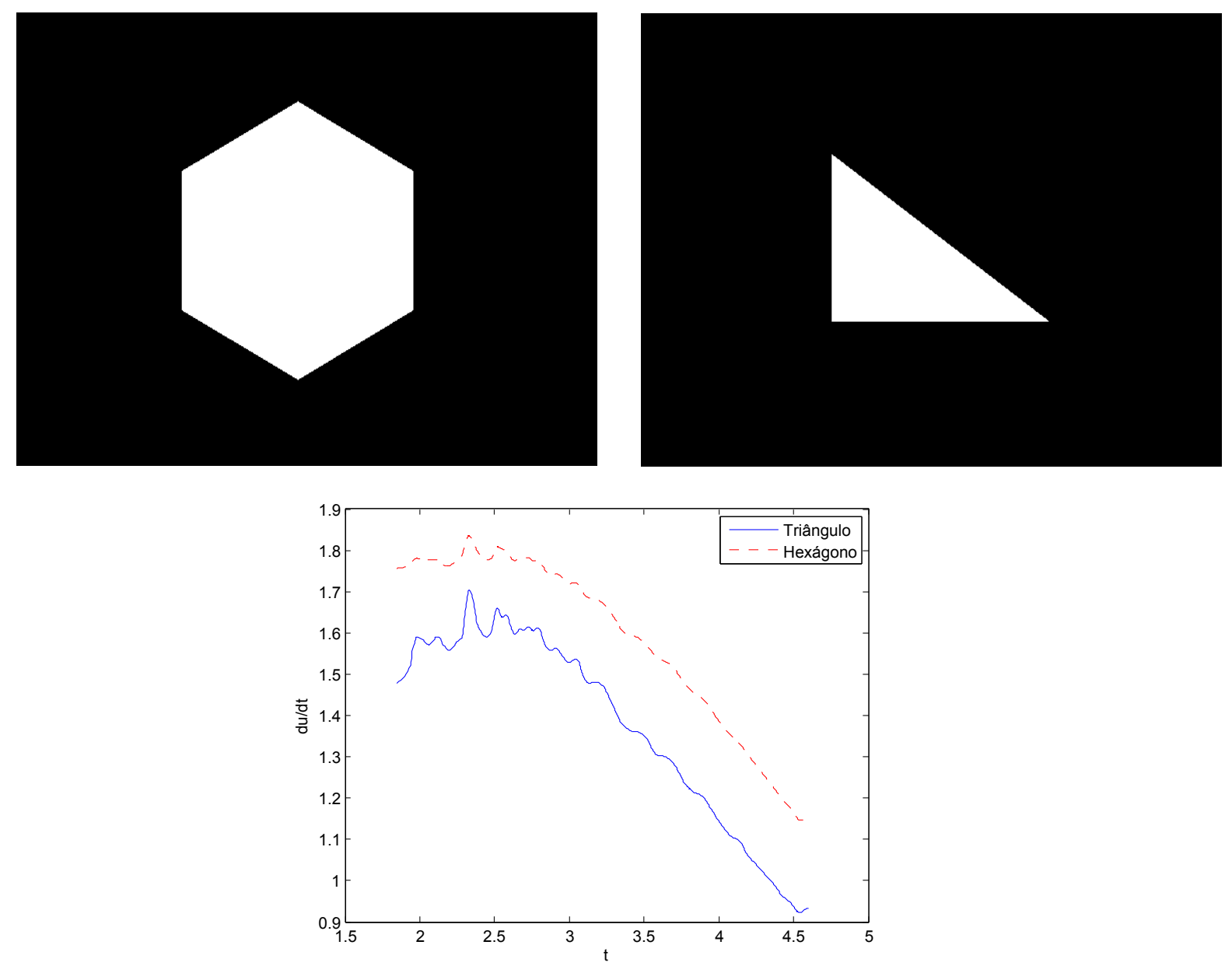

Figura 3.8 - Dois objetos com graus de complexidade distinta e gráfico da dimensão fractal mostrando a maior dimensão do objeto mais complexo.

Um processo semelhante ocorre na análise de texturas. A diferença é que, neste caso, a imagem em tons de cinza é convertida em uma superfície e a complexidade está relacionada à sua topografia, que, por sua vez, é proporcional à diferença entre as intensidades dos pixels 
em cada região. Assim, por exemplo, uma região de borda gera uma superfície com uma irregularidade drástica e, similar ao que ocorria com as quinas das formas, vai levar a um valor estimado maior de complexidade. Deste modo, a complexidade mede então a distribuição das intensidades de pixels na imagem.

Desta forma, qualquer um dos métodos de estimativa de dimensão fractal pode ser usado para determinar o grau de complexidade da textura representada em uma imagem digital. Esta complexidade por sua vez está fortemente relacionada à percepção humana de propriedades dos materiais como rugosidade, porosidade, luminância, etc. Assim, é uma consequência natural que este tipo de modelagem constitua uma ferramenta poderosa no desenvolvimento de metodologias que automatizem o reconhecimento de padrões em texturas (66). 


\section{CAPÍTULO 4}

\section{Medidas Fractais}

Este capítulo apresenta a generalização do conceito de dimensão fractal. Inicialmente, são apresentadas as limitações do uso direto da dimensão e a motivação para o desenvolvimento de alternativas para a análise de imagens por modelagem fractal. Em seguida, são mostradas abordagens para a extração de um conjunto de medidas do objeto analisado a partir da geometria fractal, no lugar do valor único da dimensão.

\subsection{Dimensão Escalar versus Medidas Vetoriais}

Nas últimas décadas, sobretudo após o trabalho de Mandelbrot (1), que formalizou a geometria fractal, a literatura vem apresentando um número crescente de trabalhos que empregam conceitos desta geometria nos mais variados campos da ciência (2, 67-74). Uma grande parte destas aplicações faz uso da dimensão fractal pura e simples, geralmente associada a outras medidas clássicas, para caracterizar e identificar os objetos de interesse (texturas, formas, contornos, curvas de funções, etc.). Os bons resultados obtidos pelo uso da dimensão são explicados, do ponto de vista teórico, pela própria definição desta métrica, que caracteriza o nível de irregularidade do objeto ou ainda seu grau de ocupação do espaço ao seu redor. Essas são propriedades que determinam por si o aspecto geral do objeto, que é usado pelo próprio sistema visual humano na identificação daquela estrutura. Assim, é natural que esta abordagem apresente resultados interessantes quando empregada em um sistema automático como o de visão computacional.

Ocorre, entretanto, que a dimensão fractal por si só é apenas um valor real e, em cenários mais complexos, com maior número de objetos analisados e na presença de situações adversas, como ruídos e objetos transformados geometricamente, a dimensão não é suficiente, sendo necessário então o desenvolvimento de metodologias que permitam a extração de uma in- 
formação mais rica acerca do objeto de interesse. De fato, não é raro que se encontrem dois objetos de topologia e aspecto totalmente distintos, mas com a mesma dimensão. A Figura 4.1 mostra duas formas distintas com a mesma dimensão, enquanto a Figura 4.2 exibe duas texturas com o mesmo comportamento.

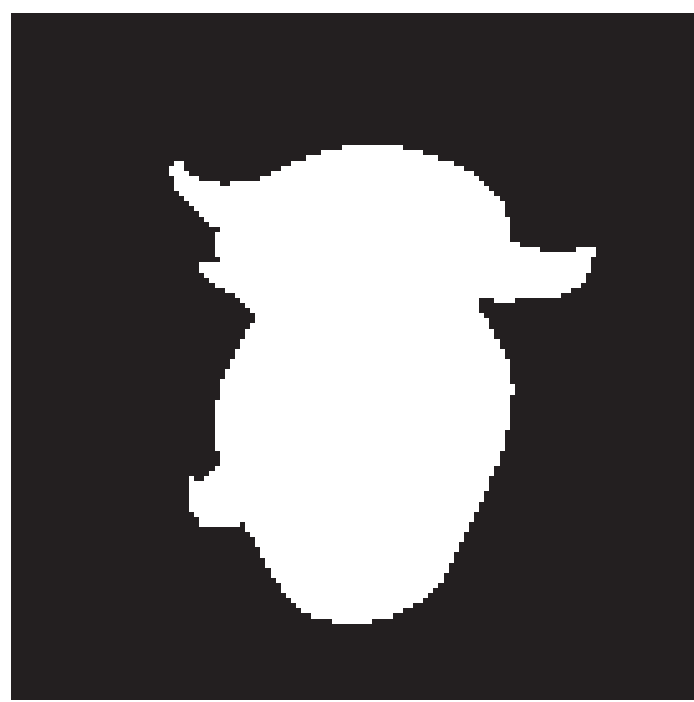

$\mathrm{DF}=1.672$

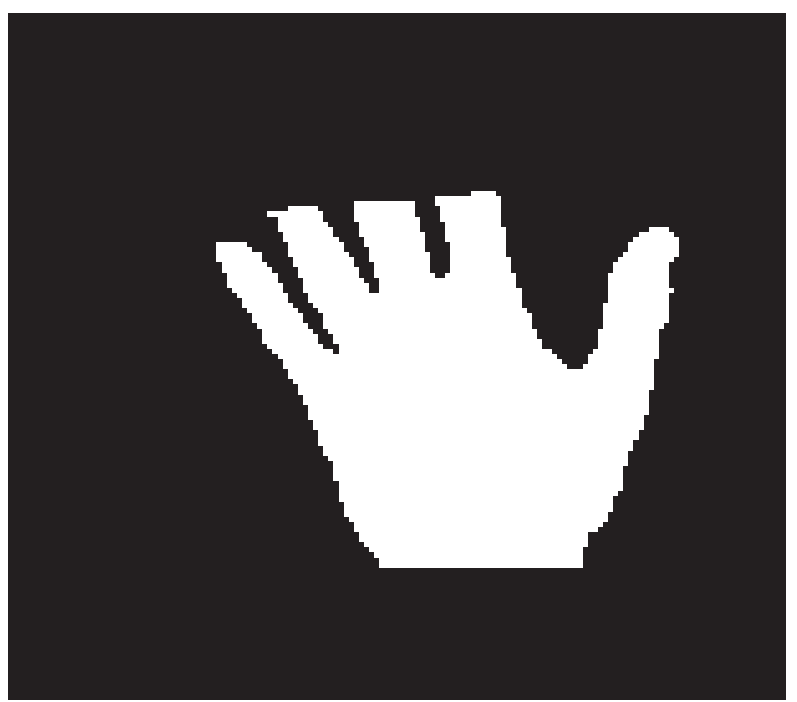

$\mathrm{DF}=1.672$

Figura 4.1 - Duas formas de aspecto totalmente distinto, mas com a mesma dimensão fractal.

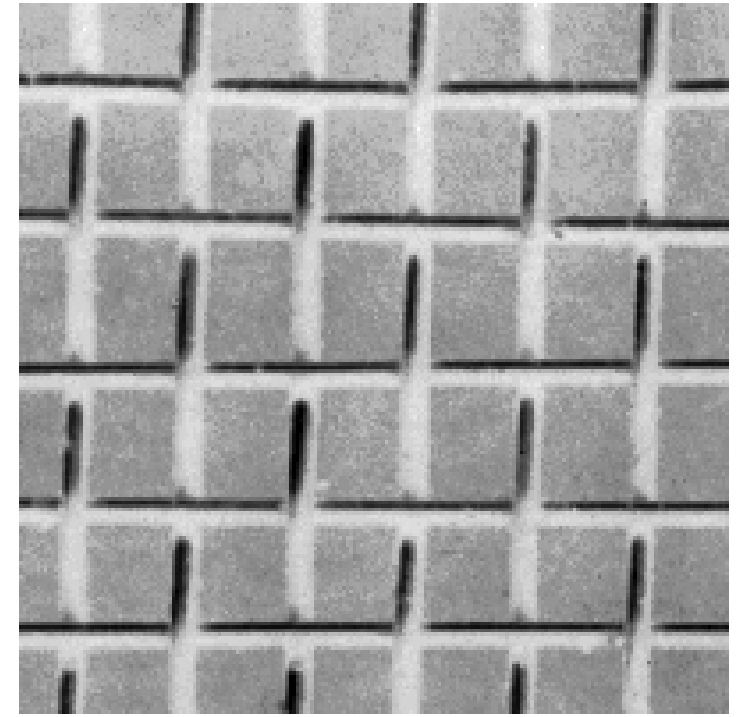

$\mathrm{DF}=1.327$

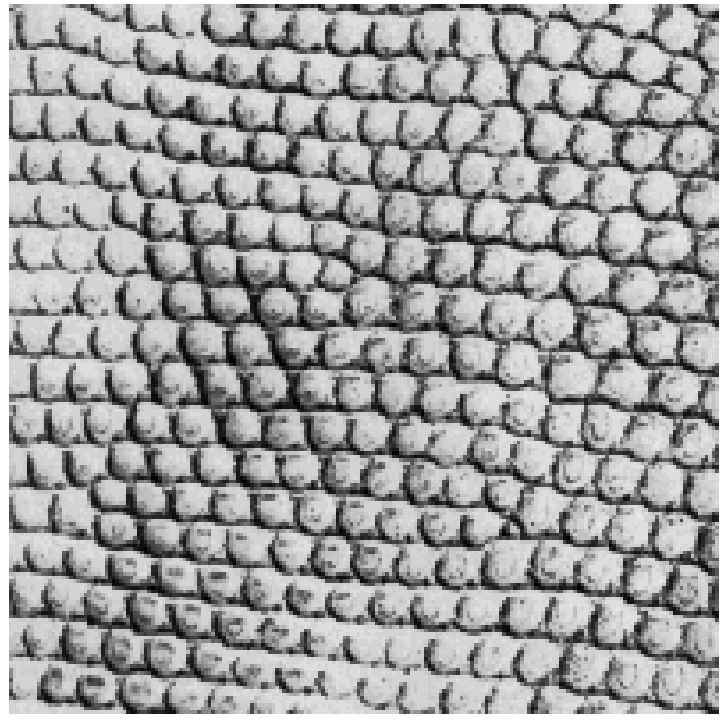

$\mathrm{DF}=1.327$

Figura 4.2 - Duas texturas de aspecto diferente, mas com a mesma dimensão fractal.

Ainda um outro problema, que é frequentemente encontrado na análise de imagens pela dimensão fractal, é que os objetos do mundo real representados nestas imagens não apresentam 
uma única medida global da dimensão. Em vez disso, este valor varia, em algumas situações severamente, dependendo do intervalo de escalas no qual a medida é tomada. Este problema ocorre tanto com formas bimensionais quanto com texturas, representadas em imagens de superfícies de intensidade. A Figura 4.3 ilustra tal fato para formas e a Figura 4.4 mostra o mesmo fenômeno em texturas.
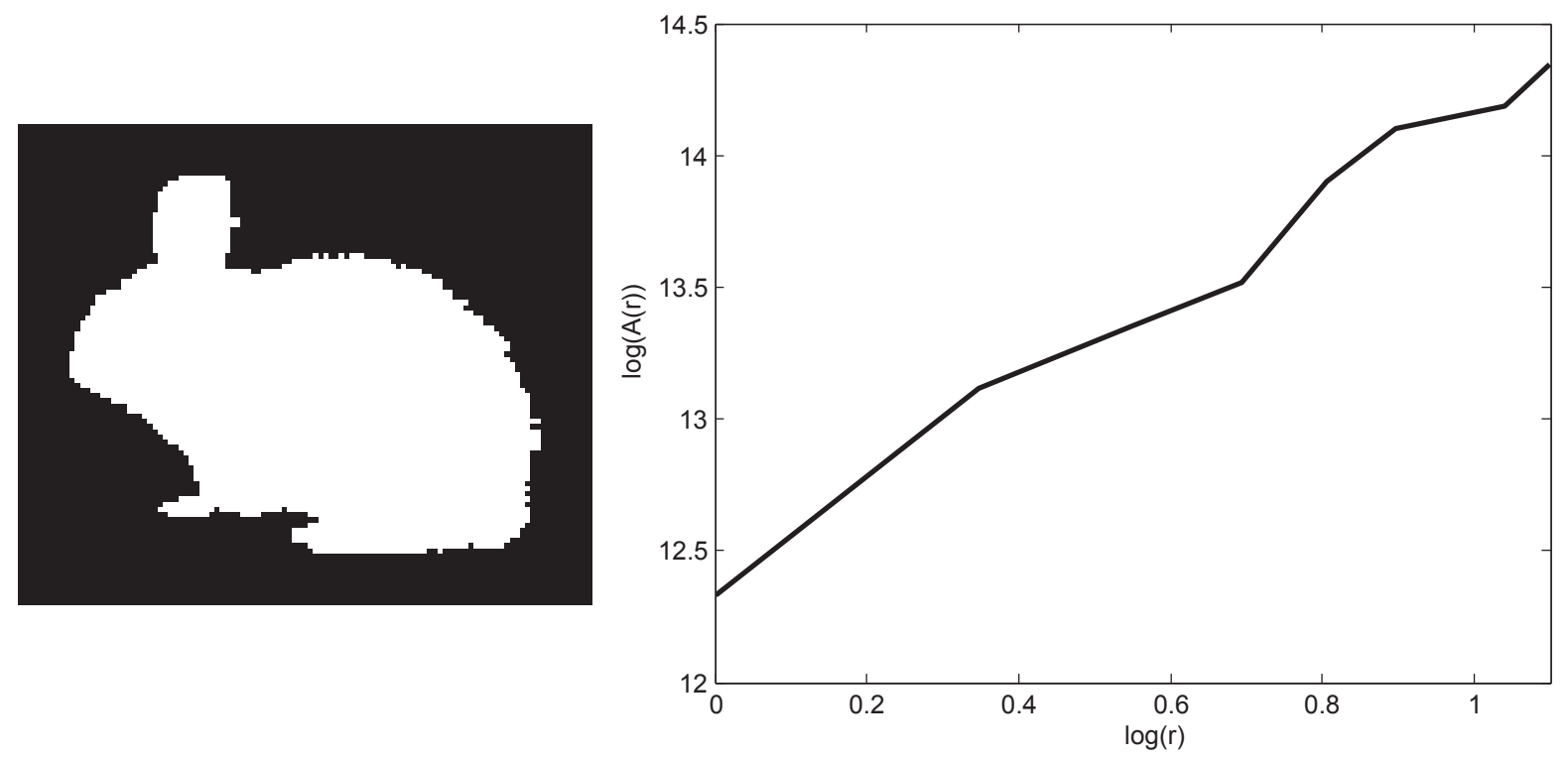

Figura 4.3 - Curva de fractalidade de uma forma exibindo a existência de diferentes valores da dimensão fractal dependendo do intervalo de escala tomado.
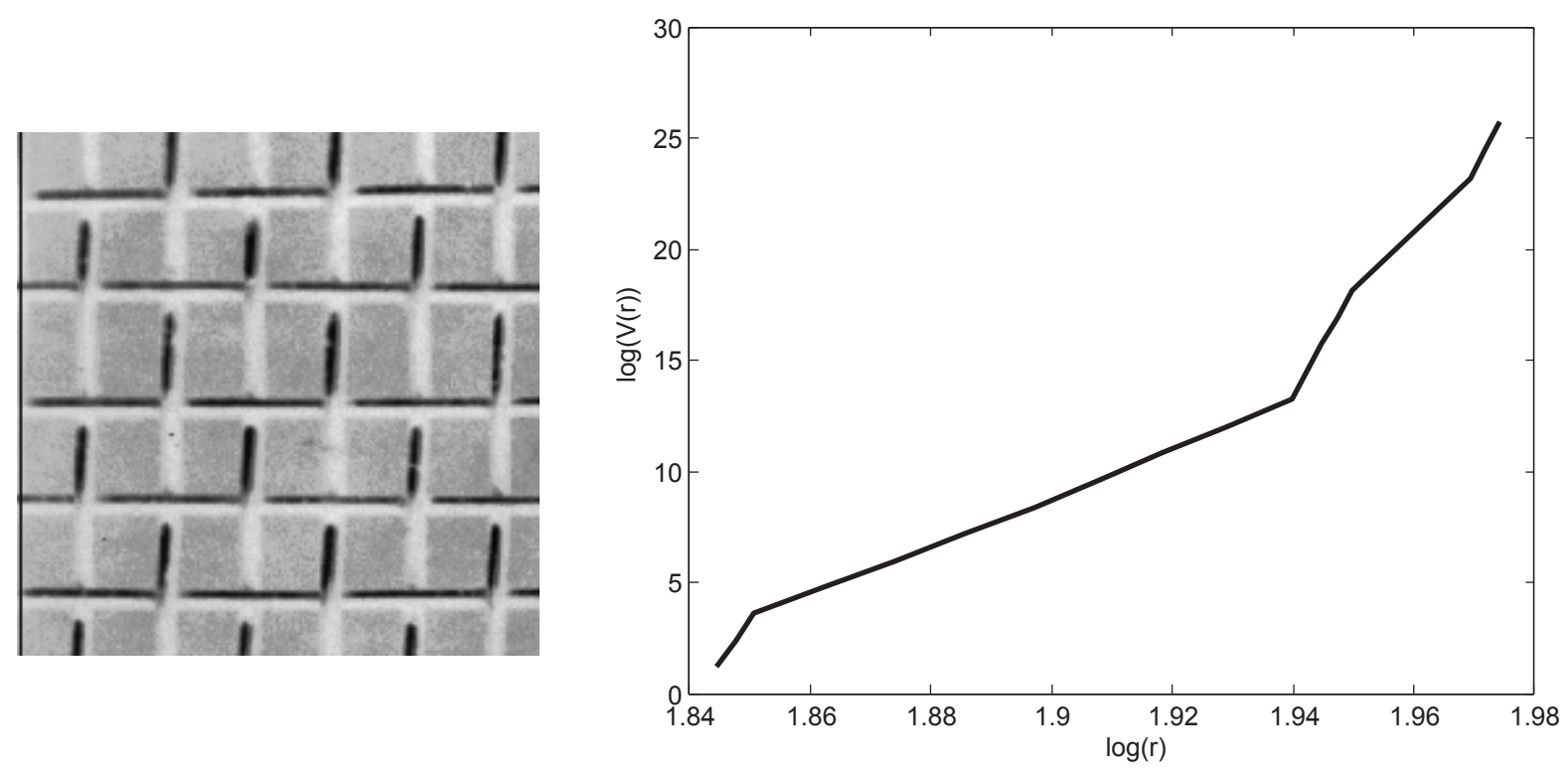

Figura 4.4 - Curva de fractalidade de uma textura exibindo a existência de diferentes valores da dimensão fractal dependendo do intervalo de escala tomado.

Partindo destas constatações, a literatura vem propondo então novas soluções que permitam uma análise mais robusta e precisa baseada na geometria fractal. Neste sentido, a 
primeira técnica mais conhecida a ser proposta é a teoria de multifractais (18, $75-78)$.

\subsection{Multifractais}

Nesta abordagem, incialmente aplica-se algum tipo de categorização pré-definida, que atribui uma classe a cada pixel da imagem original. Em seguida, calcula-se a dimensão fractal de cada conjunto de pontos que pertençam à mesma classe na imagem. Este conjunto de valores de dimensão fractal é chamado então de espectro multifractal e compõe o vetor de características a ser usado para a descrição do objeto representado na imagem.

Na prática, costuma-se fazer a categorização por meio de uma função de densidade, que garante maior robustez, por exemplo, a ruídos e variações de iluminação. Considere-se então $\mu$ uma medida de Borel regular finita (51) em $\Re^{2}$ e $B(x, r)$ uma bola com centro em $x \in \Re^{2}$ e raio $r>0$, tal que:

$$
\mu(x, r)=k r^{D}(x)
$$

sendo $k$ uma constante real. Define-se então a função de densidade $D(x)$ por:

$$
D(x)=\lim _{r \rightarrow 0} \frac{\log \mu(B(x, r))}{\log r} .
$$

Assim, a função de densidade mede a velocidade de crescimento local da medida $\mu$, que por sua vez corresponde ao grau de uniformidade da imagem naquele ponto. A seguir, são definidos então os conjuntos categóricos $E_{\alpha}$ :

$$
E_{\alpha}=\left\{x \in \Re^{2}: D(x)=\alpha\right\}
$$

ou seja, $E_{\alpha}$ é o conjunto de pontos $x$ da imagem para os quais a função de densidade vale $\alpha$. Finalmente, o espectro multifractal $f(\alpha)$ é dado pelos valores de dimensão fractal de cada conjunto $E_{\alpha}$ :

$$
f(\alpha)=\operatorname{dim}\left(E_{\alpha}\right): \alpha \in \Re .
$$

Entre as funções de densidade usadas na literatura, pode se citar, por exemplo, a convolução com uma função gaussiana (78) ou a chamada wavelets leaders (77), que correspondem a máximos tomados dentro de uma vizinhança e em determinado intervalo de escalas da transformada wavelet multinível. A dimensão fractal mais usada na literatura é a de Boxcounting, embora qualquer outro método de estimativa possa ser empregado. 


\subsection{Dimensão Fractal Multiescala}

Uma alternativa aos multifractais é a chamada Dimensão Fractal Multiescala (DFM) (19. 21, 79). Este método consiste em se aplicar uma transformação multiescala (espaço-escala) à curva logarítmica da dimensão fractal descrita nas seções anteriores e extrair algumas medidas desta curva transformada para compor o vetor de características.

Esse tipo de transformação multiescala será definido posteriormente. Por ora, pode-se considerar que a curva multiescala, como definida em (19), que usa a dimensão de BouligandMinkowski em duas dimensões, é obtida pela seguinte expressão:

$$
D F M=2-\frac{d(\log (A(r)))}{d(\log (r))} * g_{a}
$$

em que $A(r)$ é a área de dilatação de raio $r$ e $g_{a}$ é uma função Gaussiana com parâmetro de suavização $a$ definido empiricamente.

Por uma questão de otimização computacional, a área de dilatação é calculada por meio de um método chamado Transformada Exata da Distância (TED) (55). Esta transformação atribui, a cada pixel de um objeto de interesse em uma imagem binária, a distância deste pixel ao fundo da imagem (região fora do objeto de interesse). Neste caso, usa-se a distância Euclidiana $d$, que entre dois pixels de coordenadas $p=(x, y)$ e $p^{\prime}=\left(x^{\prime}, y^{\prime}\right)$ é dada por:

$$
d\left(p, p^{\prime}\right)=\left\|p-p^{\prime}\right\|=\sqrt{\left(x-x^{\prime}\right)^{2}+\left(y-y^{\prime}\right)^{2}}
$$

Assim, a área de dilatação $A(r)$ corresponde ao número de pontos para os quais a transformada da distância apresente valor menor ou igual a $r$.

A Gaussiana tem o papel de suavizar a derivada, que naturalmente realça qualquer tipo de ruído eventualmente presente na curva logarítmica. A derivada numérica empregada neste caso ainda possui um sério problema, que é seu caráter fortemente local, que pode gerar artefatos que não são relevantes para o papel dos descritores. Assim, esta derivada é calculada usualmente pelo método de Fourier.

Sabe-se que a derivada pode ser obtida por uma transformação de Fourier seguida de uma multiplicação no plano complexo e da inversão desta multiplicação (80). Assim, considerandose a curva $\log (A(r)) \times \log (r)$ como $u(t)$, para efeitos de simplificação, a derivada pode ser calculada pela seguinte expressão:

$$
\frac{d u}{d t}=\mathfrak{T}^{-1}\{\mathfrak{T}\{u(t)\}(i 2 \pi f)\},
$$


em que $i$ é o número imaginário, T é a transformada de Fourier e $f$ é a frequência. Associandose a Gaussiana:

$$
\frac{d u}{d t}=\mathfrak{T}^{-1}\{\mathfrak{T}\{u(t)\} \mathfrak{T}\{g(t, a)\}(i 2 \pi f)\},
$$

em que a multiplicação $\mathfrak{T}\{u(t)\} \mathfrak{T}\{g(t, a)\}$ representa a convolução $u(t) * g(t, a)$ no domínio da frequência.

Na prática, dois problemas ainda precisam ser resolvidos. O primeiro é que a transformada de Fourier exige uma boa amostragem para um resultado significativo. Como neste caso essa amostragem é logarítmica, os primeiros pontos são mais espaçados e, em função disso, devem ser eliminados da curva para garantir um resultado mais preciso. Outro problema é que a transformada de Fourier diverge nas descontinuidades, fato este chamado de fenômeno de Gibbs (81). Para solucionar esta anomalia, a curva é replicada e espelhada à direita e à esquerda e o resultado da derivada é extraído apenas da parte intermediária da curva replicada (82).

Em (19), os autores compõem o vetor de atributos com medidas geométricas da curva DFM, como máximo, mínimo, área sob a curva do gráfico, etc. Naquele trabalho, os autores aplicam essa técnica à análise de expressão gênica, obtendo bons resultados. Já em (21), é observado que a curva DFM apresenta dois picos e uma depressão bem definidos. Assim, naquele trabalho foram usadas as coordenadas destes pontos para compor o vetor descritivo e assim obter excelentes resultados em um problema de identificação de espécies vegetais a partir da imagem da folha.

\subsection{Descritores fractais}

Como abordado anteriormente, a dimensão fractal por si só é insuficiente para caracterizar objetos e, particularmente, texturas em problemas mais complexos, uma vez que esta é apenas uma medida global da complexidade da imagem. Além disso, os cenários do mundo real representados nessas imagens não apresentam um nível constante de auto-similaridade como ocorre com fractais matemáticos. Isso pode ser observado quando se analisa a curva de fractalidade $\log (\mathfrak{M}) \times \log (\epsilon)$. Enquanto para um fractal clássico, esta curva apresenta o aspecto de uma reta perfeita, para uma imagem real ela contém várias irregularidades, apenas se aproximando de uma reta. Essa observação sugere que a curva $\log$ - $\log$ como um todo possa ser usada para descrever com maior riqueza a complexidade de um objeto em diferentes escalas de análise. 
O método de DFM visto anteriormente já faz uso desta curva, embora use apenas poucos pontos de interesse para compor o vetor de características. Esta ainda não é uma abordagem ideal, sobretudo na análise de texturas, quando se apresentam muitos detalhes e micro-padrões em todos os níveis de escala e o uso de valores tomados apenas em escalas específicas não é suficiente na maioria dos casos. Além disso, o método DFM depende fortemente da estratégia usada para a identificação dos pontos de interesse na curva multiescala e a obtenção destes pontos pode ser difícil em muitas situações, além de poder fornecer informações redundantes entre si. Assim sendo, em $(20,83)$, propôs-se o conceito de descritores fractais, no qual toda a curva $\log$ - log é usada diretamente para compor o vetor de características.

O conceito de descritores de imagens não é algo recente, mas já é usado amplamente na literatura, por exemplo, quando se fala de descritores de Fourier (12) ou descritores de wavelets (84). O conceito geral é de que descritores são os conjuntos de valores de uma função que é obtida de algum tipo de modelagem da imagem original. Assim, descritores de Fourier e wavelets são os valores da função de espectro/energia da transformada respectiva. Em uma analogia simples, os descritores fractais podem ser entendidos como o conjunto de valores da função $\log -\log$ da dimensão fractal.

A ideia então é extrair características (descritores) relevantes de um objeto a partir da curva $\log -\log$ do método de estimativa da dimensão fractal daquele objeto. Como observado, na descrição dos métodos de estimativa de dimensão, de um modo geral, todos esses métodos são baseados na relação logarítmica entre algum tipo de medida $\mathfrak{M}$ e a escala $\epsilon$ em que essa medida é analisada. Assim, a dimensão $D$ pode ser representada por uma expressão genérica:

$$
D \propto \frac{\log (\mathfrak{M})}{\log (\epsilon)}
$$

Os descritores são então obtidos a partir da seguinte relação:

$$
u: \log (\epsilon) \rightarrow \log (\mathfrak{M})
$$

Para simplificar a notação, a variável independente $\log (\epsilon)$ é substituída por $t$. Assim, os descritores correspondem a valores obtidos a partir da função $u(t)$.

Na prática, os descritores fractais conseguem efetuar um mapeamento completo da complexidade da textura na imagem. Assim, os primeiros descritores (valores pequenos de $\epsilon$ ) fornecem a complexidade de microestruturas presentes na imagem, enquanto os últimos fornecem a complexidade global. Desta forma, os descritores apresentam um alto nível de eficiência na caracterização e discriminação de texturas, mesmo aquelas que apresentam estruturas que são difíceis de ser analisadas até mesmo a olho nu. Em seguida, são mostradas duas figuras 
que ilustram a eficácia dos descritores fractais. A Figura 4.5 exibe as imagens de duas formas já exibidas na Figura 4.1 e cujas dimensões são idênticas. Abaixo das imagens, os descritores fractais discriminam visualmente as formas, apresentando uma informação significativamente mais rica do que a dimensão. O mesmo ocorre na Figura 4.6, neste caso com duas imagens de texturas.

Imagem 1
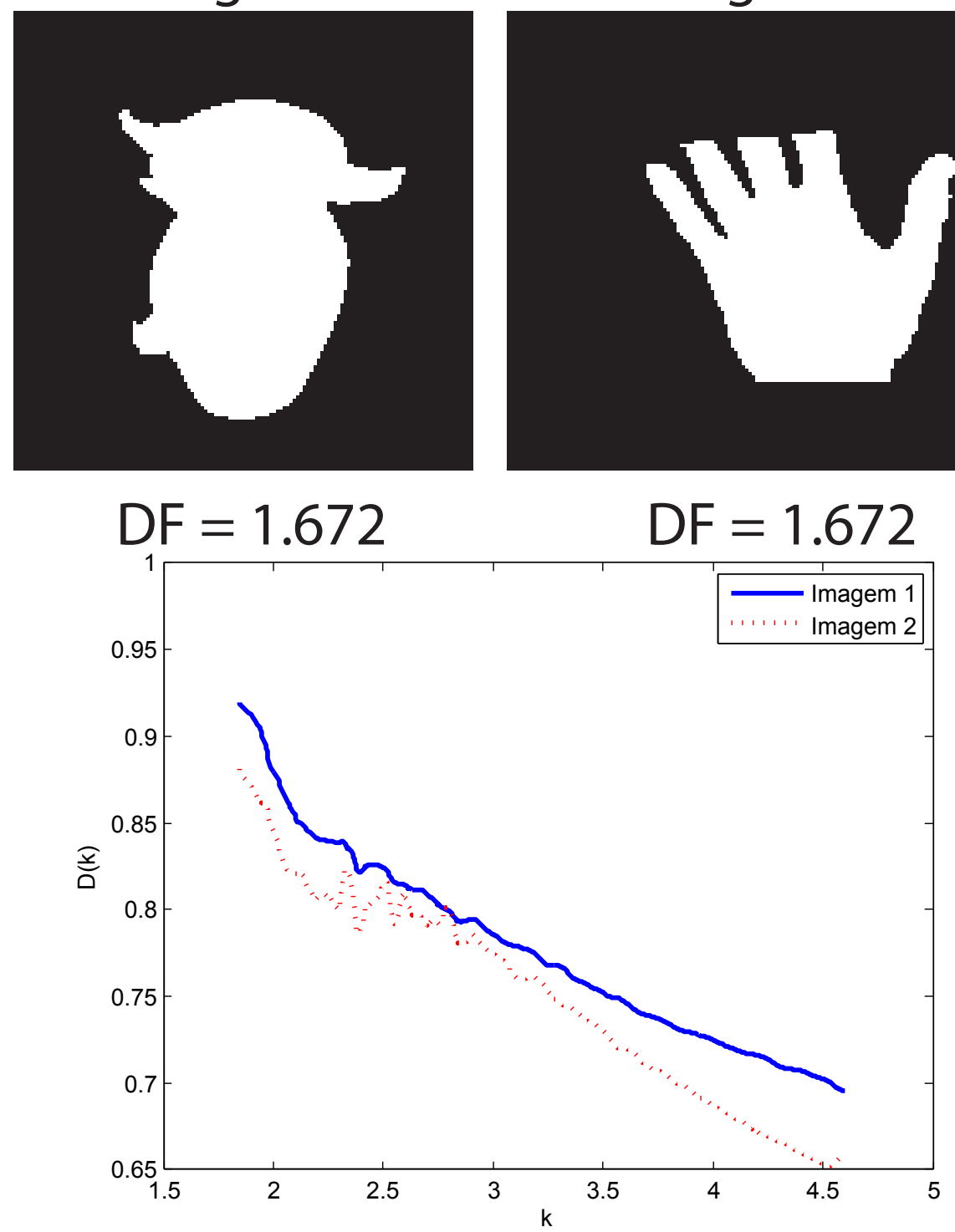

Imagem 2

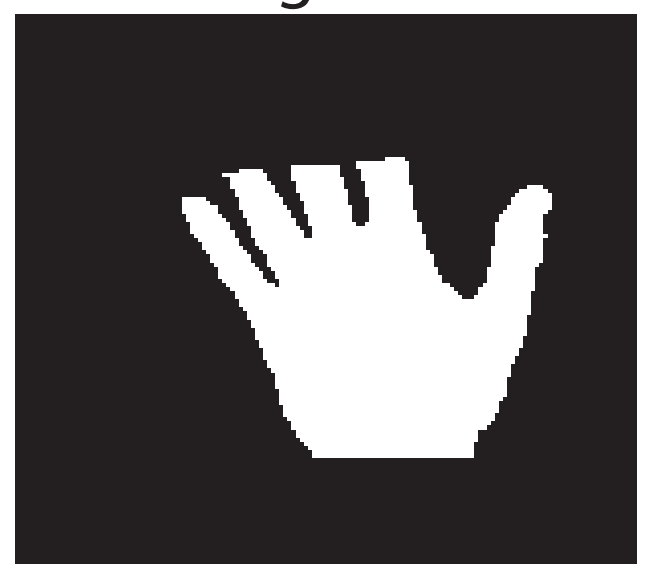




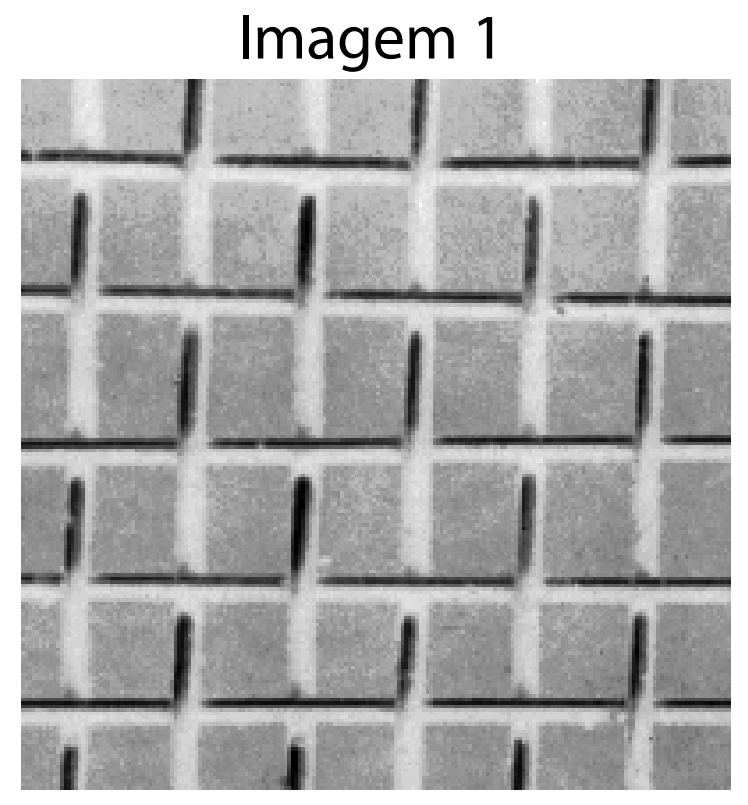

DF $=1.327$
Imagem 2

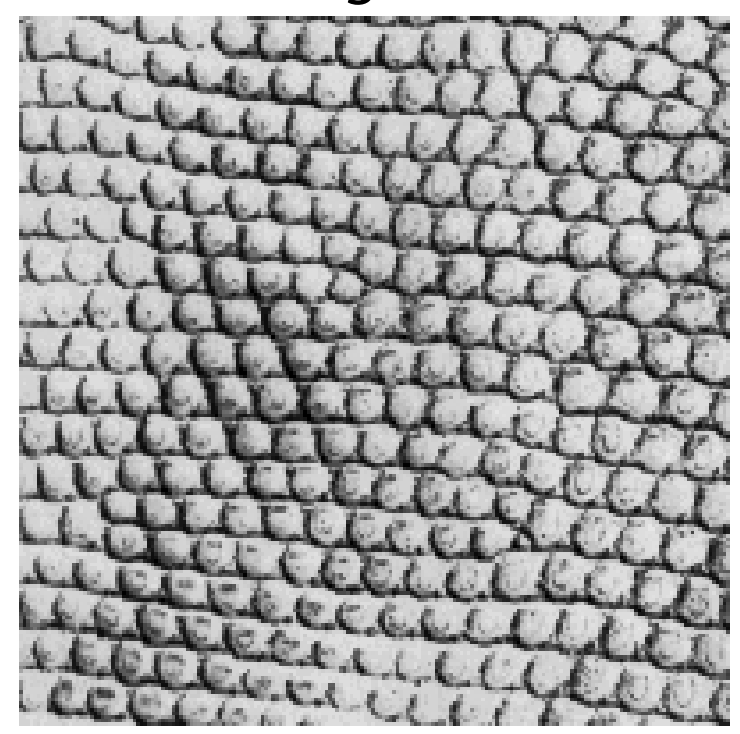

DF $=1.327$

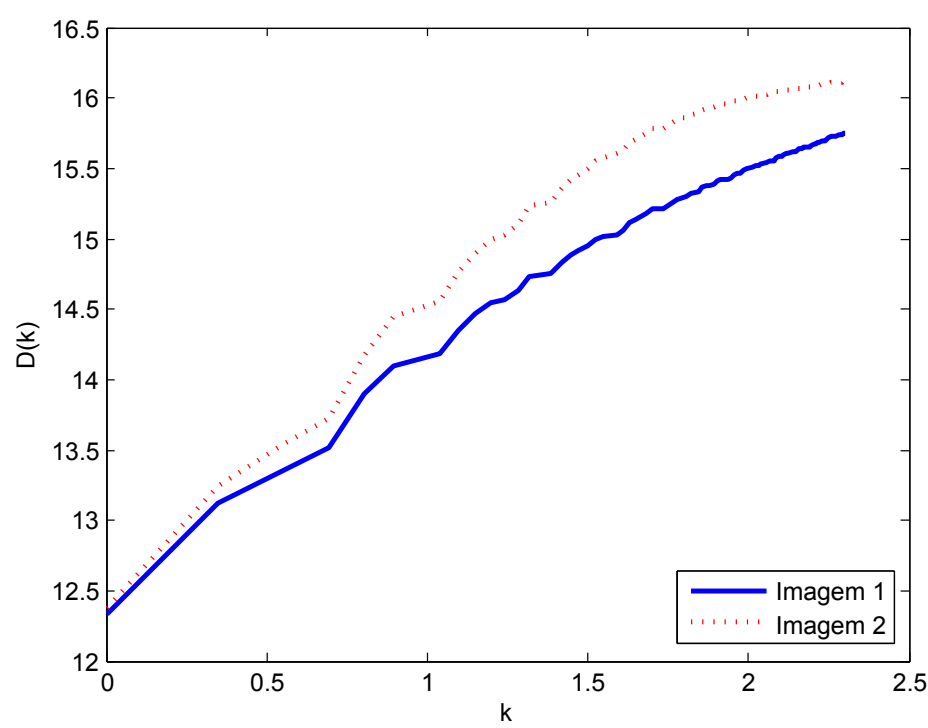

Figura 4.6 - Duas texturas com dimensões fractais idênticas sendo discriminadas pelos descritores fractais. 
tipo de transformação ou redução de dimensionalidade, como discutido nas seções a seguir. 


\section{CAPÍTULO 5}

\section{Metodologia Desenvolvida}

Este capítulo trata de todos os métodos desenvolvidos durante este projeto de doutorado. Nele, são abordadas as novas estratégias usadas para a obtenção de descritores fractais por transformada espaço-escala, tempo-frequência, tempo-escala, ainda por análise de dados funcionais, além dos descritores fractais multiníveis. É descrito ainda um novo método para a estimativa da dimensão fractal, além de um método de segmentação baseado em descritores fractais e de uma metodologia baseada em janelas para a análise de imagens de dimensões grandes como as obtidas em nanotecnologia.

\subsection{Descritores Fractais}

Como descrito no capítulo anterior, os descritores fractais fazem uso de toda a curva $\log$ - $\log$ de fractalidade da imagem analisada. Assim, em geral, para qualquer método de estimativa, a dimensão fractal $D$ é dada por:

$$
D \propto \frac{\log (\mathfrak{M})}{\log (\epsilon)}
$$

em que $\mathfrak{M}$ é algum tipo de medida de complexidade, seja no espaço ou no espectro de frequências, e $\epsilon$ é o parâmetro de escala. O descritor $u$ é dado então por:

$$
u: \log (\epsilon) \rightarrow \log (\mathfrak{M})
$$

Deste modo, os atributos fornecidos pelos descritores fractais para a descrição de uma textura fornecem uma visão ampla a respeito daquele objeto, uma vez que expressam informações de complexidade a respeito dos detalhes da imagem para valores pequenos de $\epsilon$ até características globais expressas nos valores maiores do parâmetro de escala. Este conjunto de dados provê uma descrição robusta e precisa de imagens de cenários mais complexos em 
que outras abordagens clássicas de análise de texturas falham, tornando possível o desenvolvimento de metodologias que automatizem o processo de classificação, descrição e segmentação de objetos em problemas nos quais uma análise visual seria dispendiosa ou mesmo inviável.

Na Figura 5.1, são exemplificadas duas texturas que apresentam os mesmos valores para a dimensão fractal e são difíceis de serem distinguidas mesmo pelo olho humano e que, entretanto, possuem curvas de descritores fractais claramente diferenciadas. Já a Figura 5.2 mostra texturas pertencentes a materiais (classes) distintos. Nota-se que as curvas dos descritores separam com clareza as duas classes.
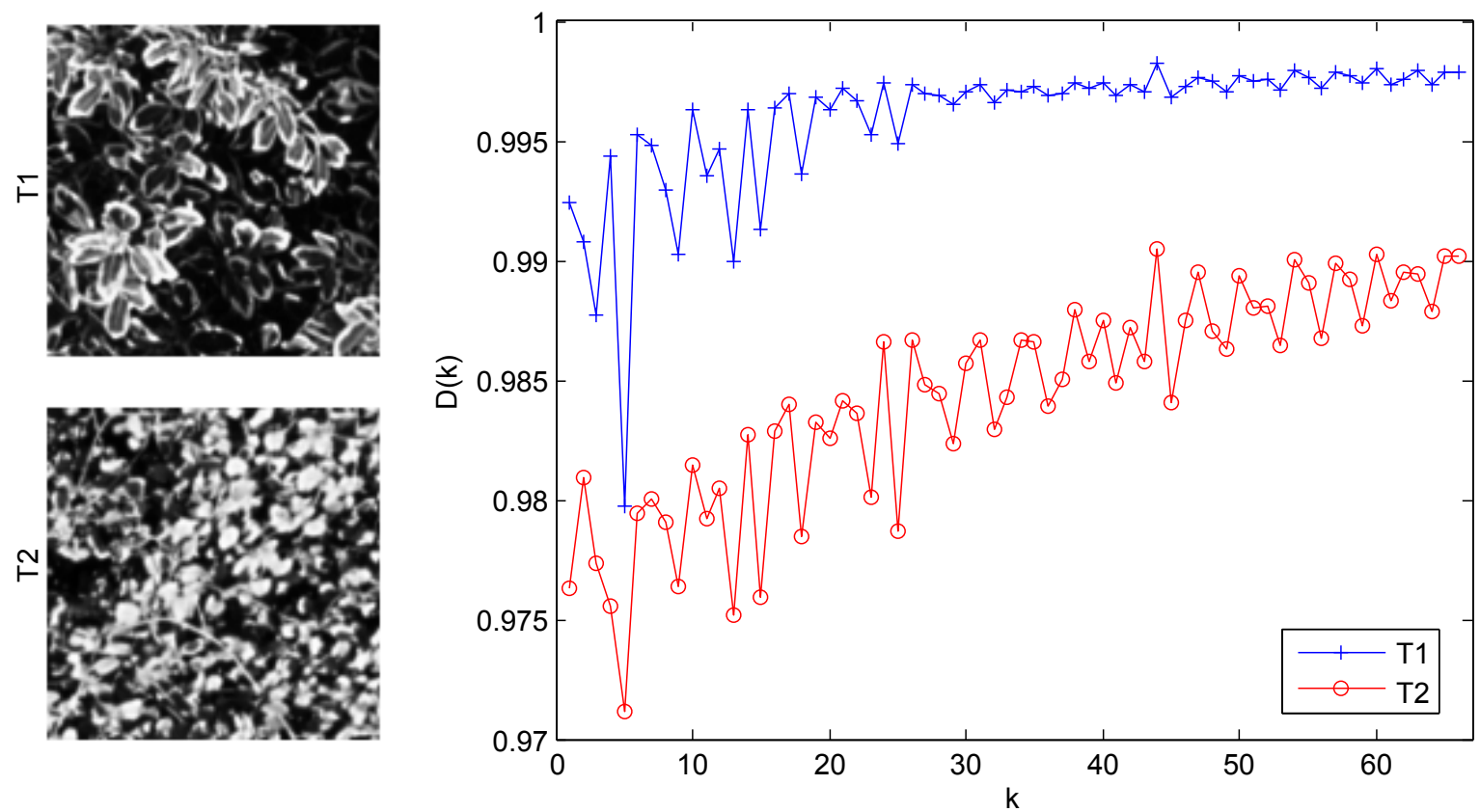

Figura 5.1 - Descritores fractais. À esquerda, duas imagens de texturas que apresentam dimensões fractais idênticas e são de difícil distinção mesmo a um ser humano. À direita, os descritores fractais das respectivas imagens separando claramente as amostras.

Os descritores fractais, tais como definidos no capítulo anterior, foram propostos, tanto para formas (20), quanto para texturas (83), usando-se apenas a dimensão de BouligandMinkowski. Em (82), os autores abordam o possível uso de outras dimensões mais clássicas, como Box-counting e Massa-raio, porém de forma superficial e sem apresentar resultados relevantes.

Este projeto estuda os descritores fractais em profundidade na análise de texturas. Neste sentido, os descritores são estendidos para mais de uma dezena de métodos de estimativa de dimensão fractal. A Figura 5.3 ilustra a curva de descritores obtida para cada método de dimensão fractal discutido anteriormente. Este trabalho também propõe uma nova forma de se extraírem os descritores, não mais a partir da imagem globalmente, mas dividindo-se esta imagem de modo recursivo e extraindo-se medidas estatísticas da relação entre os descritores 

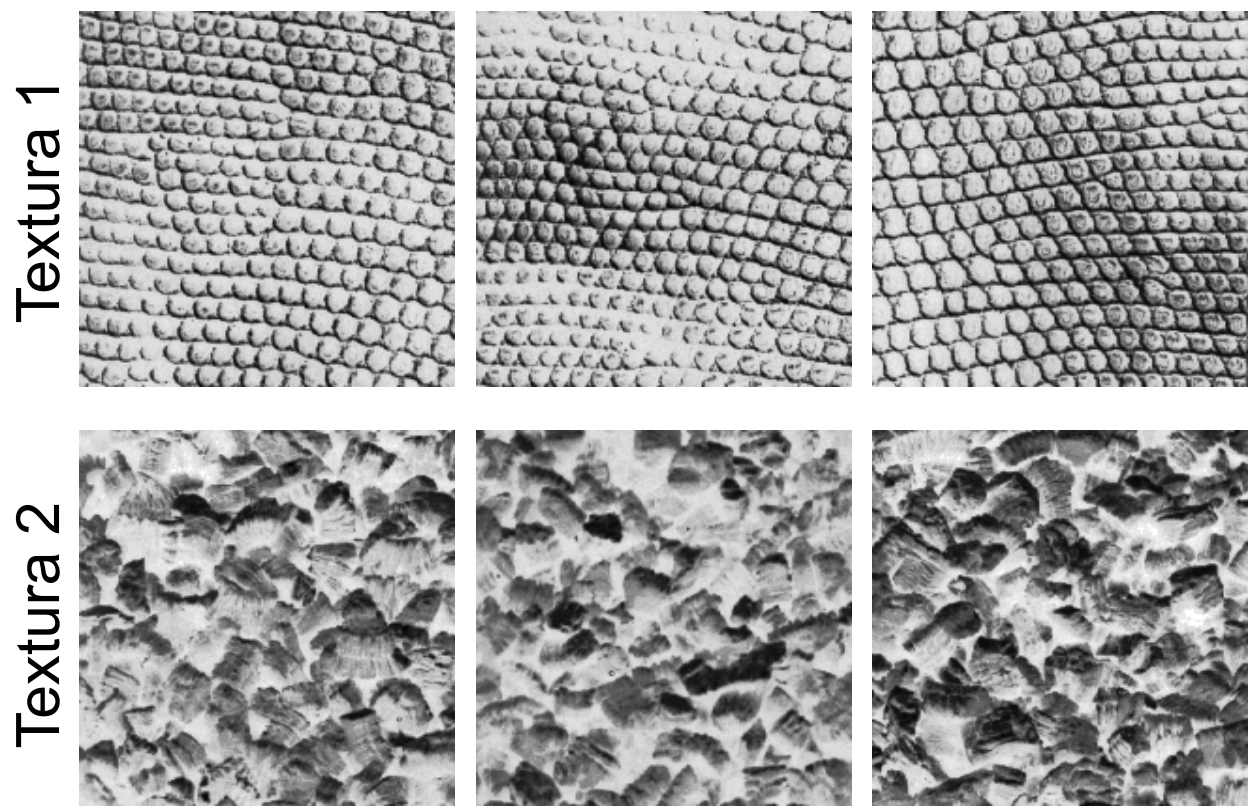

(a)

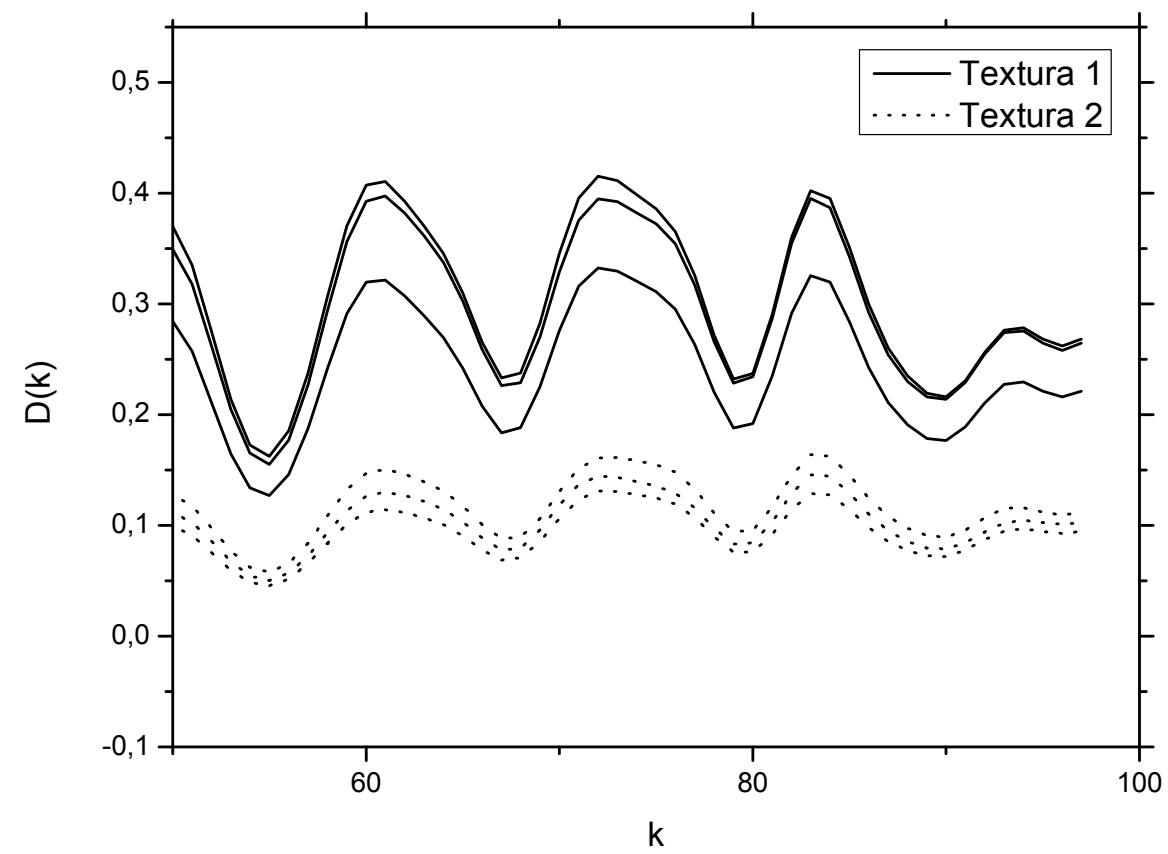

(b)

Figura 5.2 - Discriminação dos descritores fractais. (a) Texturas de dois materiais diferentes. (b) Descritores de cada textura representados em um mesmo gráfico e ilustrando a separação entre as classes. 
nos diferentes níveis de recursão. Ainda outra forma explorada de descritores fractais é por meio da aplicação de diferentes transformadas sobre a curva log - log com o objetivo de realçar diferentes aspectos desta curva. São usadas a transformada espaço-escala, tempo-frequência, tempo-escala, além da análise de dados funcionais. Novos descritores fractais também são propostos para a análise de texturas coloridas. Uma primeira abordagem neste sentido baseia-se no uso de filtros $E E E$, uma transformada de natureza física proposta em (85). Outro método é uma extensão do processo de dilatação morfológica, porém com as superfícies que representam canais de cores crescendo concomitantemente. Por fim, desenvolve-se uma metodologia que combina descritores baseados em diferentes métodos de dimensão fractal. As seções seguintes descrevem com maiores detalhes cada nova proposta.

\subsection{Descritores Multiníveis}

Nesta proposta, aqui chamada de Wavelike, a imagem de textura original é decomposta recursivamente em 4 partes. Em cada nível de decomposição são obtidos os descritores de Bouligand-Minkowski para cada parte. A partir disso, são calculados os descritores médios e desvio-padrão para cada nível. Os descritores finais são obtidos pelo cálculo da entropia dos descritores médios e de desvio.

Parte-se então de uma imagem $I:[N \times N] \rightarrow \Re$. Esta é decomposta em $l_{\text {max }}$ níveis $\left\{l \mid 1 \leq l \leq l_{\max }\right\}$, tal que $l_{\max }=$ ceil $\left(\log _{2}(N)\right)$. Então, em cada nível, a imagem é particionada em regiões $R_{l j k}$ :

$$
R_{l j k}=\left\{x, y \mid(j-1) * 2^{l} \leq x \leq(j) * 2^{l},(k-1) * 2^{l} \leq x \leq(k) * 2^{l}\right\} .
$$

Para cada região $R$, são obtidos os descritores de Bouligand-Minkowski $D_{l j k}$. Para um nível $l$, são obtidos os descritores médios $D_{l}^{M}$ e de desvio $D_{l}^{\sigma}$ :

$$
\begin{gathered}
D_{l}^{M}=\frac{\sum_{j k} D_{l j k}}{2^{l}}, \\
D_{l}^{\sigma}=\sum\left(D_{l j k}-D_{l}^{M}\right)^{2} .
\end{gathered}
$$

A partir disso, a entropia de Shannon (59) é calculada sobre cada índice $i$ dos descritores de Bouligand-Minkowski médios em todos os níveis, compondo o vetor $\varphi(\vec{i})$ :

$$
\varphi \overrightarrow{(i)}=\left[D_{1}^{M}(i) D_{2}^{M}(i) D_{3}^{M}(i) \ldots D_{l_{\max }}^{M}(i)\right]
$$




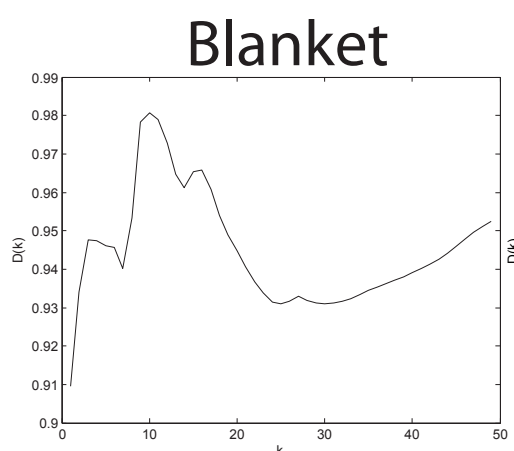

Fourier
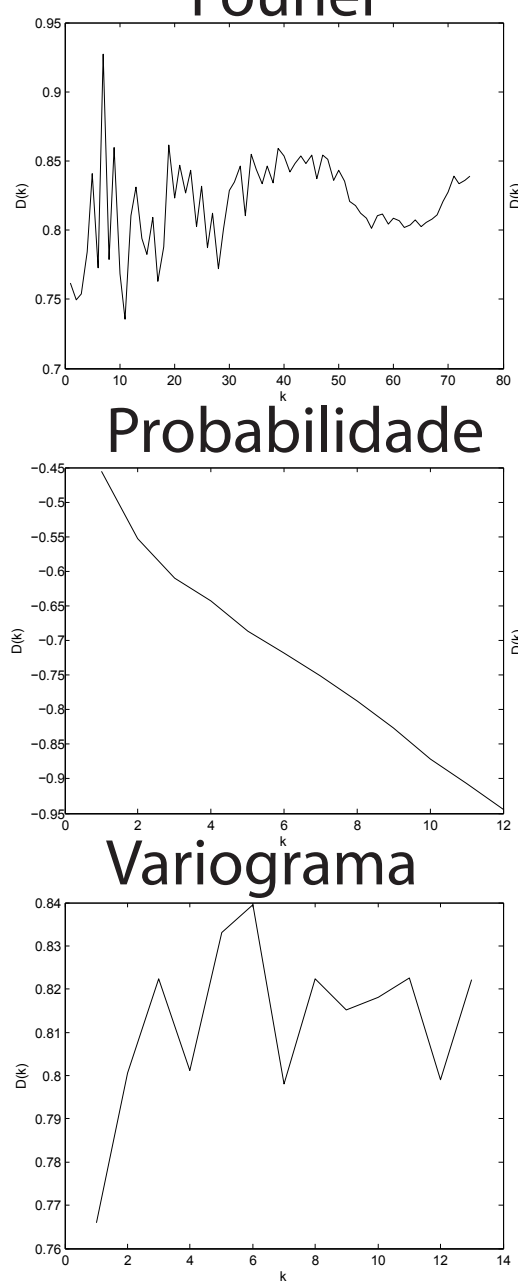

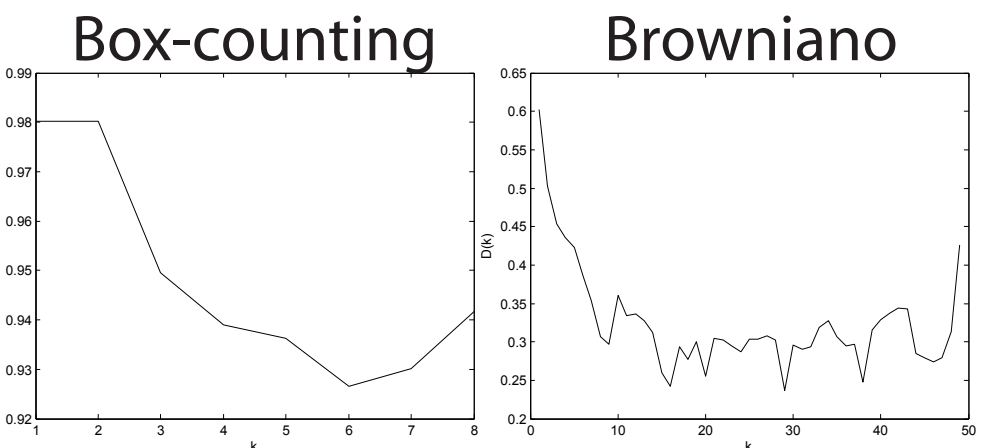

Lacunaridade Bouligand-Minkowski

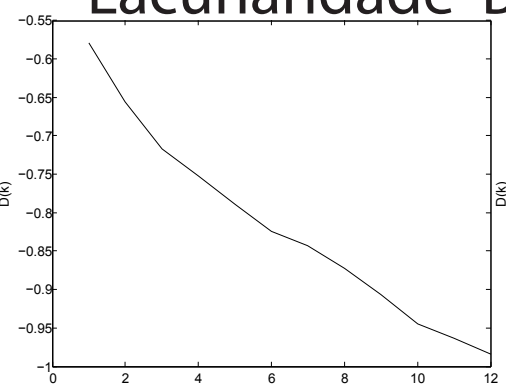

Triangular

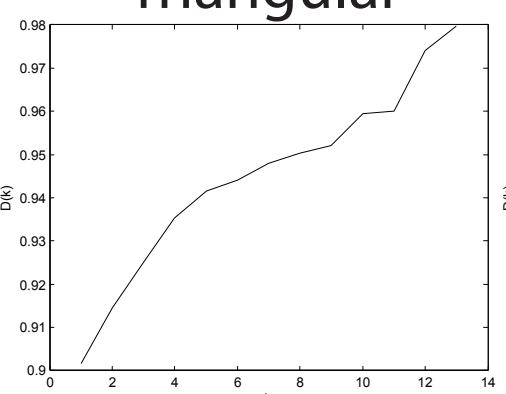

Wavelets

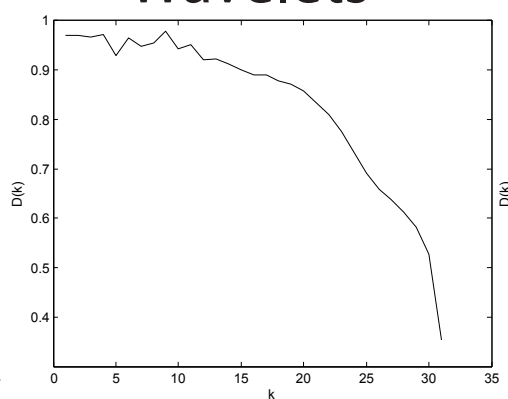

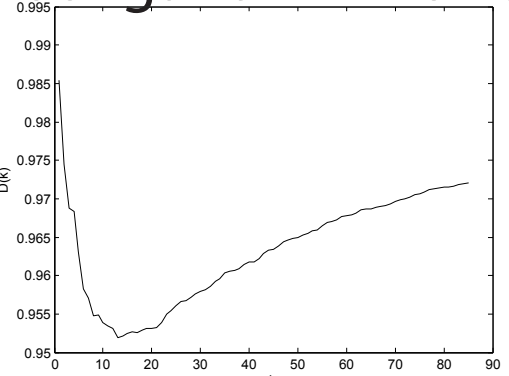

Variação

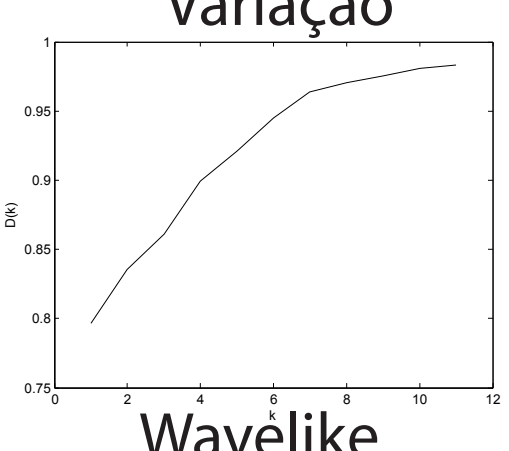

Wavélike

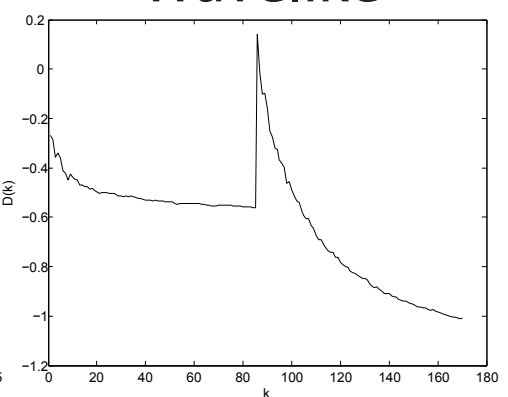

Figura 5.3 - Curva dos descritores fractais, já com cada variável normalizada, para cada método de dimensão fractal numérica discutido neste trabalho. 
O mesmo processo é aplicado sobre os descritores de desvio-padrão, formando o vetor $\psi \overrightarrow{\psi(i)}$ :

$$
\psi \overrightarrow{(i)}=\left[D_{1}^{\sigma}(i) D_{2}^{\sigma}(i) D_{3}^{\sigma}(i) \ldots D_{l_{\max }}^{\sigma}(i)\right]
$$

Em seguida, a entropia de Shannon $K$ é calculada para cada valor nos vetores acima. Simplificando a notação, assume-se que $u$ é um vetor genérico de comprimento $N$ e a entropia de Shannon é dada então por:

$$
K(u)=\sum_{i=1}^{N} u(i) \log (u(i))
$$

O vetor de entropia $\overrightarrow{V E}$ é dado então por:

$$
\overrightarrow{V E}=[K(\varphi \overrightarrow{(1)}) K(\varphi \overrightarrow{(2)}) \ldots K(\varphi \overrightarrow{(n)}) K(\psi \overrightarrow{(1)}) K(\psi \overrightarrow{(2)}) \ldots K(\psi \overrightarrow{(n)})]
$$

em que $n$ é o número de componentes no vetor de descritores médios e de desvio.

Por fim, aplica-se uma etapa de seleção de atributos baseada no classificador. Assim, dado que $S$ é uma medida de acerto para cada componente de $\overrightarrow{V E}$ individualmente, ordenada crescentemente, tem-se então o vetor de ordenação $\overrightarrow{\mathfrak{I}}$ :

$$
\overrightarrow{\mathfrak{I}}=\operatorname{index}(\operatorname{sort}(S(E F \vec{V}(i))))
$$

Os descritores fractais multiníveis $M L D$ são obtidos pela indexação de $\overrightarrow{V E}$ usando-se os $n$ primeiros índices em $\overrightarrow{\mathfrak{I}}$, sendo $n$ o número mínimo de componentes para obter o maior índice de acerto, isto é:

$$
M L D=\max _{i}(S(E F V(\overrightarrow{\mathfrak{I}} \overrightarrow{(1} . . i)))
$$

A Figura 5.4 mostra um diagrama das etapas seguidas.

\subsection{Análise de Dados Funcionais}

Análise de Dados Funcionais (usa-se aqui a sigla em Inglês FDA) (86, 87) é uma técnica de análise estatística alternativa à análise multivariada convencional. O diferencial da técnica é que, em vez de simplesmente analisar relações entre as variáveis observadas, a FDA propõe o tratamento do conjunto de observações como sendo provenientes de uma função analítica. Assim, a técnica possibilita a aplicação de uma série de ferramentas, como análise de derivadas, integrais, pontos de inflexão, etc. Cada uma destas ferramentas pode fornecer informações importantes sobre o dado originalmente observado. 

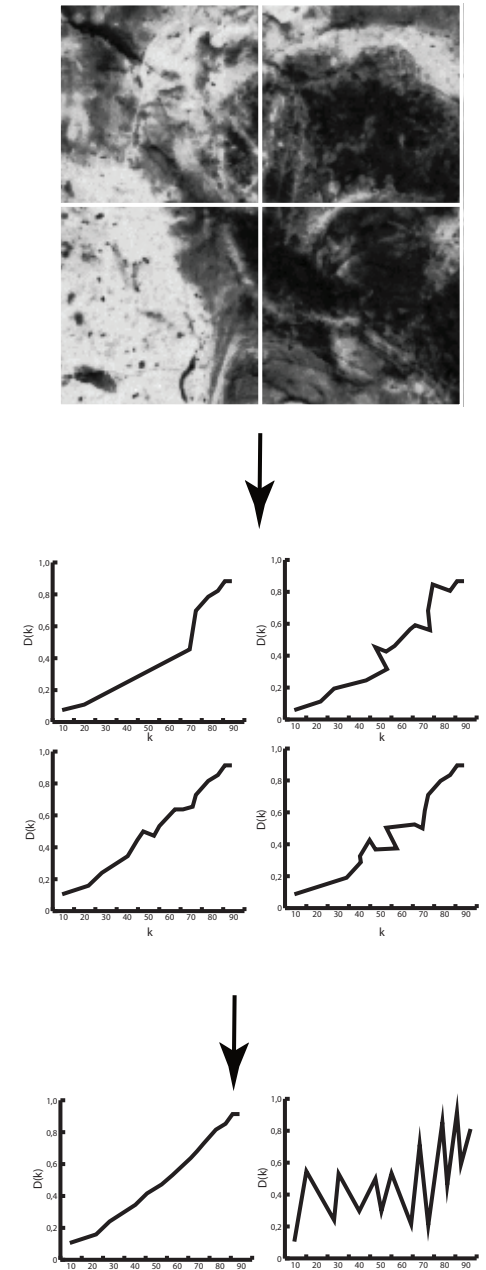

$\mathrm{D}_{1} \mathrm{M}$

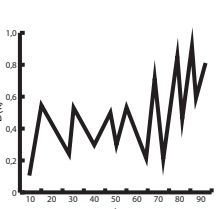

$\mathrm{D}_{1} \rho$
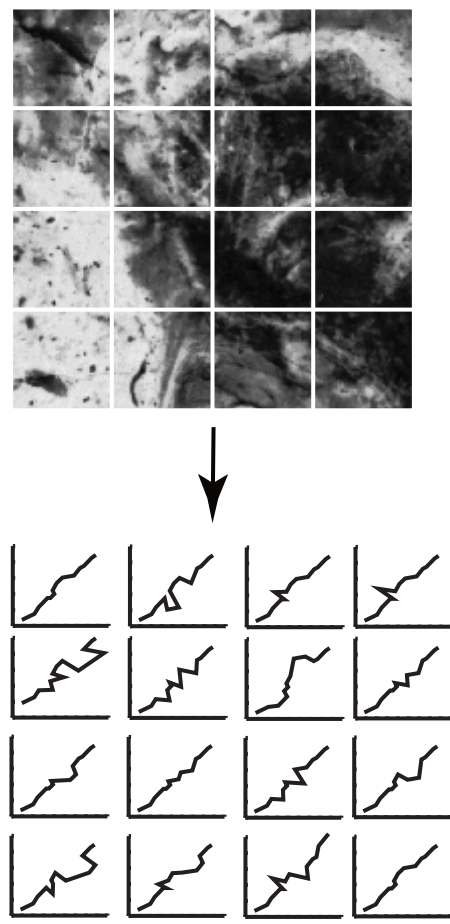
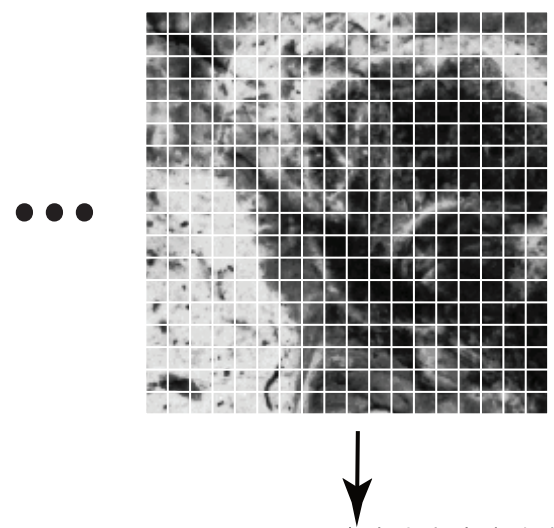

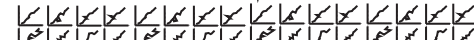

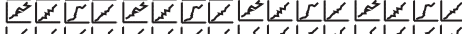

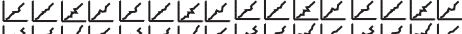

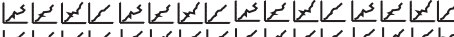
C.

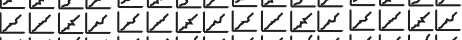

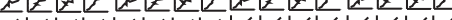

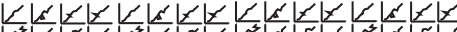
r

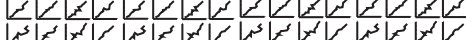

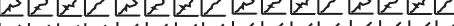

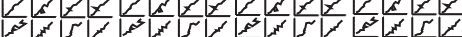
S)

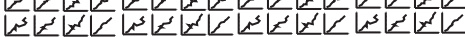

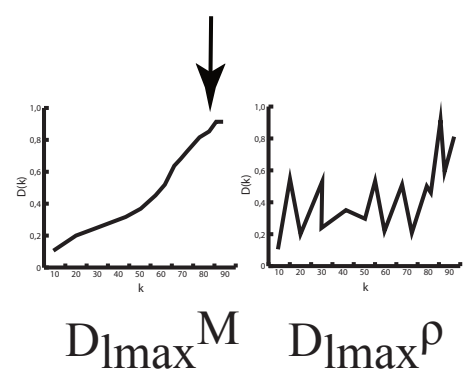

$\mathrm{D}_{\operatorname{lmax}} \mathrm{M}$

$x^{\rho}$
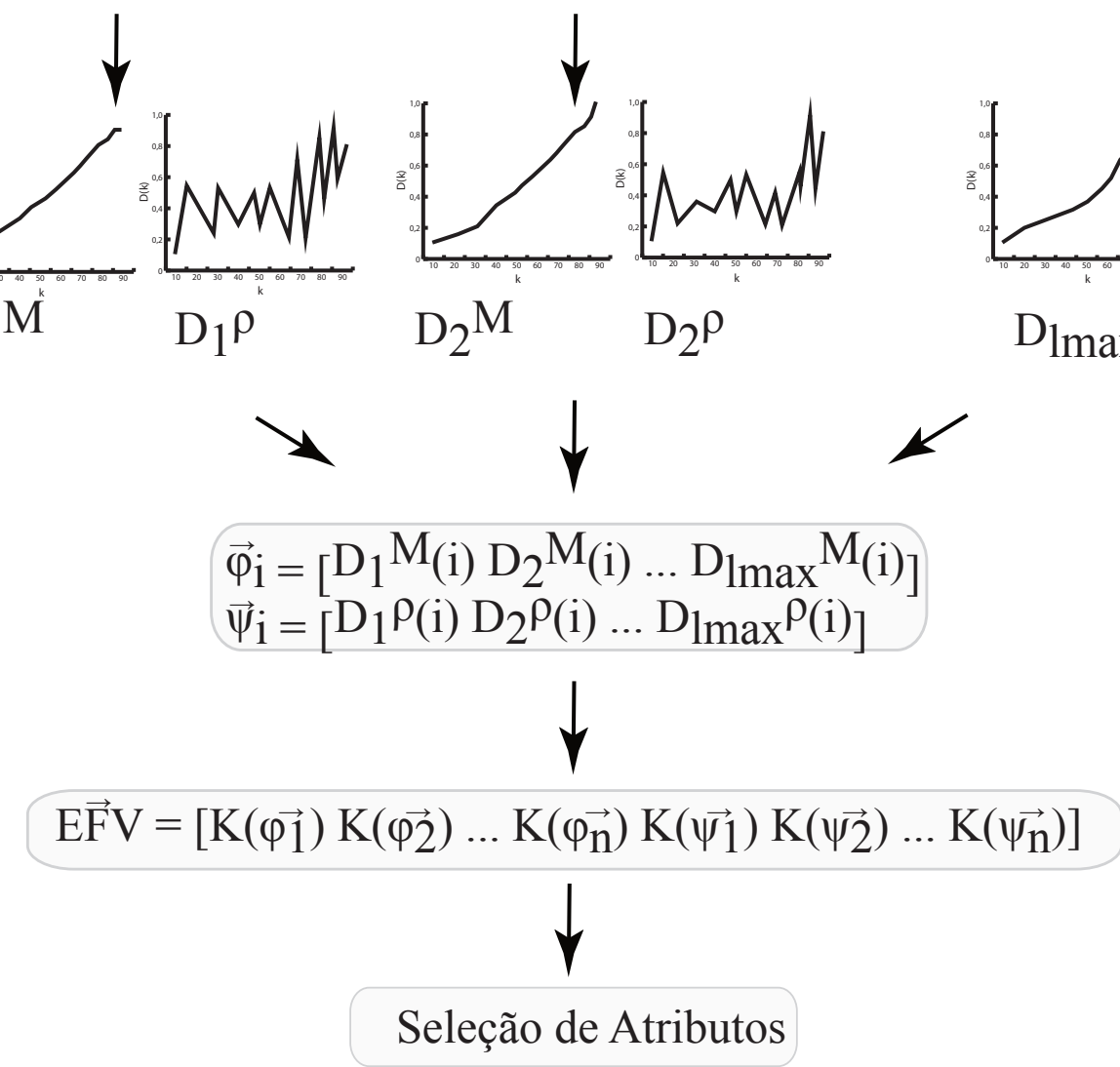

$\mathrm{D}_{2} \mathrm{M}$

$\mathrm{D}_{2} \rho$

Figura 5.4 - Etapas do método multinível de descritores fractais. De cima para baixo, imagens originais, descritores de cada janela, descritores médio e de desvio, vetor contendo $i$-ésimo componente de todos os níveis de decomposição (tanto para os descritores médios $(\varphi)$ como de desvio $\psi$ ), entropia dos vetores anteriores, seleção de atributos. 
A ideia principal do método é que qualquer conjunto de observações pode ser representado por uma função real, desde que se assuma que existe um erro intrínseco de medida. Assumindose que uma observação possa ser representada por um par de variáveis $(x, y)$ (por exemplo, tempo e temperatura) $u=\left(x_{j}^{i}, y_{j}^{i}\right)_{1 \leq j \leq m^{i}, 1 \leq i \leq n}$, em que $x_{j}^{i} \in V, y_{j}^{i} \in \Re$ são os pares de variáveis $i$ e $m^{i}$ é o número de pares observados, então pode-se obter a função analítica $y$ :

$$
y_{j}^{i}=u^{i}\left(x_{j}^{i}\right)+\epsilon_{j}^{i}
$$

em que $\epsilon_{j}^{i}$ é o erro de medida associado.

A função $u$ pode ser obtida por métodos de interpolação baseados no desenvolvimento da função a ser estimada em um espaço de funções-base. Os coeficientes de desenvolvimento são obtidos a partir de um ajuste aos dados da observação conhecidos. Desta forma, a função aproximante $u^{i^{\prime}}$ é dada por:

$$
u^{i^{\prime}}=\sum_{j=1}^{q} \alpha_{j}\left(u^{i^{\prime}}\right) \phi_{j} .
$$

em que $\phi$ são as bases e os coeficientes $\alpha$ são tais que minimizem:

$$
\sum_{j=1}^{m^{i}}\left\{y_{j}^{i}-\sum_{k=1}^{q} \alpha_{k}\left(u^{i^{\prime}}\right) \phi_{k}\left(x_{j}^{i}\right)\right\}^{2}, i=1, \ldots, n .
$$

Neste trabalho, as bases usadas foram as do tipo $B$-spline, dada sua maior flexibilidade no tratamento de dados que não possuem características bem identificadas como periodicidade, exponencialidade, etc. Para a geração dos descritores propriamente, a curva log - log é tratada como um dado de observação e o procedimento descrito é aplicado. A partir disso, duas abordagens podem ser usadas. Na primeira, os coeficientes $\alpha$ são usados diretamente como descritores. Na segunda, os coeficientes são submetidos a uma transformação descrita em (88), na qual, os descritores são obtidos dos coeficientes transformados $\beta$, dados por:

$$
\beta(u)=S \alpha(u),
$$

em que $S$ representa a decomposição de Choleski (89) da matriz de bases $\Phi$ :

$$
\Phi(k, l)=<\phi_{k}, \phi_{l}>
$$

Neste projeto, usou-se a abordagem direta, em função de prover resultados similares à segunda opção, porém com menor custo computacional. 


\subsection{Transformada Multiescala}

Neste caso, os descritores são obtidos após a aplicação de uma transformação multiescala à curva $\log$ - $\log$ da dimensão fractal (80). Uma transformada multiescala mapeia um sinal unidimensional $u(t)$ em um bidimensional $U(b, a)$, em que $b$ se relaciona linearmente a $t$ e $a$ é um parâmetro que indica a escala em que a variável $t$ foi medida. A literatura apresenta três principais categorias de transformadas multiescala, que serão descritas brevemente a seguir.

\subsubsection{Espaço-escala}

Aqui, conforme descrito em (90, 91), a transformação é obtida pela aplicação de uma operação de derivada, seguida pela convolução com um filtro gaussiano de parâmetro $a$, ou seja:

$$
U(b, a)=\sum_{n=-\infty}^{+\infty} u(t-n) G(n, a),
$$

em que $G$ é a função gaussiana:

$$
G(n, a)=\frac{1}{\sqrt{2 \pi a}} \exp \left(-n^{2} / 2 t\right)
$$

\subsubsection{Tempo-frequência}

Nesta abordagem, desenvolvida em (92-94), a multiescala é fornecida a partir da transformada de Gabor do sinal original:

$$
G(b, a)=\int_{-\infty}^{+\infty} g^{*}(t-b) u(t) e^{-2 \pi a t} d t
$$

em que $g$ é uma função gaussiana. Na prática, essa operação equivale a uma transformada de Fourier janelada usando janelas gaussianas, garantindo assim uma maior flexibilidade na análise de frequências locais no sinal. 


\subsubsection{Tempo-escala}

Nesse caso, a multiescala é obtida com o auxílio da transformada wavelet (95, 96). O sinal transformado $U(b, a)$ é obtido por:

$$
U(b, a)=\frac{1}{a} \int_{\Re} \psi\left(\frac{t-b}{a}\right) u(t) d t
$$

sendo $\psi$ a função das bases wavelets (97).

\subsection{Descritores para Imagens Coloridas}

\subsubsection{Filtro $E E E$}

Esta solução é derivada do uso direto da curva $\log$ - log, porém com uma adaptação para seu emprego na análise de imagens coloridas, contendo 3 canais de cor. O método consiste em trabalhar cada canal separadamente e concatenar os descritores obtidos. O desafio é encontrar o espaço ideal para a análise dos canais. A literatura apresenta diversas soluções para essa questão, entretanto, aqui se escolheu a abordagem desenvolvida em (85), uma vez que esta permite um tratamento mais flexível do espaço, preservando a informação espacial de cada cor dentro da imagem.

A técnica se baseia em uma transformada do espaço de cor, conhecida por $E E E$ (85), e derivada do conceito físico de cada cor, mais precisamente da energia luminosa associada a cada comprimento de onda. Na prática, a transformada se resume a uma operação linear aplicada por uma matriz cujos coeficientes são obtidos empiricamente. Os componentes transformados $\tilde{E}_{\lambda}, \tilde{E}_{\lambda \lambda}$ e $\tilde{E}_{\lambda \lambda \lambda}$ são obtidos a partir dos canais $R, G$ e $B$ originais da seguinte maneira:

$$
\left(\begin{array}{c}
\tilde{E}_{\lambda} \\
\tilde{E}_{\lambda \lambda} \\
\tilde{E}_{\lambda \lambda \lambda}
\end{array}\right)=\left(\begin{array}{ccc}
0.06 & 0.63 & 0.31 \\
0.19 & 0.18 & -0.37 \\
0.22 & -0.44 & 0.06
\end{array}\right)\left(\begin{array}{c}
R \\
G \\
B
\end{array}\right) .
$$

Os descritores fractais são então aplicados sobre cada canal $E$ e concatenados, compondo assim os descritores finais usados para a classificação das imagens coloridas. No presente trabalho, o filtro EEE foi aplicado sobre os descritores fractais de Bouligand-Minkowski e de Fourier. 


\subsubsection{Descritores volumétricos de Bouligand-Minkowski}

Esta solução pode ser dividida em três etapas. Inicialmente, cada canal RGB da imagem de textura colorida é mapeado para uma superfície tridimensional de modo semelhante ao que ocorre na estimativa da dimensão de Bouligand-Minkowski convencional de texturas em tons de cinza. Em seguida, cada uma das três superfícies é dilatada compartilhando o mesmo espaço tridimensional, de forma que as estruturas dilatadas interferem-se mutuamente. Por fim, os descritores são obtidos pela concatenação dos valores de volume de dilatação em cada superfície.

A Figura 5.5 a seguir ilustra o processo de dilatação multicanal. Aqui, cada pixel é representado por uma esfera vermelha (intensidade R), verde (intensidade G) e azul (intensidade B). Nota-se que à medida que a dilatação vai ocorrendo, as esferas coloridas se chocam e os volumes de cada canal vão sendo distorcidos pela interferência mútua.

O método proposto combina informações a respeito de duas das mais importantes características de uma imagem de textura colorida, ou seja, a complexidade da distribuição de intensidades com a distribuição de cores dentro da imagem. Os primeiros raios de dilatação fornecem uma informação mais precisa acerca da morfologia local dos pixels, enquanto os raios maiores, além de expressarem a complexidade em um nível mais global, ainda revelam dados importantes do posicionamento das cores dentro da imagem, uma vez que essa distribuição dita o padrão de interferência entre os canais. Assim, esses descritores se apresentam como uma ferramenta poderosa na representação de texturas coloridas em diferentes aplicações.

\subsection{Descritores Fractais em Segmentação}

O objetivo é automatizar o processo de identificação de áreas urbanas e rurais dentro da região mapeada na imagem. Este é um problema importante e de grande desafio na área de planejamento urbano e arquitetura, uma vez que a delimitação dessas regiões permite uma melhor compreensão do crescimento de uma cidade ou país, possibilitando a aplicação de medidas específicas para conter, por exemplo, o desmatamento ou o êxodo desproporcional de pessoas entre áreas, além de, ao longo do tempo, fornecer uma ferramenta de análise do movimento histórico de uma determinada área.

A literatura apresenta algumas soluções interessantes na segmentação de texturas usando 


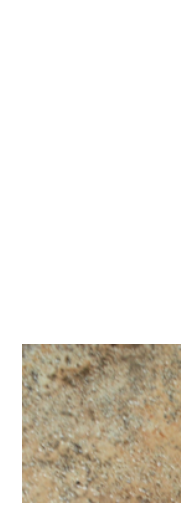

(a)

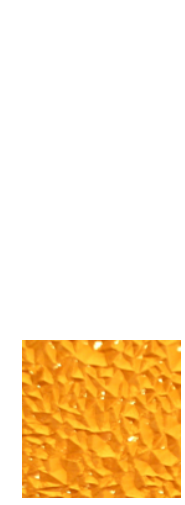

(a)

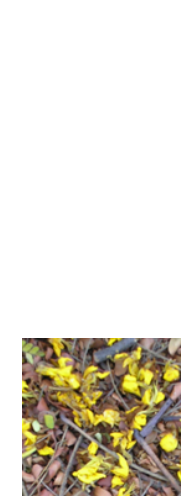

(a)

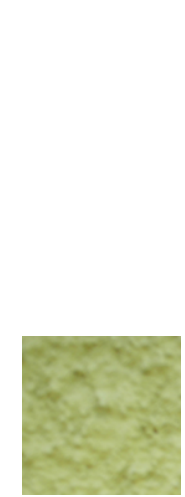

(a)

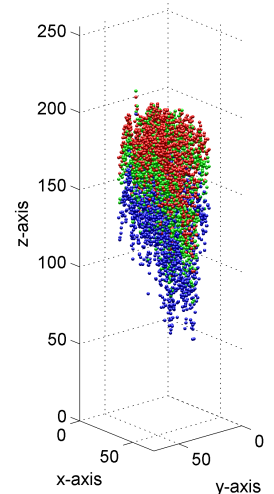

(b)

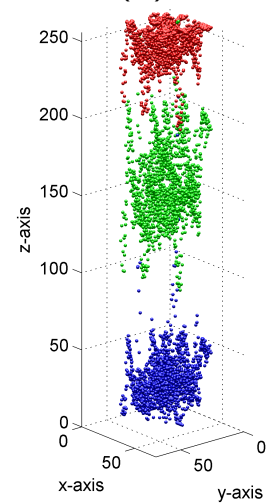

(b)

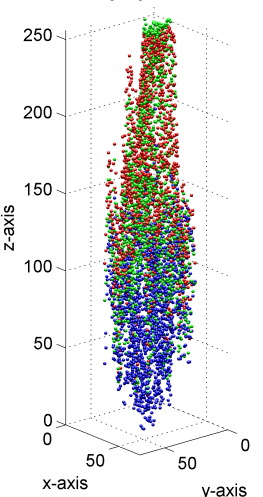

(b)

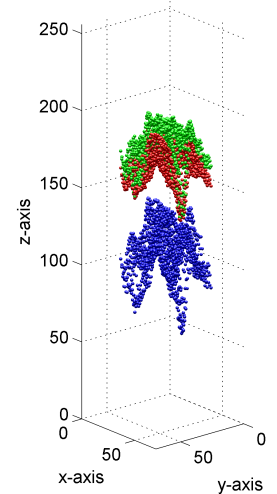

(b)

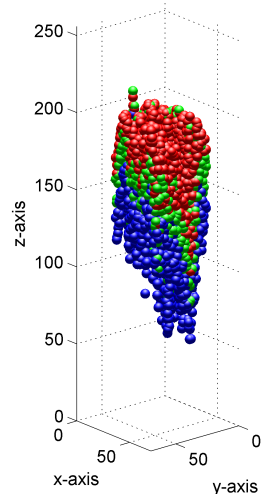

(c)

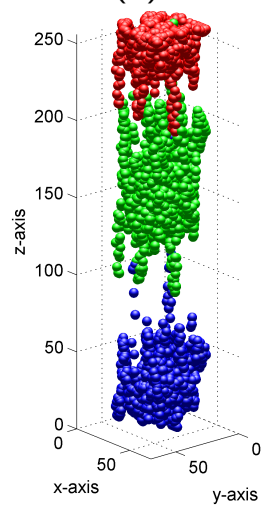

(c)

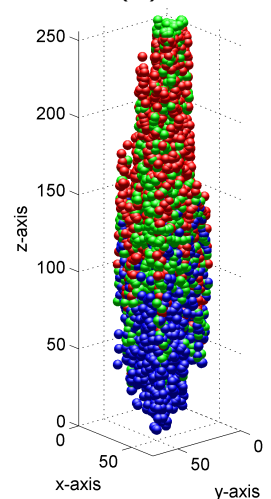

(c)

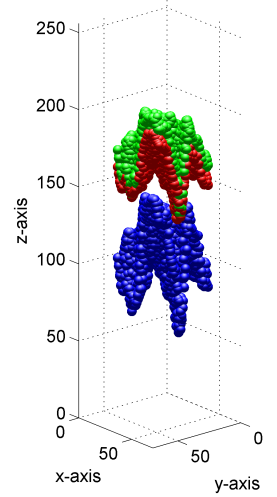

(c)

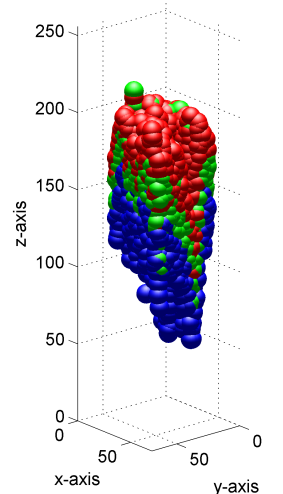

(d)

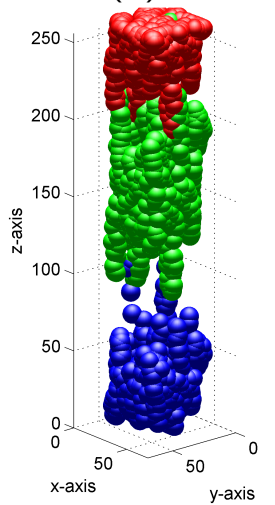

(d)

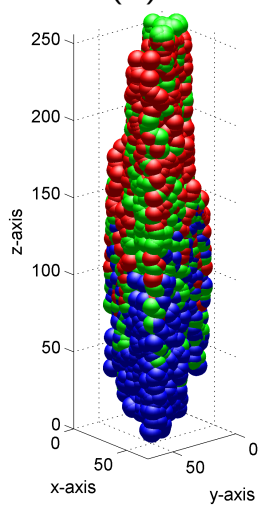

(d)

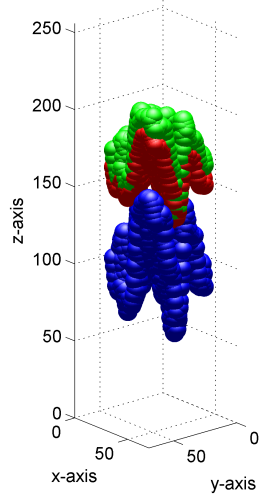

(d)

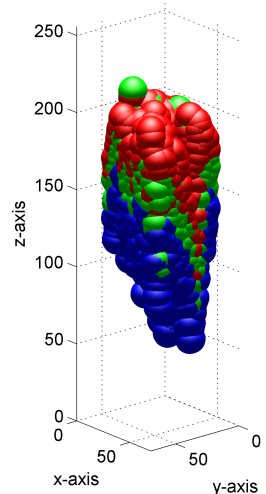

(e)

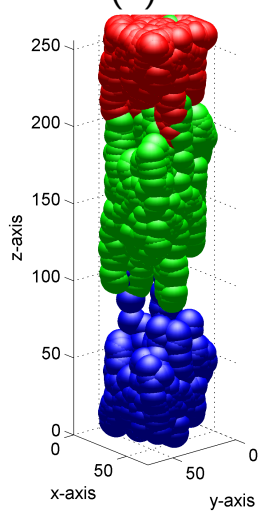

(e)

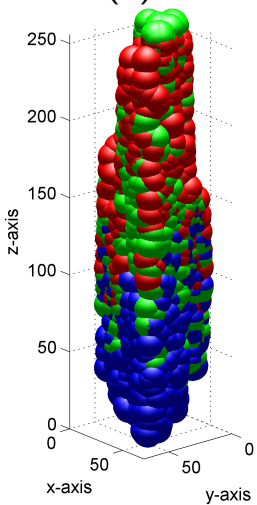

(e)

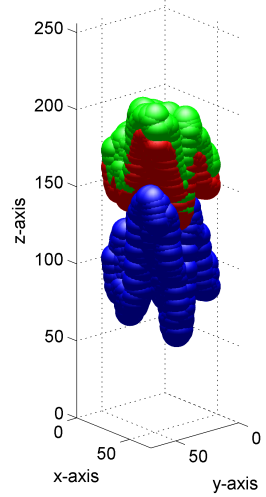

(e)

Figura 5.5 - Aplicação dos descritores coloridos propostos sobre 4 imagens de texturas: (a) Imagem original; (b) $r=1$; (c) $r=2$; (d) $r=4$; (e) $r=6$. 
multifractais (5, 98), entretanto, não se conhece nenhuma abordagem mais relevante baseada em descritores fractais.

Deste modo, a segmentação em si é feita pela divisão da imagem da área analisada em janelas (quadrados), variando-se o comprimento dos lados empiricamente. A seguir, para cada janela são extraídos descritores fractais de Bouligand-Minkowski e tais descritores são submetidos a um classificador que vai identificar se aquela janela corresponde a uma região urbana ou rural.

\subsection{Descritores por Janelas}

Um problema importante na Ciência dos Materiais é identificar um material a partir de informações colhidas do mesmo, porém processado em situações distintas (alterando a data do experimento, o equipamento, etc). Na maioria das vezes, o material é processado sob diferentes parâmetros experimentais, compondo um conjunto de treinamento, no qual cada amostra é uma imagem nanométrica do material e cada classe corresponde a um conjunto específico de parâmetros. Em outro momento, este mesmo material é processado repetindo-se os parâmetros usados no treinamento e gerando-se replicatas do primeiro conjunto, replicatas estas que vão compor o conjunto de teste. O classificador deve ser capaz de identificar a classe de cada amostra no conjunto de testes a partir dos dados do treinamento.

Ocorre que, entre o primeiro e o segundo experimento, são inseridas microvariações externas ao processo, que são capazes de gerar imagens totalmente distintas no aspecto morfológico global nos dois conjuntos. Assim, os descritores extraídos diretamente de cada amostra não se mostram uma abordagem interessante.

Deste modo, foi proposta uma abordagem que extrai os descritores fractais de janelas locais dentro das imagens. Inicialmente, cada imagem $I:[M \times N] \rightarrow \Re$ nos conjuntos de treinamento e teste é dividida em janelas menores $W_{i, j}=I([i: i+l, j: j+1])$, com lado de comprimento $l$. Em seguida, são calculados os descritores fractais (no caso de BouligandMinkowski) $D_{i, j}^{(W)}$ para cada uma. Finalmente, são selecionados os descritores de pares de janelas (uma do treinamento, outra do teste) que apresentam as menores distâncias Euclidianas entre si:

$$
D=\left\{D_{i, j}^{(W)} \mid d\left(D_{i_{1}, j_{1}}^{(W)}, D_{i_{2}, j_{2}}^{(W)}\right)<\tau\right\}
$$

em que $\tau$ é um limiar definido para cada aplicação e $d$ é a distância Euclidiana entre dois 
vetores $\mathbf{p}_{\mathbf{1}}=\left(x_{1}, x_{2}, x_{3}, \ldots, x_{n}\right)$ e $\mathbf{p}_{\mathbf{2}}=\left(y_{1}, y_{2}, y_{3}, \ldots, y_{n}\right)$ :

$$
d(p 1, p 2)=\sqrt{\left(x_{1}-y_{1}\right)^{2}+\left(x_{2}-y_{2}\right)^{2}+\left(x_{3}-y_{3}\right)^{2}+\ldots\left(x_{n}-y_{n}\right)^{2}} .
$$

Estes descritores são então submetidos ao classificador, no caso, KNN, para obter a classificação do conjunto de testes. O diagrama na Figura 5.6 ilustra o processo.

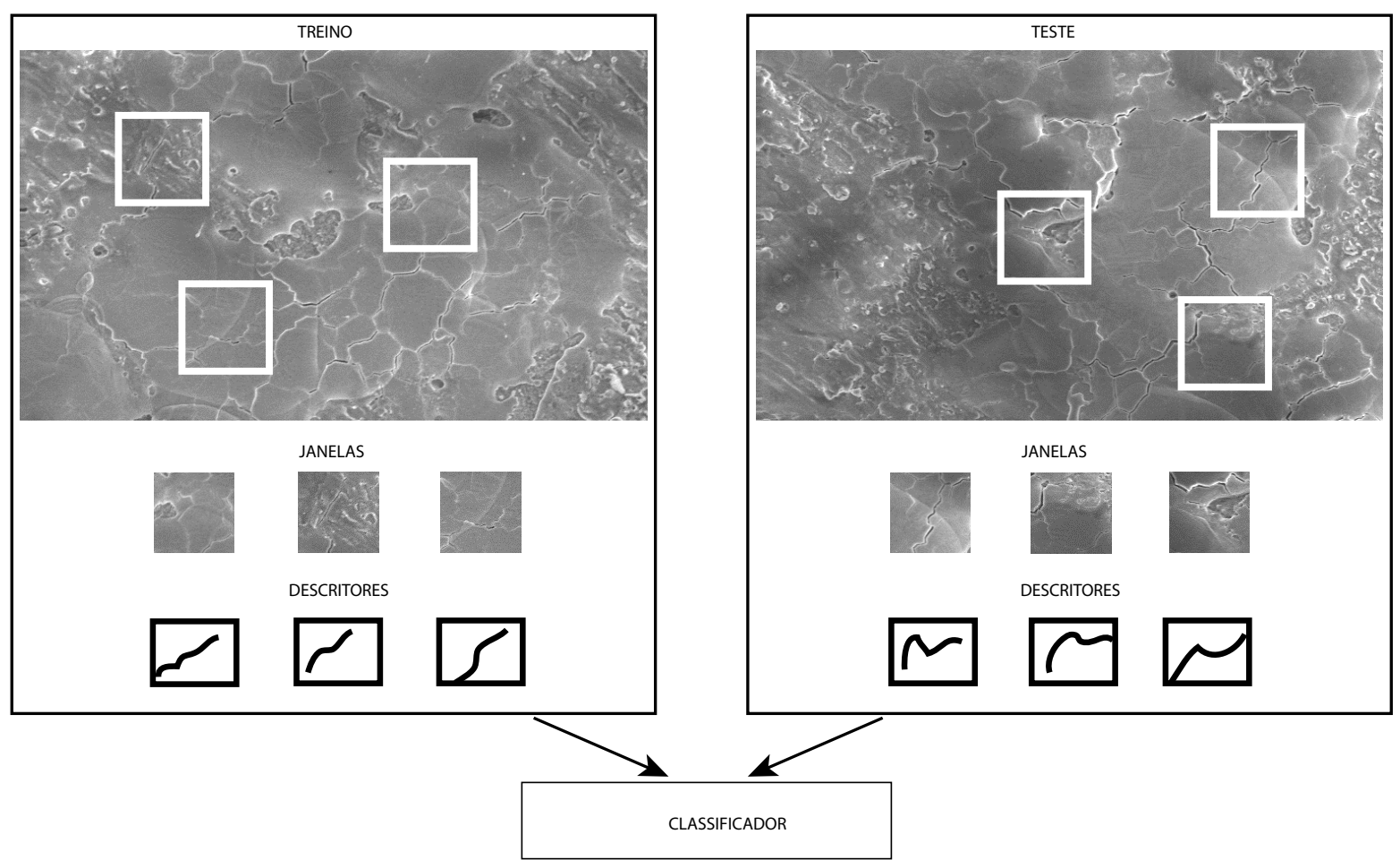

Figura 5.6 - Diagrama ilustrando o processo de extração dos descritores fractais da imagem nanométrica por janelas.

\subsection{Descritores Combinados}

Por fim, uma abordagem que gerou excelentes resultados foi a combinação de descritores baseados em diferentes definições de dimensão fractal.

Desta forma, dado um descritor de $n_{1}$ componentes, representado por um vetor $n$ dimensional $\overrightarrow{D_{1}}=\left\{x_{1}, x_{2}, \ldots, x_{n_{1}}\right\}$, e seja um segundo descritor para a mesma textura representado por $\overrightarrow{D_{2}}=\left\{y_{1}, y_{2}, \ldots, y_{n_{1}}\right\}$. Um conjunto com $m$ imagens de texturas pode então ser representado pela chamada matriz de características da base de imagens, que possui, em cada linha, os descritores calculados para cada imagem. Assim, obtém-se uma matriz $M_{m \times n_{1}}^{(1)}$ para o descritor 1 e $M_{m \times n_{2}}^{(2)}$ para o descritor 2 . 
Para cada matriz, calcula-se então a matriz de covariância $\Sigma$, tal que:

$$
\Sigma(i, j)=\frac{\sum_{i=1}^{n}(M(., i)-\overline{M(., i)})(M(., j)-\overline{M(., j)})}{n-1}
$$

em que $n$ é o número de variáveis (colunas na matriz de características), $M(i,$.$) corresponde$ à coluna $i$ da matriz $M$ e $\overline{M(, i)}$ expressa a média do vetor-coluna.

Em seguida, são calculados os autovalores e autovetores correspondentes da matriz $\Sigma$. Um vetor e, diferente do vetor nulo, é um autovetor de $\Sigma$ se:

$$
\Sigma \mathbf{e}=\lambda \mathbf{e}
$$

para algum valor real $\lambda$. $\lambda$ é então chamado de autovalor da matriz.

Os autovalores de $\Sigma$ são então ordenados decrescentemente $\lambda_{1} \geq \lambda_{2} \geq \ldots \lambda_{n}$ e os autovetores correspondentes $\mathbf{e}_{1}, \mathbf{e}_{2}, \ldots, \mathbf{e}_{\mathbf{n}}$ são as colunas de uma matriz de transformação linear $U$.

Voltando às matrizes de características originais $M^{(1)}$ e $M^{(2)}$, elas são então concatenadas horizontalmente formando a matriz $M^{(C)}$, de modo que cada linha de $M^{(C)}$ seja dada por $x_{1}, x_{2}, x_{n_{1}}, y_{1}, y_{2}, \ldots, y_{n_{2}}$. Em seguida, a matriz combinada é multiplicada pela transposta de $U$. Assim, a matriz de descritores combinados é dada por:

$$
D^{(C)}=U^{T} M^{(C)} .
$$

Na prática, não são usados todos os descritores, mas apenas um pequeno conjunto deles mais relevante para cada aplicação específica. Neste projeto, foram usados os 20 primeiros atributos de cada combinação, embora estratégias mais avançadas possam ser usadas em casos mais complexos (104).

Pode-se usar ainda uma forma alternativa de se combinarem os descritores, na qual inicialmente a matriz de características $M$ é transformada da seguinte maneira:

$$
\tilde{M}=M_{\text {inter }} M_{\text {intra }}^{-1}
$$

em que $M_{\text {intra }}$ e $M_{\text {inter }}$ são, respectivamente, as matrizes inter e intraclasses. A matriz intraclasse é dada por:

$$
S_{\text {intra }}=\sum_{i=1}^{K} \sum_{i \in C_{i}}\left(X(i, .)-\overline{C_{i}}\right)\left(X(i, .)-\overline{C_{i}}\right)^{T},
$$

em que $C_{i}$ é a $i$-ésima das $K$ classes de amostras representadas em $M, M(i,$.$) representa a$ 
$i$-ésima linha (amostra) de $M$ e $\overline{C_{i}}$ é um vetor-linha que representa a média entre as linhas (descritores) correspondentes a cada amostra na classe $C_{i}$. Já a matriz interclasses é definida por:

$$
S_{\text {inter }}=\sum_{i=1}^{K} N_{i}\left(\overline{C_{i}}-\bar{M}\right)\left(\overline{C_{i}}-\bar{M}\right)^{T},
$$

em que $N_{i}$ é o número de amostras da $i$-ésima classe e novamente as médias representam vetores-linha médios. Em situações reais, estas matrizes podem ser estimadas a partir de um conjunto de texturas de treinamento.

Na prática, as transformações descritas são variantes da transformada de Karhunen-Loève (115), que será base também para a definição da análise de componentes principais e canônica nas seções 6.2.3 e 6.2.4. Essas operações desempenham o papel de decorrelacionar os dados originais, permitindo que os componentes sejam gerados em ordem decrescente de relevância. A alta correlação entre dados surge naturalmente quando se junta um número grande de descritores como no caso e o uso dos primeiros componentes após a transformação garante que apenas a informação mais relevante seja expressa no resultado final.

Os descritores combinados possibilitam que abordagens tão distintas quanto as baseadas na dimensão de Lacunaridade e de Fourier forneçam informação relevante para compor um novo descritor que junte características discriminatórias de ambos os métodos individuais. A partir de uma análise mais detalhada do tipo de informação realçado por cada dimensão, observa-se que elas expressam perspectivas diferentes da mesma textura, neste caso de exemplo, uma visão da morfologia espacial e da energia espectral da imagem. Assim, é esperado que a concatenação, seguida da transformação linear aplicada, forneça uma informação mais ampla e descritiva de cada textura. Tal fato é constatado nos excelentes resultados obtidos na classificação das texturas analisadas. A Figura 5.7 ilustra um caso em que os descritores combinados apresentam maior potencial do que os individuais. Neste exemplo, os descritores combinados são de Lacunaridade e Fourier. Nota-se que a curva dos 5 primeiros atributos para a combinação apresentou uma discriminação visual para todos os atributos, fato que não ocorreu de forma tão evidente para os descritores individuais.

\subsection{Dimensão Fractal}

Este trabalho também desenvolveu um novo método para a estimava numérica da dimensão fractal de contornos fechados. 
Imagem 1

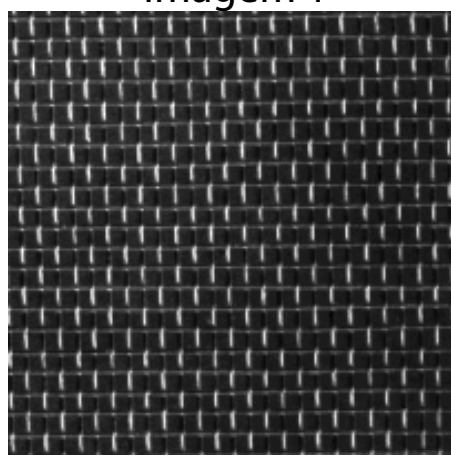

Lacunaridade

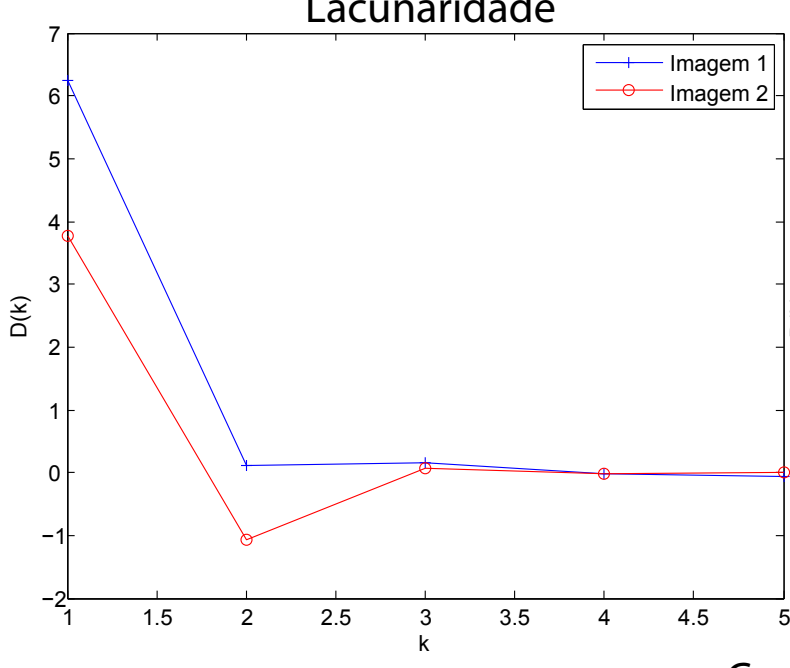

Combinado

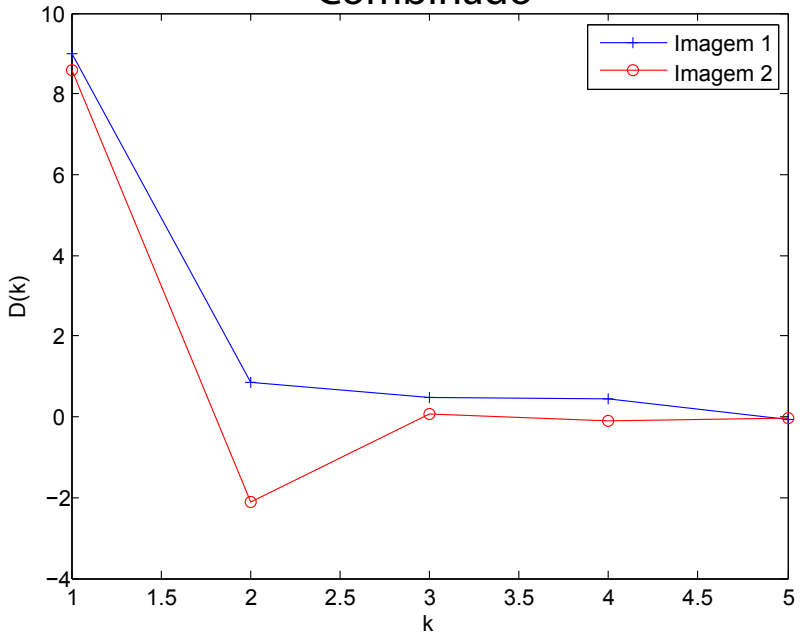

Figura 5.7 - Diagrama exemplificando o poder de discriminação dos descritores fractais individuais (Fourier e Lacunaridade) e combinados.

Fourier

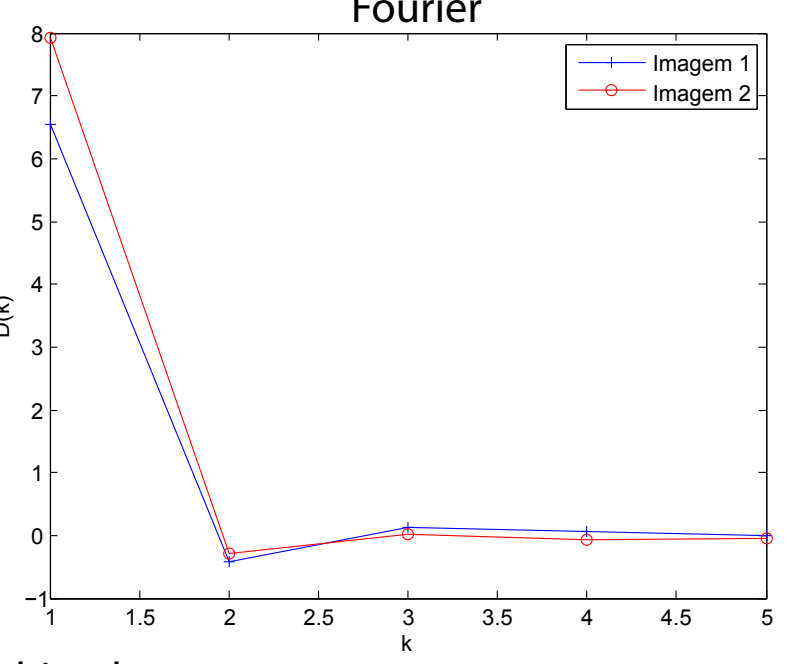

Imagem 2

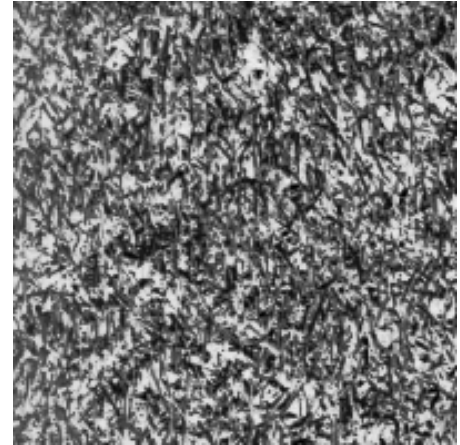

. 
Inicialmente, o contorno é parametrizado, gerando duas funções (uma para cada coordenada no espaço bidimensional). Parte-se, então, de um ponto inicial pré-definido e faz-se um percurso seguindo determinada direção e, em cada passo $t$, anota-se a coordenada $(x(t), y(t))$ do ponto (80). Este processo é amplamente empregado em análise de formas e tem o papel de reduzir as redundâncias inerentes à representação por imagem binária.

No método proposto, as coordenadas parametrizadas são mapeadas então para uma função $c(t)$ no plano complexo:

$$
c(t)=x(t)+i y(t)
$$

em que $i$ é a constante imaginária. Em seguida, calcula-se a série de Fourier da função de contorno $c(t)$, gerando a função complexa $C(u)$ :

$$
C(u)=\mathfrak{T}(c(t))=\int_{-\infty}^{+\infty} C(t) e^{-2 \pi i t u} d t
$$

em que $u$ é a variável de frequência. De forma semelhante ao que ocorre no caso da dimensão por Fourier de texturas, a dimensão pode ser extraída a partir do espectro de potência $P$ da transformada:

$$
P=\|C(u)\|^{2}
$$

sendo $\|$.$\| a norma em \Re^{1}$.

Novamente, como ocorrido no caso de texturas, observa-se empiricamente que existe uma relação exponencial entre a frequência e o espectro e que o parâmetro desta relação está linearmente relacionado à dimensão fractal $D$, isto é:

$$
P \propto u^{D}
$$

Equivalentemente, pode-se escrever:

$$
D \propto \log _{u} P
$$

Esta expressão pode ser reescrita, usando-se propriedades básicas dos logaritmos por:

$$
D=k_{1} \frac{\log (P)}{\log (u)}+k_{2}
$$

sendo $k_{1}$ e $k_{2}$ apenas constantes de ajuste. O resultado deste quociente é tanto mais preciso quanto menor o intervalo tomado no cálculo numérico:

$$
D=k_{1} \lim _{h \rightarrow 0} \frac{\log (P+h)-\log (P)}{\log (u+h)-\log (u)}+k_{2} .
$$

A menos de constantes, esta expressão coincide com a definição de derivada de $\log (P)$ em 
relação a $\log (u)$, que, por sua vez, na estimativa numérica, pode ser obtida pelo coeficiente angular da curva $\log (P(u)) \times \log (u)$ ajustada por uma reta, usando-se métodos como mínimos quadrados.

Empiricamente chega-se aos seguintes valores para as constantes:

$$
k_{1}=-\frac{3}{4} ; k_{2}=\frac{1}{4}
$$

Para garantir estabilidade na estimativa da dimensão de fractais matemáticos, os primeiros $10 \%$ dos pontos na curva $\log$ - log são descartados, uma vez que a informação mais relevante nestes casos está armazenada nos detalhes da forma e os primeiros descritores apresentam um valor instável para o coeficiente angular.

O método proposto é aplicado sobre fractais matemáticos cuja dimensão analítica é conhecida, tais como, conjunto de Mandelbrot e de Julia, Vicsek, Terdragon, etc. A Figura 5.8 mostra os conjuntos fractais usados. Os resultados são comparados com os valores da dimensão de Hausdorff-Besicovitch e de outras abordagens de dimensão numérica na literatura. São verificados também os resultados para os casos em que o fractal sofre transformações geométricas básicas e é afetado por ruído.

De um modo geral, o novo método mostrou-se preciso, robusto a transformações geométricas e substancialmente mais rápido computacionalmente do que seus pares na literatura, conforme demonstrado nos experimentos a seguir. 


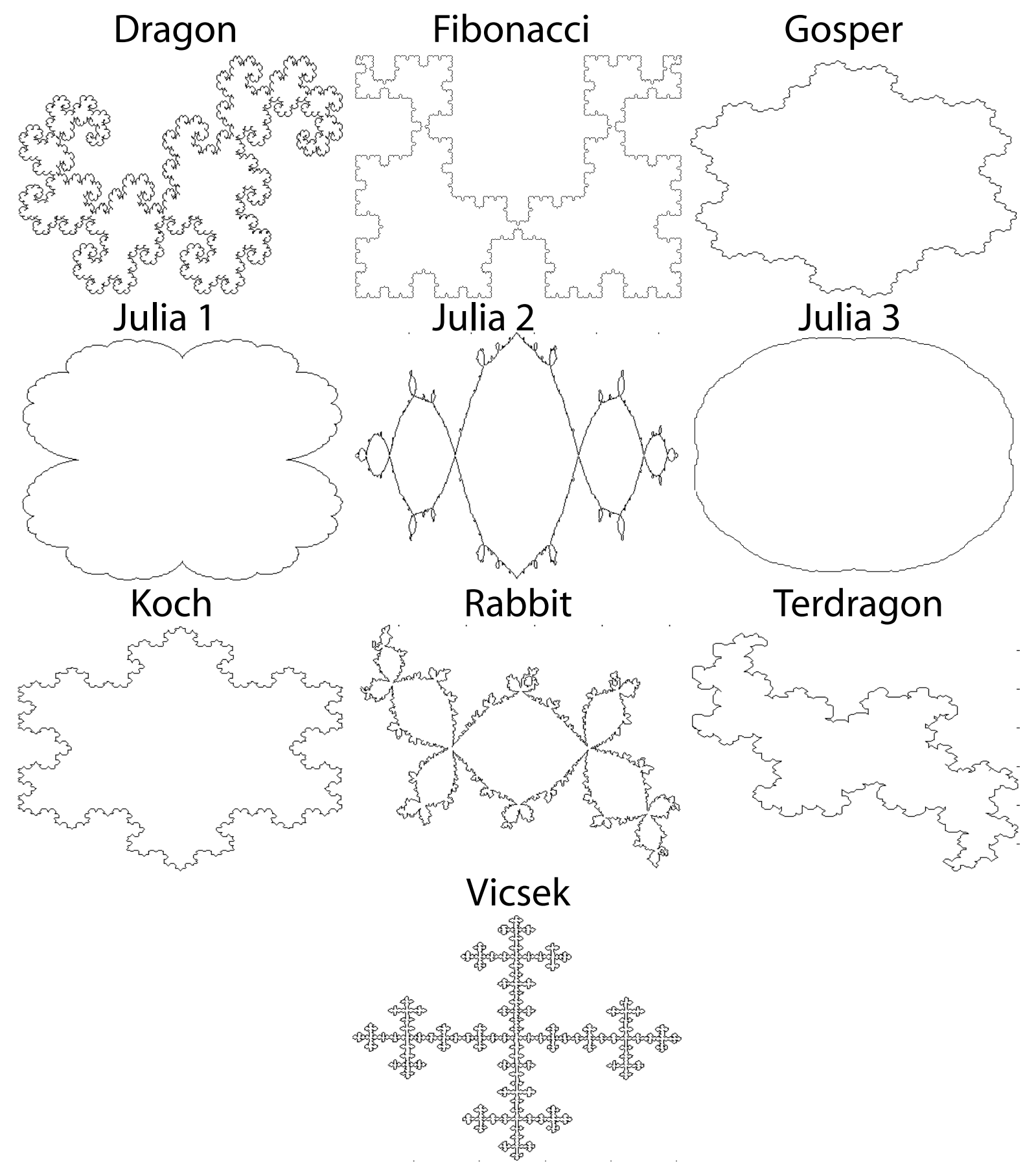

Figura 5.8 - Objetos fractais matemáticos usados para validação do método de dimensão fractal proposto. 


\section{CAPÍTULO 6}

\section{Experimentos}

Os descritores fractais desenvolvidos e estudados neste projeto tiveram sua eficiência e eficácia testados na análise de imagens, tanto de bases de texturas consagradas na literatura e usadas como benchmark, quanto em situações práticas nas quais a imagem pode ser analisada como uma textura.

Assim, em um primeiro momento, os descritores são usados para a classificação das imagens em bases cujas classes são conhecidas previamente e desta classificação são observados os índices de acerto e outras medidas estatísticas. As bases usadas são Brodatz (99), Vistex (100) e Outex (101). Os descritores são extraídos de cada imagem e classificados por métodos conhecidos. No caso, foram usados os classificadores SVM (sigla em Inglês de Máquina de Suporte Vetorial) (102) e KNN (sigla em Inglês de K vizinhos mais próximos) (103). A classificação foi feita em um esquema de $k$-fold (104), no qual, a base é particionada em conjuntos de treinamento e teste, variando-se esta partição para cada rodada de validação. No caso, usou-se $k=2$ e os descritores foram normalizados de forma direta (entre 0 e 1 ).

Os resultados obtidos são então comparados com métodos conhecidos na literatura de análise de imagens. No caso das abordagens em tons de cinza, foram comparados os seguintes métodos: LBP (Padrões Locais Binários) (105), filtros de Gabor-wavelets (106), matriz de co-ocorrência em níveis de cinza (sigla GLCM em Inglês) (107), matriz de diferenças em níveis de cinza (sigla GLDM em Inglês) (108), Laws (109), três abordagens multifractais descritas em (77, 78, 98) e descritores clássicos de Fourier (não fractal) (12). Para a análise de texturas coloridas, foram comparados os métodos razão de histogramas (110), momentos cromáticos (111) e Gabor-wavelets, versão para texturas coloridas (112).

As seções seguintes fazem uma breve descrição das bases de imagens, classificadores e demais métodos usados. 


\subsection{Bases de Dados}

Em seguida, são apesentadas as principais informações das bases de texturas da literatura utilizadas nos experimentos.

\subsubsection{Brodatz}

Esta base é composta originalmente de 111 imagens de textura em tons de cinza, extraídas de um álbum de fotografias de Brodatz (99). Para este trabalho, cada imagem foi dividida em 10 janelas de dimensões $200 \times 200$ pixels e cada imagem original passa a corresponder a uma classe. Assim, são obtidas 111 classes com 10 amostras em cada uma, totalizando 1110 imagens de textura com 256 níveis de cinza em cada. Esta base possui amplo uso na literatura de análise de imagens e reconhecimento de padrões, sendo um importante benchmark quando são comparadas diferentes abordagens de análise de textura em tons de cinza. A Figura 6.1 ilustra a base com alguns exemplos de imagens de cada classe.

\subsubsection{Vistex}

Este é um conjunto de imagens de texturas coloridas, composto por 54 classes com 16 imagens em cada uma, totalizando 864 texturas de dimensões $128 \times 128$. É também um dos conjuntos de benchmark mais usados na literatura. A base é mantida pelo MIT Media Lab e contém texturas obtidas a partir de fotografias de cenários do mundo real sob diferentes condições de iluminação, perspectiva, etc. A base também foi usada em experimentos de tons de cinza após a conversão cromática. Na Figura 6.2, são exibidos alguns exemplares da base.

\subsubsection{Outex}

A base Outex também aparece com frequência na literatura, em comparativos de métodos de análise de texturas. É composta por 68 classes, cada qual com 20 imagens de textura 

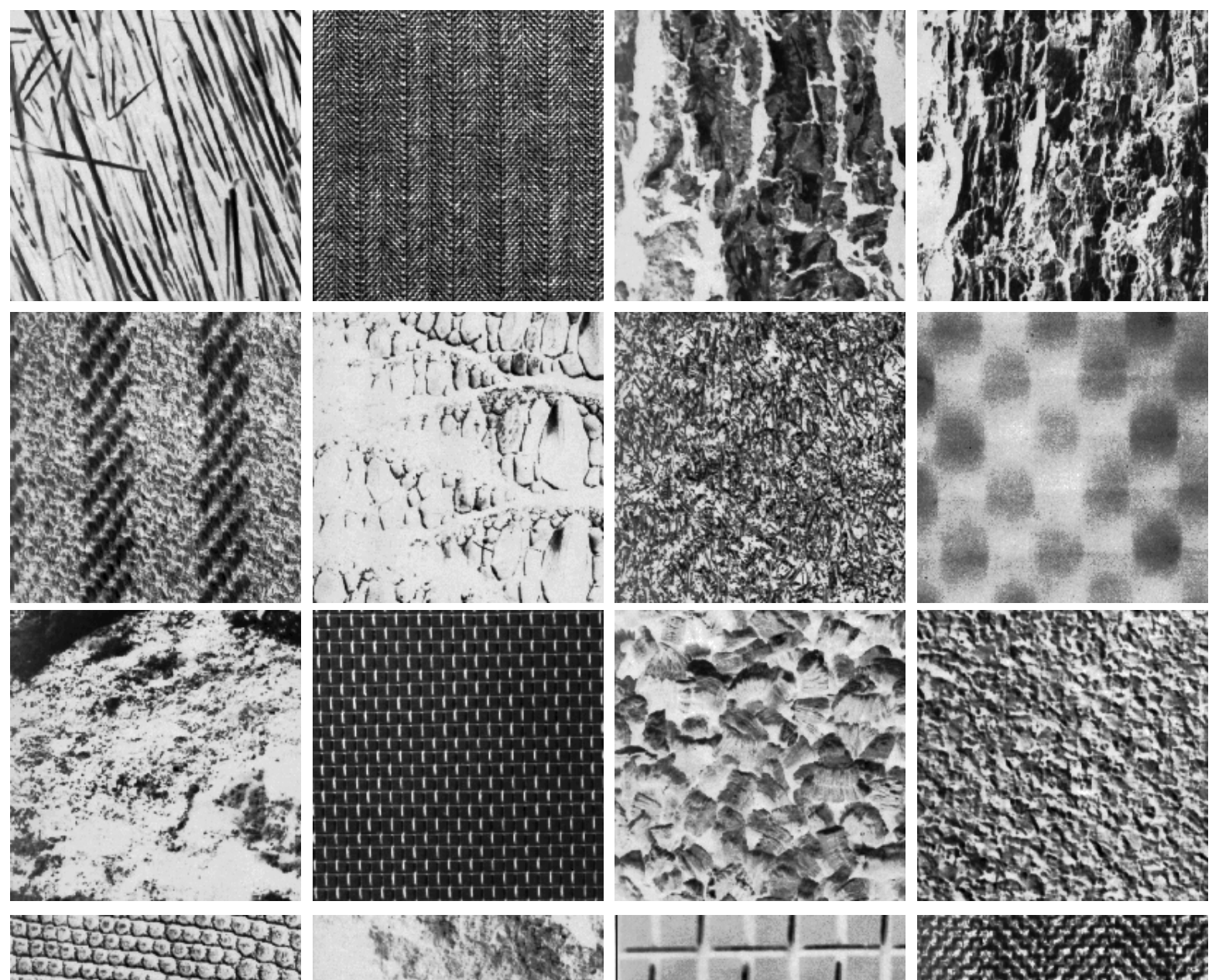

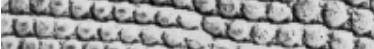

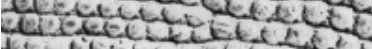

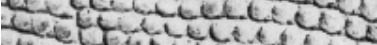

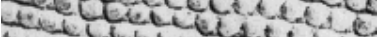

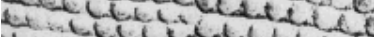

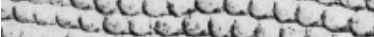

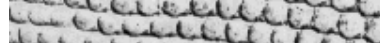
bit idathot

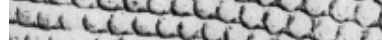

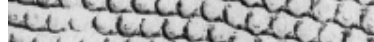
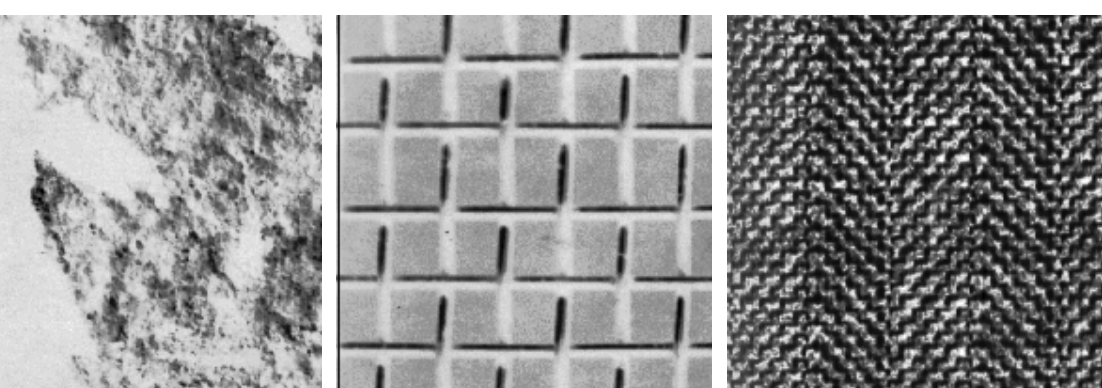

Figura 6.1 - Amostras de algumas imagens da base de texturas Brodatz (uma imagem por classe).

coloridas, com dimensão de $128 \times 128$ pixels. As imagens apresentam padrões mais regulares do que as de Vistex, mas o alto número de classes faz com que a classificação seja complexa e algumas classes distintas apresentem amostras com padrões de textura muito próximos. A Figura 6.3 ilustra a base.

\subsection{Técnicas Estatísticas}

Nesta seção, são introduzidas as técnicas estatísticas empregadas para a avaliação da metodologia desenvolvida. 

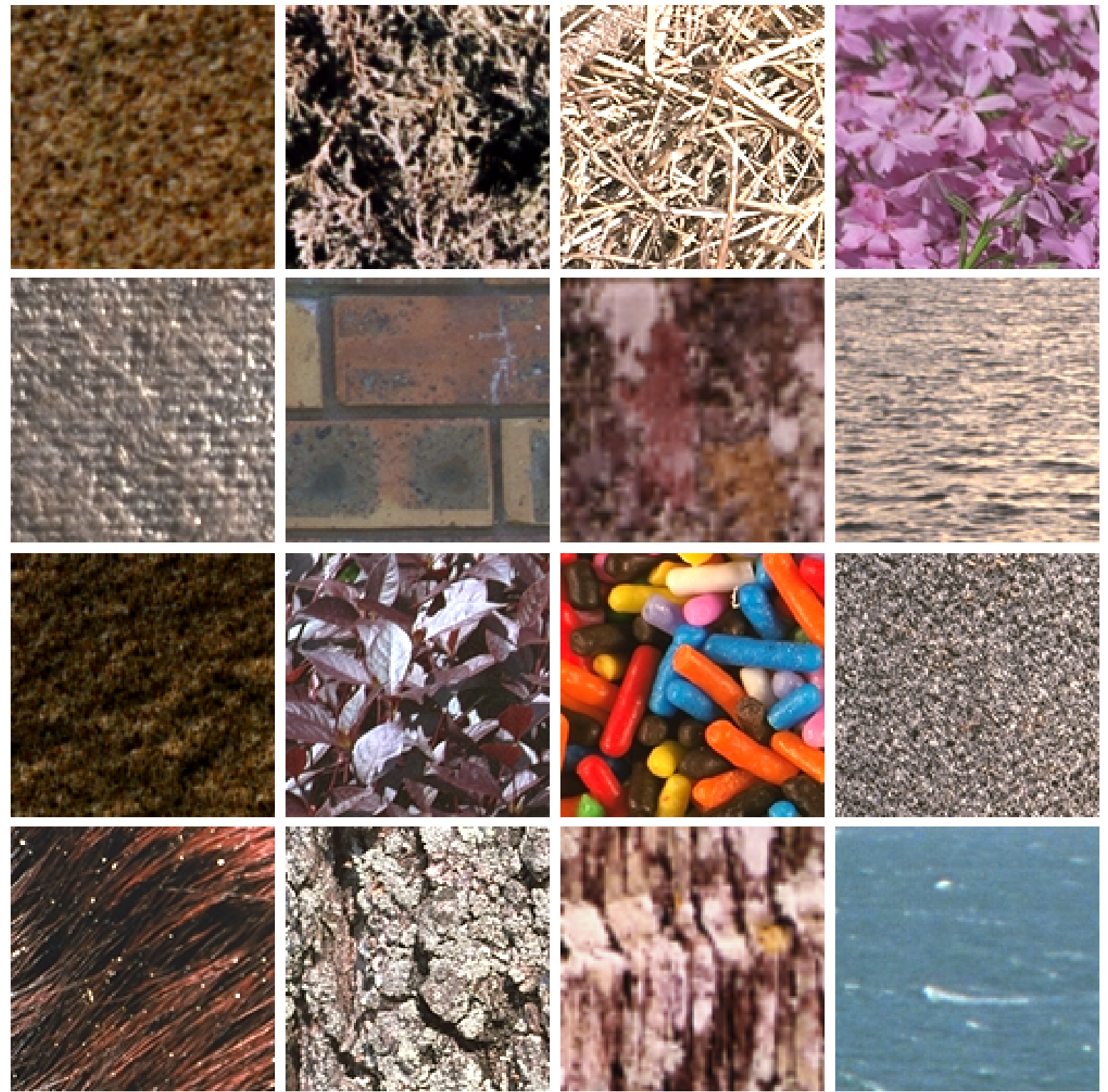

Figura 6.2 - Amostras de algumas imagens da base de texturas Vistex (uma imagem por classe).

\subsubsection{KNN}

Este é um método de classificação bastante simplista e que, entretanto, pode alcançar bons resultados em determinadas situações, além de fornecer informação a respeito da distribuição dos vetores de descritores no espaço de atributos, de maneira direta, sem o uso de qualquer tipo de transformação no espaço ou distribuição estatística.

A essência da técnica consiste em selecionar os $K$ elementos (vetores) mais próximos (vizinhos) na base de treino, segundo uma métrica pré-definida, em relação ao vetor que se deseja classificar. Este vetor é então atribuído à classe à qual a maioria dos $K$ vizinhos 

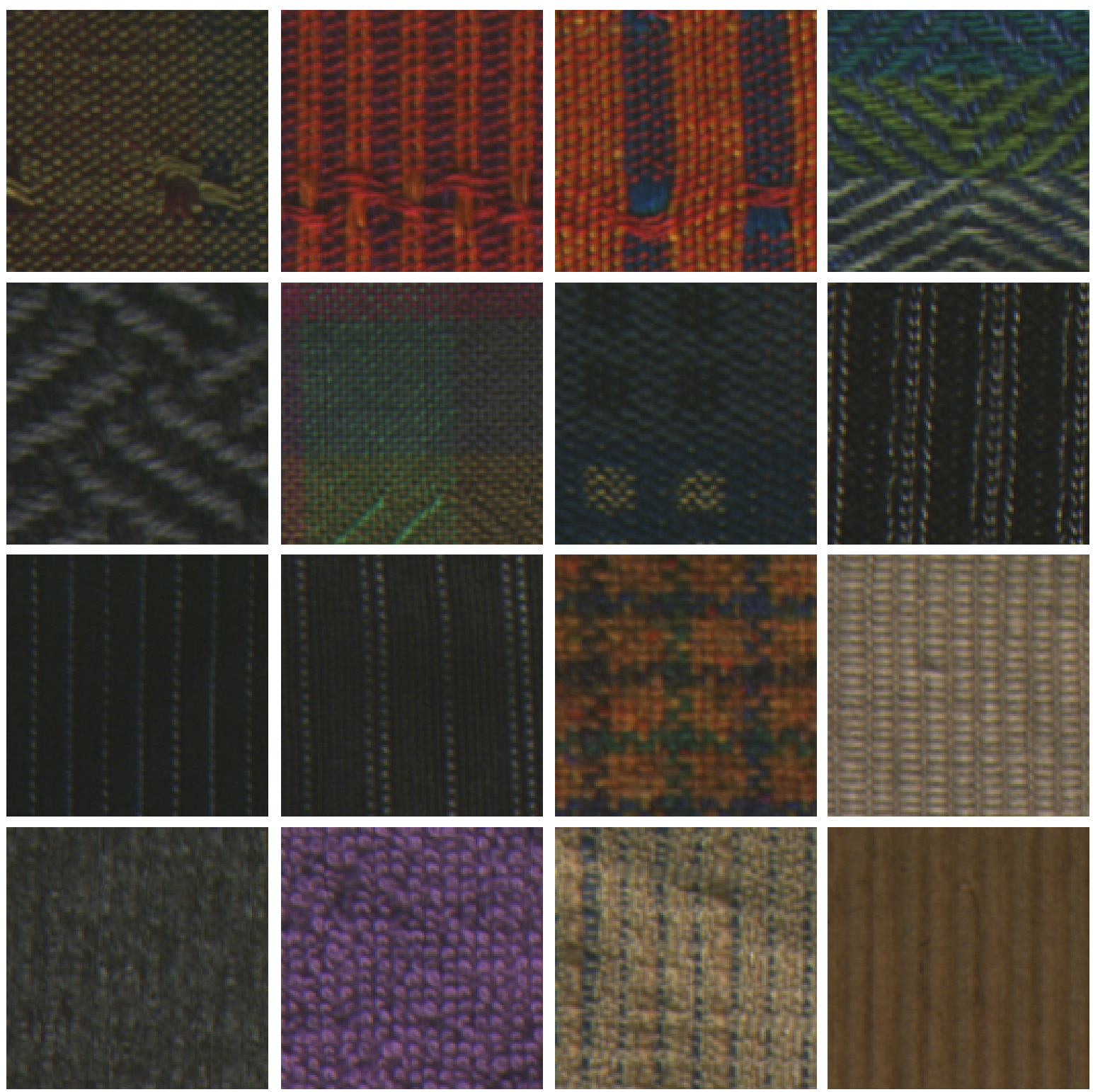

Figura 6.3 - Amostras de algumas imagens da base de texturas Outex (uma imagem por classe).

pertence.

No presente projeto, a métrica escolhida foi a Euclidiana, dada sua simplicidade de interpretação aliada aos bons resultados produzidos. No caso, a distância $d$ entre dois vetores $x=\left[x_{1} x_{2} \ldots x_{n}\right]$ e $y=\left[y_{1} y_{2} \ldots y_{n}\right]$ é dada por:

$$
d(x, y)=\sqrt{\left(x_{1}-y_{1}\right)^{2}+\left(x_{2}-y_{2}\right)^{2}+\ldots+\left(x_{n}-y_{n}\right)^{2}} .
$$




\subsubsection{SVM}

A Máquina de Vetores de Suporte (em Inglês, Support Vector Machine, sigla SVM) é uma técnica de classificação baseada na teoria de aprendizagem estatística e proposta em (102).

Inicialmente, o método foi concebido para análise de dados que possam ser categorizados linearmente e que possuam apenas duas classes (positiva e negativa). Existem, porém, estratégias para que este classificador possa ser aplicado em situações mais genéricas, como será visto a seguir.

Quando os dados são linearmente separáveis, o classificador $f$ é um hiperplano $f(x)=$ $(\mathbf{w} \cdot \mathbf{x})+b$. O hiperplano ideal é aquele em que a margem é máxima, sendo margem, neste caso, a menor distância encontrada entre os objetos do treinamento e o hiperplano. Os vetores destas menores distâncias são chamados vetores de suporte. O hiperplano que maximiza esta margem é chamado de hiperplano ótimo. Na prática, este hiperplano é definido por:

$$
<\mathbf{w} \cdot \mathbf{x}>+b=0,
$$

em que w é o chamado vetor-peso e $b$ é o bias.

Para o problema de duas classes, estas podem ser consideradas +1 e -1 . Assim, o hiperplano também deve satisfazer as seguintes restrições:

$$
\begin{aligned}
& <\mathbf{w} \cdot \mathbf{x}_{\mathbf{i}}>+b \geq+1, \text { se } y_{i}=+1 \\
& <\mathbf{w} \cdot \mathbf{x}_{\mathbf{i}}>+b \leq-1, \text { se } y_{i}=-1
\end{aligned}
$$

Estas podem ser sintetizadas em apenas uma equação:

$$
y_{i}\left(<\mathbf{w} \cdot \mathbf{x}_{\mathbf{i}}>+b\right) \geq 1
$$

Pode-se deduzir que a maximização da margem é obtida pela minimização da norma $\|\mathbf{w}\|$, restrita à condição da Equação 6.2.5. A solução deste problema quadrático de otimização leva ao surgimento de um problema dual:

$$
\max _{\alpha} \sum_{i=1}^{n} \alpha_{i}-\frac{1}{2} \sum_{i, j=1}^{n} \alpha_{i} \alpha_{j} y_{i} y_{j}\left(\mathbf{x}_{\mathbf{i}} \cdot \mathbf{x}_{\mathbf{j}}\right),
$$

com as restrições $\alpha_{i} \geq 0$ e $\sum_{i=1}^{n} \alpha_{i} y_{i}=0$. 
Por fim, os valores otimizados $\mathbf{w}^{*}$ e $b^{*}$ são obtidos por:

$$
\begin{gathered}
\mathbf{w}^{*}=\sum_{i=1}^{n} \alpha_{i} * y_{i} \mathbf{x}_{\mathbf{i}} \\
b^{*}=y_{j}-<\mathbf{w}^{*} \cdot \mathbf{x}_{\mathbf{j}}>,
\end{gathered}
$$

em que $\mathbf{x}_{\mathbf{j}}$ é um vetor de suporte.

Quando um novo padrão $\mathbf{z}$ é apresentado, sua classe é atribuída pelo sinal do resultado da aplicação da equação do hiperplano:

$$
\operatorname{sgn}\left(<\mathbf{w}^{*} \cdot \mathbf{z}>+b^{*}\right)
$$

No caso de problemas não linearmente separáveis, o método de SVM pode ser aplicado normalmente após a aplicação de um mapeamento $\Phi$ sobre os dados originais que os torna separáveis por um hiperplano.

Finalmente, quando o problema apresenta múltiplas classes, como os que são abordados neste trabalho, existem duas abordagens principais para tornar possível e útil o uso deste classificador.

Na primeira, chamada de um-contra-todos, constrói-se um classificador binário para cada classe e cada padrão novo recebido é atribuído à classe cujo classificador apresentou a maior saída.

Na segunda, denominada todos-contra-todos, constrói-se um classificador para cada par de classes. A classe atribuída ao novo elemento é dada por um esquema de votação por maioria.

Neste trabalho, a primeira opção foi empregada devido ao seu menor custo computacional e resultado de confiabilidade semelhante à segunda estratégia.

\subsubsection{PCA}

A Análise de Componentes Principais (em Inglês Principal Component Analysis, sigla PCA) (113) é uma técnica já consagrada para a redução de dimensionalidade de vetores de atributos na análise multivariada.

O papel desta ferramenta agindo sobre os descritores fractais é, além de diminuir o esforço 
computacional do classificador com menos variáveis de entrada, também prover atributos com maior significância, eliminando-se correlações que acrescentam redundâncias e mascaram o poder discriminante dos elementos que expressam mais informação útil. Para isso, o método gera novas variáveis em um novo espaço formado por combinações lineares das variáveis antigas. Essas novas variáveis, chamadas de componentes, são apresentadas em ordem decrescente de variância. Assim, os primeiros componentes expressam uma grande parte de toda a variabilidade contida no dado e, deste modo, são suficientes para um bom resultado na etapa de classificação.

A partir de um dado representado em uma matriz $\chi$, em que cada linha $\chi_{i, \text {. representa }}$ uma amostra com $n$ medidas (colunas), o primeiro passo para aplicação de PCA é extrair os chamados Z-scores de cada atributo $\chi_{., i}$, obtidos por:

$$
X_{., i}=\frac{\chi_{., i}-\overline{\chi_{., i}}}{\sigma_{\chi_{., i}}}
$$

em que $\overline{\chi_{., i}}$ é a média da coluna $\chi_{., i}$ e $\sigma_{\chi_{., i}}$ o desvio-padrão do mesmo atributo $i$.

Em seguida, calcula-se a matriz de covariância das variáveis na matriz $X$. Para cada par de variáveis, temos os vetores $i$ e $j$ correspondendo às respectivas colunas em $X$. A matriz de covariância $\Sigma$ é dada então por:

$$
\Sigma(i, j)=\frac{\sum k=1^{n}\left(X_{., i}-\overline{X_{., i}}\right) \cdot\left(X_{., j}-\overline{X_{., j}}\right)}{n},
$$

em que $n$ é o número de atributos.

Por fim, são calculados os autovetores de $\Sigma$ e são ordenados $e_{1}, e_{2}, e_{3}, \ldots, e_{n}$ por ordem decrescente dos respectivos autovalores. As novas variáveis (componentes) $z_{i}$ são dadas então por:

$$
z_{i}=e_{i 1} X_{., 1}+e_{i 2} X_{., 2}+\ldots+e_{i n} X_{., n}
$$

\subsubsection{CCA}

A Análise de Correlação Canônica (em Inglês Canonical Correlation Analysis, sigla CCA) (114) é uma alternativa à PCA.

Diferentemente da análise PCA, que visa encontrar novas variáveis com um mínimo de correlação a partir da combinação linear no conjunto de variáveis originais, na análise CCA, o processo de decorrelação não considera apenas um conjunto de variáveis, mas sim dois: o 
das variáveis dependentes e o das independentes. No caso tratado neste projeto, o conjunto de variáveis independentes corresponde ao conjunto de descritores da base de treinamento e o das variáveis dependentes equivale ao conjunto das respectivas classes.

Supõe-se então que o dado a ser analisado seja constituído de dois conjuntos $A_{x}$ (variáveis dependentes) e $A_{y}$ (variáveis independentes), de dimensões $m \times n$ e $m \times q$, respectivamente. O objetivo então é encontrar dois vetores de projeção $\mathbf{x}$ e $\mathbf{y}$ para os objetos, tais que os dois conjuntos, quando projetados, apresentem a máxima correlação entre si.

A projeção dos dados sobre $\mathbf{x}$ e $\mathbf{y}$ gera novos vetores $\mathbf{z}_{x}$ e $\mathbf{z}_{y}$, chamados também de variáveis canônicas do sistema:

$$
\begin{aligned}
& \mathbf{z}_{x}=A_{x} \mathbf{x}, \\
& \mathbf{z}_{y}=A_{y} \mathbf{y} .
\end{aligned}
$$

A correlação $\rho$ entre $\mathbf{z}_{x}$ e $\mathbf{z}_{y}$ é dada por:

$$
\rho=\frac{\mathbf{z}_{y}^{\prime} \cdot \mathbf{z}_{x}}{\sqrt{\mathbf{z}_{y}^{\prime} \cdot \mathbf{z}_{y}} \sqrt{\mathbf{z}_{x}^{\prime} \cdot \mathbf{z}_{x}}} .
$$

O objetivo na análise canônica é encontrar vetores $\mathrm{x}$ e $\mathbf{y}$ que maximizem essa correlação.

Rearranjando o sistema acima e aplicando uma maximização Lagrangeana, conforme Hotelling (115), chega-se às duas equações principais da análise canônica, segundo as quais, os vetores de projeção devem obedecer às seguintes restrições:

$$
\begin{aligned}
& \left(\Sigma_{x y}^{\prime} \Sigma_{x x}^{-1} \Sigma_{x y}-\rho^{2} \Sigma_{y y}\right) y=0 \\
& \left(\Sigma_{x y} \Sigma_{y y}^{-1} \Sigma_{x y}^{\prime}-\rho^{2} \Sigma_{x x}\right) x=0,
\end{aligned}
$$

sendo $\Sigma$ a matriz de covariância:

$$
\Sigma_{i j}=\frac{1}{m-1} \sum_{k=1}^{m}\left(X_{k i}-\mu_{i}\right)\left(X_{k j}-\mu_{j}\right) .
$$

A solução para as equações acima não precisa de mais do que técnicas clássicas em álgebra linear. Os coeficientes de correlação $\rho$ são obtidos da raiz quadrada dos autovalores da equação do vetor $\mathbf{x}$ : $\Sigma_{x y}^{\prime} \Sigma_{x x}^{-1} \Sigma_{x y}$. Os autovalores do vetor $\mathbf{y}$ estão diretamente relacionados. Já os vetores em si são os autovetores correspondentes. Na prática, entretanto, para diminuir o uso de multiplicações, que propagam erros de aproximação, são usadas estratégias mais avançadas para a solução das equações, como decomposição de Choleski e SVD (116). 


\subsection{Métodos de Análise de Texturas}

Esta seção descreve brevemente os métodos de análise de texturas clássicos e estado-daarte comparados com os descritores fractais.

\subsubsection{LBP}

Proposto originalmente em (105), o método de análise de texturas chamado LBP (sigla em Inglês de Local Binary Patterns ou Padrões Locais Binários, em Português), é tido hoje como uma das abordagens mais precisas e robustas na classificação e segmentação de imagens de texturas.

Em essência, o método é simples e de fácil compreensão. $A$ imagem de textura é dividida em janelas de tamanho $N \times N$. Na versão original empregada neste trabalho, $N=3$, gerando então uma vizinhança de 8 . Nesta vizinhança, define-se então um sentido circular (horário ou anti-horário) e os pixels de mesma distância ao centro são comparados ao valor da intensidade do central, se for menor, atribui-se 0 , se for maior, atribui-se 1 . Deste modo, obtém-se um código binário de 8 bits para cada janela. Este código é então convertido em número decimal (entre 0 e 255). O LBP propriamente é obtido do histograma dos valores em cada janela.

\subsubsection{GLDM}

Sigla do Inglês Gray-level Difference Method ou Método de Diferenças de Tons de Cinza em Português, esta abordagem é clássica na literatura de análise de texturas e, embora não seja uma técnica recente, ainda produz excelentes resultados em muitas situações, mesmo sendo um método simples (108).

Para a apresentação do método, faz-se necessário o conceito de função densidade de probabilidade de deslocamento $p_{\delta}$. Assume-se inicialmente que os valores de intensidade dos pixels na textura sejam representados pela função $f(x, y)$. Seja então um deslocamento $\delta=(\Delta x, \Delta y)$ e ainda a função $f_{\delta}(x, y)=|f(x, y)-f(x+\Delta x, y+\Delta y)|$. Dado que existem $m$ níveis de cinza, cada componente $i$ do vetor $p_{\delta}$ corresponde à probabilidade de $f_{\delta}(x, y)=i$. Na prática, esta densidade de probabilidade é obtida a partir do histograma de $f_{\delta}(x, y)$. 
$O$ vetor de características da textura é obtido calculando-se $p_{\delta}$ para vários valores de $\delta \mathrm{e}$ para cada $p_{\delta}$, extraindo-se algumas medidas estatísticas. As medidas mais utilizadas são:

- Contraste: $\sum i^{2} p_{\delta}(i)$

- Segundo momento angular: $\sum p_{\delta}(i)^{2}$

- Entropia: $-\sum p_{\delta}(i) \log p_{\delta}(i)$

- Média: $(1 / m) \sum i p_{\delta}(i)$

Ao final, todos os valores são concatenados formando o vetor de descritores.

\subsubsection{GLCM}

O método chamado GLCM (sigla em Inglês de Gray-level Co-occurrence Matrix, também chamado de matriz de coocorrência em Português) guarda várias semelhanças com GLDM (107).

Neste caso, o que deve ser calculada é a distribuição de probabilidade conjunta $h_{\delta}(i, j)$, que representa a probabilidade de dois pixels à distância $\delta$ na imagem $f(x, y)$ possuírem intensidades de cinza $i$ e $j$. Na prática, é computado o número de pares de pixels com intensidade $i$ e $j$ à distância $\delta$. A matriz formada pelos componentes $h_{\delta}(i, j)$, para cada valor de $\delta$, representada por $M_{\delta}$, é chamada matriz de coocorrência.

De modo similar ao que ocorria com GLDM, Haralick (107) propôs algumas medidas que podem ser extraídas da matriz e usadas como descritor da textura analisada. Algumas dessas medidas são:

- Contraste: $\sum(i-j)^{2} p(i, j)$

- Segundo momento angular: $\sum p(i, j)^{2}$

- Entropia: $-\sum p(i, j) \log p(i, j)$

- Correlação: $\sum\left[i j p(i, j)-\mu_{x} \mu_{y}\right] /\left(\sigma_{x} \sigma_{y}\right)$,

em que $p(i, j)=M_{\delta}(i, j) / \sum\left(M_{\delta}\right)$, enquanto $\mu_{x}$ e $\sigma_{x}$ são, respectivamente, a média e desviopadrão da soma das linhas de $M_{\delta}$ e $\mu_{y}$ e $\sigma_{y}$ são as estatísticas equivalentes para a soma das colunas. 


\subsubsection{Descritores de Fourier}

Este método, desenvolvido em (12), usa o espectro de Fourier da imagem de textura para computar os descritores. Seja $f(x, y)$ uma imagem em tons de cinza, sua transformada de Fourier é dada por:

$$
F(u, v)=\int_{-\infty}^{+\infty} \int_{-\infty}^{+\infty} e^{-2 \pi \sqrt{-1}(u x+v y)} f(x, y) d x d y
$$

O espectro de potência $P$ de Fourier é dado então por:

$$
P=\|F\|^{2}=F F^{*}
$$

em que * denota o conjugado complexo.

Os descritores $\phi_{r}$ são obtidos então a partir da média anelar do espectro, sob diferentes distâncias $r$ em relação ao centro:

$$
\phi_{r}=\int_{0}^{2 \pi}\|F(r, \theta)\|^{2} d \theta,
$$

para diferentes valores de $r$.

Os descritores também podem ser extraídos a partir de médias radiais, sob diferentes ângulos $\theta$ :

$$
\phi_{\theta}=\int_{0}^{\infty}\|F(r, \theta)\|^{2} d r
$$

Na prática, são usadas combinações de raio e ângulo para compor o vetor de descritores.

\subsubsection{Gabor-wavelets}

Assim, como os descritores de Fourier, os descritores de Gabor-wavelets (106) também são baseados na análise espectral da imagem.

Basicamente, o método consiste em aplicar filtros Gabor-wavelets bidimensionais sobre a imagem e calcular as energias dos resultados obtidos.

Um filtro de Gabor bidimensional no domínio espacial $g(x, y)$ ou da frequência $G(u, v)$ é 
definido, respectivamente, por:

$$
\begin{gathered}
g(x, y)=\left(\frac{1}{2 \pi \sigma_{x} \sigma_{y}}\right) e^{-0.5\left(x^{2} / \sigma_{x}^{2}+y^{2} / \sigma_{y}^{2}\right)+2 \pi j W x} \\
G(u, v)=e^{-0.5\left(\frac{(u-W)^{2}}{\sigma_{u}^{2}}+\frac{v^{2}}{\sigma_{v}^{2}}\right)}
\end{gathered}
$$

em que $W$ é uma determinada frequência e $\sigma_{u}=1 / 2 \pi \sigma_{x}$ e $\sigma_{v}=1 / 2 \pi \sigma_{y}$.

Embora estes filtros sejam completos, eles ainda não são capazes de fornecer uma informação localizada das frequências. Para este fim, foram desenvolvidos os filtros de Gaborwavelets, que agregam um parâmetro de escala $m$ e de rotação $\theta$. O novo filtro, denotado $g_{m n}$ é definido por:

$$
g_{m n}=a^{-m} G\left(x^{\prime}, y^{\prime}\right),
$$

em que $x^{\prime}=a^{-m}(x \cos (\theta)+y \sin (\theta))$ e $y^{\prime}=a^{-m}(-x \cos (\theta)+y \sin (\theta))$, em que $\theta=n \pi / K$, sendo $K$ o número de rotações aplicadas e $S$ o número de escalas analisadas.

Para a obtenção dos descritores, a imagem de textura $f(x, y)$ é convoluída com os filtros $g_{m n}$, obtendo as saídas $r_{m n}$ :

$$
r_{m n}=f(x, y) * g_{m n}(x, y) .
$$

Em seguida para cada combinação $(m, n)$, são calculadas as energias $E_{m n}$ :

$$
E_{m n}=\frac{1}{p q} \sum_{u, v}\left\|R_{m n}(u, v)\right\|^{2},
$$

em que $p$ e $q$ são as dimensões da imagem e $R_{m n}(u, v)$ é a transformada de Fourier de $r_{m n}(x, y)$.

Os valores de energia são concatenados para forma o vetor de caractertísticas nesta abordagem.

\subsubsection{Laws}

Outro método baseado em filtros e que alcança bons resultados em várias aplicações é o método de Laws (109).

Este se baseia na aplicação de 5 tipos de filtros sobre a imagem original. Estes fitros são 
representados pelas seguintes máscaras:

$$
\begin{aligned}
& L 5=[1,4,6,4,1] \\
& E 5=[-1,-2,0,2,1] \\
& S 5=[-1,0,2,0,-1] \\
& W 5=[-1,2,0,-2,1] \\
& R 5=[1,-4,6,-4,1]
\end{aligned}
$$

Estes vetores são multiplicados entre si, formando máscaras $5 \times 5$ e convoluídos com a imagem $f(x, y)$ original. Para cada convolução, calcula-se a energia total da imagem obtida e esta energia é usada na composição do vetor de características.

\subsubsection{Multifractal 1}

Esta primeira abordagem de multifractais para descritores de texturas (98) faz uso do espectro multifractal obtido a partir da dimensão de probabilidade.

Seja então um conjunto $S$ composto por $N$ pontos no espaço. Este conjunto de pontos é dividido em caixas e define-se então a probabilidade de massa da caixa $i$ como sendo $\mu_{i}=$ $N_{i} / N$, em que $N_{i}$ é o número de pontos de $S$ que ficam delimitados pela caixa $i$. Em seguida, define-se uma medida ponderada $M_{d}(q, \delta)$ por:

$$
M_{d}(q, \delta)=\lim _{\delta \rightarrow 0} \sum_{i} \mu_{i}^{q} \delta^{d}=\lim _{\delta \rightarrow 0} N(q, \delta) \delta^{d}
$$

A medida $M_{d}$ vale 0 , se $d>\tau(q)$ e vai para o infinito (diverge) quando $d<\tau(q)$. Na prática, os expoentes $\tau(q)$ controlam o quanto o $q$-ésimo momento de $\mu_{i}$ varia em relação ao parâmetro de escala $\delta$. Assim, assumindo-se uma aproximação para um valor pequeno de $\delta$, vale:

$$
N(q, \delta)=\sum_{i} \mu_{i}^{q} \approx \delta^{-\tau(q)}
$$

e, consequentemente:

$$
\tau(q)=-\lim _{\delta \rightarrow 0} \frac{\log (N(q, \delta))}{\log (\delta)} .
$$

Para que o valor de $\tau(0)$ corresponda à dimensão topológica do conjunto, pode-se ainda aplicar a seguinte normalização:

$$
D(q)=\frac{\tau(q)}{1-q}=\frac{1}{q-1} \lim _{\delta \rightarrow 0} \frac{\log (N(q, \delta))}{\log (\delta)} .
$$


Os valores de $D(q)$ formam o chamado espectro multifractal e são usados como descritores para a textura analisada.

\subsubsection{Multifractal 2}

Para este método, descrito em (78), define-se inicialmente uma medida Boreliana $\mu$ em $\Re^{2}$. Um exemplo de tal medida é a soma dos valores dos pixels em uma área específica. Seja então $\mu(x, r)$ tomado sobre um ponto $x \in \Re^{2}$ com raio $r$ :

$$
\mu(x, r)=k r^{d(x)}(x)
$$

em que $d(x)$ é a função densidade da medida e $k$ uma constante real. A função densidade é fornecida então por:

$$
d(x)=\lim _{r \rightarrow 0} \frac{\log (\mu(B(x, r)))}{\log (r)},
$$

em que $B(x, r)$ é uma bola centrada em $x$ com raio $r$.

Nesta metodologia, o espectro multifractal $f(\alpha)$ é definido então por:

$$
\{f(\alpha), \alpha \in \Re\}=\left\{\operatorname{dim}\left(E_{\alpha}\right): \alpha \in \Re\right\}
$$

em que dim é a dimensão fractal e $E_{\alpha}$ é o conjunto de categorização:

$$
E_{\alpha}=\left\{x \in \Re^{2}: d(x)=\alpha\right\}
$$

O vetor de descritores é obtido dos valores de $f(\alpha)$, variando-se $\alpha$ dentro de um intervalo específico. Em (78), são usadas diferentes medidas $\mu(B(x, r))$ para tratar da invariância à iluminação que a textura deve apresentar.

\subsubsection{Multifractal 3}

Estes descritores de textura baseados na teoria multifractal foram propostos em (77) e o método consiste em combinar a decomposição multiníveis e transformada wavelets com o cálculo do espectro multifractal.

A transformada discreta convencional de wavelets decompõe uma imagem $I$ em $J$ níveis 
de escala, gerando assim um canal de baixa frequência $D_{J}(I)$ e três de alta frequência $W_{k, j}(I)$, $k=1,2,3$ e $j=1, \ldots, J$.

Nesta abordagem multifractal, com o objetivo de criar um procedimento invariante a rotação, a imagem é rotacionada por um número pré-definido de ângulos $\theta$. Para cada valor de $\theta$, define-se o chamado wavelet leader $L_{j_{0}, \theta}$, corespondendo à máxima resposta da transformada em uma vizinhança espacial $\Omega$ de cada ponto $r_{0}$ para escalas menores ou iguais a $j_{0}$ :

$$
L_{j_{0}, \theta}\left(r_{0}\right)=\max _{j \leq j_{0}} \max _{1 \leq k \leq 3} \max _{r \in \Omega\left(r_{0}\right)}\left|W_{k, j, \theta}(r)\right|
$$

No método descrito em (77), o epectro $M F S$ é calculado para $D_{j, \theta}, W_{k, j, \theta}$ e $L_{j, \theta}$. Para este cálculo, o procedimento é idêntico ao descrito na seção anterior.

Finalmente, os descritores WMFS são então obtidos pela concatenação das médias dos espectros sobre os $K$ valores usados para $\theta$ :

$$
W M F S=\left\{\sum_{\theta} M F S\left(D_{J, \theta}\right) / K, \sum_{\theta} M F S\left(W_{k, j, \theta}\right) / K, \sum_{\theta} M F S\left(L_{j, \theta}\right) / K\right\}
$$

\subsubsection{Histograma de Cores}

Este é um método simples, mas que obtém resultados interessantes em (110).

O primeiro passo é calcular um histograma unidimensional da imagem colorida. Usualmente, estes histogramas são definidos em $n$ dimensões por pares $b, c$, em que $b$ é um vetor com as $n$ coordenadas do intervalo de classe e $c$, o número de elementos naquele intervalo. Para imagens coloridas, o vetor $b$ possui três coordenadas, uma para cada canal. Entretanto, é possível tornar este histograma unidimensional fazendo-se uma varredura da esquerda para a direita, de cima para baixo, no espaço $n$-dimensional e atribuindo-se um rótulo a cada intervalo que possua algum elemento.

Considere-se então uma base de treinamento com $N$ classes e $K$ imagens por classe. Cada imagem produz um histograma $H_{i k}(0 \leq i<N, 0 \leq k<K)$, representado pelo conjunto de intervalos $B$ e de contagens $C$ :

$$
\begin{aligned}
& B_{i k}=\left\{b_{i k_{0}}, b_{i k_{1}}, \ldots, b_{i k_{M_{i k}-1}}\right\}, \\
& C_{i k}=\left\{c_{i k_{0}}, c_{i k_{1}}, \ldots, c_{i k_{M_{i k^{-1}}}}\right\}
\end{aligned}
$$


A seguir, para cada classe $i$, define-se então o histograma $H_{i}$ pela intersecção dos histogramas da classe:

$$
H_{i}=\bigcap_{k} H_{i k}
$$

Este histograma também é definido pelos conjuntos $B$ e $C$ :

$$
\begin{aligned}
& B_{i}=\left\{b_{i_{0}}, b_{i_{1}}, \ldots, b_{i_{M_{i}-1}}\right\}, \\
& C_{i}=\left\{c_{i_{0}}, c_{i_{1}}, \ldots, c_{i_{M_{i}-1}}\right\}
\end{aligned}
$$

Para cada par $b_{l}, b_{m}$ em $B_{i}$, com $l<m$, define-se então o atributo de razão $r_{l m}$ por:

$$
r_{l m}=\left(\left(b_{l}, b_{m}\right),\left[r_{l m}^{\min }, r_{l m}^{\max }\right]\right),
$$

em que:

$$
\begin{aligned}
r_{l m}^{\min } & =\min _{0 \leq k<K} \frac{c_{l}^{(k)}}{c_{m}^{(k)}} \\
r_{l m}^{\max } & =\max _{0 \leq k<K} \frac{c_{l}^{(k)}}{c_{m}^{(k)}}
\end{aligned}
$$

Os descritores $R_{i}$ em si são formados pelo conjunto de atributos de razão:

$$
R_{i}=\left(\left(b_{l}, b_{m}\right),\left[r_{l m}^{\min }, r_{l m}^{\max }\right]\right), 0 \leq l<m<M_{i}
$$

\subsubsection{Momentos Cromáticos}

Este método, proposto em (111), trata o histograma $H$ da imagem colorida como sendo uma função distribuição de probabilidades e calcula os $k$ primeiros momentos $M_{k}$ para compor o vetor de características, em que:

$$
M_{k}=\sum i^{k} H_{i}
$$




\subsubsection{Gabor em Cores}

Este método é idêntico ao descrito na Seção 6.3.5. exceto que existe um pré-processamento da imagem, aplicando-se a transformada $E E E$ :

$$
\left(\begin{array}{c}
\tilde{E}_{\lambda} \\
\tilde{E}_{\lambda \lambda} \\
\tilde{E}_{\lambda \lambda \lambda}
\end{array}\right)=\left(\begin{array}{ccc}
0.06 & 0.63 & 0.31 \\
0.19 & 0.18 & -0.37 \\
0.22 & -0.44 & 0.06
\end{array}\right)\left(\begin{array}{c}
R \\
G \\
B
\end{array}\right)
$$




\section{CAPÍTULO 7}

\section{Resultados}

Neste capítulo, são apresentados os principais resultados obtidos durante o presente projeto. Para fins de organização, o capítulo é dividido em seções para cada diferente aplicação da metodologia proposta.

\subsection{Brodatz}

Nesta seção são descritos os resultados para a classificação da base de texturas em tons de cinza denominada Brodatz.

As tabelas e gráficos a seguir mostram uma avaliação estatística de cada método comparado. Assim, são usadas várias métricas estatísticas conhecidas na literatura, cada qual mostrando um aspecto de interesse na análise dos resultados. A Tabela 7.1 a seguir descreve brevemente cada métrica usada.

Tabela 7.1 - Breve descrição de cada métrica estatística usada na análise dos resultados.

\begin{tabular}{|ll|}
\hline Métrica & O que mede \\
\hline ND & Número de descritores (características) \\
TA & Taxa de acerto \\
$\kappa$ & Ganho da taxa de acerto em relação a uma classificação aleatória das amostras \\
E1 & Probabilidade de um elemento ser classificado como sendo da classe $j \neq i$ quando pertence à classe $i$ \\
E2 & Probabilidade de um elemento ser classificado como sendo da classe $i$ quando pertence à classe $j \neq i$ \\
\hline
\end{tabular}

A Tabela 7.2 ainda mostra o significado das siglas empregadas nas tabelas e figuras que exibem os resultados para a análise de texturas.

Tabela 7.2 - Siglas das transformadas empregadas nos resultados.

\begin{tabular}{|ll|}
\hline Sigla & Significado \\
\hline FDA & Análise de Dados Funcionais \\
EE & Transformada Espaço-Escala \\
TF & Transformada Tempo-Frequência \\
TE & Transformada Tempo-Escala \\
\hline
\end{tabular}


Ainda outra abreviação foi necessária para tornar possível a exibição das matrizes de combinação de descritores no texto. Nestas, o nome de cada descritor fractal foi representado por um número, como definido na Tabela 7.3

Tabela 7.3 - Representação dos descritores fractais por números nas matrizes de combinação.

\begin{tabular}{|ll|}
\hline Número & Descritor \\
\hline 1 & Blanket \\
2 & Bouligand-Minkowski \\
3 & Box-counting \\
4 & Browniano \\
5 & Fourier \\
6 & Lacunaridade \\
7 & Probabilidade \\
8 & Triangular \\
9 & Variação \\
10 & Variograma \\
11 & Wavelets \\
12 & Wavelike \\
\hline
\end{tabular}

\subsubsection{KNN}

Inicialmente, são descritos os resultados da classificação usando-se o classificador KNN. Trata-se de uma abordagem mais simplista, capaz de melhor expressar a capacidade bruta de cada descritor na discriminação das amostras.

O processo de classificação em si foi dividido em duas etapas. Na primeira, foram usados os descritores de forma direta. Esta abordagem não se mostrou interessante devido aos menores índices de acerto e ao alto número de atributos necessários para um resultado satisfatório, o que, além de comprometer o desempenho computacional, ainda gera resultados menos confiáveis em função de um possível processo de sobre-treinamento.

A Tabela 7.4 resume os melhores resultados alcançados pelos descritores fractais usados de forma direta e pelos métodos da literatura comparados. Entre os métodos da literatura, é interessante observar-se a alta taxa de acerto alcançada pelos descritores de Fourier, abordagem conhecida e muitas vezes negligenciada nos comparativos deste tipo. Já entre os descritores fractais, nota-se a vantagem dos métodos de Probabilidade e Lacunaridade, que alcançaram os melhores resultados com um número baixo de descritores, superando métodos estado-da-arte como LBP e Gabor. A eficácia das abordagens fractais reflete o caráter complexo e auto-similar das imagens na base de Brodatz, que, em essência, exibem uma característica amplamente difundida em toda a natureza conhecida e reforça a aplicabilidade e eficácia de métodos como os descritores fractais na solução deste tipo de problema.

Já na segunda etapa, cada descritor (fractal ou não) foi submetido a uma operação do 
Tabela 7.4 - Taxa de acerto para os descritores fractais usados de forma direta e outras medidas, na base de Brodatz, com classificador KNN.

\begin{tabular}{cccccc}
\hline Método & ND & TA $(\%)$ & $\kappa$ & E1 & E2 \\
\hline LBP & 32 & 89.73 & 0.90 & 0.10 & 0.10 \\
GLCM & 79 & 62.97 & 0.63 & 0.35 & 0.37 \\
Fourier clássico & 61 & $\mathbf{9 0 . 3 6}$ & 0.90 & 0.09 & 0.10 \\
Gabor & 20 & 84.23 & 0.84 & 0.15 & 0.16 \\
GLDM & 17 & 58.56 & 0.58 & 0.41 & 0.41 \\
Laws & 12 & 45.95 & 0.46 & 0.54 & 0.54 \\
Multifractal 1 & 96 & 35.68 & 0.36 & 0.64 & 0.64 \\
Multifractal 2 & 42 & 84.41 & 0.84 & 0.15 & 0.16 \\
Multifractal 3 & 336 & 84.95 & 0.85 & 0.14 & 0.15 \\
\hline Blanket + TF & 41 & 79.46 & 0.79 & 0.20 & 0.21 \\
Bouligand-Minkowski + TE & 57 & 89.10 & 0.89 & 0.10 & 0.11 \\
Box-counting + TF & 18 & 85.86 & 0.86 & 0.13 & 0.14 \\
Browniano + TE & 18 & 70.36 & 0.70 & 0.28 & 0.30 \\
Fourier + TF & 84 & 78.29 & 0.78 & 0.21 & 0.22 \\
Lacunaridade + TE & 11 & 90.72 & 0.91 & 0.09 & 0.09 \\
Probabilidade + TE & 8 & $\mathbf{9 4 . 3 2}$ & 0.94 & 0.05 & 0.06 \\
Triangular + TF & 25 & 82.97 & 0.83 & 0.17 & 0.17 \\
Variação + TE & 7 & 69.10 & 0.69 & 0.30 & 0.31 \\
Variograma + TE & 7 & 82.07 & 0.82 & 0.17 & 0.18 \\
Wavelets & 31 & 80.99 & 0.81 & 0.19 & 0.19 \\
Wavelike + TE & 55 & 88.20 & 0.88 & 0.11 & 0.12 \\
\hline
\end{tabular}

tipo PCA ou CCA, com o fim de reduzir a dimensionalidade e garantir melhor proveito de cada abordagem com um mínimo possível de descritores. O número de descritores foi reduzido a um máximo de 20 em cada experimento e o tipo de redução de dimensionalidade empregado (PCA ou CCA) foi aquele que propiciou os melhores resultados em cada caso.

A Tabela 7.5 exibe as taxas de acerto, além do número de descritores e de algumas medidas estatísticas relacionadas para os descritores fractais em seu estado original, isto é, com os valores extraídos diretamente da curva $\log -\log$ de fractalidade. Em um primeiro momento, destaca-se claramente o desempenho dos métodos de Bouligand-Minkowski e Wavelike. Os demais métodos, como Wavelets, Variograma e Probabilidade encontram-se em um segundo patamar, na faixa dos $80 \%$ de acerto. A maior eficiácia do método de Bouligand-Minkowski e seu derivado (Wavelike) se deve à capacidade deste em representar a morfologia da superfície mapeada da textura de forma fiel e rica. De fato, os valores dos volumes de dilatação mensuram, para os raios menores, o índice de irregularidade da superfície. À medida que este raio vai crescendo, os descritores vão agregando informações relativas ao aspecto das estruturas mais globais. O conjunto total de descritores concentra toda essa extensão da complexidade da textura em um vetor de valores reais. A aplicação de CCA faz com que a informação de variabilidade, fundamental para o processo de discriminação, seja extraída dos descritores iniciais, permitindo assim, uma classificação eficiente e confiável.

Neste capítulo, as tabelas de descritores fractais combinados exibem, para cada par de descritores, a taxa de acerto e o número de atributos usados, entre parêntesis. Os métodos são rotulados por números, como descrito na Tabela 7.3 
Tabela 7.5 - Taxa de acerto para os descritores fractais individuais na base de Brodatz, classificados por KNN.

\begin{tabular}{lccccc}
\hline Método & ND & TA $(\%)$ & $\kappa$ & E1 & E2 \\
\hline Blanket & 18 & 78.20 & 0.78 & 0.20 & 0.22 \\
Bouligand-Minkowski & 14 & 99.10 & 0.99 & 0.01 & 0.01 \\
Box-counting & 6 & 75.86 & 0.76 & 0.23 & 0.24 \\
Browniano & 14 & 63.06 & 0.63 & 0.34 & 0.37 \\
Fourier & 10 & 82.16 & 0.82 & 0.16 & 0.18 \\
Lacunaridade & 8 & 79.10 & 0.79 & 0.19 & 0.21 \\
Probabilidade & 7 & 81.98 & 0.82 & 0.16 & 0.18 \\
Triangular & 8 & 79.46 & 0.79 & 0.18 & 0.21 \\
Variação & 8 & 58.74 & 0.59 & 0.40 & 0.41 \\
Variograma & 8 & 80.90 & 0.81 & 0.17 & 0.19 \\
Wavelets & 8 & 81.26 & 0.81 & 0.18 & 0.19 \\
Wavelike & 17 & 98.56 & 0.99 & 0.01 & 0.01 \\
\hline
\end{tabular}

A Tabela 7.6 mostra as taxas de acerto e respectivos números de descritores para o caso em que os atributos de diferentes abordagens fractais são combinados. Neste caso, os descritores originais são simplesmente concatenados, aplicando-se CCA sobre o resultado desta concatenação. Nota-se que os melhores ganhos foram obtidos pelos descritores que já haviam se sobressaído no teste anterior. Observa-se, entretanto, que no caso de BouligandMinkowski, nenhuma combinação alcançou um resultado tão bom quanto o uso do descritor sem combinação. Já no caso de Wavelike, com exceção de Wavelets e Box-counting, todas as outras combinações possibilitaram taxas de acerto mais altas, em alguns casos usando um número menor de descritores. Os números ainda mostram outras combinações interessantes como Blanket+Probabilidade, Fourier+Lacunaridade, Lacunaridade+Triangular, etc. Cada uma destas diferentes abordagens fractais oferece, individualmente, uma visão específica sobre a complexidade da textura. Por exemplo, enquanto o método de Lacunaridade extrai uma medida de morfologia espacial da superfície tridimensional associada à imagem, o método de Fourier analisa a complexidade a partir de uma perspectiva espectral, em que os níveis de irregularidade/suavidade são tomados em relação às frequências presentes na imagem. Assim, dois métodos que, individualmente, apresentam uma taxa de acerto relativamente baixa (82.16 e $79.10 \%$ ) juntam-se para compor descritores que fornecem uma taxa de acerto de $94.59 \%$.

Tabela 7.6 - Taxa de acerto para os descritores fractais individuais combinados na base de Brodatz, classificados por KNN.

\begin{tabular}{|c|c|c|c|c|c|c|c|c|c|c|c|c|}
\hline & 1 & 2 & 3 & 4 & 5 & 6 & 7 & 8 & 9 & 10 & 11 & 12 \\
\hline 1 & & $97.65(17)$ & & $.86(14)$ & $92.9(14)$ & $94.9(13)$ & $5.85(20)$ & $91.89(20)$ & $84.32(20)$ & $92.79(19)$ & $82.16(8)$ & $99.09(20)$ \\
\hline 2 & $97.65(17)$ & - & $63.78(20)$ & $97.11(18)$ & $98.37(16)$ & $3.91(20)$ & $3.91(16)$ & 98.19(2 & 8.91(19) & 98.0 & 78.0 & $9.09(16)$ \\
\hline 3 & & $63.78(20)$ & & $81.80(16)$ & & & 39.54( & 85.94( & & & 81.4 & \\
\hline 4 & $86(14)$ & & $80(16)$ & & $.0(2$ & & & & & & & \\
\hline 5 & & 9 & & $87.0(20)$ & & 94.59( & 9 & 87.3 & & & & (20) \\
\hline 6 & & & & & & s & $33(1$ & & & & & \\
\hline 7 & 95 & $.91(16)$ & & 5) & 91.89 & $3.33(14)$ & - & $94.77(10)$ & 93.1 & 92.61 & & $99.27(19)$ \\
\hline 8 & & & & & & & .77( & - & 88.82(1 & & & \\
\hline 9 & 84.3 & .9 & & 5 & 85.5 & ) & 93.15( & 88.82 & - & $90.27(18)$ & $79.09(19)$ & 98.91(13) \\
\hline 10 & & & & & $86.66(14)$ & & $92.61(16)$ & $89.0(14)$ & & & & $99.27(17)$ \\
\hline 11 & 82.1 & 78.0( & & 84.86 & & 90.8 & & & & & - & $98.19(14)$ \\
\hline 12 & $99.09(20)$ & $99.09(16)$ & $49.54(19)$ & $99.45(19)$ & $99.45(20)$ & $99.45(11)$ & 99.27(19) & $99.09(19)$ & 98.91(13) & $99.27(17)$ & $98.19(14)$ & \\
\hline
\end{tabular}

A Tabela 7.7 ilustra as taxas de acerto obtidas pelos descritores fractais após aplicação da transformada FDA. Nesta situação, a análise funcional não se mostrou útil, levando a 
uma queda drástica de desempenho para todos os casos. A eficiência desta ferramenta está fortemente atrelada ao classificador e ao método de redução de dimensionalidade usado. Neste caso, em que se usou um classificador baseado em distâncias simples, a transformação para o espaço funcional acarreta uma perda de significância dos dados originais, explicando assim a queda geral nas taxas de acerto obtidas.

Tabela 7.7 - Taxa de acerto para os descritores fractais FDA na base de Brodatz, classificados por KNN.

\begin{tabular}{lccccc}
\hline Método & ND & TA $(\%)$ & $\kappa$ & E1 & E2 \\
\hline Blanket & 14 & 75.32 & 0.75 & 0.22 & 0.25 \\
Bouligand-Minkowski & 18 & 97.12 & 0.97 & 0.02 & 0.03 \\
Box-counting & 17 & 59.28 & 0.59 & 0.36 & 0.41 \\
Browniano & 9 & 58.38 & 0.58 & 0.38 & 0.42 \\
Fourier & 7 & 77.84 & 0.78 & 0.19 & 0.22 \\
Lacunaridade & 19 & 61.44 & 0.61 & 0.37 & 0.39 \\
Probabilidade & 19 & 76.76 & 0.77 & 0.20 & 0.23 \\
Triangular & 5 & 71.35 & 0.71 & 0.26 & 0.29 \\
Variação & 5 & 46.13 & 0.46 & 0.52 & 0.54 \\
Variograma & 7 & 65.41 & 0.65 & 0.32 & 0.35 \\
Wavelets & 9 & 72.97 & 0.73 & 0.26 & 0.27 \\
Wavelike & 18 & 95.50 & 0.95 & 0.04 & 0.05 \\
\hline
\end{tabular}

Este fenômeno se repete quando os descritores são combinados na Tabela 7.8. Entretanto, nota-se que a transformada não influenciou de maneira homogênea sobre as combinações. Por exemplo, o método de Wavelike apresentou uma queda menor em sua combinação com Bouligand-Minkowski, tendo caído um pouco mais quando combinado com Blanket e mais ainda na combinação com Browniano. Esta variação está relacionada ao quanto a transformada alterou o descritor original. E este nível de alteração depende do aspecto da curva inicial. Descritores mais suavizados tendem a sofrer menor influência, enquanto aqueles mais irregulares vão apresentar deformações mais significativas após o processo de transformação. Por fim, a taxa final de classificação também vai depender do quanto a irregularidade do descritor original é importante para o processo discriminatório.

Tabela 7.8 - Taxa de acerto para os descritores fractais FDA combinados na base de Brodatz, classificados por KNN.

\begin{tabular}{|c|c|c|c|c|c|c|c|c|c|c|c|c|}
\hline & 1 & 2 & 3 & 4 & 5 & 6 & 7 & 8 & 9 & 10 & 11 & 12 \\
\hline 1 & & 95.31(13) & $67.92(15)$ & $80.72(17)$ & $92.25(14)$ & 75.31(5) & $70.81(7)$ & $80.72(7)$ & $68.28(10)$ & $79.27(9)$ & $59.81(10)$ & $93.87(12)$ \\
\hline 2 & $95.31(13)$ & & $19(1$ & $88.10(13)$ & $7.29(20)$ & $54.41(18)$ & $69.72(1$ & $85.40(8)$ & $77.65(7)$ & $65.94(5)$ & $63.78(20)$ & $97.65(13)$ \\
\hline 3 & & $8.19(12)$ & & $5.22(17)$ & & & & & & & & \\
\hline 4 & & & $522(17)$ & & $9.45(1$ & & & & & & & \\
\hline 5 & & 97 & & $79.45(12)$ & - & $.89(16)$ & & & & & & \\
\hline 6 & & & & & $.89(16$ & - & $.87(17)$ & & & & & \\
\hline 7 & $81(7)$ & .72( & 58.73 & 76.2 & $84.14(7)$ & 73.87(17) & & $89.0(9)$ & $65.40(7)$ & 70.27 & 79.09( & $61.9(20)$ \\
\hline 8 & & & & & & & & - & 6) & & & \\
\hline 9 & $28(10)$ & 77.65 & 61. & & 70.27 & 68.6 & $65.40(7)$ & 7656 & - & 79.81(13) & 71.5 & $68.10(5)$ \\
\hline 10 & & & & & & & & & & - & $76.57(9)$ & \\
\hline 11 & $9.81(10)$ & & & & & & $79.09(10)$ & & & & - & $87.74(10)$ \\
\hline 12 & $93.87(12)$ & $97.65(13)$ & $47.92(8)$ & $90.81(13)$ & $95.67(9)$ & $61.62(4)$ & $61.9(20)$ & $85.22(8)$ & $68.10(5)$ & $64.32(6)$ & $87.74(10)$ & \\
\hline
\end{tabular}

Por sua vez, a Tabela 7.9 mostra as taxas de acerto para os descritores fractais após uma transformação espaço-escala. Neste caso, vários métodos não puderam ser testados, pois apresentaram um alto índice de correlação entre os descritores transformados, levando a uma 
matriz CCA (que relaciona a matriz inter com a intra-classe) cuja covariância não é inversível. O único método que experimentou um ganho após a transformação foi Box-counting. Este é um método simples de estimativa de complexidade, para o qual, a variação no número de caixas quando se varia o tamanho destas é uma informação importante. Nos demais casos, essa variação, expressa pela derivada na transformação espaço-escala, não foi útil e até mesmo levou a uma queda expressiva no significado dos descritores em relação à representação da textura analisada.

Tabela 7.9 - Taxa de acerto para os descritores fractais espaço-escala na base de Brodatz, classificados por KNN.

\begin{tabular}{lccccc}
\hline Método & ND & TA (\%) & $\kappa$ & E1 & E2 \\
\hline Bouligand-Minkowski & 20 & 70.27 & 0.70 & 0.27 & 0.30 \\
Box-counting & 13 & 82.16 & 0.82 & 0.16 & 0.18 \\
Fourier & 10 & 52.61 & 0.52 & 0.44 & 0.47 \\
Variograma & 18 & 75.50 & 0.75 & 0.22 & 0.25 \\
Wavelets & 20 & 68.83 & 0.69 & 0.28 & 0.31 \\
\hline
\end{tabular}

A Tabela 7.10 ilustra os resultados para as combinações possíveis entre os descritores fractais transformados por espaço-escala. Novamente, as taxas de acerto foram menores do que nas combinações de descritores individuais . A melhor combinação foi fornecida por Boxcounting+Variograma. O resultado demonstra que a informação extraída pela transformada, no caso, a partir da derivada suavizada por filtro Gaussiano, não é eficiente para o classificador, ainda que os descritores sejam combinados.

Tabela 7.10 - Taxa de acerto para os descritores fractais espaço-escala combinados na base de Brodatz, classificados por KNN.

\begin{tabular}{|c|c|c|c|c|c|c|c|c|c|c|c|c|}
\hline & 1 & 2 & 3 & 4 & 5 & 6 & 7 & 8 & 9 & 10 & 11 & 12 \\
\hline 1 & - & & & & & & & & & & & \\
\hline 2 & & - & $57.47(7)$ & & $44.86(18)$ & & & & & $70.45(20)$ & $67.20(15)$ & \\
\hline 3 & & $57.47(7)$ & - & & $42.34(16)$ & & & & & $88.28(18)$ & 70.63(19) & \\
\hline 4 & & & & - & & & & & & & & \\
\hline 5 & & $44.86(18)$ & $42.34(16)$ & & - & & & & & $75.31(15)$ & $55.67(16)$ & \\
\hline 6 & & & & & & - & & & & & & \\
\hline 7 & & & & & & & - & & & & & \\
\hline 8 & & & & & & & & - & & & & \\
\hline 9 & & & & & & & & & - & & & \\
\hline 10 & & $70.45(20)$ & $88.28(18)$ & & $75.31(15)$ & & & & & - & $75.67(20)$ & \\
\hline 11 & & $67.20(15)$ & $70.63(19)$ & & $55.67(16)$ & & & & & $75.67(20)$ & - & \\
\hline 12 & & & & & & & & & & & & - \\
\hline
\end{tabular}

Já a Tabela 7.11 expressa os resultados para os descritores fractais após a aplicação da transformação tempo-frequência. Neste caso, a transformada extrai informação relativa às frequências locais (em uma janela) presentes na curva dos descritores e verifica-se a relevância deste tipo de informação para o classificador KNN. O efeito desta transformação sobre os descritores foi bem distinto para diferentes abordagens. Assim, em casos como dos descritores de Box-counting, Lacunaridade e Probabilidade, houve aumento na taxa de acerto, enquanto que para os métodos de Bouligand-Minkowski, Fourier e Wavelike, houve queda significativa. Em particular, os métodos espectrais (Fourier e Wavelets) obtiveram resultados ruins, dado 
que a transformada capta medidas de frequência em janelas de tamanho fixo de dados que já estão neste domínio, reduzindo assim a resolução do dado original e levando a uma menor eficácia no processo de classificação. Já no caso das abordagens baseadas em dilatação de superfície (Bouligand-Minkowski e Wavelike), os descritores originais apresentam um aspecto mais homogêneo que faz com que a informação de frequência apresente pouca riqueza para o classificador.

Tabela 7.11 - Taxa de acerto para os descritores fractais tempo-frequência na base de Brodatz, classificados por KNN.

\begin{tabular}{lccccc}
\hline Método & ND & TA $(\%)$ & $\kappa$ & E1 & E2 \\
\hline Blanket & 17 & 69.91 & 0.70 & 0.26 & 0.30 \\
Bouligand-Minkowski & 11 & 79.64 & 0.80 & 0.20 & 0.20 \\
Box-counting & 18 & 83.96 & 0.84 & 0.14 & 0.16 \\
Browniano & 18 & 67.39 & 0.67 & 0.28 & 0.33 \\
Fourier & 18 & 43.96 & 0.44 & 0.55 & 0.56 \\
Lacunaridade & 19 & 85.23 & 0.85 & 0.13 & 0.15 \\
Probabilidade & 18 & 89.73 & 0.90 & 0.10 & 0.10 \\
Triangular & 19 & 71.71 & 0.72 & 0.27 & 0.28 \\
Variação & 18 & 58.56 & 0.58 & 0.39 & 0.41 \\
Variograma & 20 & 71.71 & 0.72 & 0.27 & 0.28 \\
Wavelets & 20 & 72.25 & 0.72 & 0.26 & 0.28 \\
Wavelike & 20 & 66.31 & 0.66 & 0.31 & 0.34 \\
\hline
\end{tabular}

A Tabela 7.12 apresenta os resultados para os descritores combinados. Nota-se em geral que as melhores combinações foram obtidas usando-se os descritores fractais de Probabilidade. Como estes descritores são obtidos da distribuição estatística da densidade de pixels na imagem e dado o caráter inerentemente homogêneo por partes, usual em imagens de texturas, este descritor acaba sendo mais fortemente caracterizado por padrões locais de periodicidade, bem representados na transformada de Gabor associada à abordagem tempo-frequência. A adição de outros descritores em outras perspectivas colabora para um gradual aumento na taxa de acerto.

Tabela 7.12 - Taxa de acerto para os descritores fractais tempo-frequência combinados na base de Brodatz, classificados por KNN.

\begin{tabular}{|c|c|c|c|c|c|c|c|c|c|c|c|c|}
\hline & 1 & 2 & 3 & 4 & 5 & 6 & 7 & 8 & 9 & 10 & 11 & 12 \\
\hline 1 & - & $66.12(14)$ & $76.93(20)$ & $64.86(20)$ & $47.56(14)$ & $79.27(18)$ & $89.0(19)$ & $79.27(20)$ & $56.93(11)$ & $73.15(20)$ & $70.81(20)$ & $64.68(14)$ \\
\hline 2 & $66.12(14)$ & - & $49.18(6)$ & $59.27(18)$ & $45.76(4)$ & $70.09(20)$ & $88.10(14)$ & $78.37(13)$ & $67.74(12)$ & $70.9(18)$ & $72.25(20)$ & $67.0(12)$ \\
\hline 3 & $76.93(20)$ & $49.18(6)$ & - & $60.54(19)$ & $49.18(18)$ & $85.76(20)$ & $89.0(15)$ & $75.31(20)$ & $82.16(18)$ & $70.9(20)$ & $72.79(20)$ & $66.12(9)$ \\
\hline 4 & $64.86(20)$ & $59.27(18)$ & $60.54(19)$ & - & $50.09(13)$ & $87.92(20)$ & $84.50(17)$ & $77.29(20)$ & $61.62(19)$ & $71.53(20)$ & $74.05(18)$ & $67.38(18)$ \\
\hline 5 & $47.56(14)$ & $45.76(4)$ & $49.18(18)$ & $50.09(13)$ & - & $73.69(18)$ & $86.48(19)$ & $67.74(20)$ & $41.26(4)$ & $71.35(18)$ & $71.53(17)$ & $69.18(18)$ \\
\hline 6 & $79.27(18)$ & $70.09(20)$ & $85.76(20)$ & $87.92(20)$ & $73.69(18)$ & - & $86.48(20)$ & $71.17(19)$ & 78.91(20) & 72.61(19) & $72.07(16)$ & $69.18(12)$ \\
\hline 7 & $89.0(19)$ & $88.10(14)$ & $89.0(15)$ & $84.50(17)$ & $86.48(19)$ & $86.48(20)$ & - & $78.0(20)$ & $86.48(15)$ & $74.23(19)$ & $75.13(18)$ & $70.45(15)$ \\
\hline 8 & $79.27(20)$ & $78.37(13)$ & $75.31(20)$ & $77.29(20)$ & $67.74(20)$ & $71.17(19)$ & $78.0(20)$ & 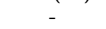 & $67.92(13)$ & $72.25(19)$ & $72.61(20)$ & $69.72(14)$ \\
\hline 9 & $56.93(11)$ & $67.74(12)$ & $82.16(18)$ & $61.62(19)$ & $41.26(4)$ & 78.91(20) & $86.48(15)$ & $67.92(13)$ & - & $73.51(19)$ & $76.21(20)$ & $66.30(14)$ \\
\hline 10 & $73.15(20)$ & $70.9(18)$ & $70.9(20)$ & $71.53(20)$ & $71.35(18)$ & $72.61(19)$ & $74.23(19)$ & $72.25(19)$ & 73.51(19) & - & $72.07(18)$ & $68.10(19)$ \\
\hline 11 & $70.81(20)$ & $72.25(20)$ & $72.79(20)$ & $74.05(18)$ & $71.53(17)$ & $72.07(16)$ & $75.13(18)$ & $72.61(20)$ & $76.21(20)$ & $72.07(18)$ & - & $66.84(20)$ \\
\hline 12 & $64.68(14)$ & $67.0(12)$ & $66.12(9)$ & $67.38(18)$ & $69.18(18)$ & $69.18(12)$ & $70.45(15)$ & $69.72(14)$ & $66.30(14)$ & $68.10(19)$ & $66.84(20)$ & - \\
\hline
\end{tabular}

A Tabela 7.13 ilustra as taxas de acerto, número de descritores e outras medidas para a transformada tempo-escala. Assim como na abordagem tempo-frequência, a influência da transformação depende de cada método fractal analisado. Entretanto, agora, a maioria dos métodos apresentou ganho significativo ou se mantiveram com acerto similar. Métodos 
como Box-counting, Browniano, Lacunaridade, Probabilidade e outros apresentam melhora significativa em seus índices de acerto, enquanto que no caso de Fourier, houve uma queda drástica na taxa de acerto. Esta queda se dá pela incompatibilidade entre as duas formas de análise. Os descritores de Fourier e a transformada tempo-escala realizam uma análise de frequências em diferentes estágios no processo da análise de texturas. O descritor fractal expressa a complexidade a partir do comportamento do espectro de potência. A transformação tempo-escala analisa os descritores fractais na busca por padrões locais de frequência. Porém, a curva do espectro de potência é mais suave e a transformada wavelets não é capaz de representar toda a riqueza presente em sua versão original. O mesmo não ocorre com os descritores de Gabor que, por realizarem uma análise com bandas variáveis de frequência, já fornecem uma informação menos homogênea, permitindo assim uma análise do tipo tempoescala.

Tabela 7.13 - Taxa de acerto para os descritores fractais tempo-escala na base de Brodatz, classificados por KNN.

\begin{tabular}{lccccc}
\hline Método & ND & TA $(\%)$ & $\kappa$ & E1 & E2 \\
\hline Blanket & 10 & 77.84 & 0.78 & 0.21 & 0.22 \\
Bouligand-Minkowski & 19 & 98.92 & 0.99 & 0.01 & 0.01 \\
Box-counting & 7 & 82.52 & 0.82 & 0.15 & 0.17 \\
Browniano & 17 & 70.45 & 0.70 & 0.27 & 0.30 \\
Fourier & 7 & 53.69 & 0.54 & 0.43 & 0.46 \\
Lacunaridade & 10 & 87.75 & 0.88 & 0.11 & 0.12 \\
Probabilidade & 8 & 92.25 & 0.92 & 0.06 & 0.08 \\
Triangular & 10 & 82.52 & 0.82 & 0.15 & 0.17 \\
Variação & 7 & 64.86 & 0.65 & 0.33 & 0.35 \\
Variograma & 7 & 80.18 & 0.80 & 0.18 & 0.20 \\
Wavelets & 8 & 84.14 & 0.84 & 0.14 & 0.16 \\
Wavelike & 18 & 98.92 & 0.99 & 0.01 & 0.01 \\
\hline
\end{tabular}

Por fim, a Tabela 7.14 exibe as taxas de acerto e números de descritores para as combinações dois a dois dos descritores fractais. A tabela mostra várias combinações com altas taxas de acerto, comprovando a eficiência deste tipo de solução na análise de texturas. É o caso das concatenações Bouligand-Minkowski+Wavelike, Bouligand-Minkowski+Probabilidade, Browniano+Probabilidade, etc. Os métodos que apresentaram as melhores combinações foram também aqueles que em sua maioria apresentaram as maiores taxas de acerto individualmente. Entretanto, após as combinações, os resultados são incrementados, pois os descritores finais armazenam a informação mais significativa relativa a cada uma das abordagens puras.

\subsubsection{Outros Métodos}

A Tabela 7.15 mostra as taxas de acerto para outros métodos da literatura, alguns mais recentes como LBP, Gabor e as abordagens multifractais, outras mais clássicas, como GLCM, GLDM, Fourier e Laws. Neste ponto, é importante destacar que o método de Fourier aqui 
Tabela 7.14 - Taxa de acerto para os descritores fractais tempo-escala combinados na base de Brodatz, classificados por KNN.

\begin{tabular}{|c|c|c|c|c|c|c|c|c|c|c|c|c|}
\hline & 1 & 2 & 3 & 4 & 5 & 6 & 7 & 8 & 9 & 10 & 11 & 12 \\
\hline 1 & - & $96.75(12)$ & $88.82(7)$ & 78.73(12) & $88.82(17)$ & 91.71(11) & $93.15(8)$ & $84.32(9)$ & $74.23(7)$ & $84.68(8)$ & $92.25(10)$ & $97.65(12)$ \\
\hline 2 & $96.75(12)$ & - & $98.73(20)$ & $95.67(17)$ & $98.0(20)$ & $98.37(12)$ & $98.91(13)$ & $98.19(20)$ & $98.55(17)$ & $98.19(19)$ & $98.0(16)$ & $99.27(20)$ \\
\hline 3 & $88.82(7)$ & $98.73(20)$ & & $85.40(14)$ & $76.93(6)$ & $87.92(18)$ & $93.69(15)$ & $84.86(17)$ & $82.70(9)$ & $82.34(15)$ & $83.78(8)$ & $99.27(17)$ \\
\hline 4 & $78.73(12)$ & $95.67(17)$ & $85.40(14)$ & & $81.08(10)$ & $93.15(20)$ & $97.29(20)$ & $82.34(19)$ & $85.94(19)$ & $84.50(12)$ & $90.45(15)$ & $97.65(17)$ \\
\hline 5 & $88.82(17)$ & $98.0(20)$ & $76.93(6)$ & $81.08(10)$ & - & $90.09(17)$ & $94.9(9)$ & $86.12(8)$ & $80.72(10)$ & $77.83(10)$ & $90.45(13)$ & $98.73(15)$ \\
\hline 6 & $91.71(11)$ & $98.37(12)$ & $87.92(18)$ & $93.15(20)$ & $90.09(17)$ & - & $96.57(11)$ & $97.11(19)$ & 93.51(18) & $96.21(18)$ & $94.9(13)$ & $99.09(14)$ \\
\hline 7 & $93.15(8)$ & 98.91(13) & $93.69(15)$ & $97.29(20)$ & $94.9(9)$ & $96.57(11)$ & 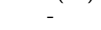 & $96.57(18)$ & $95.13(12)$ & $95.85(15)$ & $94.23(11)$ & $99.27(16)$ \\
\hline 8 & 84.32(9) & $98.19(20)$ & $84.86(17)$ & $82.34(19)$ & $86.12(8)$ & 97.11(19) & $96.57(18)$ & & $85.76(14)$ & $87.74(14)$ & $90.81(14)$ & $96.93(19)$ \\
\hline 9 & $74.23(7)$ & $98.55(17)$ & $82.70(9)$ & $85.94(19)$ & $80.72(10)$ & $93.51(18)$ & $95.13(12)$ & $85.76(14)$ & - & $86.30(15)$ & $87.0(15)$ & $98.73(19)$ \\
\hline 10 & $84.68(8)$ & $98.19(19)$ & $82.34(15)$ & $84.50(12)$ & $77.83(10)$ & $96.21(18)$ & $95.85(15)$ & $87.74(14)$ & $86.30(15)$ & - & $92.43(12)$ & $97.29(17)$ \\
\hline 11 & $92.25(10)$ & $98.0(16)$ & $83.78(8)$ & $90.45(15)$ & $90.45(13)$ & $94.9(13)$ & $94.23(11)$ & $90.81(14)$ & $87.0(15)$ & $92.43(12)$ & - & $98.73(20)$ \\
\hline 12 & $97.65(12)$ & $99.27(20)$ & $99.27(17)$ & $97.65(17)$ & $98.73(15)$ & $99.09(14)$ & $99.27(16)$ & $96.93(19)$ & $98.73(19)$ & $97.29(17)$ & $98.73(20)$ & - \\
\hline
\end{tabular}

citado não tem relação direta com a abordagem de descritores fractais por Fourier. Os melhores resultados foram alcançados por LBP e pelo método multifractal por kernel Gaussiano. Estes são dois métodos estado-da-arte e com excelentes resultados demonstrados na literatura (105). Métodos mais clássicos como Fourier e GLCM também obtiveram bons resultados no processo de classificação por KNN. Este fato mostra que, embora mais antigos e simples, estes métodos podem ser uma excelente solução na análise de texturas e não devem ser descartadas em um comparativo com metodologias mais recentes.

Tabela 7.15 - Taxa de acerto para os métodos da literatura na base de Brodatz, classificados por KNN.

\begin{tabular}{lccccc}
\hline Método & ND & TA (\%) & $\kappa$ & E1 & E2 \\
\hline Multifractal 2 & 17 & 92.61 & 0.93 & 0.06 & 0.07 \\
Multifractal 3 & 7 & 51.35 & 0.51 & 0.46 & 0.49 \\
LBP & 20 & 92.61 & 0.93 & 0.07 & 0.07 \\
GLCM & 20 & 88.83 & 0.89 & 0.09 & 0.11 \\
Fourier & 16 & 89.01 & 0.89 & 0.09 & 0.11 \\
Gabor & 7 & 86.85 & 0.87 & 0.12 & 0.13 \\
GLDM & 8 & 52.79 & 0.53 & 0.45 & 0.47 \\
Laws & 10 & 72.61 & 0.72 & 0.23 & 0.27 \\
Multifractal 1 & 8 & 40.00 & 0.40 & 0.57 & 0.60 \\
\hline
\end{tabular}

\subsubsection{Resumo dos Resultados}

A Tabela 7.16 exibe um resumo dos resultados obtidos pelos métodos da literatura, descritores fractais e combinação de descritores fractais para a base de Brodatz, classificados por KNN. Para cada descritor fractal, foi escolhida a abordagem (FDA, espaço-escala, tempofrequência ou tempo-escala) que propiciou a maior taxa de acerto. Os resultados estão apresentados em ordem decrescente de sucesso na classificação.

Entre os descritores fractais, as melhores soluções apresentadas foram Bouligand-Minkowski, Wavelike e Probabilidade. A base de Brodatz é caracterizada pela presença de um grande número de imagens com padrões espaciais bem definidos. Este fato explica as altas taxas de acerto (próximas a 100\%) que podem ser obtidas mesmo com um baixo número de descritores, bem como justifica o maior sucesso de métodos espaciais e, em particular, Bouligand- 
Minkowski que, por meio de uma dilatação morfológica por um objeto simétrico (esfera), é capaz de medir de forma direta e eficiente e em múltiplos níveis de escala a complexidade da textura.

Já para as combinações de descritores, as melhores soluções foram Lacunaridade+Wavelike, Browniano+Wavelike e Fourier+Wavelike. De um modo geral, todas as combinações envolvendo Wavelike apresentaram excelente desempenho. Tal fato confirma o poder discriminatório deste método e o quanto que ele pode ter seu poderio incrementado pela combinação com outros métodos, menos eficientes individualmente, mas que quando concatenados oferecem taxas de acerto que superam outras abordagens estado-da-arte.

Tabela 7.16 - Resumo das taxas de acerto obtidas para a base de Brodatz, classificada por KNN.

\begin{tabular}{lccccc}
\hline Método & ND & TA (\%) & $\kappa$ & E1 & E2 \\
\hline Multifractal 2 & 17 & 92.61 & 0.93 & 0.06 & 0.07 \\
LBP & 20 & 92.61 & 0.93 & 0.07 & 0.07 \\
Fourier & 16 & 89.01 & 0.89 & 0.09 & 0.11 \\
GLCM & 20 & 88.83 & 0.89 & 0.09 & 0.11 \\
Gabor & 7 & 86.85 & 0.87 & 0.12 & 0.13 \\
Laws & 10 & 72.61 & 0.72 & 0.23 & 0.27 \\
GLDM & 8 & 52.79 & 0.53 & 0.45 & 0.47 \\
Multifractal 3 & 7 & 51.35 & 0.51 & 0.46 & 0.49 \\
Multifractal 1 & 8 & 40.00 & 0.40 & 0.57 & 0.60 \\
\hline \hline Bouligand-Minkowski & 14 & 99.10 & 0.99 & 0.01 & 0.01 \\
Wavelike + TE & 18 & 98.92 & 0.99 & 0.01 & 0.01 \\
Probabilidade + TE & 8 & 92.25 & 0.92 & 0.06 & 0.08 \\
Lacunaridade + TE & 10 & 87.75 & 0.88 & 0.11 & 0.12 \\
Wavelets + TE & 8 & 84.14 & 0.84 & 0.14 & 0.16 \\
Box-counting + TF & 18 & 83.96 & 0.84 & 0.14 & 0.16 \\
Triangular + TE & 10 & 82.52 & 0.82 & 0.15 & 0.17 \\
Fourier & 10 & 82.16 & 0.82 & 0.16 & 0.18 \\
Variograma & 8 & 80.90 & 0.81 & 0.17 & 0.19 \\
Blanket & 18 & 78.20 & 0.78 & 0.20 & 0.22 \\
Browniano + TE & 17 & 70.45 & 0.70 & 0.27 & 0.30 \\
Variação + TE & 7 & 64.86 & 0.65 & 0.33 & 0.35 \\
\hline \hline Lacunaridade+Wavelike & 11 & 99.46 & 0.99 & 0.00 & 0.01 \\
Browniano+Wavelike & 19 & 99.46 & 0.99 & 0.00 & 0.01 \\
Fourier+Wavelike & 20 & 99.46 & 0.99 & 0.01 & 0.01 \\
Probabilidade+Wavelike + TE & 16 & 99.28 & 0.99 & 0.01 & 0.01 \\
Box-counting+Wavelike + TE & 17 & 99.28 & 0.99 & 0.01 & 0.01 \\
Variograma+Wavelike & 17 & 99.28 & 0.99 & 0.01 & 0.01 \\
Bouligand-Minkowski+Wavelike + TE & 20 & 99.28 & 0.99 & 0.01 & 0.01 \\
Triangular+Wavelike & 19 & 99.10 & 0.99 & 0.01 & 0.01 \\
Blanket+Wavelike & 20 & 99.10 & 0.99 & 0.01 & 0.01 \\
Probabilidade+Variação + TE & 12 & 95.14 & 0.95 & 0.04 & 0.05 \\
Lacunaridade+Wavelets + TE & 13 & 94.95 & 0.95 & 0.04 & 0.05 \\
\hline & & & & &
\end{tabular}

A Figura 7.1 ilustra a relação entre o número de descritores e a taxa de acerto para os três melhores métodos em cada categoria (métodos da literatura, descritores fractais e descritores combinados). Como se observa, os descritores combinados apresentam taxas acima de $90 \%$ com apenas 5 descritores. Este resultado é importante, uma vez que garante uma metodologia de classificação (descritores + classificador) precisa com um baixo custo computacional, o que pode ser útil, sobretudo em conjuntos maiores ou em aplicações em tempo real. Além disso, o uso de poucos descritores evita problemas como o "mal da dimensionalidade" e ainda garante 
um resultado mais robusto, uma vez que o uso de muitos atributos pode levar a um processo de sobre-treinamento e gerar um resultado alto, mas de baixa confiabilidade.

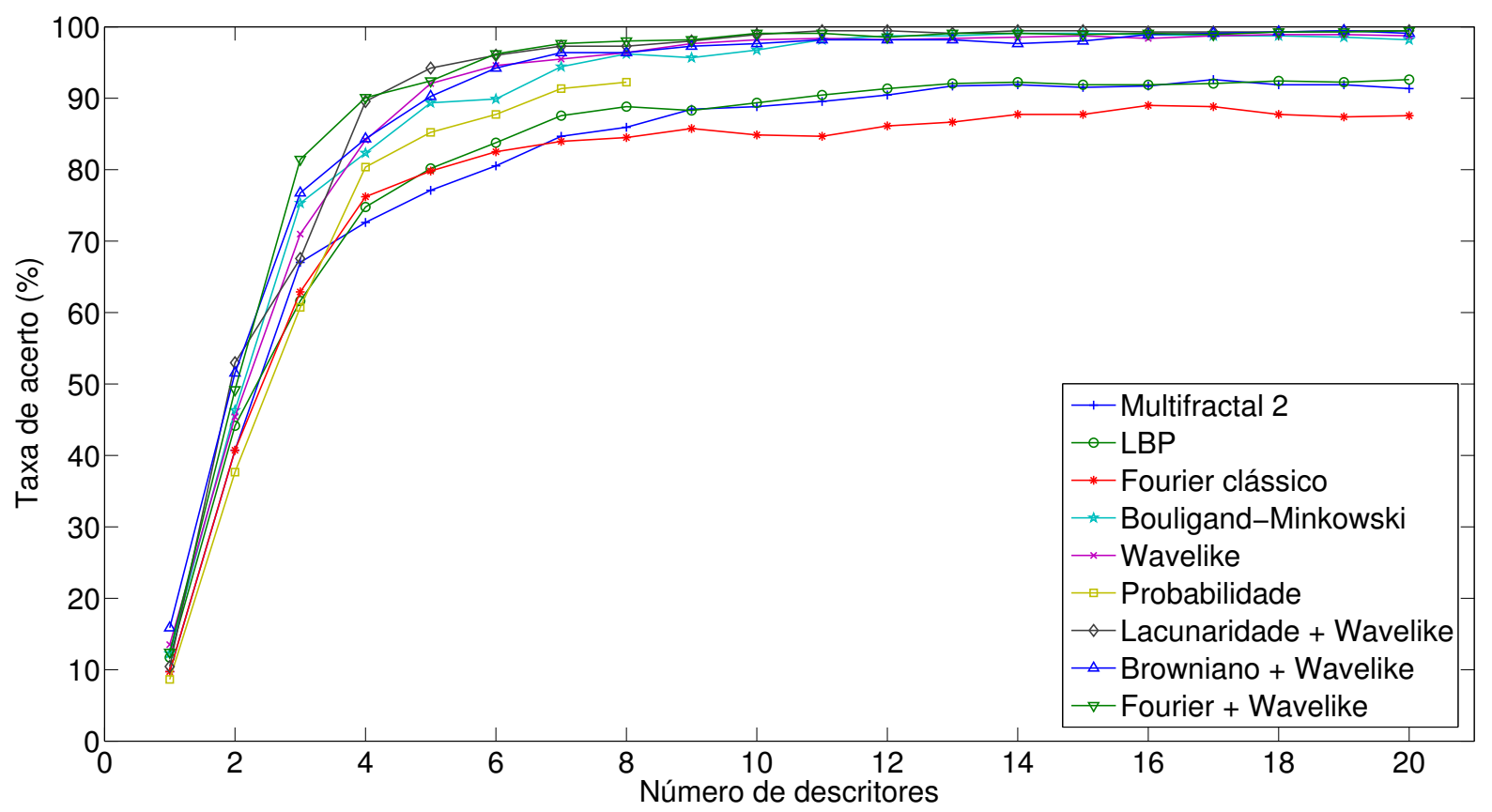

Figura 7.1 - Taxas de acerto em função do número de descritores na base de Brodatz, com classificador KNN.

Por fim, as Figuras 7.2 e 7.3 mostram as matrizes de confusão dos melhores métodos representados no gráfico da Figura 7.1. As matrizes são representadas em uma escala gradativa de tons de cinza, em que pixels mais escuros representam um número maior de imagens. Estas matrizes servem como um indicativo geral do comportamento da base de Brodatz diante do classificador KNN, usando-se os descritores propostos. As matrizes refletem um comportamento regular, sendo que no caso dos métodos com menor precisão, estas apresentam pontos escuros espalhados por todas as regiões fora da diagonal, indicando que não existem conjuntos específicos de classes com discriminação mais difícil. Em particular, entre os descritores fractais (individuais e combinados), não existe de fato nenhuma classe com deficiência relevante.

\subsubsection{SVM}

A seguir, são exibidos os resultados para aplicação do classificador SVM. Este é um método de aprendizado de máquinas mais complexo e que tende a fornecer melhores resultados, uma vez que realiza uma análise mais completa dos descritores, não se baseando simplesmente em 


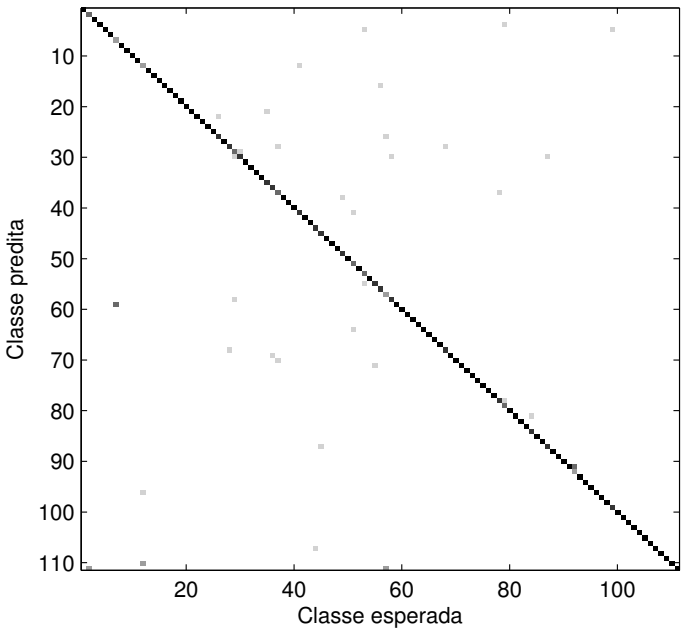

(a)

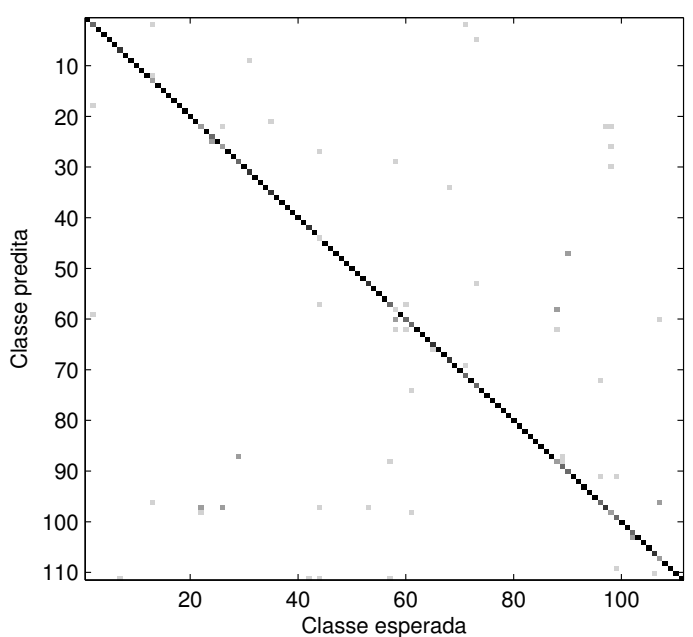

(c)

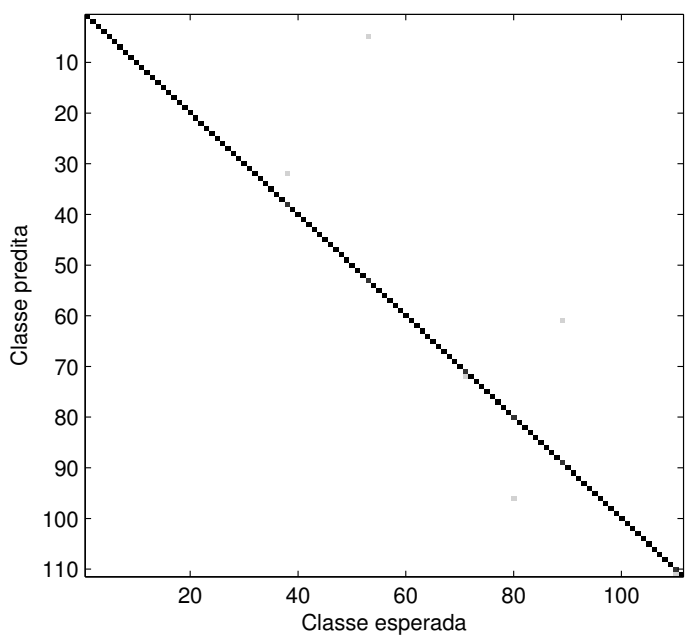

(e)

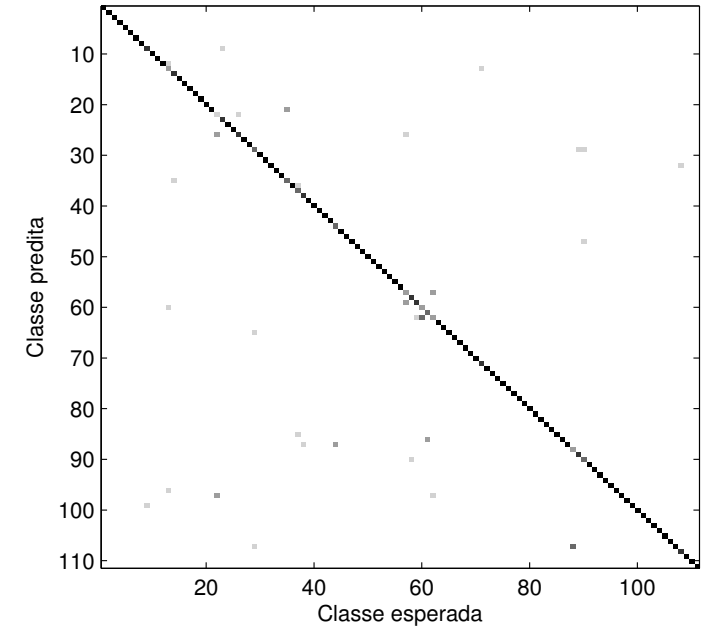

(b)

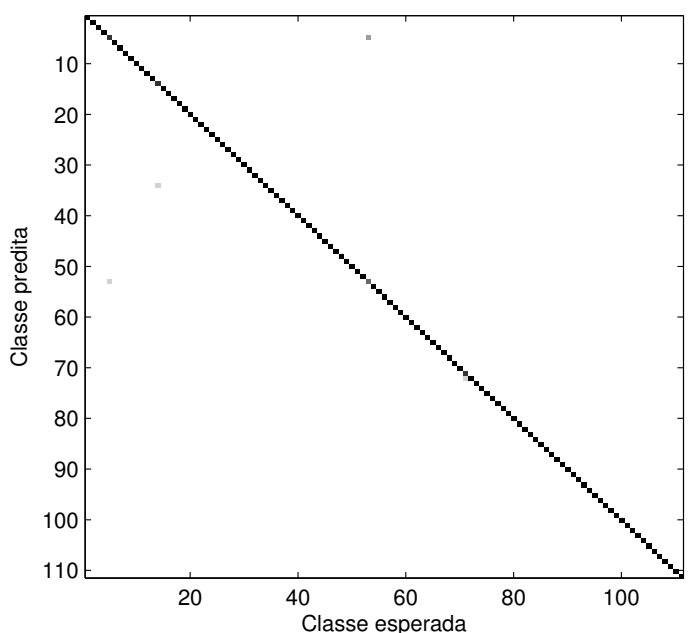

(d)

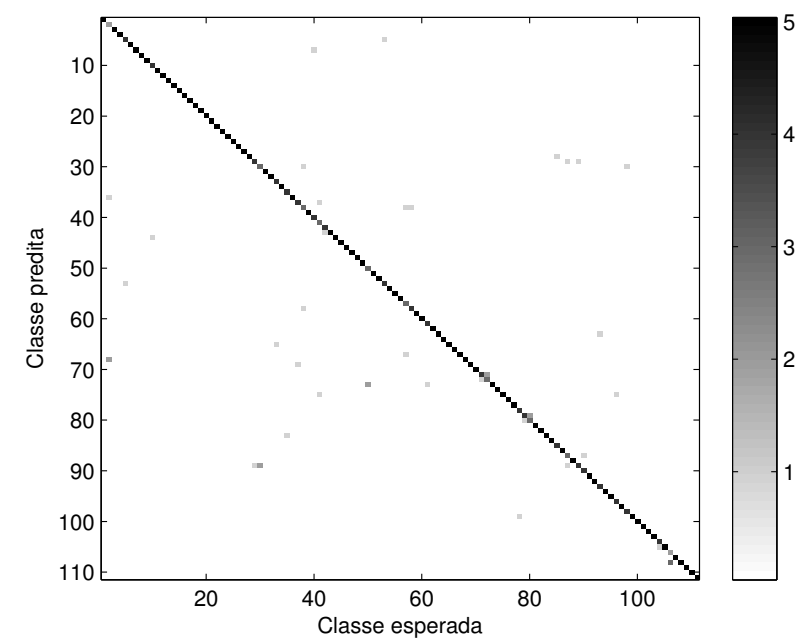

(f)

Figura 7.2 - Matrizes de confusão (parte 1) para os métodos comparados sobre a base de Brodatz, usando classificador KNN. (a) Multifractal 2. (b) LBP. (c) Fourier. (d) BouligandMinkowski. (e) Wavelike. (f) Probabilidade. 


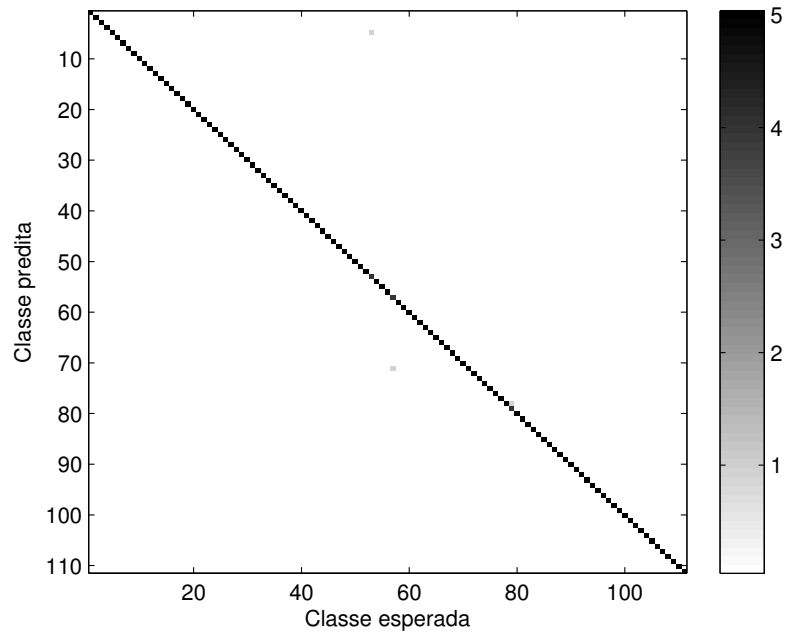

(a)

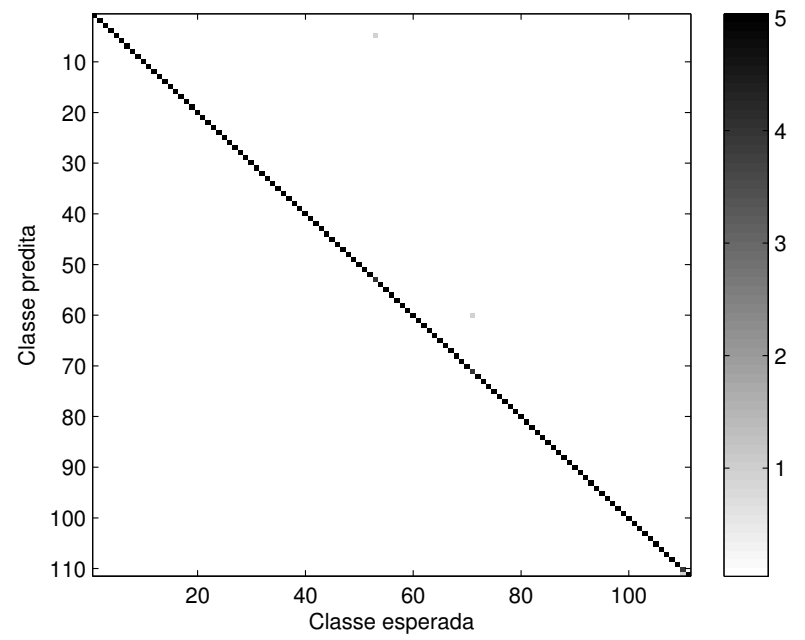

(b)

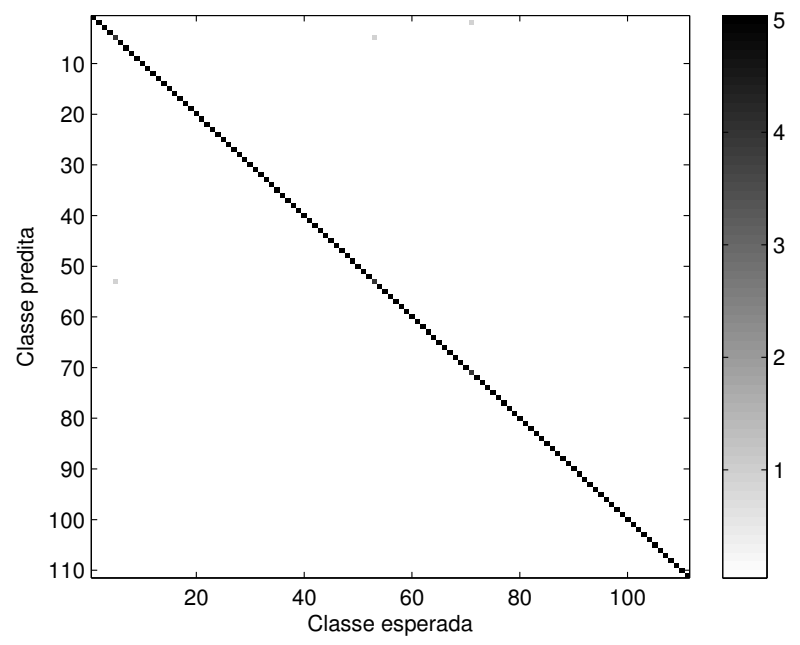

(c)

Figura 7.3 - Matrizes de confusão (parte 2) para os métodos comparados sobre a base de Brodatz, usando classificador KNN. (a) Lacunaridade + Wavelike. (b) Browniano + Wavelike. (c) Fourier + Wavelike. 
distâncias diretas.

A Tabela 7.17 mostra os resultados para o uso direto dos descritores, desta vez usando-se o classificador SVM. Os resultados mostram que, neste caso, o melhor método foi o descritor fractal de Bouligand-Minkowski, além da abordagem de Probabilidade e Wavelike, que obtiveram taxas de acerto idênticas aos métodos de LBP e Fourier clássico. A vantagem das abordagens fractais, neste caso, foram menos evidentes em função da manipulação mais complexa dos dados por parte do classificador. Ocorre que as abordagens fractais apresentam forte correlação em seus dados, dada a natureza acumulativa da construção da curva de fractalidade. Assim, a essência mais relevante destes descritores é revelada por métodos de redução de dimensionalidade, como PCA, e estes resultados serão exibidos em seguida.

Tabela 7.17 - Taxa de acerto para os descritores fractais diretos na base de Brodatz, classificados por SVM.

\begin{tabular}{cccccc}
\hline Método & ND & TA $(\%)$ & $\kappa$ & E1 & E2 \\
\hline LBP & 25 & 98.20 & 0.95 & 0.05 & 0.05 \\
GLCM & 58 & 86.49 & 0.77 & 0.23 & 0.24 \\
Fourier clássico & 37 & 98.20 & 0.91 & 0.09 & 0.09 \\
Gabor & 20 & 92.79 & 0.86 & 0.14 & 0.13 \\
GLDM & 17 & 83.78 & 0.77 & 0.23 & 0.22 \\
Laws & 15 & 81.98 & 0.75 & 0.25 & 0.25 \\
Multifractal 1 & 75 & 52.25 & 0.42 & 0.57 & 0.60 \\
Multifractal 2 & 37 & 88.29 & 0.73 & 0.27 & 0.20 \\
Multifractal 3 & 54 & 80.18 & 0.74 & 0.26 & 0.25 \\
\hline Blanket + TF & 31 & 90.09 & 0.80 & 0.20 & 0.20 \\
Bouligand-Minkowski + TE & 53 & 99.10 & 0.95 & 0.05 & 0.05 \\
Box-counting + TF & 18 & 92.79 & 0.86 & 0.14 & 0.13 \\
Browniano + TF & 32 & 81.08 & 0.70 & 0.30 & 0.30 \\
Fourier + TF & 93 & 90.99 & 0.78 & 0.22 & 0.22 \\
Lacunaridade + TE & 10 & 97.30 & 0.90 & 0.10 & 0.10 \\
Probabilidade + TE & 7 & 98.20 & 0.93 & 0.07 & 0.06 \\
Triangular + TE & 9 & 90.09 & 0.80 & 0.20 & 0.19 \\
Variação + TE & 7 & 71.17 & 0.67 & 0.33 & 0.34 \\
Variograma + FDA & 35 & 90.09 & 0.79 & 0.21 & 0.20 \\
Wavelets + TF & 50 & 93.69 & 0.85 & 0.15 & 0.15 \\
Wavelike + TE & 42 & 98.20 & 0.92 & 0.07 & 0.07 \\
\hline
\end{tabular}

A Tabela 7.18 exibe as taxas de acerto obtidas pelos descritores fractais em sua versão original, sem qualquer tipo de transformação, após redução da dimensionalidade por PCA. A Tabela mostra uma boa taxa de acerto para os descritores de Bouligand-Minkowski, bem como para os descritores de Probabilidade. Um aspecto de certa forma inesperado é que as taxas de acerto em geral diminuíram para este classificador em relação aos resultados para a classificação por KNN. Particularmente, o método de Wavelike apresentou uma queda marcante na taxa de acerto. Essas taxas menores podem ser explicadas pelo uso de uma abordagem diferente de redução de dimensionalidade. O uso de CCA tende a aumentar as taxas de acerto por levar em conta o comportamento da correlação entre as variáveis aleatórias dentro de cada classe. Por outro lado, mesmo com menor taxa, os componentes principais levam a um resultado que pode ser extrapolado mais facilmente para outras bases de imagens. 
Tabela 7.18 - Taxa de acerto para os descritores fractais individuais na base de Brodatz, classificados por SVM.

\begin{tabular}{lccccc}
\hline Método & ND & TA $(\%)$ & $\kappa$ & E1 & E2 \\
\hline Blanket & 10 & 70.09 & 0.70 & 0.30 & 0.27 \\
Bouligand-Minkowski & 20 & 95.86 & 0.96 & 0.04 & 0.04 \\
Box-counting & 7 & 81.62 & 0.81 & 0.18 & 0.15 \\
Browniano & 14 & 43.60 & 0.43 & 0.56 & 0.53 \\
Fourier & 4 & 58.92 & 0.59 & 0.41 & 0.35 \\
Lacunaridade & 9 & 84.86 & 0.85 & 0.15 & 0.13 \\
Probabilidade & 9 & 90.63 & 0.91 & 0.09 & 0.08 \\
Triangular & 13 & 76.76 & 0.77 & 0.23 & 0.21 \\
Variação & 10 & 51.17 & 0.51 & 0.49 & 0.46 \\
Variograma & 10 & 79.46 & 0.79 & 0.21 & 0.17 \\
Wavelets & 5 & 78.92 & 0.79 & 0.21 & 0.18 \\
Wavelike & 17 & 72.07 & 0.72 & 0.28 & 0.23 \\
\hline
\end{tabular}

A Tabela 7.19 exibe as taxas de acerto (com os respectivos números de descritores) para as combinações dois a dois possíveis dos descritores fractais. Excelentes resultados foram obtidos com algumas combinações como Box-counting+Variograma, Blanket+Probabilidade, Lacunaridade + Blanket, entre outros. Estes são exemplos em que os descritores combinados provêem um resultado melhor do que os individuais. Tal fato ocorre quando estes descritores fornecem informações que se complementam, expressando diferentes perspectivas da mesma imagem. É o caso, por exemplo, de Box-counting e Variograma. Enquanto o primeiro representa a complexidade da textura levando em conta a distribuição de pontos na superfície mapeada, o segundo se baseia na diferença entre intensidades de pixels. São dois tipos de informação importantes e que se somam para possibilitar uma classificação altamente precisa.

Tabela 7.19 - Taxa de acerto para os descritores fractais individuais combinados na base de Brodatz, classificados por SVM.

\begin{tabular}{|c|c|c|c|c|c|c|c|c|c|c|c|c|}
\hline & 1 & 2 & 3 & 4 & 5 & 6 & 7 & 8 & 9 & 10 & 11 & 12 \\
\hline 1 & - & $84.32(13)$ & $89.36(16)$ & $61.26(16)$ & $73.15(6)$ & 93.33(15) & 95.31(15) & $85.76(17)$ & 78.19(14) & $89.0(16)$ & $89.54(8)$ & $81.08(20)$ \\
\hline 2 & $84.32(13)$ & - & $93.87(20)$ & $55.67(18)$ & $68.82(4)$ & $94.41(20)$ & $92.61(12)$ & $91.71(20)$ & $83.24(20)$ & $93.69(20)$ & $81.62(6)$ & $77.83(18)$ \\
\hline 3 & $89.36(16)$ & $93.87(20)$ & - & $45.58(9)$ & $70.9(4)$ & $94.41(19)$ & 92.07(18) & $94.23(16)$ & $87.0(14)$ & $96.21(20)$ & $83.06(6)$ & 78.91(17) \\
\hline 4 & $61.26(16)$ & $55.67(18)$ & $45.58(9)$ & - & $65.22(6)$ & $69.18(18)$ & 77.11(19) & $45.76(9)$ & $54.9(16)$ & $49.0(9)$ & 73.33(9) & $66.84(16)$ \\
\hline 5 & $73.15(6)$ & $68.82(4)$ & $70.9(4)$ & $65.22(6)$ & - & $86.48(6)$ & $87.20(6)$ & $68.28(5)$ & 78.91(6) & $75.31(5)$ & $86.66(6)$ & $79.63(10)$ \\
\hline 6 & $93.33(15)$ & $94.41(20)$ & $94.41(19)$ & $69.18(18)$ & $86.48(6)$ & - & $95.49(15)$ & $93.87(20)$ & $91.35(13)$ & $94.59(14)$ & 93.33(11) & $86.84(16)$ \\
\hline 7 & $95.31(15)$ & $92.61(12)$ & $92.07(18)$ & 77.11(19) & $87.20(6)$ & $95.49(15)$ & - & $94.77(13)$ & $93.69(12)$ & $95.67(20)$ & 95.31(11) & $88.28(19)$ \\
\hline 8 & $85.76(17)$ & $91.71(20)$ & $94.23(16)$ & $45.76(9)$ & $68.28(5)$ & $93.87(20)$ & $94.77(13)$ & - & $85.22(12)$ & $89.36(18)$ & $82.16(6)$ & $82.16(16)$ \\
\hline 9 & $78.19(14)$ & $83.24(20)$ & $87.0(14)$ & $54.9(16)$ & 78.91(6) & $91.35(13)$ & $93.69(12)$ & $85.22(12)$ & - & $89.54(14)$ & $88.28(7)$ & $76.57(20)$ \\
\hline 10 & $89.0(16)$ & $93.69(20)$ & $96.21(20)$ & $49.0(9)$ & $75.31(5)$ & $94.59(14)$ & $95.67(20)$ & $89.36(18)$ & $89.54(14)$ & - & 89.36(9) & $85.0(19)$ \\
\hline 11 & $89.54(8)$ & $81.62(6)$ & $83.06(6)$ & $73.33(9)$ & $86.66(6)$ & $93.33(11)$ & $95.31(11)$ & $82.16(6)$ & $88.28(7)$ & $89.36(9)$ & - & $83.60(11)$ \\
\hline 12 & $81.08(20)$ & $77.83(18)$ & 78.91(17) & $66.84(16)$ & $79.63(10)$ & $86.84(16)$ & $88.28(19)$ & $82.16(16)$ & $76.57(20)$ & $85.0(19)$ & $83.60(11)$ & - \\
\hline
\end{tabular}


Já a Tabela 7.20 ilustra as taxas de acerto obtidas pelos descritores fractais após a execução da transformada FDA. Os resultados são similares aos obtidos pelos descritores originais, havendo pequenas diferenças para mais ou para menos, que podem ser explicadas pelo erro inerente ao experimento. Contudo, chama atenção o comportamento dos descritores espectrais (Fourier e Wavelets). Estes apresentaram uma forte queda na taxa de acerto, quando comparados aos descritores sem transformação. Isso confirma que a informação de frequência não é representada satisfatoriamente pelos coeficientes funcionais. Tal falha é justificada sob dois aspectos. O primeiro é que estes descritores apresentam micro-padrões de variação (de frequências) que são atenuados ou mesmo eliminados no processo de transformação FDA. O segundo é que o espectro de potência representa uma medida indireta da complexidade e os coeficientes FDA, que estão em um terceiro espaço, não apresentam a mesma significância dos descritores individuais.

Tabela 7.20 - Taxa de acerto para os descritores fractais FDA na base de Brodatz, classificados por SVM.

\begin{tabular}{lccccc}
\hline Método & ND & TA $(\%)$ & $\kappa$ & E1 & E2 \\
\hline Blanket & 12 & 69.91 & 0.70 & 0.30 & 0.26 \\
Bouligand-Minkowski & 17 & 95.50 & 0.95 & 0.05 & 0.04 \\
Box-counting & 7 & 81.80 & 0.82 & 0.18 & 0.15 \\
Browniano & 11 & 43.96 & 0.44 & 0.56 & 0.51 \\
Fourier & 2 & 35.68 & 0.36 & 0.64 & 0.60 \\
Lacunaridade & 9 & 84.14 & 0.84 & 0.16 & 0.14 \\
Probabilidade & 10 & 89.91 & 0.90 & 0.10 & 0.09 \\
Triangular & 13 & 77.30 & 0.77 & 0.23 & 0.20 \\
Variação & 10 & 53.51 & 0.53 & 0.46 & 0.41 \\
Variograma & 13 & 79.28 & 0.79 & 0.21 & 0.19 \\
Wavelets & 7 & 64.50 & 0.64 & 0.35 & 0.32 \\
Wavelike & 15 & 71.53 & 0.71 & 0.28 & 0.24 \\
\hline
\end{tabular}

A Tabela 7.21 exibe as taxas de acerto para os descritores fractais combinados dois a dois. Algumas combinações apresentaram maior taxa de acerto em relação à original. É o caso de Blanket+Box-counting, Blanket+Bouligand-Minkowski, Blanket+Wavelike, entre outros. O método de Blanket constrói uma mapa mais global da imagem em cada nível, sem ser significativamente influenciado por irregularidades locais, o que faz com que a aplicação de FDA não danifique, mas realce aspectos importantes da informação.

Tabela 7.21 - Taxa de acerto para os descritores fractais FDA combinados na base de Brodatz, classificados por SVM.

\begin{tabular}{lcccccccccccc}
\hline & $\mathbf{1}$ & $\mathbf{2}$ & $\mathbf{3}$ & $\mathbf{4}$ & $\mathbf{5}$ & $\mathbf{6}$ & $\mathbf{7}$ & $\mathbf{8}$ & $\mathbf{9}$ & $\mathbf{1 0}$ & $\mathbf{1 1}$ & $\mathbf{1 2}$ \\
\hline $\mathbf{1}$ & - & $84.32(13)$ & $93.87(17)$ & $56.39(13)$ & $51.71(3)$ & $92.79(15)$ & $93.69(16)$ & $86.84(19)$ & $75.13(18)$ & $90.9(19)$ & $83.24(10)$ & $80.90(20)$ \\
$\mathbf{2}$ & $84.32(13)$ & - & $94.05(20)$ & $48.10(12)$ & $47.56(3)$ & $94.77(20)$ & $91.71(20)$ & $91.53(20)$ & $81.80(20)$ & $93.87(19)$ & $74.9(8)$ & $78.0(20)$ \\
$\mathbf{3}$ & $93.87(17)$ & $94.05(20)$ & - & $60.72(17)$ & $56.0(3)$ & $94.41(19)$ & $92.07(13)$ & $94.05(15)$ & $86.84(15)$ & $96.21(20)$ & $81.62(12)$ & $83.60(17)$ \\
$\mathbf{4}$ & $56.39(13)$ & $48.10(12)$ & $60.72(17)$ & - & $46.12(17)$ & $74.05(16)$ & $79.27(15)$ & $54.59(14)$ & $61.80(14)$ & $67.0(15)$ & $69.72(10)$ & $55.85(14)$ \\
$\mathbf{5}$ & $51.71(3)$ & $47.56(3)$ & $56.0(3)$ & $46.12(17)$ & - & $76.0(5)$ & $78.0(5)$ & $50.09(7)$ & $58.73(8)$ & $73.15(6)$ & $72.61(6)$ & $52.61(6)$ \\
$\mathbf{6}$ & $92.79(15)$ & $94.77(20)$ & $94.41(19)$ & $74.05(16)$ & $76.0(5)$ & - & $94.77(11)$ & $93.15(13)$ & $90.27(14)$ & $96.0(16)$ & $90.45(14)$ & $87.92(19)$ \\
$\mathbf{7}$ & $93.69(16)$ & $91.71(20)$ & $92.07(13)$ & $79.27(15)$ & $78.0(5)$ & $94.77(11)$ & - & $94.77(18)$ & $92.25(12)$ & $95.67(17)$ & $94.23(14)$ & $88.10(15)$ \\
$\mathbf{8}$ & $86.84(19)$ & $91.53(20)$ & $94.05(15)$ & $54.59(14)$ & $50.09(7)$ & $93.15(13)$ & $94.77(18)$ & - & $81.9(13)$ & $88.28(18)$ & $84.32(11)$ & $82.34(20)$ \\
$\mathbf{9}$ & $75.13(18)$ & $81.80(20)$ & $86.84(15)$ & $61.80(14)$ & $58.73(8)$ & $90.27(14)$ & $92.25(12)$ & $81.9(13)$ & - & $90.45(14)$ & $83.9(11)$ & $71.35(18)$ \\
$\mathbf{1 0}$ & $90.9(19)$ & $93.87(19)$ & $96.21(20)$ & $67.0(15)$ & $73.15(6)$ & $96.0(16)$ & $95.67(17)$ & $88.28(18)$ & $90.45(14)$ & - & $87.56(11)$ & $86.48(19)$ \\
$\mathbf{1 1}$ & $83.24(10)$ & $74.9(8)$ & $81.62(12)$ & $69.72(10)$ & $72.61(6)$ & $90.45(14)$ & $94.23(14)$ & $84.32(11)$ & $83.9(11)$ & $87.56(11)$ & - & $78.37(10)$ \\
$\mathbf{1 2}$ & $80.90(20)$ & $78.0(20)$ & $83.60(17)$ & $55.85(14)$ & $52.61(6)$ & $87.92(19)$ & $88.10(15)$ & $82.34(20)$ & $71.35(18)$ & $86.48(19)$ & $78.37(10)$ & - \\
\hline
\end{tabular}


Já a Tabela 7.22 explicita os resultados para os descritores fractais transformados por espaço-escala. Mais uma vez, existem melhoras e pioras no desempenho dos descritores em cada situação. Destaca-se a queda brusca do método de Blanket, que se deve à forte correlação entre as variáveis que gera resultados deformados para os componentes canônicos. Por sua vez, o método de Wavelike, neste caso, apresentou maior taxa de acerto do que com o uso dos descritores individuais. Esta solução apresenta uma natureza de formação diferente dos demais métodos fractais aqui presentes, uma vez que não se baseia nos valores extraídos diretamente da curva de fractalidade, mas sim em valores de entropia dos descritores de Bouligand-Minkowski em diferentes níveis de escala. Assim, a derivada constitui um ferramental importante na expressão desses dados que não são intrinsicamente relacionados.

Tabela 7.22 - Taxa de acerto para os descritores fractais espaço-escala na base de Brodatz, classificados por SVM.

\begin{tabular}{lccccc}
\hline Método & ND & TA $(\%)$ & $\kappa$ & E1 & E2 \\
\hline Blanket & 9 & 8.11 & 0.08 & 0.92 & 0.93 \\
Bouligand-Minkowski & 20 & 95.86 & 0.96 & 0.04 & 0.03 \\
Box-counting & 6 & 79.28 & 0.79 & 0.21 & 0.17 \\
Browniano & 16 & 50.63 & 0.50 & 0.49 & 0.42 \\
Fourier & 13 & 49.73 & 0.50 & 0.50 & 0.48 \\
Lacunaridade & 8 & 80.36 & 0.80 & 0.20 & 0.16 \\
Probabilidade & 7 & 88.47 & 0.88 & 0.12 & 0.09 \\
Triangular & 14 & 75.32 & 0.75 & 0.25 & 0.22 \\
Variação & 7 & 55.14 & 0.55 & 0.45 & 0.40 \\
Variograma & 11 & 66.85 & 0.67 & 0.33 & 0.27 \\
Wavelets & 9 & 49.19 & 0.49 & 0.51 & 0.49 \\
Wavelike & 16 & 96.94 & 0.97 & 0.03 & 0.02 \\
\hline
\end{tabular}

A Tabela 7.23 mostra as taxas de acerto para os descritores combinados dois a dois. Os resultados refletem também as taxas de acerto alcançadas por cada descritor individualmente. Assim, métodos como Wavelike e Lacunaridade apresentaram melhora sensível em suas combinações, ao passo que as combinações envolvendo Blanket tiveram desempenho ruim. Entre as melhores abordagens, pode se selecionar as melhores para assim obter uma classificação mais precisa, usando-se muitas vezes um número reduzido de descritores.

Tabela 7.23 - Taxa de acerto para os descritores fractais espaço-escala combinados na base de Brodatz, classificados por SVM.

\begin{tabular}{|c|c|c|c|c|c|c|c|c|c|c|c|c|}
\hline & 1 & 2 & 3 & 4 & 5 & 6 & 7 & 8 & 9 & 10 & 11 & 12 \\
\hline 1 & & $5.94(19)$ & $3.15(18)$ & $7.38(16)$ & $30(20)$ & $8.64(20)$ & $19.09(9)$ & $12.9(20)$ & $6.84(7)$ & $18.91(8)$ & $9.18(14)$ & $7.20(20)$ \\
\hline 2 & $5.94(19)$ & & $.67(15)$ & $83.06(19)$ & & & $97.47(12)$ & $93.33(20)$ & $95.85(17)$ & $92.9(2$ & & $31(18)$ \\
\hline 3 & & $67(15)$ & & & & & & & & & & \\
\hline 4 & & ) & $85.22(18)$ & & 52.61( & 87 & $93.15(15)$ & 19) & & 72.2 & & \\
\hline 5 & & & & $52.61(15)$ & & $.37(17)$ & & & & & & \\
\hline 6 & & $.0(18)$ & $93.15(15)$ & $87.0(15)$ & $5837(17)$ & - & $94.9(15)$ & & & & & \\
\hline 7 & & & & & & 0 & - & 5) & & & & \\
\hline 8 & & b) & 93.15( & 73.3 & & & & - & $84.32(14)$ & & & \\
\hline 9 & & & & & & & & & - & 84.32(13) & & \\
\hline 10 & & $92.9(20)$ & 77 & 72.2 & & & & & & - & 14) & \\
\hline 11 & $18(14)$ & $1.89(20)$ & $73.87(20)$ & $65.58(12)$ & 62.52( & & $81.26(18)$ & 69.36 & $66.48(10)$ & $72.9(14)$ & & $72.07(19)$ \\
\hline 12 & ( & $95.31(18)$ & $95.67(15)$ & $80.18(17)$ & $52.43(14)$ & $96.21(18)$ & $98.0(12)$ & $95.31(20)$ & $95.85(19)$ & $95.31(20)$ & $72.07(19)$ & \\
\hline
\end{tabular}

A Tabela 7.24 expressa as taxas de acerto, números de descritores e medidas estatísticas para os descritores fractais transformados por tempo-frequência. Na maior parte das situações, 
nota-se um incremento na taxa de acerto alcançada. Este ganho é ainda mais robusto em métodos como Browniano e Wavelike. Sendo baseado na distribuição estatística das intensidades dos pixels a distâncias variáveis dentro da imagem, o método de Browniano é menos suscetível à homogeneidade local comum nas texturas naturais e pode apresentar comportamentos periódicos com diferentes frequências em diferentes pontos, tornando a análise por transformada de Gabor eficiente. Já o método Wavelike se baseia em valores multiescala de entropias dos descritores de Bouligand-Minkowski, valores estes que também apresentam padrões de frequência mais interessantes para o classificador do que o próprio descritor original.

Tabela 7.24 - Taxa de acerto para os descritores fractais tempo-frequência na base de Brodatz, classificados por SVM.

\begin{tabular}{lccccc}
\hline Método & ND & TA $(\%)$ & $\kappa$ & E1 & E2 \\
\hline Blanket & 7 & 73.87 & 0.74 & 0.26 & 0.22 \\
Bouligand-Minkowski & 16 & 96.04 & 0.96 & 0.04 & 0.03 \\
Box-counting & 7 & 82.52 & 0.82 & 0.17 & 0.14 \\
Browniano & 14 & 62.16 & 0.62 & 0.38 & 0.31 \\
Fourier & 12 & 57.12 & 0.57 & 0.43 & 0.39 \\
Lacunaridade & 12 & 84.14 & 0.84 & 0.16 & 0.14 \\
Probabilidade & 8 & 90.81 & 0.91 & 0.09 & 0.08 \\
Triangular & 13 & 77.12 & 0.77 & 0.23 & 0.21 \\
Variação & 10 & 53.15 & 0.53 & 0.47 & 0.42 \\
Variograma & 11 & 80.36 & 0.80 & 0.20 & 0.16 \\
Wavelets & 6 & 75.50 & 0.75 & 0.25 & 0.21 \\
Wavelike & 19 & 96.04 & 0.96 & 0.04 & 0.02 \\
\hline
\end{tabular}

A Tabela 7.25 ilustra as taxas de acerto e números de descritores usados para cada combinação entre os diferentes métodos de descritores fractais propostos, associados à transformação de tempo-frequência. Assim como no uso dos descritores individuais, a maioria dos resultados foi melhorada em relação aos descritores sem transformação. Destacam-se as combinações envolvendo os descritores de Bouligand-Minkowski, Wavelike e Probabilidade. Mais uma vez, surgem casos interessantes em que dois métodos com taxas de acerto bem menores juntam-se para compor um descritor poderoso para texturas. Um exemplo ilustrativo é a combinação Blanket+Probabilidade que alcança 97.65\% de acerto, enquanto Probabilidade obtinha $90.81 \%$ e Blanket apenas $73.87 \%$, quando aplicados individualmente. Embora ambas sejam abordagens espaciais, diferenciam-se na informação extraída, pois enquanto Blanket se baseia na morfologia da superfície de intensidade, o método de Probabilidade é estatístico e detecta melhor aspectos mais globais.

Ainda tratando dos descritores transformados, a Tabela 7.26 exibe os resultados para a transformada tempo-escala. O efeito da transformada é altamente variável de método para método. De fato, cada transformação deve ser testada em cada caso para uma melhor avaliação de qual estratégia é mais eficaz. Neste caso, os métodos de frequência apresentaram queda substancial nas taxas de acerto. Esta queda se explica, como apontado anteriormente, 
Tabela 7.25 - Taxa de acerto para os descritores fractais tempo-frequência combinados na base de Brodatz, classificados por SVM.

\begin{tabular}{|c|c|c|c|c|c|c|c|c|c|c|c|c|}
\hline & 1 & 2 & 3 & 4 & 5 & 6 & 7 & 8 & 9 & 10 & 11 & 12 \\
\hline 1 & - & $96.39(17)$ & $94.77(13)$ & $72.61(15)$ & $85.0(11)$ & $94.05(19)$ & $97.65(19)$ & $88.28(18)$ & $78.19(15)$ & $91.89(18)$ & $91.35(9)$ & $96.75(13)$ \\
\hline 2 & $96.39(17)$ & - & $96.21(15)$ & $95.13(17)$ & 96.93(18) & $97.29(19)$ & $98.19(16)$ & $96.0(14)$ & $95.85(15)$ & $96.57(19)$ & 97.11(19) & $96.39(14)$ \\
\hline 3 & $94.77(13)$ & $96.21(15)$ & & $.73(19)$ & 87.0 & & & & & & & \\
\hline 4 & 72.61(1 & $5.13(17)$ & 78.73(19) & - & $74.41(1 \mathrm{C}$ & 90.81 & 94.59 & $68.28(11)$ & $74.77(20)$ & (10) & $85.58(11)$ & $84.50(20)$ \\
\hline 5 & 85 & $5.93(18)$ & $87.0(18)$ & $74.41(10)$ & & $90.81(14)$ & & & & & & \\
\hline 6 & $94.05(1$ & $97.29(19)$ & 95.1 & $90.81(13)$ & $90.81(14)$ & & $95.49(17)$ & $92.9(16)$ & $90.81(14)$ & $93.69(19)$ & $5(14)$ & (18) \\
\hline 7 & & & 96.3 & & & 5.4 & - & $97.29(13)$ & & & & \\
\hline 8 & $88.28(18)$ & $96.0(14)$ & $94.41(15)$ & $68.28(11)$ & $80.90(12)$ & $92.9(16)$ & $97.29(13)$ & & $82.34(17)$ & $84.32(18)$ & $87.92(10)$ & $96.57(18)$ \\
\hline 9 & & & & & & & & $82.34(17)$ & - & $89.90(16)$ & & \\
\hline 10 & $91.89(18)$ & $96.57(19)$ & $96.21(20)$ & $77.83(10)$ & $81.62(15)$ & $93.69(19)$ & $98.0(16)$ & $84.32(18)$ & $89.90(16)$ & - & $89.36(13)$ & $96.21(18)$ \\
\hline 11 & & & & & & $94.05(14)$ & & $87.92(10)$ & & $9.36(13)$ & - & 94.9(11) \\
\hline 12 & $96.75(13)$ & $96.39(14)$ & $96.57(17)$ & $84.50(20)$ & $91.35(16)$ & $96.21(18)$ & $97.11(14)$ & $96.57(18)$ & $94.05(18)$ & $96.21(18)$ & $94.9(11)$ & \\
\hline
\end{tabular}

pela dificuldade de interpretação do descritor após duas análises sobrepostas de frequência. Diferentemente do que ocorria com o classificador KNN, em que o método de Wavelets teve até uma pequena melhora após a aplicação desta transformada, o classificador SVM envolve um esquema de aprendizado mais complexo, que faz com que a interpretação incorreta se propague pelos estágios da classificação e comprometa fortemente a eficácia do método. Assim como ocorreu na transformação tempo-frequência, o método de Wavelike obteve significativa melhora, novamente pela natureza menos inter-relacionada daqueles descritores.

Tabela 7.26 - Taxa de acerto para os descritores fractais tempo-escala na base de Brodatz, classificados por SVM.

\begin{tabular}{lccccc}
\hline Método & ND & TA $(\%)$ & $\kappa$ & E1 & E2 \\
\hline Blanket & 15 & 49.19 & 0.49 & 0.51 & 0.47 \\
Bouligand-Minkowski & 17 & 95.68 & 0.96 & 0.04 & 0.03 \\
Box-counting & 7 & 82.34 & 0.82 & 0.18 & 0.15 \\
Browniano & 15 & 59.64 & 0.59 & 0.40 & 0.35 \\
Fourier & 16 & 14.41 & 0.14 & 0.86 & 0.85 \\
Lacunaridade & 8 & 83.24 & 0.83 & 0.17 & 0.14 \\
Probabilidade & 8 & 93.33 & 0.93 & 0.07 & 0.06 \\
Triangular & 10 & 74.77 & 0.75 & 0.25 & 0.20 \\
Variação & 7 & 55.14 & 0.55 & 0.45 & 0.39 \\
Variograma & 8 & 75.68 & 0.76 & 0.24 & 0.21 \\
Wavelets & 20 & 36.04 & 0.36 & 0.64 & 0.58 \\
Wavelike & 17 & 95.68 & 0.96 & 0.04 & 0.03 \\
\hline
\end{tabular}

O resultado para os descritores combinados dois a dois é explicitado na Tabela 7.27. Os números apresentam novamente um ganho em alguns casos relevante para o uso da combinação de métodos. Interessante aqui observar um fenômeno que ocorre também em combinações de descritores individuais ou com outros tipos de transformações. Trata-se dos casos em que o acerto da combinação é menor do que o dos descritores separadamente. Nesta tabela, vê-se isto na combinação Blanket+Probabilidade. Nestas situações, os descritores se interferem mutuamente de forma negativa, sendo que um camufla a informação expressa pelo outro. Isso ocorre, por exemplo, quando os atributos apresentam comportamento conflitante, que persiste quando se analisa as variâncias inter-variáveis na redução de dimensionalidade. 
Tabela 7.27 - Taxa de acerto para os descritores fractais tempo-escala combinados na base de Brodatz, classificados por SVM.

\begin{tabular}{|c|c|c|c|c|c|c|c|c|c|c|c|c|}
\hline & 1 & 2 & 3 & 4 & 5 & 6 & 7 & 8 & 9 & 10 & 11 & 12 \\
\hline 1 & - & $63.24(20)$ & $56.57(15)$ & $54.05(20)$ & $49.18(14)$ & $65.22(20)$ & $49.0(15)$ & $49.18(15)$ & $49.18(14)$ & $56.39(16)$ & $50.63(20)$ & $56.0(15)$ \\
\hline 2 & $63.24(20)$ & - & $94.9(14)$ & $92.9(13)$ & $62.16(4)$ & $95.85(16)$ & $96.57(20)$ & $95.31(20)$ & $95.67(18)$ & $95.85(19)$ & $77.65(8)$ & $94.9(19)$ \\
\hline 3 & $56.57(15)$ & $94.9(14)$ & & $90.45(20)$ & 28.64(9) & $95.13(18)$ & $97.47(14)$ & $94.41(17)$ & $90.81(12)$ & $95.49(14)$ & $50.09(14)$ & $95.49(20)$ \\
\hline 4 & $54.05(20)$ & $92.9(13)$ & $90.45(20)$ & & $34.59(8)$ & $90.63(15)$ & $91.35(20)$ & $76.75(9)$ & $80.54(18)$ & $80.54(17)$ & $61.80(9)$ & $91.89(16)$ \\
\hline 5 & $49.18(14)$ & $62.16(4)$ & $28.64(9)$ & $34.59(8)$ & - & $62.70(10)$ & $14.77(16)$ & $23.24(8)$ & $21.08(5)$ & $32.43(9)$ & (13) & $41.08(7)$ \\
\hline 6 & $65.22(20)$ & $95.85(16)$ & $95.13(18)$ & $90.63(15)$ & $62.70(10)$ & - & $95.13(19)$ & $92.61(17)$ & $90.45(14)$ & $93.69(18)$ & $76.57(12)$ & $94.77(20)$ \\
\hline 7 & $49.0(15)$ & $96.57(20)$ & $97.47(14)$ & $91.35(20)$ & $14.77(16)$ & $95.13(19)$ & - & $97.65(18)$ & $95.67(15)$ & $97.47(16)$ & $49.90(20)$ & $97.47(15)$ \\
\hline 8 & $49.18(15)$ & $95.31(20)$ & $94.41(17)$ & $76.75(9)$ & $23.24(8)$ & $92.61(17)$ & $97.65(18)$ & - & $86.30(13)$ & $86.48(18)$ & $53.69(20)$ & $96.57(20)$ \\
\hline 9 & $49.18(14)$ & $95.67(18)$ & $90.81(12)$ & $80.54(18)$ & $21.08(5)$ & $90.45(14)$ & $95.67(15)$ & $86.30(13)$ & & $87.20(12)$ & $46.84(17)$ & $95.49(18)$ \\
\hline 10 & $56.39(16)$ & $95.85(19)$ & $95.49(14)$ & $80.54(17)$ & $32.43(9)$ & $93.69(18)$ & $97.47(16)$ & $86.48(18)$ & $87.20(12)$ & - & $62.52(8)$ & $96.75(17)$ \\
\hline 11 & $50.63(20)$ & $77.65(8)$ & $50.09(14)$ & $61.80(9)$ & (13) & $76.57(12)$ & $49.90(20)$ & $53.69(20)$ & $46.84(17)$ & $62.52(8)$ & - & $71.89(8)$ \\
\hline 12 & $56.0(15)$ & 94.9(19) & $95.49(20)$ & $91.89(16)$ & $41.08(7)$ & $94.77(20)$ & $97.47(15)$ & $96.57(20)$ & $95.49(18)$ & $96.75(17)$ & $71.89(8)$ & - \\
\hline
\end{tabular}

\subsubsection{Outros Métodos}

A Tabela 7.28 ilustra o desempenho dos demais métodos comparados neste trabalho, neste caso, métodos abordados na literatura de análise de texturas. Mais uma vez, o método LBP se sobressai confirmando as indicações da literatura (105). Métodos clássicos e consagrados, como Fourier e GLCM, também fornecem excelentes resultados para a classificação desta base. Já as abordagens mais recentes em multifractais tiveram desempenho abaixo do esperado em relação ao resultado apresentado em outras aplicações. Esta queda pode ser explicada, sobretudo pela menor flexibilidade (forte dependência de parâmetros) desta abordagem e menor capacidade de expressar propriedades globais, pois ficam atrelados a funções de densidade mais localizadas.

Tabela 7.28 - Taxa de acerto para os métodos da literatura na base de Brodatz, classificados por SVM.

\begin{tabular}{lccccc}
\hline Método & ND & TA $(\%)$ & $\kappa$ & E1 & E2 \\
\hline Fourier & 17 & 88.11 & 0.88 & 0.12 & 0.10 \\
GLCM & 18 & 89.91 & 0.90 & 0.10 & 0.08 \\
GLDM & 15 & 81.08 & 0.81 & 0.19 & 0.17 \\
Gabor & 12 & 86.67 & 0.87 & 0.13 & 0.12 \\
LBP & 16 & 93.33 & 0.93 & 0.07 & 0.06 \\
Laws & 13 & 87.75 & 0.88 & 0.12 & 0.11 \\
Multifractal 1 & 12 & 50.27 & 0.50 & 0.50 & 0.44 \\
Multifractal 2 & 13 & 64.32 & 0.64 & 0.36 & 0.33 \\
Multifractal 3 & 7 & 43.96 & 0.44 & 0.56 & 0.50 \\
\hline
\end{tabular}

\subsubsection{Resumo dos Resultados}

A Tabela 7.29 resume os resultados obtidos para a base de Brodatz, com o classificador SVM. Os resultados para os descritores fractais apresentaram ligeira queda em relação à classificação por KNN. Como apontado, esta queda se deve ao método de redução de dimensionalidade escolhido em cada caso, uma vez que a transformada CCA usa informação da correlação em relação a cada classe tratada separadamente, agregando assim mais informação relevante para o classificador. 
Em relação aos descritores fractais, os métodos de Bouligand-Minkowski, Wavelike e Probabilidade fizeram frente aos métodos da literatura, superando aqueles com maior taxa de acerto e/ou menor número de descritores. O método de Bouligand-Minkowski tem seu poder de descrição e discriminação de texturas derivado do potencial de seus descritores na representação da morfologia topológica da textura, característica esta que está fortemente associada a propriedades físicas do material que deu origem à imagem desta textura, como rugosidade, porosidade, luminosidade, etc. O arranjo de pixels medido por esta abordagem também está relacionado à identificação de padrões no sistema visual humano (80). Já o método de Wavelike é derivado dos descritores de Bouligand-Minkowski, embora a análise multiníveis da imagem tenha demonstrado potencial para incrementar o resultado daquele método. Por sua vez, o método de Probabilidade representa outro paradigma de representação estatística da complexidade da textura e também é capaz de expressar informações ricas para o classificador sobre a distribuição de detalhes ao longo de diferentes níveis de escala na imagem.

Por fim, as melhores combinações demonstram o potencial de associação entre os descritores de Bouligand-Minkowski/Wavelike e Probabilidade, com suas diferentes perspectivas sobre o mesmo dado. Ainda neste caso, nota-se a existência de mais de uma dezena de combinações que alcançaram resultados melhores que outros métodos na literatura, mesmo usando um número baixo de descritores nesta base de texturas. Como já observado, os bons descritores e mesmo aqueles que não possuem eficiência tão alta se sobressaem quando combinados dentro do método de redução de dimensionalidade, uma vez que cada descritor fornece visões diferentes e complementares da textura.

A Figura 7.4 ilustra em um gráfico a relação entre as taxas de acerto obtidas e o número de descritores usados pelas melhores abordagens comparadas. No geral, as curvas mostram-se comportadas e com aspecto dentro do esperado para a aplicação de PCA, com rápido crescimento, seguido de estabilização. Entre os descritores individuais, o método de Probabilidade se destaca por obter resultados próximos de $90 \%$ usando apenas 5 descritores. Este é um feito relevante considerando-se uma base de mais de 100 classes. Observa-se ainda que para o caso de descritores combinados, são necessários mais atributos para alcançar os melhores resultados. Este é um efeito da combinação de dados de naturezas diferentes, aumentando o número de componentes com variância significativa.

Finalmente, as Figuras 7.5 e 7.6 exibem as matrizes de confusão correspondentes aos meIhores resultados obtidos para os métodos comparados. Enquanto até mesmo LBP apresentou deficiências em algumas classes como a 62, os descritores fractais apresentam diagonais mais homogêneas, demonstrando que os erros estão mais bem distribuídos ao longo da base, como também confirmado pelo formato esparso e sem agrupamentos dos pontos fora desta diagonal. 
Tabela 7.29 - Resumo das taxas de acerto obtidas para a base de Brodatz, classificada por SVM.

\begin{tabular}{lccccc}
\hline Método & ND & TA $(\%)$ & $\kappa$ & E1 & E2 \\
\hline LBP & 16 & 93.33 & 0.93 & 0.07 & 0.06 \\
GLCM & 18 & 89.91 & 0.90 & 0.10 & 0.08 \\
Fourier & 17 & 88.11 & 0.88 & 0.12 & 0.10 \\
Laws & 13 & 87.75 & 0.88 & 0.12 & 0.11 \\
Gabor & 12 & 86.67 & 0.87 & 0.13 & 0.12 \\
GLDM & 15 & 81.08 & 0.81 & 0.19 & 0.17 \\
Multifractal 2 & 13 & 64.32 & 0.64 & 0.36 & 0.33 \\
Multifractal 1 & 12 & 50.27 & 0.50 & 0.50 & 0.44 \\
Multifractal 3 & 7 & 43.96 & 0.44 & 0.56 & 0.50 \\
\hline \hline Wavelike + EE & 16 & 96.94 & 0.97 & 0.03 & 0.02 \\
Bouligand-Minkowski + TF & 16 & 96.04 & 0.96 & 0.04 & 0.03 \\
Probabilidade + TE & 8 & 93.33 & 0.93 & 0.07 & 0.06 \\
Lacunaridade & 9 & 84.86 & 0.85 & 0.15 & 0.13 \\
Box-counting + TF & 7 & 82.52 & 0.82 & 0.17 & 0.14 \\
Variograma + TF & 11 & 80.36 & 0.80 & 0.20 & 0.16 \\
Wavelets & 5 & 78.92 & 0.79 & 0.21 & 0.18 \\
Triangular + FDA & 13 & 77.30 & 0.77 & 0.23 & 0.20 \\
Blanket + TF & 7 & 73.87 & 0.74 & 0.26 & 0.22 \\
Browniano + TF & 14 & 62.16 & 0.62 & 0.38 & 0.31 \\
Fourier & 4 & 58.92 & 0.59 & 0.41 & 0.35 \\
Variação + EE & 7 & 55.14 & 0.55 & 0.45 & 0.40 \\
\hline Bouligand-Minkowski+Probabilidade + TF & 16 & 98.20 & 0.98 & 0.02 & 0.01 \\
Probabilidade+Wavelike + EE & 12 & 98.02 & 0.98 & 0.02 & 0.02 \\
Probabilidade+Triangular + TE & 18 & 97.66 & 0.98 & 0.02 & 0.02 \\
Blanket+Probabilidade + TF & 19 & 97.66 & 0.98 & 0.02 & 0.02 \\
Box-counting+Probabilidade + TE & 14 & 97.48 & 0.97 & 0.03 & 0.02 \\
Probabilidade+Wavelets + TF & 13 & 97.30 & 0.97 & 0.03 & 0.02 \\
Bouligand-Minkowski+Lacunaridade + TF & 19 & 97.30 & 0.97 & 0.03 & 0.02 \\
Box-counting+Variograma & 20 & 96.22 & 0.96 & 0.04 & 0.03 \\
Probabilidade+Variação + TE & 15 & 95.68 & 0.96 & 0.04 & 0.04 \\
Fourier+Probabilidade & 11 & 95.32 & 0.95 & 0.05 & 0.04 \\
Browniano+Probabilidade + TF & 16 & 94.59 & 0.95 & 0.05 & 0.05 \\
\hline & & & & &
\end{tabular}

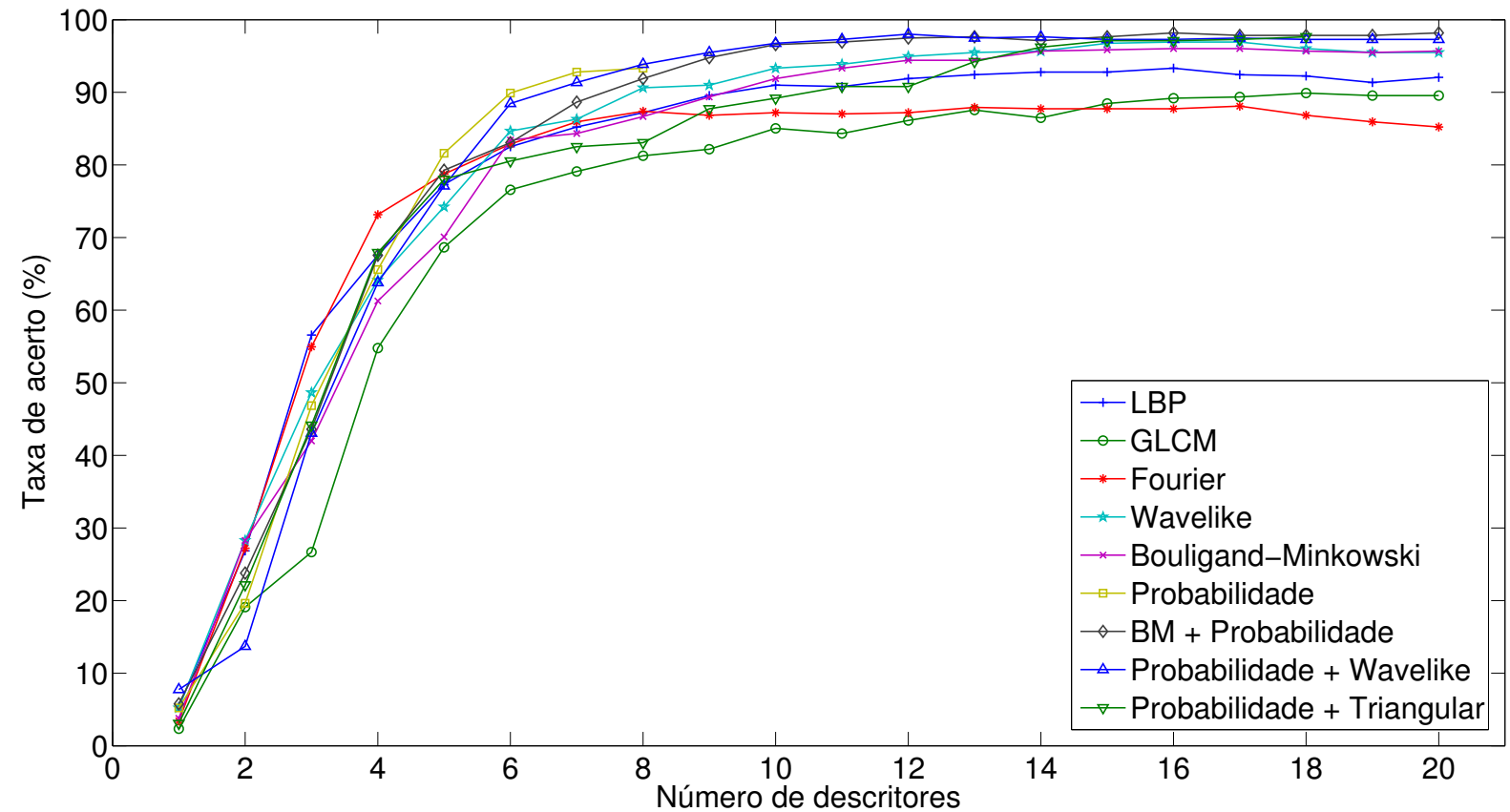

Figura 7.4 - Taxas de acerto em função do número de descritores para a Base de Brodatz, com classificador SVM. 
Essas matrizes refletem não apenas as altas taxas de acerto obtidas pelos descritores fractais, como também a maior regularidade em cada classe, o que implica um resultado mais confiável e passível de extensão para outras bases de texturas.

\subsection{Vistex}

A seguir, são exibidos os resultados para a classificação da base de texturas de Vistex. Este é um conjunto de imagens sensivelmente mais complexo, com ampla variabilidade de iluminação e mesmo entre os arranjos de pixels de uma mesma classe. Ainda é importante ressaltar que esta é uma base de texturas coloridas e em muitas classes a informação mais relevante está concentrada exatamente no dado de cor. Assim, espera-se que no geral as taxas de acerto sejam reduzidas.

\subsubsection{KNN}

Inicialmente, a base é classificada pela abordagem mais simples de KNN, visando analisar o comportamento bruto de cada descritor, apenas por meio de medidas simples de distâncias.

A Tabela 7.30 mostra os resultados para o uso direto, sem qualquer aplicação de PCA ou CCA, sobre os descritores fractais e de outras abordagens na literatura. Esta base de dados mostra-se demasiado complexa para o uso dos descritores em sua forma original, sem qualquer ferramenta de decorrelação. Aqui, medidas de caráter localizado como LBP se sobressaem, por capturarem variações na distribuição de pixels de forma mais precisa.

A Tabela 7.31 mostra as taxas de acerto e outras medidas relevantes para o uso dos descritores fractais individuais, após redução de dimensionalidade. Em uma primeira análise, nota-se a grande vantagem do método de Wavelike, mesmo em relação aos descritores de Bouligand-Minkowski. Este resultado mostra que, em situações mais severas como nesta base, os descritores de Bouligand-Minkowski variam mais, dependendo do nível de decomposição tomado na textura, e esta variação contém informação relevante para a discriminação do objeto, particularmente quando se usa um método simples como KNN. Um aspecto negativo realçado ocorre com os descritores de Probabilidade que apresentaram bons resultados na base de Brodatz e neste caso não obtiveram mais que 59.95\% de acerto. Esta queda pode ser explicada pelo paradigma estatístico empregado naquele método, que acaba sendo menos 


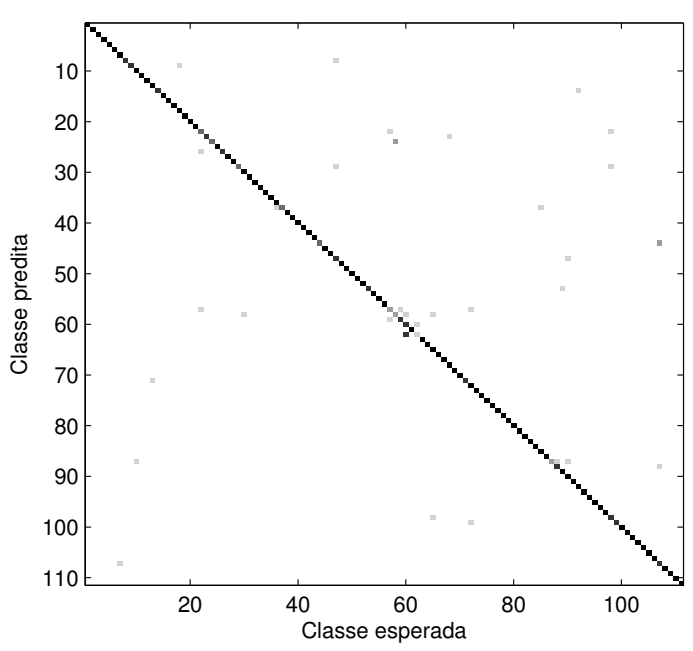

(a)

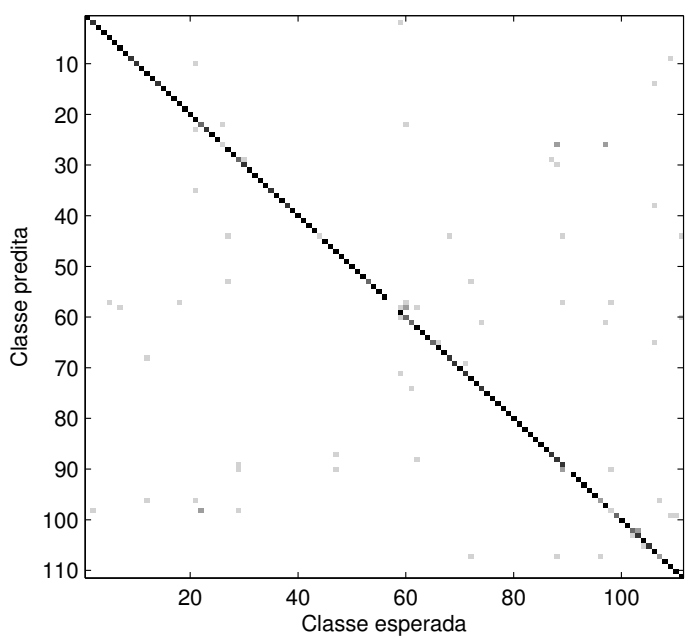

(c)

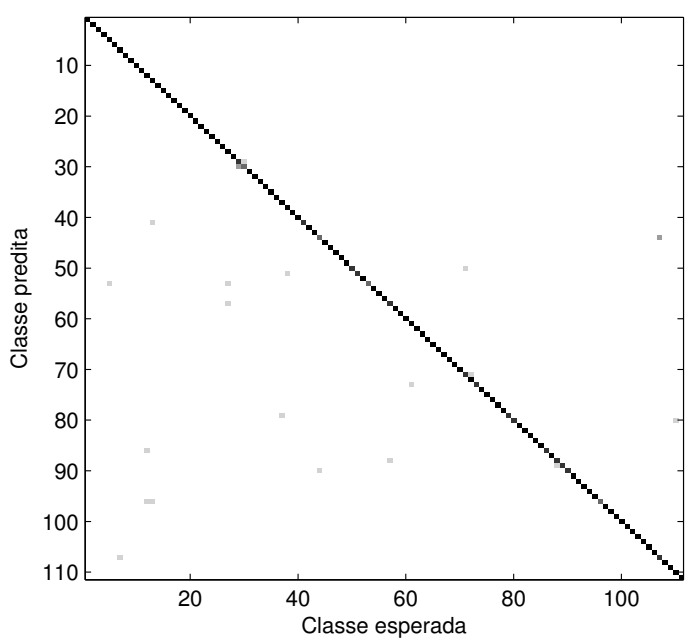

(e)

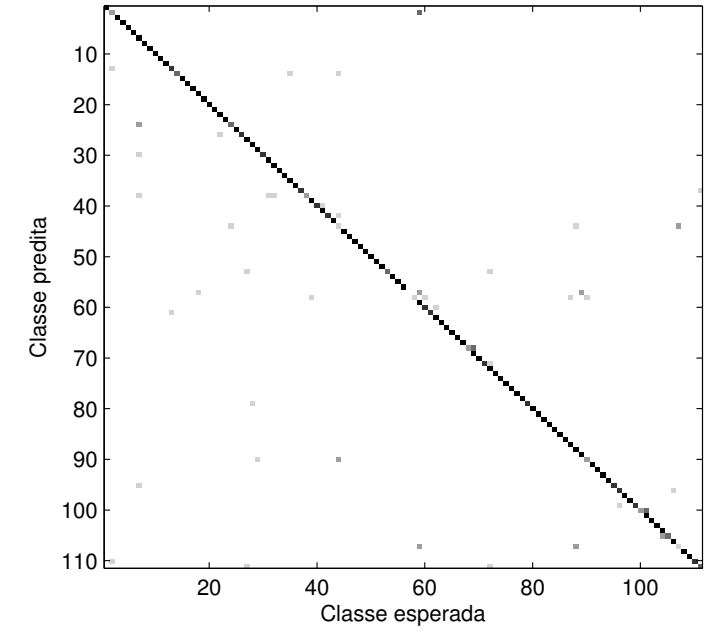

(b)

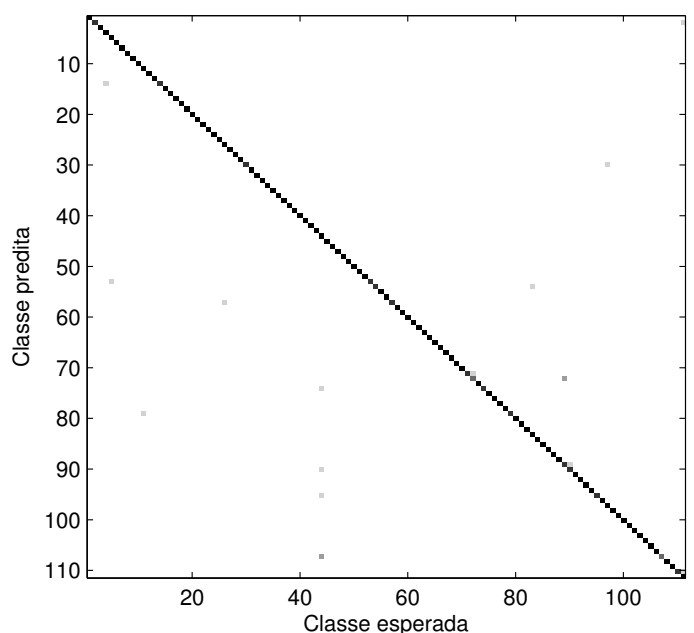

(d)

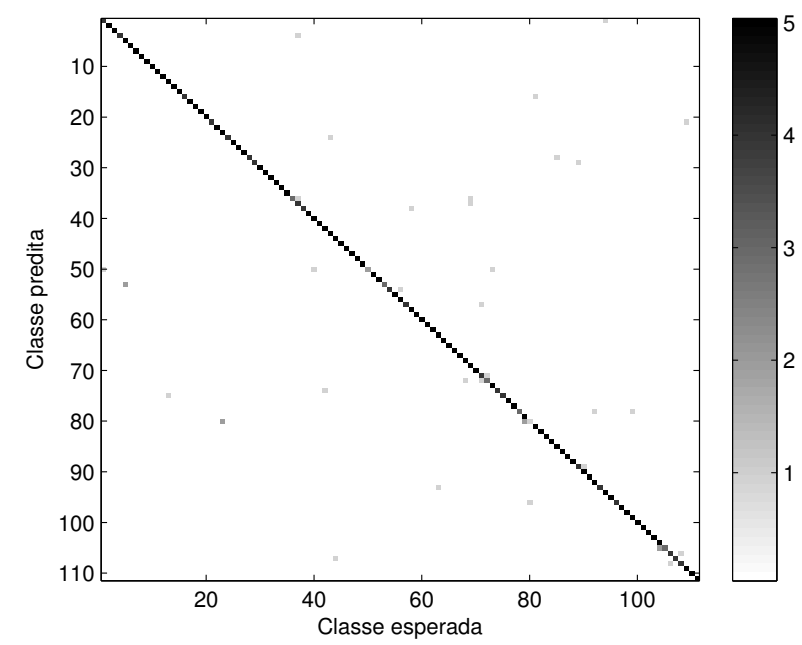

(f)

Figura 7.5 - Matrizes de confusão (parte 1) para os métodos comparados sobre a base de Brodatz, usando classificador SVM. (a) LBP. (b) GLCM. (c) Fourier. (d) Wavelike. (e) Bouligand-Minkowski. (f) Probabilidade. 


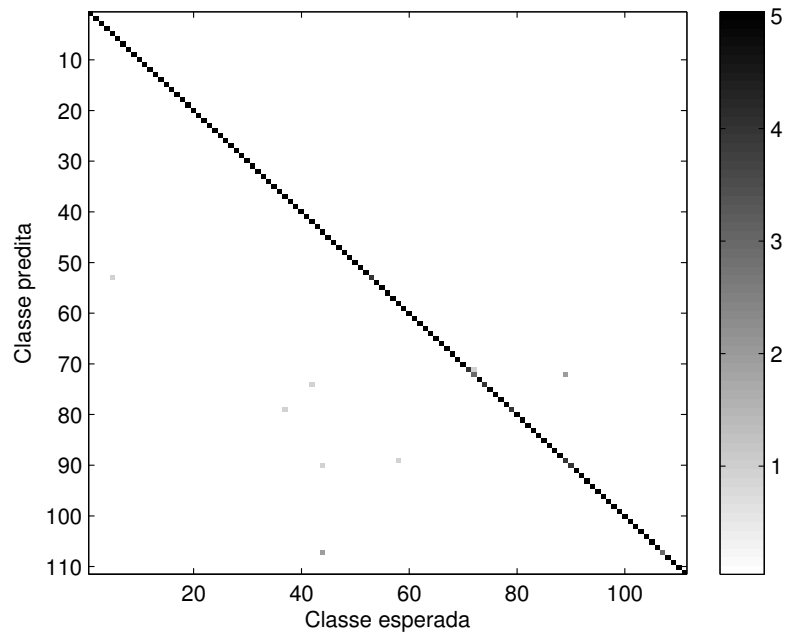

(a)

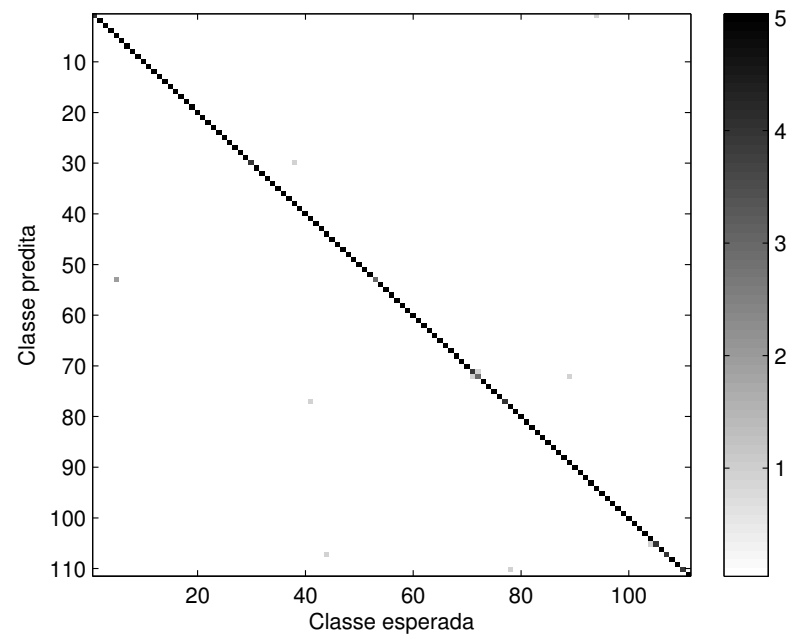

(b)
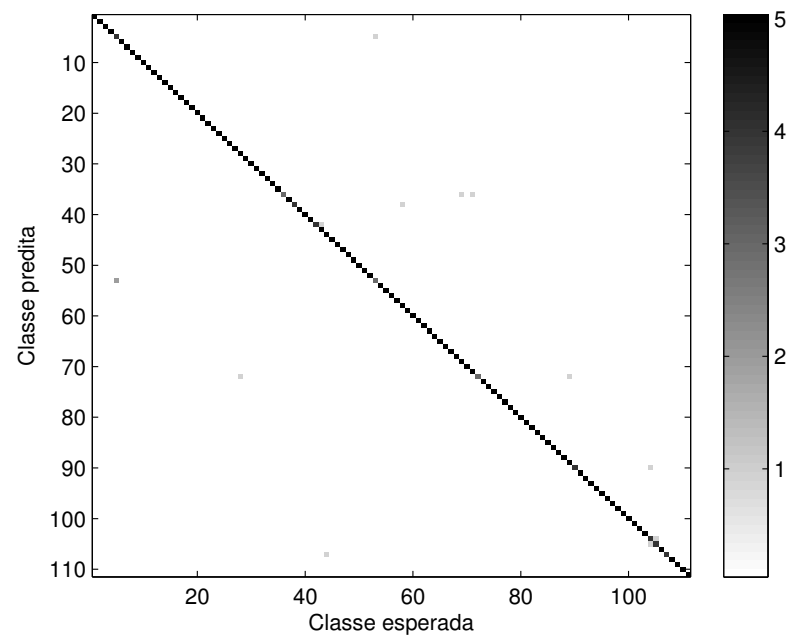

(c)

Figura 7.6 - Matrizes de confusão (parte 2) para os métodos comparados sobre a base de Brodatz, usando classificador SVM. (a) Bouligand-Minkowski + Probabilidade. (b) Probabilidade + Wavelike. (c) Probabilidade + Triangular. 
Tabela 7.30 - Taxa de acerto para os descritores fractais em uso direto e outras medidas para a base de Vistex, com classificador KNN.

\begin{tabular}{cccccc}
\hline Método & ND & TA $(\%)$ & $\kappa$ & E1 & E2 \\
\hline LBP & 32 & 92.71 & 0.93 & 0.07 & 0.07 \\
Fourier & 62 & 85.88 & 0.86 & 0.14 & 0.14 \\
GLCM & 70 & 66.89 & 0.67 & 0.32 & 0.33 \\
GLDM & 17 & 47.93 & 0.48 & 0.53 & 0.52 \\
Gabor & 20 & 81.72 & 0.81 & 0.18 & 0.18 \\
Laws & 15 & 47.23 & 0.47 & 0.53 & 0.53 \\
Multifractal 1 & 76 & 25.00 & 0.25 & 0.74 & 0.75 \\
Multifractal 2 & 39 & 80.90 & 0.81 & 0.18 & 0.19 \\
Multifractal 3 & 323 & 29.17 & 0.29 & 0.70 & 0.71 \\
\hline Blanket + TF & 59 & 77.90 & 0.78 & 0.22 & 0.22 \\
Bouligand-Minkowski + TE & 83 & 81.60 & 0.81 & 0.18 & 0.18 \\
Box-counting + TF & 15 & 64.93 & 0.65 & 0.36 & 0.35 \\
Browniano + TE & 13 & 57.19 & 0.57 & 0.44 & 0.43 \\
Fourier + TF & 78 & 81.49 & 0.81 & 0.19 & 0.19 \\
Lacunaridade + TE & 8 & 67.36 & 0.67 & 0.33 & 0.33 \\
Probabilidade + TE & 7 & 74.18 & 0.74 & 0.24 & 0.26 \\
Triangular + TE & 7 & 82.65 & 0.82 & 0.17 & 0.17 \\
Variação + TE & 7 & 64.35 & 0.64 & 0.36 & 0.36 \\
Variograma + TE & 7 & 75.02 & 0.75 & 0.25 & 0.25 \\
Wavelets + TF & 35 & 46.76 & 0.46 & 0.52 & 0.53 \\
Wavelike + TE & 80 & 79.52 & 0.79 & 0.21 & 0.20 \\
\hline \hline
\end{tabular}

robusto sob variações bruscas de iluminação dentro da classe, situação esta que é agravada em um classificador baseado apenas em distâncias simples e sem um processamento mais avançado. Por outro lado, o método de Fourier se mostrou razoável como uma opção aos descritores baseados em volumes de dilatação, mostrando que a análise espectral é uma técnica poderosa quando não se dispõe da informação de cor neste tipo de textura.

Tabela 7.31 - Taxa de acerto para os descritores fractais individuais na base de Vistex, classificados por KNN.

\begin{tabular}{lccccc}
\hline Método & ND & TA $(\%)$ & $\kappa$ & E1 & E2 \\
\hline Blanket & 6 & 71.76 & 0.71 & 0.27 & 0.28 \\
Bouligand-Minkowski & 20 & 89.12 & 0.89 & 0.11 & 0.11 \\
Box-counting & 5 & 59.03 & 0.59 & 0.40 & 0.41 \\
Browniano & 11 & 51.16 & 0.51 & 0.47 & 0.49 \\
Fourier & 9 & 84.95 & 0.85 & 0.14 & 0.15 \\
Lacunaridade & 8 & 53.70 & 0.53 & 0.45 & 0.46 \\
Probabilidade & 4 & 59.95 & 0.60 & 0.39 & 0.40 \\
Triangular & 9 & 71.76 & 0.71 & 0.28 & 0.28 \\
Variação & 6 & 59.72 & 0.59 & 0.39 & 0.40 \\
Variograma & 6 & 65.28 & 0.65 & 0.35 & 0.35 \\
Wavelike & 13 & 95.83 & 0.96 & 0.04 & 0.04 \\
\hline
\end{tabular}

A Tabela 7.32 ilustra as taxas de acerto alcançadas por combinações dos descritores fractais. Os melhores resultados foram obtidos por combinações envolvendo os descritores de Wavelike. É interessante que a melhor combinação foi obtida com o método de Blanket, que não obteve uma das taxas de acerto mais altas. Nota-se, por exemplo, que a combinação Wavelike+Bouligand-Minkowski não obteve um resultado tão alto, sendo até menor do que o de Wavelike apenas. O método de Wavelike é derivado de Bouligand-Minkowski e assim apresenta uma perspectiva semelhante de análise e baixa complementaridade nos descritores, levando a uma combinação com resultados de classificação não tão altos quanto podia se 
esperar. Já o método de Blanket, embora também use um processo similar à dilatação, extrai medidas das diferenças entre alturas das estruturas que envolvem a superfície e não de volume como as abordagens de Bouligand-Minkowski e derivados.

Tabela 7.32 - Taxa de acerto para os descritores fractais individuais combinados na base de Vistex, classificados por KNN.

\begin{tabular}{|c|c|c|c|c|c|c|c|c|c|c|c|c|}
\hline & 1 & 2 & 3 & 4 & 5 & 6 & 7 & 8 & 9 & 10 & 11 & 12 \\
\hline 1 & - & $95.37(20)$ & $82.87(6)$ & $82.17(18)$ & 93.(10) & $84.72(19)$ & $83.56(14)$ & $87.73(12)$ & $80.55(9)$ & $87(9)$ & $33.79(9)$ & $98.37(17)$ \\
\hline 2 & $95.37(20)$ & - & $89.58(18)$ & $91.43(17)$ & $95.13(12)$ & $90.04(17)$ & 87.9(14) & 93.(20) & $90.97(13)$ & $91.89(20)$ & $8.56(20)$ & $97.68(20)$ \\
\hline 3 & $82.87(6)$ & $89.58(18)$ & - & $81.7(13)$ & 86.34(13) & $68.98(11)$ & $71.52(6)$ & $84.02(14)$ & $74.5(7)$ & $83.56(13)$ & 43.(12) & $96.75(20)$ \\
\hline 4 & $82.17(18)$ & $91.43(17)$ & $81.7(13)$ & - & $90.04(18)$ & $77.54(13)$ & $80.7(15)$ & $77.54(16)$ & $79.62(20)$ & $84.02(12)$ & $38.42(13)$ & $95.60(12)$ \\
\hline 5 & 93.(10) & $95.13(12)$ & $86.34(13)$ & $90.04(18)$ & & $92.12(16)$ & $88.42(20)$ & $90.04(13)$ & $88.19(20)$ & $91.89(12)$ & 35.87( & $98.14(17)$ \\
\hline 6 & $84.72(19)$ & $90.04(17)$ & $68.98(11)$ & $77.54(13)$ & $92.12(16)$ & & 73.61(11) & $80.09(16)$ & $72.45(17)$ & $76.62(12)$ & 35.8 & $95.13(20)$ \\
\hline 7 & $83.56(14)$ & $87.9(14)$ & $71.52(6)$ & $80.7(1$ & $88.42(2)$ & 3.61( & - & $84.49(7)$ & $76.62(11)$ & $0(15)$ & $0(14)$ & $96.52(14)$ \\
\hline 8 & $87.73(12)$ & 93.(20) & $84.02(14)$ & $77.54(16)$ & $90.04(13)$ & $80.09(16)$ & $84.49(7)$ & - & $83.10(12)$ & $85.41(15)$ & $36.11(14)$ & $97.45(12)$ \\
\hline 9 & & & & & & & & & - & $83.33(14)$ & & \\
\hline 10 & $\begin{array}{l}87(9) \\
\text { (a) }\end{array}$ & $91.89(20)$ & $83.56(13)$ & $84.02(12)$ & $91.89(12)$ & $76.62(12)$ & $82.40(15)$ & $85.41(15)$ & $83.33(14)$ & - & $36.80(13)$ & 97.91(14) \\
\hline 11 & $33.79(9)$ & & 43.(12) & & $35.87(15)$ & & & $36.11(14)$ & $45.83(5)$ & $6.80(13)$ & & $8.33(1)$ \\
\hline 12 & $98.37(17)$ & $97.68(20)$ & $96.75(20)$ & $95.60(12)$ & 98.14(17) & $95.13(20)$ & $96.52(14)$ & $97.45(12)$ & $96.29(16)$ & $97.91(14)$ & $8.33(1)$ & \\
\hline
\end{tabular}

A Tabela 7.33 mostra a precisão dos descritores fractais agora transformados por FDA. De um modo geral, todas as taxas de acerto caíram, exceto para Lacunaridade, embora tenha usado um número bem maior de descritores. Nota-se ainda uma queda maior no acerto de métodos cujas curvas de descritores apresentam maior irregularidade relevante, como Browniano e Triangular, irregularidade esta que se perde no processo de suavização inerente à transformada FDA. Essa transformação também influencia mais negativamente aqueles métodos que geram um número maior de descritores, pois estes têm sua informação reduzida para ser expressa pelos coeficientes funcionais.

Tabela 7.33 - Taxa de acerto para os descritores fractais FDA na base de Vistex, classificados por KNN.

\begin{tabular}{lccccc}
\hline Método & ND & TA (\%) & $\kappa$ & E1 & E2 \\
\hline Blanket & 7 & 66.44 & 0.66 & 0.35 & 0.34 \\
Bouligand-Minkowski & 12 & 84.72 & 0.84 & 0.15 & 0.15 \\
Box-counting & 14 & 58.10 & 0.58 & 0.42 & 0.42 \\
Browniano & 5 & 38.89 & 0.39 & 0.59 & 0.61 \\
Fourier & 14 & 83.10 & 0.83 & 0.16 & 0.17 \\
Lacunaridade & 20 & 57.87 & 0.58 & 0.41 & 0.42 \\
Probabilidade & 20 & 44.21 & 0.44 & 0.56 & 0.56 \\
Triangular & 3 & 56.94 & 0.57 & 0.44 & 0.43 \\
Variação & 14 & 48.15 & 0.48 & 0.53 & 0.52 \\
Variograma & 20 & 51.62 & 0.51 & 0.48 & 0.48 \\
Wavelets & 3 & 59.03 & 0.59 & 0.41 & 0.41 \\
Wavelike & 16 & 89.58 & 0.89 & 0.09 & 0.10 \\
\hline
\end{tabular}

A Tabela 7.34 explicita as taxas de acerto para as combinações dos descritores transformados. Assim como para os descritores individuais, os resultados caíram, em alguns casos drasticamente, como na combinação Box-counting + Wavelike, em que a taxa de acerto caiu de $96.75 \%$ para $62.26 \%$, ainda que neste caso a queda em cada método não tenha sido tão forte. Esta queda foi bem suave nos descritores individuais, mostrando que a transformação FDA muda a perspectiva de análise dos métodos e pode danificar fortemente a eficiência da combinação de descritores. 
Tabela 7.34 - Taxa de acerto para os descritores fractais FDA combinados na base de Vistex, classificados por KNN.

\begin{tabular}{|c|c|c|c|c|c|c|c|c|c|c|c|c|}
\hline & 1 & 2 & 3 & 4 & 5 & 6 & 7 & 8 & 9 & 10 & 11 & 12 \\
\hline 1 & - & $88.65(9)$ & $58.56(10)$ & $71.99(6)$ & $91.20(13)$ & $55.32(20)$ & $66.89(5)$ & $66.43(7)$ & $65.50(6)$ & $53.24(6)$ & $59.72(9)$ & (10) \\
\hline 2 & $88.65(9)$ & - & $53.93(20)$ & $76.62(7)$ & $95.37(20)$ & $49.30(16)$ & $59.02(3)$ & $75.69(8)$ & $59.02(4)$ & 68.(5) & $74.76(4)$ & $92.12(20)$ \\
\hline 3 & $58.56(10)$ & $53.93(20)$ & - & $65.74(17)$ & $68.05(19)$ & $54.39(7)$ & 43.(13) & $54.62(14)$ & $55.09(19)$ & $62(13)$ & $66.66(12)$ & $62.26(20)$ \\
\hline 4 & $71.99(6)$ & $76.62(7)$ & $65.74(17)$ & - & $82.40(13)$ & (19) & $62.73(7)$ & $60.18(4)$ & $60.41(19)$ & 56.(17) & $70.37(9)$ & $75.69(4)$ \\
\hline 5 & $91.20(13)$ & $95.37(20)$ & $68.05(19)$ & $82.40(13)$ & - & $67.12(7)$ & $67.12(8)$ & $72.68(4)$ & $74.5(5)$ & $77.08(7)$ & $66.66(19)$ & $93.05(16)$ \\
\hline 6 & $55.32(20)$ & $49.30(16)$ & $54.39(7)$ & (19) & $67.12(7)$ & - & 68.(6) & $61.34(15)$ & $59.95(3)$ & $58.79(9)$ & $56.7(11)$ & $59.25(7)$ \\
\hline 7 & $66.89(5)$ & $59.02(3)$ & 43.(13) & $62.73(7)$ & $67.12(8)$ & 68.(6) & - & $50.23(17)$ & $57.17(20)$ & $56.94(12)$ & $58.56(3)$ & $55.7(5)$ \\
\hline 8 & $66.43(7)$ & $75.69(8)$ & $54.62(14)$ & $60.18(4)$ & $72.68(4)$ & $61.34(15)$ & $50.23(17)$ & - & $63.19(14)$ & $59.02(4)$ & $59.02(4)$ & $65.04(7)$ \\
\hline 9 & $65.50(6)$ & $59.02(4)$ & $55.09(19)$ & $60.41(19)$ & $74.5(5)$ & $59.95(3)$ & $57.17(20)$ & $63.19(14)$ & & $55.55(5)$ & $69.44(4)$ & $59.95(5)$ \\
\hline 10 & $53.24(6)$ & $68 .(5)$ & $62(13)$ & 56.(17) & $77.08(7)$ & $58.79(9)$ & $56.94(12)$ & $59.02(4)$ & $55.55(5)$ & - & $69.44(7)$ & $61.57(6)$ \\
\hline 11 & $59.72(9)$ & $74.76(4)$ & $66.66(12)$ & $70.37(9)$ & $66.66(19)$ & $56.7(11)$ & $58.56(3)$ & $59.02(4)$ & $69.44(4)$ & $69.44(7)$ & - & $79.62(4)$ \\
\hline 12 & (10) & $92.12(20)$ & $62.26(20)$ & $75.69(4)$ & $93.05(16)$ & $59.25(7)$ & $55.7(5)$ & $65.04(7)$ & $59.95(5)$ & $61.57(6)$ & 79.62(4) & - \\
\hline
\end{tabular}

Por sua vez, a Tabela 7.35 mostra os resultados para os descritores fractais transformados por espaço-escala (derivada com suavização Gaussiana). Esta solução faz com que alguns métodos apresentem matriz de covariância intra-classe não invertível e impossibilite a aplicação da redução de dimensionalidade por análise canônica, explicando a ausência de resultados para alguns métodos como Wavelets, Blanket e Probabilidade, por exemplo. Em vários casos houve uma queda na taxa de acerto, enquanto em outros, aumentou. Novamente, nota-se a importância de se testar cada transformada para cada situação. O método com ganho mais significativo foi Triangular, uma vez que o baixo atrelamento entre as áreas dos prismas com diferentes comprimentos faz com que a informação de diferença entre os atributos (expressa na derivada) seja relevante para o classificador.

Tabela 7.35 - Taxa de acerto para os descritores fractais espaço-escala na base de Vistex, classificados por KNN.

\begin{tabular}{lccccc}
\hline Método & ND & TA $(\%)$ & $\kappa$ & E1 & E2 \\
\hline Box-counting & 12 & 61.34 & 0.61 & 0.39 & 0.39 \\
Browniano & 16 & 34.03 & 0.34 & 0.65 & 0.66 \\
Fourier & 13 & 51.16 & 0.51 & 0.45 & 0.49 \\
Triangular & 19 & 75.93 & 0.76 & 0.22 & 0.24 \\
Variação & 11 & 49.07 & 0.49 & 0.52 & 0.51 \\
Variograma & 15 & 59.26 & 0.59 & 0.38 & 0.41 \\
Wavelike & 12 & 65.97 & 0.66 & 0.32 & 0.34 \\
\hline
\end{tabular}

A Tabela 7.36 mostra os resultados para a classificação usando os descritores transformados por espaço-escala e combinados dois a dois. Assim, como com os descritores separadamente, nenhuma combinação apresentou um resultado interessante, mostrando que esta não é uma abordagem interessante para classificação das texturas na base de Vistex por KNN.

Já a Tabela 7.37 mostra os resultados para os descritores transformados por tempofrequência. Enquanto em outras situações aqui descritas essa transformada apresentou bom desempenho, neste caso, não houve contribuição significativa. Em particular, os métodos de Fourier e Wavelike apresentaram uma queda substancial na taxa de acerto após a aplicação desta operação. No caso de Fourier, a análise de frequências usando janelas de tamanho fixo na transformada de Gabor perdeu informações importantes apresentadas em diferentes níveis de resolução no espectro de potência. Já para o método de Wavelike, as medidas de 
Tabela 7.36 - Taxa de acerto para os descritores fractais espaço-escala combinados na base de Vistex, classificados por KNN.

\begin{tabular}{|c|c|c|c|c|c|c|c|c|c|c|}
\hline & 1 & 3 & 4 & 5 & $\begin{array}{ll}6 & 7 \\
\end{array}$ & 8 & 9 & 10 & 11 & 12 \\
\hline 1 & - & 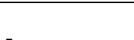 & & & & & & & & \\
\hline 3 & & - & $70.60(20)$ & $41.89(10)$ & & $79.16(20)$ & $70.13(17)$ & $82.17(20)$ & & $65.04(13)$ \\
\hline 4 & & $70.60(20)$ & - & $42.36(15)$ & & $73.84(15)$ & $56.48(16)$ & $58.33(18)$ & & $63.88(19)$ \\
\hline 5 & & $41.89(10)$ & $42.36(15)$ & - & & $76.62(14)$ & $67.59(15)$ & $58.56(19)$ & & $60.87(18)$ \\
\hline 6 & & & & & - & & & & & \\
\hline 7 & & & & & - & & & & & \\
\hline 8 & & $79.16(20)$ & $73.84(15)$ & $76.62(14)$ & & - & $76.38(18)$ & $78.47(17)$ & & $61.11(9)$ \\
\hline 9 & & $70.13(17)$ & $56.48(16)$ & $67.59(15)$ & & $76.38(18)$ & - & $70.83(18)$ & & $67.82(20)$ \\
\hline 10 & & $82.17(20)$ & $58.33(18)$ & $58.56(19)$ & & $78.47(17)$ & $70.83(18)$ & - & & $63.42(14)$ \\
\hline 11 & & & & & & & & & - & \\
\hline 12 & & $65.04(13)$ & 63.88(19) & $60.87(18)$ & & 61.11(9) & $67.82(20)$ & $63.42(14)$ & & - \\
\hline
\end{tabular}

entropia em diferentes volumes de dilatação também apresentam informações relevantes em vários níveis de resolução que são perdidas pelo uso da janela deslizante.

Tabela 7.37 - Taxa de acerto para os descritores fractais tempo-frequência na base de Vistex, classificados por KNN.

\begin{tabular}{lccccc}
\hline Método & ND & TA $(\%)$ & $\kappa$ & E1 & E2 \\
\hline Blanket & 3 & 28.24 & 0.28 & 0.71 & 0.72 \\
Bouligand-Minkowski & 17 & 57.64 & 0.57 & 0.41 & 0.42 \\
Box-counting & 16 & 63.89 & 0.64 & 0.35 & 0.36 \\
Browniano & 17 & 53.70 & 0.53 & 0.44 & 0.46 \\
Fourier & 18 & 56.02 & 0.56 & 0.42 & 0.44 \\
Lacunaridade & 20 & 63.19 & 0.63 & 0.38 & 0.37 \\
Probabilidade & 16 & 64.35 & 0.64 & 0.36 & 0.36 \\
Triangular & 15 & 72.22 & 0.72 & 0.26 & 0.28 \\
Variação & 19 & 59.03 & 0.59 & 0.41 & 0.41 \\
Variograma & 19 & 66.90 & 0.67 & 0.32 & 0.33 \\
Wavelets & 11 & 68.52 & 0.68 & 0.30 & 0.31 \\
Wavelike & 8 & 73.15 & 0.73 & 0.25 & 0.27 \\
\hline
\end{tabular}

Por sua vez, a Tabela 7.38 apresenta os resultados para as combinações de descritores. A maioria das combinações apresentou queda na taxa de acerto. Novamente, observam-se casos em que a combinação apresentou taxa de acerto sensivelmente mais baixa do que os descritores separados. Esta base de texturas se mostra mais propícia para o uso dos descritores em suas versões originais. A combinação de técnicas complexas de transformação com um classificador simplista faz com que informações relevantes de uma base mais heterogênea como Vistex sejam perdidas e, como consequência, os acertos caem após estas transformações.

Tabela 7.38 - Taxa de acerto para os descritores fractais tempo-frequência combinados na base de Vistex, classificados por KNN.

\begin{tabular}{ccccccccccccc}
\hline & $\mathbf{1}$ & $\mathbf{2}$ & $\mathbf{3}$ & $\mathbf{4}$ & $\mathbf{5}$ & $\mathbf{6}$ & $\mathbf{7}$ & $\mathbf{8}$ & $\mathbf{9}$ & $\mathbf{1 0}$ & $\mathbf{1 1}$ & $\mathbf{1 2}$ \\
\hline $\mathbf{1}$ & - & $53.24(18)$ & $55.7(19)$ & $69.67(20)$ & $60.41(19)$ & $53.70(19)$ & $54.86(17)$ & $67.36(20)$ & $56 .(19)$ & $55.32(19)$ & $51.85(16)$ & $56.01(19)$ \\
$\mathbf{2}$ & $53.24(18)$ & - & $54.16(11)$ & $55.09(18)$ & $60.87(20)$ & $54.16(20)$ & $53.47(20)$ & $68.51(14)$ & $48.61(19)$ & $64.35(18)$ & $44.44(17)$ & $56 .(19)$ \\
$\mathbf{3}$ & $55.7(19)$ & $54.16(11)$ & - & $65.74(20)$ & $58.56(15)$ & $72.45(17)$ & $51.38(13)$ & $80.55(19)$ & $64.58(20)$ & $69.67(19)$ & $59.49(11)$ & $69.2(15)$ \\
$\mathbf{4}$ & $69.67(20)$ & $55.09(18)$ & $65.74(20)$ & - & $72.22(20)$ & $70.37(17)$ & $78.24(15)$ & $75.23(15)$ & $77.77(18)$ & $71.06(19)$ & $54.62(17)$ & $65.04(10)$ \\
$\mathbf{5}$ & $60.41(19)$ & $60.87(20)$ & $58.56(15)$ & $72.22(20)$ & - & $67.82(17)$ & $56.01(13)$ & $63.65(16)$ & $55.55(16)$ & $74.07(20)$ & $54.86(19)$ & $78.24(6)$ \\
$\mathbf{6}$ & $53.70(19)$ & $54.16(20)$ & $72.45(17)$ & $70.37(17)$ & $67.82(17)$ & - & $68.05(18)$ & $73.14(18)$ & $68 .(20)$ & $75.69(18)$ & $48.61(16)$ & $63.19(20)$ \\
$\mathbf{7}$ & $54.86(17)$ & $53.47(20)$ & $51.38(13)$ & $78.24(15)$ & $56.01(13)$ & $68.05(18)$ & - & $74.5(19)$ & $70.13(18)$ & $72.68(20)$ & $54.86(7)$ & $74.5(19)$ \\
$\mathbf{8}$ & $67.36(20)$ & $68.51(14)$ & $80.55(19)$ & $75.23(15)$ & $63.65(16)$ & $73.14(18)$ & $74.5(19)$ & - & $74.76(20)$ & $68 .(19)$ & $50.23(16)$ & $73.84(18)$ \\
$\mathbf{9}$ & $56 .(19)$ & $48.61(19)$ & $64.58(20)$ & $77.77(18)$ & $55.55(16)$ & $68 .(20)$ & $70.13(18)$ & $74.76(20)$ & - & $(20)$ & $51.38(19)$ & $62(20)$ \\
$\mathbf{1 0}$ & $55.32(19)$ & $64.35(18)$ & $69.67(19)$ & $71.06(19)$ & $74.07(20)$ & $75.69(18)$ & $72.68(20)$ & $68 .(19)$ & $(20)$ & - & $48.14(17)$ & $73.84(18)$ \\
$\mathbf{1 1}$ & $51.85(16)$ & $44.44(17)$ & $59.49(11)$ & $54.62(17)$ & $54.86(19)$ & $48.61(16)$ & $54.86(7)$ & $50.23(16)$ & $51.38(19)$ & $48.14(17)$ & - & $69.2(19)$ \\
$\mathbf{1 2}$ & $56.01(19)$ & $56 .(19)$ & $69.2(15)$ & $65.04(10)$ & $78.24(6)$ & $63.19(20)$ & $74.5(19)$ & $73.84(18)$ & $62(20)$ & $73.84(18)$ & $69.2(19)$ & - \\
\hline
\end{tabular}

A Tabela 7.39 ilustra as taxas de acerto para os descritores fractais transformados por tempo-escala. As taxas de acerto foram melhores do que com as transformações anteriores, 
embora alguns métodos como Wavelike e Fourier tenham apresentado taxa menor. O método de Fourier apresentou a queda mais drástica, confirmando a ineficiência desta combinação de transformada wavelets sobre o espectro de potência, dado o choque entre as informações extraídas. Nos demais casos, a informação de espectro usando banda variável de frequência mostrou-se útil para extrair aspectos ocultos nos descritores originais e úteis para o classificador.

Tabela 7.39 - Taxa de acerto para os descritores fractais tempo-escala na base de Vistex, classificados por KNN.

\begin{tabular}{lccccc}
\hline Método & ND & TA $(\%)$ & $\kappa$ & E1 & E2 \\
\hline Blanket & 8 & 73.15 & 0.73 & 0.26 & 0.27 \\
Bouligand-Minkowski & 19 & 89.81 & 0.90 & 0.09 & 0.10 \\
Box-counting & 5 & 62.50 & 0.62 & 0.37 & 0.38 \\
Browniano & 13 & 55.32 & 0.55 & 0.42 & 0.45 \\
Fourier & 3 & 21.53 & 0.21 & 0.77 & 0.78 \\
Lacunaridade & 7 & 66.67 & 0.66 & 0.34 & 0.33 \\
Probabilidade & 7 & 70.83 & 0.71 & 0.27 & 0.29 \\
Triangular & 7 & 78.24 & 0.78 & 0.21 & 0.22 \\
Variação & 7 & 61.34 & 0.61 & 0.39 & 0.39 \\
Variograma & 5 & 70.37 & 0.70 & 0.30 & 0.30 \\
Wavelets & 6 & 65.05 & 0.65 & 0.34 & 0.35 \\
Wavelike & 20 & 91.44 & 0.91 & 0.08 & 0.09 \\
\hline
\end{tabular}

Por fim, a Tabela 7.40 exibe as taxas de acerto e números de elementos para os descritores espaço-escala concatenados e analisados por CCA. De um modo geral, as combinações não se mostram interessantes em relação à tabela das combinações dos descritores individuais, confirmando que as melhores combinações foram obtidas com descritores sem qualquer transformação, como será reafirmado mais à frente. Estas transformadas possuem um papel de realçar dados importantes nos descritores, seja por uma análise de frequência ou de variação ou ainda eliminando micro-flutuações decorrentes de ruídos. Entretanto, para texturas mais complexas e com classificadores mais simples, estas mesmas transformadas acabam camuflando ou tirando a significância dos atributos originais, em função da interpretação menos direta exigida para os dados.

Tabela 7.40 - Taxa de acerto para os descritores fractais tempo-escala combinados na base de Vistex, classificados por KNN.

\begin{tabular}{|c|c|c|c|c|c|c|c|c|c|c|c|c|}
\hline & 1 & 2 & 3 & 4 & 5 & 6 & 7 & 8 & 9 & 10 & 11 & 12 \\
\hline 1 & - & $94.44(20)$ & $82.40(11)$ & $85.87(13)$ & $76.15(10)$ & $84.95(8)$ & $84.95(11)$ & $87.0(12)$ & $78.00(8)$ & $89.35(13)$ & $84.02(8)$ & $94.44(16)$ \\
\hline 2 & $94.44(20)$ & - & $91.20(17)$ & & $88.42(18)$ & & & & & & & \\
\hline 3 & 200(11) & $.20(17)$ & - & 8 & & & & & & & (5) & \\
\hline 4 & 85 & $.35(18)$ & $84.25(14)$ & - & $3.2(1$ & 82.6 & 8(11) & & & & $68.51(9)$ & \\
\hline 5 & & & & 1 & & 65.50 (ع & & & & & & \\
\hline 6 & 8 & .8 & 75 & 82.63 & & & $.00(9)$ & 79.8 & & & & \\
\hline 7 & & & & & & 78.00 & - & $73(12)$ & & & & \\
\hline 7 & & $94.2(17)$ & 85.87 & 77.54(1 & $72.68(7)$ & 79.86( & 877311 & - & $2.87(11)$ & & 78.24 & \\
\hline 9 & & & & & & & & & - & 76.85(11) & & \\
\hline 10 & 89 & & 4.95 & 84.72 & 7) & $5.57-2$ & & & 76.85 & - & (5) & \\
\hline 11 & $84.02(8)$ & $94.2(20)$ & (5) & $68.51(9)$ & 4.35(13) & 72.68 & $79.86(5)$ & $78.24(8)$ & 77.31( & 79.39(5) & & $91.20(8)$ \\
\hline 12 & $94.44(16)$ & 93.(20) & $92.12(18)$ & $93.05(20)$ & $90.74(13)$ & $90.04(20)$ & $91.89(18)$ & 93.51(19) & $91.20(15)$ & $94.67(20)$ & $91.20(8)$ & \\
\hline
\end{tabular}




\subsubsection{Outros Métodos}

A Tabela 7.41 ilustra as taxas de acerto para os métodos da literatura comparados com os descritores fractais. Novamente, o método LBP apresentou bom desempenho juntamente com Gabor-wavelets, além dos clássicos Fourier e GLCM. Contudo, a maior taxa de acerto foi obtida pelo método Multifractal 2. Esta é uma solução estado-da-arte que mostra todo seu potencial, sobretudo em bases como esta, com alto índice de sombras e sem maiores padronizações no processo de captura, uma vez que este método foi projetado para ser invariante a iluminação (101).

Tabela 7.41 - Taxa de acerto para os métodos da literatura na base de Vistex, classificados por KNN.

\begin{tabular}{lccccc}
\hline Método & ND & TA $(\%)$ & $\kappa$ & E1 & E2 \\
\hline Fourier & 15 & 85.88 & 0.86 & 0.12 & 0.14 \\
GLCM & 9 & 88.19 & 0.88 & 0.11 & 0.12 \\
GLDM & 20 & 43.52 & 0.43 & 0.56 & 0.56 \\
Gabor & 19 & 83.10 & 0.83 & 0.14 & 0.17 \\
LBP & 19 & 88.89 & 0.89 & 0.10 & 0.11 \\
Laws & 10 & 73.61 & 0.73 & 0.27 & 0.26 \\
Multifractal 1 & 4 & 29.40 & 0.29 & 0.69 & 0.71 \\
Multifractal 2 & 12 & 89.81 & 0.90 & 0.09 & 0.10 \\
\hline
\end{tabular}

\subsubsection{Resumo dos Resultados}

A Tabela 7.42 sumariza os resultados alcançados para a base de Vistex, classificada por SVM. Como nos casos anteriores, foram selecionados os descritores fractais nas versões que obtiveram as maiores taxas de acerto.

Nota-se que o método de Wavelike superou todas as demais abordagens da literatura comparadas, usando-se apenas 13 descritores. O ganho em relação a Bouligand-Minkowski foi proporcionado pela representação multiníveis, que forneceu uma descrição mais rica diante de uma situação tão severa quanto nestas imagens de discriminação mais complexa. Em relação aos resultados de Brodatz, também nota-se a queda no desempenho dos descritores de Probabilidade e melhor precisão no método de Fourier, o que se explica pela importância da informação de frequência na análise de imagens coloridas. Também se observa que a maioria dos melhores descritores foi obtida a partir de uma transformada tempo-escala, mais uma vez ressaltando a importância da análise de frequências nesta situação.

Por sua vez, entre os descritores combinados, nota-se que os melhores resultados já foram obtidos a partir de descritores individuais. Constata-se assim que embora transformadas como tempo-escala melhorem os resultados dos descritores originais, elas também alteram a visão que estes transmitem do dado analisado (no caso a imagem de textura), fazendo com que atributos 
que se complementam originalmente percam tal característica. Por fim, vale destacar também que as combinações atingiram mais de $98 \%$ de acerto em uma base altamente complicada para análise em tons de cinza e com um classificador simples. Este resultado ilustra plenamente o poder e o alcance dos descritores fractais, sobretudo quando combinados.

Tabela 7.42 - Resumo das taxas de acerto obtidas para a base de Vistex, classificada por KNN.

\begin{tabular}{lccccc}
\hline Método & ND & TA (\%) & $\kappa$ & E1 & E2 \\
\hline Multifractal 2 & 12 & 89.81 & 0.90 & 0.09 & 0.10 \\
LBP & 19 & 88.89 & 0.89 & 0.10 & 0.11 \\
GLCM & 9 & 88.19 & 0.88 & 0.11 & 0.12 \\
Fourier & 15 & 85.88 & 0.86 & 0.12 & 0.14 \\
Gabor & 19 & 83.10 & 0.83 & 0.14 & 0.17 \\
Laws & 10 & 73.61 & 0.73 & 0.27 & 0.26 \\
GLDM & 20 & 43.52 & 0.43 & 0.56 & 0.56 \\
Multifractal 1 & 4 & 29.40 & 0.29 & 0.69 & 0.71 \\
\hline \hline Wavelike & 13 & 95.83 & 0.96 & 0.04 & 0.04 \\
Bouligand-Minkowski + TE & 19 & 89.81 & 0.90 & 0.09 & 0.10 \\
Fourier & 9 & 84.95 & 0.85 & 0.14 & 0.15 \\
Triangular + TE & 7 & 78.24 & 0.78 & 0.21 & 0.22 \\
Blanket + TE & 8 & 73.15 & 0.73 & 0.26 & 0.27 \\
Probabilidade + TE & 7 & 70.83 & 0.71 & 0.27 & 0.29 \\
Variograma + TE & 5 & 70.37 & 0.70 & 0.30 & 0.30 \\
Wavelets + TF & 11 & 68.52 & 0.68 & 0.30 & 0.31 \\
Lacunaridade + TE & 7 & 66.67 & 0.66 & 0.34 & 0.33 \\
Box-counting + TF & 16 & 63.89 & 0.64 & 0.35 & 0.36 \\
Variação + TE & 7 & 61.34 & 0.61 & 0.39 & 0.39 \\
Browniano + TE & 13 & 55.32 & 0.55 & 0.42 & 0.45 \\
\hline \hline Blanket+Wavelike & 17 & 98.38 & 0.98 & 0.02 & 0.02 \\
Fourier+Wavelike & 17 & 98.15 & 0.98 & 0.02 & 0.02 \\
Variograma+Wavelike & 14 & 97.92 & 0.98 & 0.02 & 0.02 \\
Bouligand-Minkowski+Wavelike & 20 & 97.69 & 0.98 & 0.02 & 0.02 \\
Triangular+Wavelike & 12 & 97.45 & 0.97 & 0.02 & 0.03 \\
Box-counting+Wavelike & 20 & 96.76 & 0.97 & 0.03 & 0.03 \\
Probabilidade+Wavelike & 14 & 96.53 & 0.96 & 0.03 & 0.03 \\
Variação+Wavelike & 16 & 96.30 & 0.96 & 0.03 & 0.04 \\
Bouligand-Minkowski+Wavelets + TE & 20 & 94.21 & 0.94 & 0.05 & 0.06 \\
Fourier+Lacunaridade & 16 & 92.13 & 0.92 & 0.07 & 0.08 \\
Bouligand-Minkowski+Browniano & 17 & 91.44 & 0.91 & 0.07 & 0.09 \\
\hline & & & & &
\end{tabular}

A Figura 7.7 mostra a taxa de acerto em função do número de descritores para cada um dos melhores descritores de texturas comparados (fractais, combinados e da literatura). Os descritores fractais combinados se sobressaem, sendo que novamente eles apresentam crescimento na taxa de acerto em um intervalo maior do que os métodos individuais. Tal fato se justifica pelo funcionamento destas combinações, em que os descritores são concatenados e analisados por CCA. A análise canônica expressa as maiores (e mais relevantes) variâncias em seus descritores iniciais. Ocorre que com a concatenação de descritores diferentes, esta variância tende a aumentar e se propagar por mais componentes canônicos. Outro ponto que chama atenção são os descritores fractais de Fourier que apresentam queda na taxa de acerto após um limiar, indicando que estes descritores possuem variâncias relevantes em poucos componentes.

As Figuras 7.8 e 7.9 exibem as respectivas matrizes de confusão para os melhores métodos em imagens de intensidade de tons de cinza. Observa-se que diferentemente do que ocorria na base Brodatz, agora os pontos fora da diagonal são mais perceptíveis. Além disso, é 


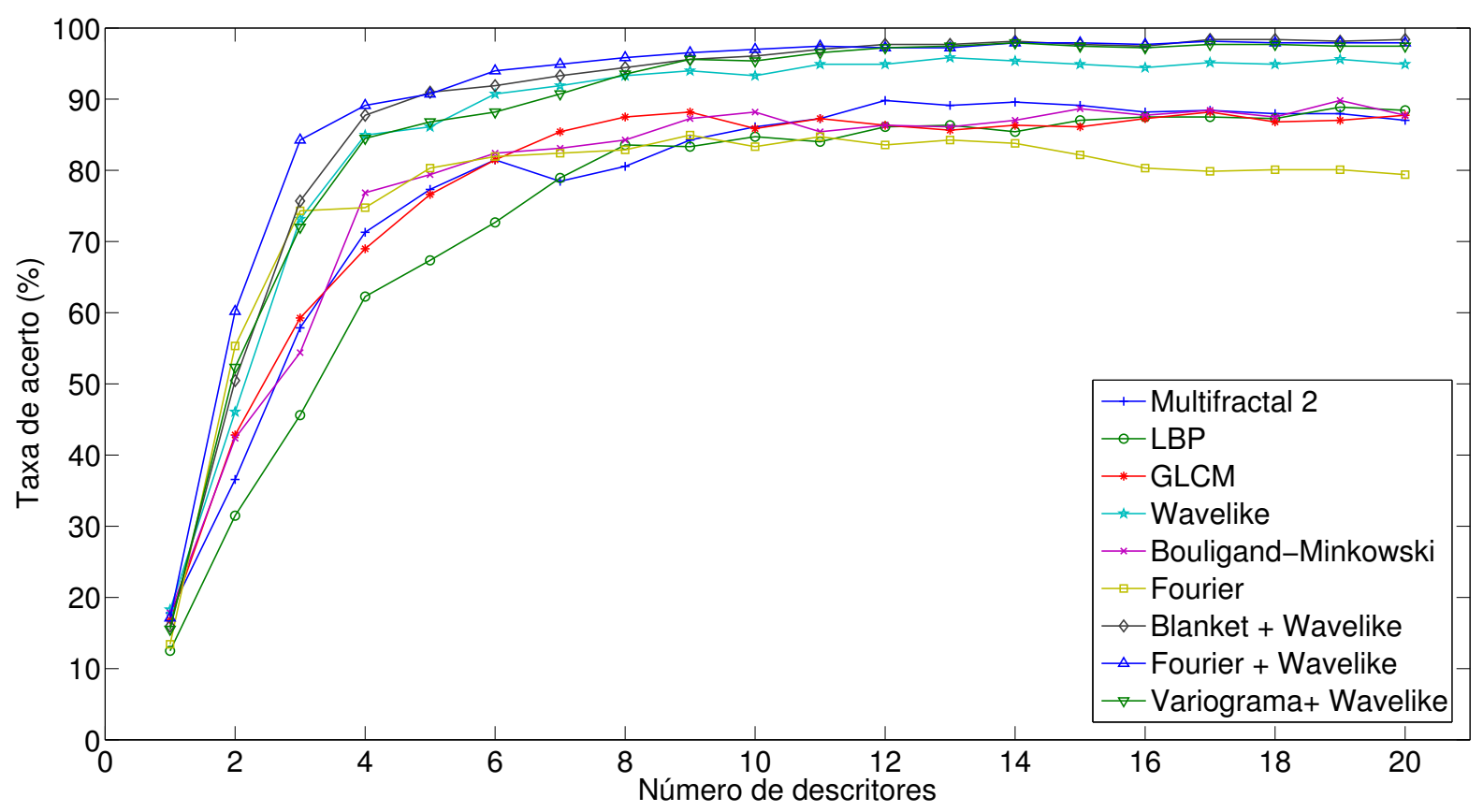

Figura 7.7 - Taxas de acerto em função do número de descritores para a base de Vistex, classificada por KNN.

visível também a presença de classes com classificação mais difícil mesmo para os descritores fractais, como é o caso das classes 33 e 34 . Estas são compostas por imagens de materiais com forte variação de luminosidade (sombras em posições variadas) e variabilidade de padrões (rachaduras de materiais em diferentes posições) dentro de uma mesma classe, sendo que estes artefatos estão presentes nas duas classes, gerando um alto índice de confusão entre ambas. Este seria o típico caso em que apenas a informação de cor seria capaz de uma discriminação mais efetiva.

\subsubsection{SVM}

A seguir, são ilustrados os resultados e discussões para a classificação da base de Vistex por um classificador mais robusto e estado-da-arte, ou seja, as máquinas de suporte vetorial.

A Tabela 7.43 apresenta as taxas de acerto e outras estatísticas para os descritores de texturas usados de forma direta, na base de Vistex, com classificação por SVM. Esta tabela confirma a eficácia de LBP quando usado em sua versão original sobre esta base, que apresenta um nível de dificuldade maior em relação a Brodatz. Esta dificuldade surge do alto nível de variações de luminosidade e do aspecto geométrico nos padrões, além do fato de grande parte da informação estar contida na cor, que não é ponderada na presente análise. Mesmo assim, os 


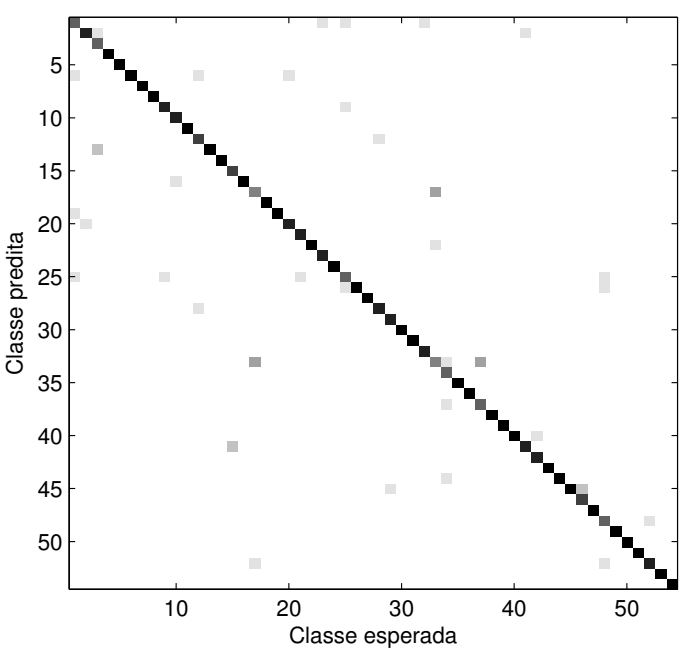

(a)

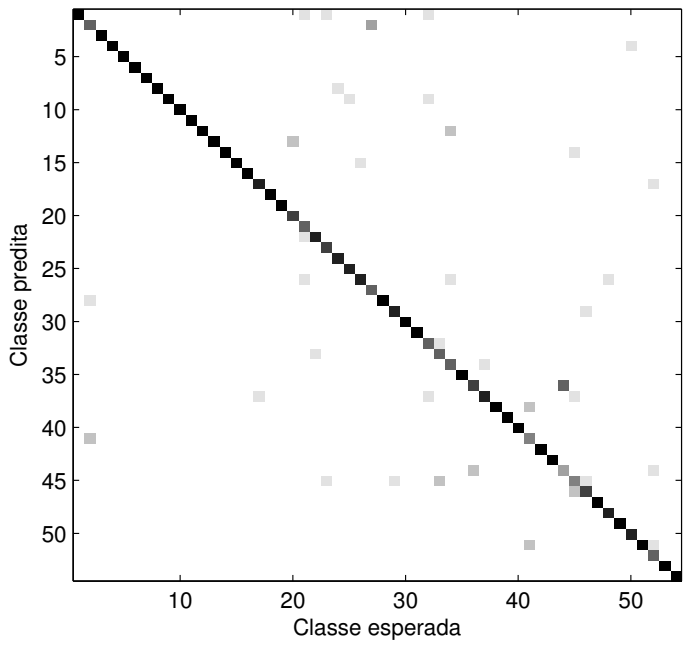

(c)

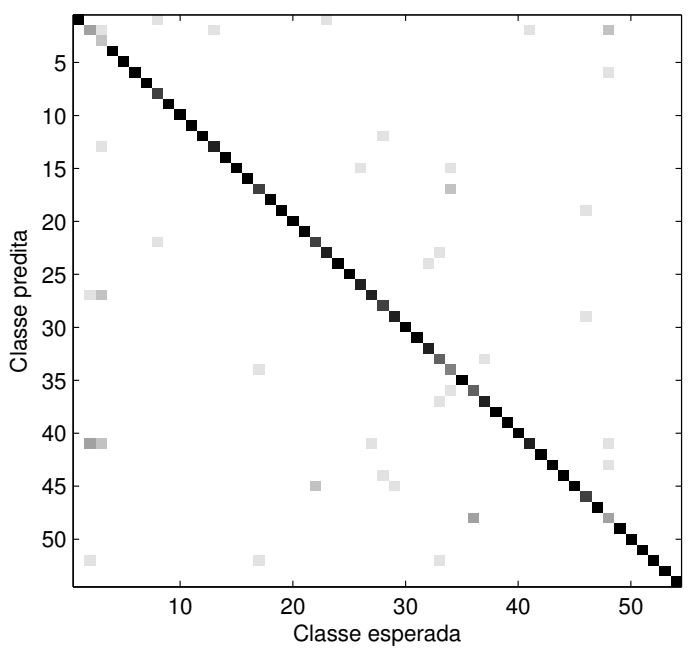

(e)

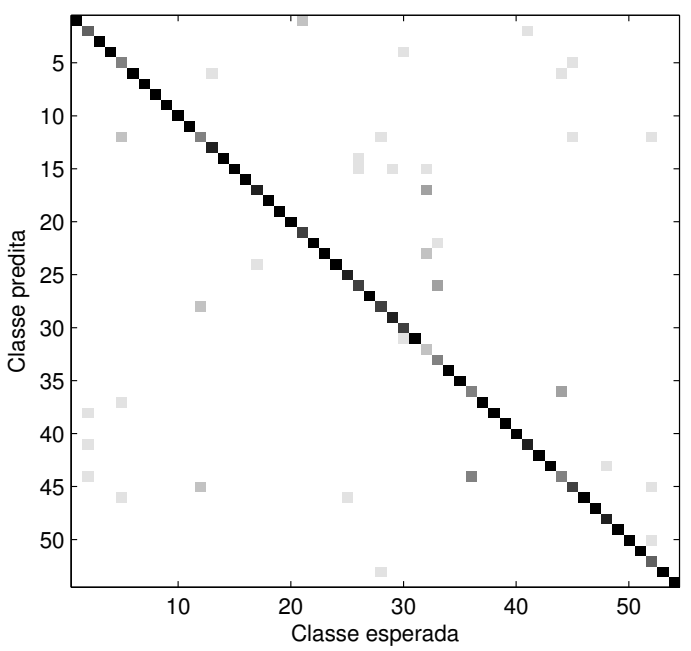

(b)

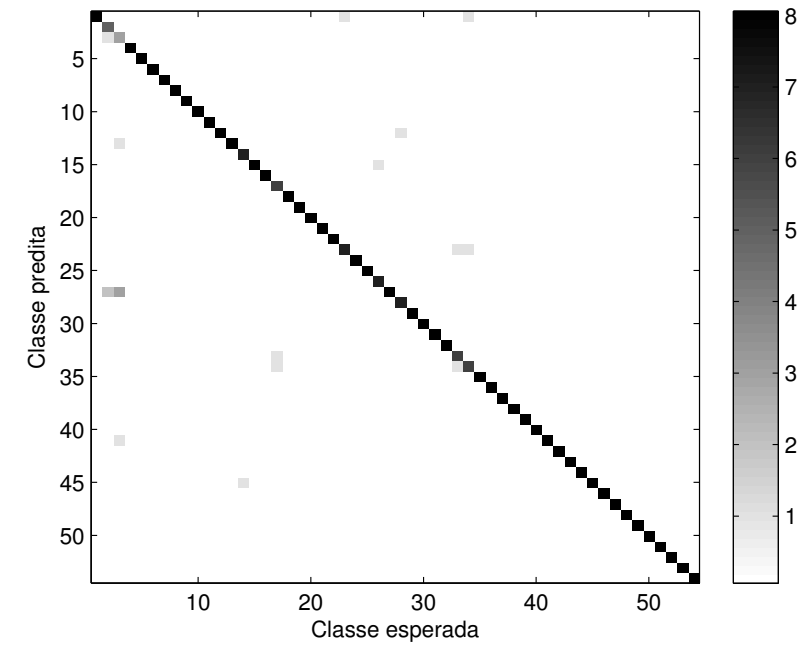

(d)

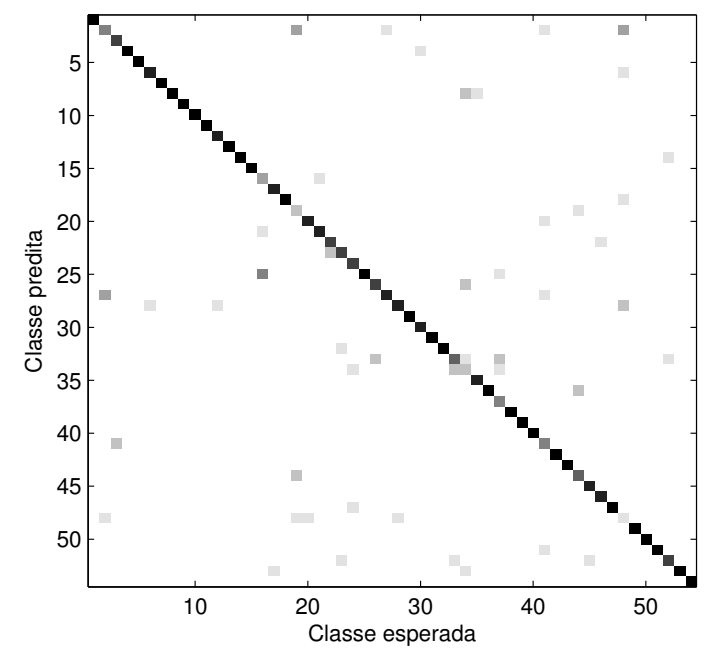

(f)

Figura 7.8 - Matrizes de confusão (parte 1) para os métodos comparados sobre a base de Vistex, usando classificador KNN. (a) Multifractal 2. (b) LBP. (c) GLCM. (d) Wavelike. (e) Bouligand-Minkowski. (f) Fourier fractal. 


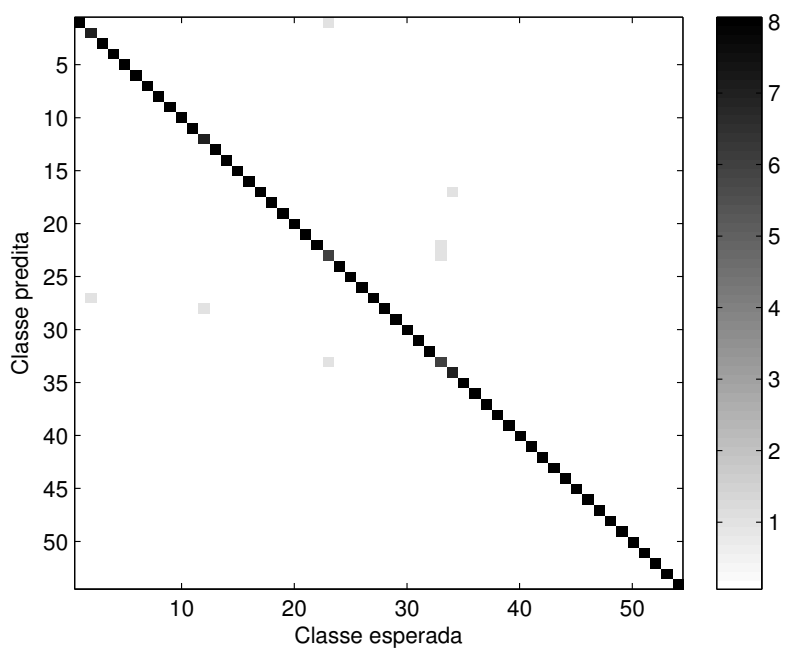

(a)

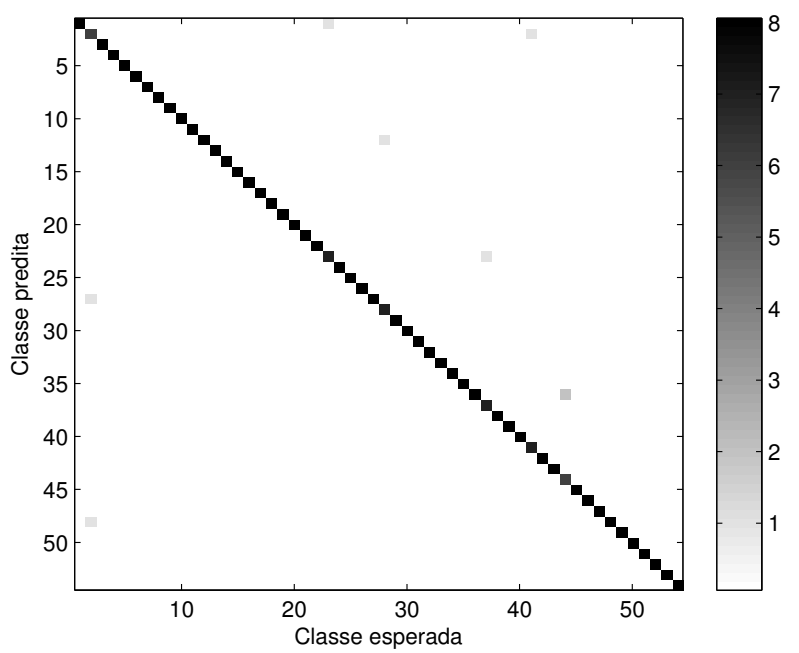

(b)

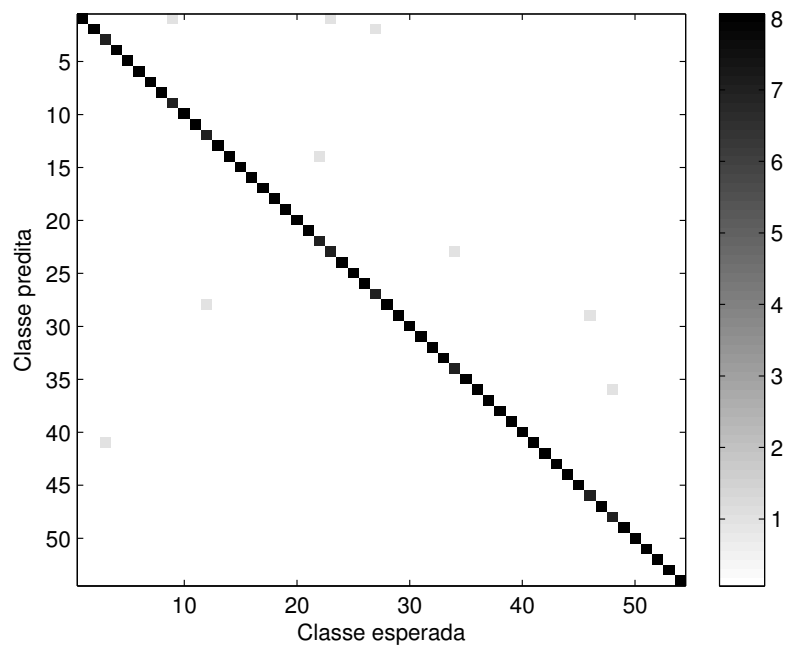

(c)

Figura 7.9 - Matrizes de confusão (parte 2) para os métodos comparados sobre a base de Vistex, usando classificador KNN. (a) Blanket + Wavelike. (b) Fourier + Wavelike. (c) Variograma + Wavelike. 
métodos fractais de Bouligand-Minkowski, Wavelike, Probabilidade e Wavelets apresentaram um índice de acerto satisfatório em relação às demais soluções na literatura.

Tabela 7.43 - Taxa de acerto para os descritores fractais em uso direto e outras medidas na base de Vistex, com classificador SVM.

\begin{tabular}{cccccc}
\hline Método & ND & TA $(\%)$ & $\kappa$ & E1 & E2 \\
\hline Fourier & 64 & 88.37 & 0.87 & 0.13 & 0.12 \\
GLCM & 67 & 70.93 & 0.69 & 0.30 & 0.31 \\
GLDM & 18 & 62.79 & 0.64 & 0.36 & 0.36 \\
Gabor & 19 & 82.56 & 0.83 & 0.17 & 0.17 \\
LBP & 16 & 97.67 & 0.95 & 0.05 & 0.04 \\
Laws & 15 & 77.91 & 0.73 & 0.27 & 0.26 \\
Multifractal 1 & 69 & 43.02 & 0.33 & 0.66 & 0.70 \\
Multifractal 2 & 17 & 68.60 & 0.71 & 0.29 & 0.29 \\
Multifractal 3 & 19 & 29.07 & 0.22 & 0.78 & 0.80 \\
\hline Blanket + TE & 11 & 81.40 & 0.72 & 0.28 & 0.28 \\
Bouligand-Minkowski + TF & 58 & 90.70 & 0.89 & 0.10 & 0.10 \\
Box-counting & 8 & 86.49 & 0.80 & 0.20 & 0.19 \\
Browniano & 24 & 73.87 & 0.65 & 0.35 & 0.37 \\
Fourier & 74 & 90.09 & 0.81 & 0.19 & 0.20 \\
Lacunaridade & 11 & 88.29 & 0.77 & 0.23 & 0.25 \\
Probabilidade & 7 & 90.09 & 0.82 & 0.18 & 0.17 \\
Triangular + EE & 19 & 88.37 & 0.82 & 0.18 & 0.18 \\
Variação + TF & 17 & 66.28 & 0.62 & 0.38 & 0.42 \\
Variograma & 9 & 84.68 & 0.76 & 0.24 & 0.22 \\
Wavelets & 31 & 90.09 & 0.83 & 0.17 & 0.16 \\
Wavelike + TF & 77 & 91.86 & 0.88 & 0.11 & 0.11 \\
\hline \hline
\end{tabular}

A Tabela 7.44 mostra as taxas de acerto e medidas correlatas para os descritores fractais individuais, após a operação de redução de dimensionalidade. Nota-se já em uma primeira análise que a taxa geral de acerto teve um leve aumento, consequência do aprendizado mais significativo de SVM. Olhando-se mais atentamente para cada método, nota-se que abordagens mais simples como os descritores de Lacunaridade e Triangular foram os que apresentaram maior ganho com a adoção do novo classificador. Estes descritores apresentam a informação de complexidade da textura de forma mais direta, permitindo que o processo de treinamento seja mais significativo e confiável para a classificação em si. Nos demais, as proporções entre as taxas de acerto se mantêm similares e mais uma vez os descritores Wavelike se destacam nesta tarefa de discriminação.

Tabela 7.44 - Taxa de acerto para os descritores fractais individuais na base de Vistex, classificados por SVM.

\begin{tabular}{lccccc}
\hline Método & ND & TA $(\%)$ & $\kappa$ & E1 & E2 \\
\hline Blanket & 8 & 75.00 & 0.75 & 0.25 & 0.23 \\
Bouligand-Minkowski & 20 & 90.05 & 0.90 & 0.10 & 0.09 \\
Box-counting & 6 & 61.81 & 0.61 & 0.38 & 0.39 \\
Browniano & 10 & 49.54 & 0.49 & 0.50 & 0.49 \\
Fourier & 13 & 85.88 & 0.86 & 0.14 & 0.13 \\
Lacunaridade & 11 & 64.35 & 0.64 & 0.36 & 0.34 \\
Probabilidade & 10 & 67.36 & 0.67 & 0.33 & 0.31 \\
Triangular & 10 & 77.55 & 0.77 & 0.22 & 0.23 \\
Variação & 9 & 61.34 & 0.61 & 0.39 & 0.35 \\
Variograma & 9 & 71.30 & 0.71 & 0.29 & 0.29 \\
Wavelike & 14 & 95.37 & 0.95 & 0.05 & 0.04 \\
\hline
\end{tabular}


A Tabela 7.45 mostra as taxas de acerto para os descritores fractais combinados e classificados por SVM. As combinações propiciam mais uma vez a obtenção de excelentes resultados, como Blanket+Wavelike, que obteve $98.61 \%$ de acerto com apenas 13 descritores. Um aspecto importante deste processo de combinação é que, diferentemente da concatenação pura e simples, a aplicação de CCA/PCA torna possível o ganho de desempenho com a composição dos diferentes paradigmas fractais, porém sem comprometer a eficiência e escalabilidade, garantindo taxas altas de acerto com um número reduzido de atributos.

Tabela 7.45 - Taxa de acerto para os descritores fractais individuais combinados na base de Vistex, classificados por SVM

\begin{tabular}{lccccccccccc}
\hline & $\mathbf{1}$ & $\mathbf{2}$ & $\mathbf{3}$ & $\mathbf{4}$ & $\mathbf{5}$ & $\mathbf{6}$ & $\mathbf{7}$ & $\mathbf{8}$ & $\mathbf{9}$ & $\mathbf{1 0}$ & $\mathbf{1 2}$ \\
\hline $\mathbf{1}$ & - & $96.29(19)$ & $83.56(13)$ & $85.64(18)$ & $93.98(14)$ & $87.9(14)$ & $87.0(17)$ & $90.97(15)$ & $84.49(15)$ & $90.97(12)$ & $98.61(13)$ \\
$\mathbf{2}$ & $96.29(19)$ & - & $92.36(18)$ & $91.89(20)$ & $97.22(15)$ & $91.66(18)$ & $91.89(18)$ & $93.98(9)$ & $93.51(20)$ & $93.98(20)$ & $97.45(12)$ \\
$\mathbf{3}$ & $83.56(13)$ & $92.36(18)$ & - & $84.49(20)$ & $90.97(8)$ & $76.85(13)$ & $78.24(7)$ & $89.81(12)$ & $78.47(16)$ & $87.26(11)$ & $96.75(20)$ \\
$\mathbf{4}$ & $85.64(18)$ & $91.89(20)$ & $84.49(20)$ & - & $93.05(20)$ & $83.56(18)$ & $82.63(18)$ & $83.79(17)$ & $80.55(15)$ & $88.65(19)$ & $95.60(11)$ \\
$\mathbf{5}$ & $93.98(14)$ & $97.22(15)$ & $90.97(8)$ & $93.05(20)$ & - & $94.67(19)$ & $95.37(18)$ & $94.67(18)$ & $93.2(17)$ & $93.98(14)$ & $99.5(18)$ \\
$\mathbf{6}$ & $87.9(14)$ & $91.66(18)$ & $76.85(13)$ & $83.56(18)$ & $94.67(19)$ & - & $80.7(12)$ & $85.18(18)$ & $78.47(11)$ & $82.17(18)$ & $96.29(19)$ \\
$\mathbf{7}$ & $87.0(17)$ & $91.89(18)$ & $78.24(7)$ & $82.63(18)$ & $95.37(18)$ & $80.7(12)$ & - & $89.58(12)$ & $80.09(14)$ & $86.34(15)$ & $97.45(20)$ \\
$\mathbf{8}$ & $90.97(15)$ & $93.98(9)$ & $89.81(12)$ & $83.79(17)$ & $94.67(18)$ & $85.18(18)$ & $89.58(12)$ & - & $87.0(20)$ & $86.11(15)$ & $97.45(20)$ \\
$\mathbf{9}$ & $84.49(15)$ & $93.51(20)$ & $78.47(16)$ & $80.55(15)$ & $93.2(17)$ & $78.47(11)$ & $80.09(14)$ & $87.0(20)$ & - & $88.42(19)$ & $96.99(19)$ \\
$\mathbf{1 0}$ & $90.97(12)$ & $93.98(20)$ & $87.26(11)$ & $88.65(19)$ & $93.98(14)$ & $82.17(18)$ & $86.34(15)$ & $86.11(15)$ & $88.42(19)$ & - & $98.14(20)$ \\
$\mathbf{1 2}$ & $98.61(13)$ & $97.45(12)$ & $96.75(20)$ & $95.60(11)$ & $99.5(18)$ & $96.29(19)$ & $97.45(20)$ & $97.45(20)$ & $96.99(19)$ & $98.14(20)$ & - \\
\hline
\end{tabular}

A Tabela 7.46 mostra o desempenho dos descritores transformados por FDA. De um modo geral, houve queda na taxa de acerto ou aumentos pequenos, que não justificam o uso da transformada neste caso. A Análise de Dados Funcionais mostra-se mais interessante diante de métodos que possuem baixa taxa de acerto em função da presença de variações (de alta frequência) que não constituem informação efetivamente útil ao classificador. Ocorre que com os descritores analisados em situações mais complexas, estas flutuações correspondem, na maioria vezes, a um dado que deve ser relevado no processo e colabora para uma representação mais rica da textura.

Tabela 7.46 - Taxa de acerto para os descritores fractais FDA na base de Vistex, classificados por SVM.

\begin{tabular}{lccccc}
\hline Método & ND & TA $(\%)$ & $\kappa$ & E1 & E2 \\
\hline Blanket & 7 & 75.46 & 0.75 & 0.25 & 0.24 \\
Bouligand-Minkowski & 19 & 86.11 & 0.86 & 0.14 & 0.14 \\
Box-counting & 8 & 65.51 & 0.65 & 0.34 & 0.35 \\
Browniano & 7 & 45.37 & 0.45 & 0.55 & 0.49 \\
Fourier & 14 & 81.25 & 0.81 & 0.19 & 0.18 \\
Lacunaridade & 19 & 65.51 & 0.65 & 0.34 & 0.34 \\
Probabilidade & 19 & 57.18 & 0.57 & 0.43 & 0.45 \\
Triangular & 8 & 69.91 & 0.70 & 0.30 & 0.28 \\
Variação & 13 & 57.41 & 0.57 & 0.43 & 0.43 \\
Variograma & 18 & 71.76 & 0.71 & 0.28 & 0.30 \\
Wavelets & 11 & 78.47 & 0.78 & 0.22 & 0.21 \\
Wavelike & 16 & 90.51 & 0.90 & 0.09 & 0.09 \\
\hline
\end{tabular}

Já a Tabela 7.47 exibe as taxas de acerto e respectivas quantidades de descritores para as combinações em pares de descritores transformados por FDA. As taxas de acerto não são satisfatórias, sendo que poucas romperam a barreira dos $90 \%$. Mais uma vez, existem 
combinações com desempenho pior que os descritores aplicados separadamente. Deste modo, prefere-se o uso dos descritores individuais, exceto em alguns casos como nos descritores de Blanket e Lacunaridade, quando a transformação pode aumentar a taxa de acerto em função da suavização de dados irrelevantes.

Tabela 7.47 - Taxa de acerto para os descritores fractais FDA combinados na base de Vistex, classificados por SVM.

\begin{tabular}{|c|c|c|c|c|c|c|c|c|c|c|c|c|}
\hline & 1 & 2 & 3 & 4 & 5 & 6 & 7 & 8 & 9 & 10 & 11 & 12 \\
\hline 1 & - & $89.12(12)$ & $81.01(9)$ & $83.79(14)$ & $95.13(20)$ & $71.52(20)$ & $80.7(10)$ & $82.40(18)$ & $79.39(9)$ & $80.55(11)$ & $82.40(12)$ & $86.34(9)$ \\
\hline 2 & $89.12(12)$ & - & 73.61(10) & $82.17(11)$ & $95.83(14)$ & $74.30(7)$ & $71.75(15)$ & $84.25(10)$ & $74.76(16)$ & $82.40(12)$ & $82.40(8)$ & $92.82(20)$ \\
\hline 3 & $81.01(9)$ & $73.61(10)$ & - & $80.09(19)$ & $87.9(20)$ & $74.30(18)$ & $59.95(9)$ & $73.14(14)$ & $69.44(11)$ & $78.70(12)$ & $86.80(20)$ & $67.36(20)$ \\
\hline 4 & 83.79(14) & $82.17(11)$ & $80.09(19)$ & - & $89.35(13)$ & $62(19)$ & $76.15(8)$ & $72.22(20)$ & $75.69(19)$ & $66.89(19)$ & $83.79(20)$ & $83.33(10)$ \\
\hline 5 & $95.13(20)$ & $95.83(14)$ & $87.9(20)$ & $89.35(13)$ & - & $87.73(11)$ & $81.7(12)$ & $87.0(14)$ & $87.9(19)$ & $88.88(12)$ & 81.(19) & $95.83(19)$ \\
\hline 6 & $71.52(20)$ & $74.30(7)$ & $74.30(18)$ & $62(19)$ & $87.73(11)$ & - & $74.07(7)$ & $74.30(14)$ & $74.07(18)$ & $79.62(13)$ & $80.7(20)$ & $77.54(8)$ \\
\hline 7 & $80.7(10)$ & $71.75(15)$ & $59.95(9)$ & $76.15(8)$ & $81.7(12)$ & $74.07(7)$ & - & $71.52(17)$ & $64.35(20)$ & $72.22(16)$ & $77.77(20)$ & $70.60(10)$ \\
\hline 8 & $82.40(18)$ & $84.25(10)$ & 73.14(14) & $72.22(20)$ & $87.0(14)$ & $74.30(14)$ & $71.52(17)$ & - & $71.52(17)$ & $79.16(13)$ & $82.40(14)$ & $83.33(9)$ \\
\hline 9 & $79.39(9)$ & $74.76(16)$ & $69.44(11)$ & $75.69(19)$ & $87.9(19)$ & $74.07(18)$ & $64.35(20)$ & $71.52(17)$ & - & $79.16(18)$ & $84.25(9)$ & (7) \\
\hline 10 & $80.55(11)$ & $82.40(12)$ & $78.70(12)$ & $66.89(19)$ & $88.88(12)$ & $79.62(13)$ & $72.22(16)$ & $79.16(13)$ & $79.16(18)$ & - & $81.01(15)$ & $75.92(12)$ \\
\hline 11 & $82.40(12)$ & $82.40(8)$ & $86.80(20)$ & $83.79(20)$ & 81.(19) & $80.7(20)$ & $77.77(20)$ & $82.40(14)$ & $84.25(9)$ & $81.01(15)$ & - & $85.87(8)$ \\
\hline 12 & $86.34(9)$ & $92.82(20)$ & $67.36(20)$ & $83.33(10)$ & $95.83(19)$ & $77.54(8)$ & $70.60(10)$ & $83.33(9)$ & (7) & $75.92(12)$ & $85.87(8)$ & - \\
\hline
\end{tabular}

Já a Tabela 7.48 mostra as taxas de acerto e outras medidas para os descritores fractais transformados por espaço-escala. Assim como ocorreu na classificação por KNN, alguns métodos não puderam ter seu acerto estimado em função da impossibilidade de cálculo dos autovalores da matriz de covariância. Entre os métodos analisados, o único que apresentou ganho em relação à versão original foram os descritores de Wavelets. Os demais apresentaram uma forte queda na maioria dos casos. O método de Wavelets é baseado no cálculo de energias da transformada de melhor base, energias estas que apresentam forte variação, sobretudo nos primeiros valores, assim o uso da derivada espaço-escala torna-se interessante uma vez que expressa essa informação que é camuflada nos descritores originais e pode ser usada dentro do processo de treinamento de SVM. Nos demais casos, os descritores se apresentam mais correlacionados entre si e a variação não exibe distinção suficiente para uma classificação precisa.

Tabela 7.48 - Taxa de acerto para os descritores fractais espaço-escala na base de Vistex, classificados por SVM.

\begin{tabular}{lccccc}
\hline Método & ND & TA (\%) & $\kappa$ & E1 & E2 \\
\hline Box-counting & 18 & 59.03 & 0.59 & 0.41 & 0.40 \\
Browniano & 16 & 35.42 & 0.35 & 0.65 & 0.56 \\
Fourier & 12 & 68.98 & 0.69 & 0.31 & 0.30 \\
Triangular & 19 & 75.00 & 0.75 & 0.25 & 0.24 \\
Variação & 14 & 53.47 & 0.53 & 0.47 & 0.42 \\
Variograma & 15 & 59.26 & 0.59 & 0.41 & 0.37 \\
Wavelets & 17 & 81.02 & 0.81 & 0.19 & 0.20 \\
Wavelike & 16 & 77.78 & 0.77 & 0.22 & 0.20 \\
\hline
\end{tabular}

A Tabela 7.49 exibe as taxas de acerto para os descritores combinados. Nota-se que mesmo com o incremento no acerto do método de Wavelets, as taxas para as combinações ainda são baixas e não se apresentam como viáveis quando comparadas a outros métodos da literatura e, sobretudo, a combinações de descritores fractais mais robustos. Ainda assim, o 
melhor resultado foi obtido por Wavelets+Variação, dois métodos que apresentam resultados ainda piores se analisados separadamente.

Tabela 7.49 - Taxa de acerto para os descritores fractais espaço-escala combinados na base de Vistex, classificados por SVM.

\begin{tabular}{lcccccccc}
\hline & $\mathbf{3}$ & $\mathbf{4}$ & $\mathbf{5}$ & $\mathbf{8}$ & $\mathbf{9}$ & $\mathbf{1 0}$ & $\mathbf{1 1}$ & $\mathbf{1 2}$ \\
\hline $\mathbf{3}$ & - & $69.67(19)$ & $36.80(10)$ & $85.41(20)$ & $72.22(20)$ & $82.87(20)$ & $69.44(20)$ & $81.01(19)$ \\
$\mathbf{4}$ & $69.67(19)$ & - & $44.2(20)$ & $74.76(13)$ & $63.65(12)$ & $62.0(13)$ & $81.48(16)$ & $74.30(20)$ \\
$\mathbf{5}$ & $36.80(10)$ & $44.2(20)$ & - & $72.91(10)$ & $71.06(15)$ & $68.05(10)$ & $79.39(20)$ & $71.52(17)$ \\
$\mathbf{8}$ & $85.41(20)$ & $74.76(13)$ & $72.91(10)$ & - & $76.38(20)$ & $85.87(17)$ & $57.63(14)$ & $79.39(19)$ \\
$\mathbf{9}$ & $72.22(20)$ & $63.65(12)$ & $71.06(15)$ & $76.38(20)$ & - & $81 .(13)$ & $67.82(10)$ & $77.54(20)$ \\
$\mathbf{1 0}$ & $82.87(20)$ & $62.0(13)$ & $68.05(10)$ & $85.87(17)$ & $81 .(13)$ & - & $67.36(20)$ & $75.4(16)$ \\
$\mathbf{1 1}$ & $69.44(20)$ & $81.48(16)$ & $79.39(20)$ & $57.63(14)$ & $67.82(10)$ & $67.36(20)$ & - & $(19)$ \\
$\mathbf{1 2}$ & $81.01(19)$ & $74.30(20)$ & $71.52(17)$ & $79.39(19)$ & $77.54(20)$ & $75.4(16)$ & $(19)$ & - \\
\hline
\end{tabular}

Por sua vez, a Tabela 7.50 explicita as taxas de acerto, números de descritores e medidas estatísticas para a base de Vistex, com os descritores fractais transformados por tempofrequência. Os resultados indicam pequenas variações para mais ou para menos nas taxas de acerto. Novamente, esta abordagem não se mostra tão eficaz para estes descritores, confirmando que a base de Vistex não aceita bem essa transformada sobre seus descritores. Esta incompatibilidade é justificada pela maior variação entre as intensidades de cores (transformadas em tons de cinza) dentro de uma mesma classe, fazendo com que a análise de frequência em janelas fixas empobreça o significado original da informação contida no descritor.

Tabela 7.50 - Taxa de acerto para os descritores fractais tempo-frequência na base de Vistex, classificados por SVM.

\begin{tabular}{lccccc}
\hline Método & ND & TA $(\%)$ & $\kappa$ & E1 & E2 \\
\hline Blanket & 4 & 59.26 & 0.59 & 0.41 & 0.40 \\
Bouligand-Minkowski & 11 & 79.17 & 0.79 & 0.21 & 0.20 \\
Box-counting & 14 & 64.35 & 0.64 & 0.36 & 0.38 \\
Browniano & 13 & 49.07 & 0.49 & 0.51 & 0.49 \\
Fourier & 13 & 83.56 & 0.83 & 0.16 & 0.15 \\
Lacunaridade & 18 & 62.96 & 0.63 & 0.37 & 0.38 \\
Probabilidade & 15 & 65.97 & 0.66 & 0.34 & 0.33 \\
Triangular & 16 & 80.09 & 0.80 & 0.20 & 0.20 \\
Variação & 18 & 64.58 & 0.64 & 0.35 & 0.35 \\
Variograma & 19 & 69.21 & 0.69 & 0.31 & 0.27 \\
Wavelets & 17 & 81.02 & 0.81 & 0.19 & 0.15 \\
Wavelike & 13 & 90.05 & 0.90 & 0.10 & 0.10 \\
\hline
\end{tabular}

Por sua vez, a Tabela 7.51 exibe as taxas de acerto obtidas pelos descritores combinados em pares. A baixa eficiência da transformação tempo-frequência é realçada pelos resultados que, quando comparados aos descritores individuais, apresentam-se menores na maioria das situações possíveis. Nota-se que até mesmo o método de Wavelike não foi capaz de produzir combinações com taxas de acerto mais altas que os métodos da literatura. Essa transformada também se mostra falha na tentativa de incrementar o poder de análise/discriminação dos descritores fractais.

Encerrando o comparativo das transformações sobre os descritores fractais, exibe-se na Tabela 7.52, o resultado para os descritores transformados por tempo-escala. Os descritores 
Tabela 7.51 - Taxa de acerto para os descritores fractais tempo-frequência combinados na base de Vistex, classificados por SVM.

\begin{tabular}{|c|c|c|c|c|c|c|c|c|c|c|c|c|}
\hline & 1 & 2 & 3 & 4 & 5 & 6 & 7 & 8 & 9 & 10 & 11 & 12 \\
\hline 1 & - & $65.04(20)$ & $59.72(20)$ & $72.45(20)$ & $60.64(19)$ & $67.12(20)$ & $63.65(15)$ & $65.04(20)$ & $59.95(20)$ & $57.87(20)$ & $76.62(16)$ & 77.77(18) \\
\hline 2 & $65.04(20)$ & - & $72.22(18)$ & $89.12(17)$ & $89.58(8)$ & $60.64(18)$ & $75.69(19)$ & $83.10(19)$ & $66.20(15)$ & $80.7(16)$ & 81.(14) & $83.10(17)$ \\
\hline 3 & $59.72(20)$ & $72.22(18)$ & & $76.85(12)$ & $61.34(19)$ & $73.37(14)$ & $75.92(20)$ & $84.95(18)$ & $76.85(19)$ & $83.79(20)$ & $77.08(10)$ & $77.77(19)$ \\
\hline 4 & $72.45(20)$ & $89.12(17)$ & $76.85(12)$ & 管 & $72.68(20)$ & $71.06(13)$ & $82.87(9)$ & $78.93(10)$ & $81.01(18)$ & $77.08(16)$ & $76.85(15)$ & $86.11(20)$ \\
\hline 5 & $60.64(19)$ & $89.58(8)$ & $61.34(19)$ & $72.68(20)$ & - & $72.45(20)$ & $78.24(20)$ & $79.62(20)$ & $76.62(20)$ & $80.7(20)$ & $84.02(19)$ & $92.12(14)$ \\
\hline 6 & $67.12(20)$ & $60.64(18)$ & $73.37(14)$ & $71.06(13)$ & $72.45(20)$ & - & $75.92(19)$ & $80.7(17)$ & $73.61(20)$ & $83.33(19)$ & $77.77(16)$ & $78.00(17)$ \\
\hline 7 & $63.65(15)$ & $75.69(19)$ & $75.92(20)$ & $82.87(9)$ & $78.24(20)$ & $75.92(19)$ & - & $81.7(18)$ & $75.69(17)$ & $79.39(20)$ & $77.77(8)$ & $79.16(20)$ \\
\hline 8 & $65.04(20)$ & $83.10(19)$ & $84.95(18)$ & 78.93(10) & $79.62(20)$ & $80.7(17)$ & $81.7(18)$ & & $80.09(20)$ & $79.86(20)$ & $84.72(20)$ & 78.93(18) \\
\hline 9 & $59.95(20)$ & $66.20(15)$ & $76.85(19)$ & $81.01(18)$ & $76.62(20)$ & $73.61(20)$ & $75.69(17)$ & $80.09(20)$ & & $83.79(18)$ & $83.33(10)$ & $81.48(19)$ \\
\hline 10 & $57.87(20)$ & $80.7(16)$ & $83.79(20)$ & $77.08(16)$ & $80.7(20)$ & $83.33(19)$ & $79.39(20)$ & $79.86(20)$ & $83.79(18)$ & - & $80.7(14)$ & $78.24(18)$ \\
\hline 11 & $76.62(16)$ & 81.(14) & $77.08(10)$ & $76.85(15)$ & $84.02(19)$ & $77.77(16)$ & $77.77(8)$ & $84.72(20)$ & $83.33(10)$ & $80.7(14)$ & - & $90.97(18)$ \\
\hline 12 & $77.77(18)$ & $83.10(17)$ & $77.77(19)$ & $86.11(20)$ & $92.12(14)$ & $78.00(17)$ & $79.16(20)$ & $78.93(18)$ & $81.48(19)$ & $78.24(18)$ & $90.97(18)$ & - \\
\hline
\end{tabular}

apresentam quedas e aumentos leves na taxa de acerto, com exceção do método de Fourier que teve queda expressiva em seu índice de sucesso na classificação. Como já discutido, este fenômeno ocorre em função do fato de uma análise de frequências como a realizada pela transformada wavelet na abordagem tempo-escala suprimir informações importantes do espectro de potência da textura. Já nos demais casos, este efeito se sente de forma menos drástica, havendo métodos que possuem maior ou menor compatibilidade com análise de frequências por banda variável.

Tabela 7.52 - Taxa de acerto para os descritores fractais tempo-escala na base de Vistex, classificados por SVM.

\begin{tabular}{lccccc}
\hline Método & ND & TA $(\%)$ & $\kappa$ & E1 & E2 \\
\hline Blanket & 13 & 76.16 & 0.76 & 0.24 & 0.23 \\
Bouligand-Minkowski & 16 & 90.97 & 0.91 & 0.09 & 0.08 \\
Box-counting & 5 & 60.88 & 0.61 & 0.39 & 0.38 \\
Browniano & 10 & 54.63 & 0.54 & 0.45 & 0.39 \\
Fourier & 7 & 26.85 & 0.27 & 0.73 & 0.73 \\
Lacunaridade & 8 & 70.60 & 0.70 & 0.29 & 0.27 \\
Probabilidade & 5 & 67.13 & 0.67 & 0.33 & 0.32 \\
Triangular & 6 & 77.55 & 0.77 & 0.22 & 0.21 \\
Variação & 7 & 63.43 & 0.63 & 0.37 & 0.39 \\
Variograma & 6 & 73.15 & 0.73 & 0.27 & 0.25 \\
Wavelets & 10 & 74.54 & 0.74 & 0.25 & 0.26 \\
Wavelike & 14 & 91.67 & 0.92 & 0.08 & 0.07 \\
\hline
\end{tabular}

Por fim, a Tabela 7.53 mostra os resultados para os descritores combinados. Os ganhos que ocorrem em algumas combinações refletem a melhoria obtida nos descritores individuais. Este tipo de comportamento é esperado estatisticamente, embora esta associação entre os resultados combinados e individuais não seja tão linear em função da forma como cada transformada age sobre a visão que cada descritor oferece da imagem.

\subsubsection{Outros Métodos}

A Tabela 7.54 exibe as taxas de acerto, números de descritores e medidas estatísticas, bem como acerto efetivo e erro para os outros métodos de análise de texturas encontrados na literatura e comparados aos descritores fractais para verificar a aplicabilidade destes últimos. Assim como ocorria no caso da classificação por KNN, os métodos LBP e Multifractal 2 se 
Tabela 7.53 - Taxa de acerto para os descritores fractais tempo-escala combinados na base de Vistex, classificados por SVM.

\begin{tabular}{ccccccccccccc}
\hline & $\mathbf{1}$ & $\mathbf{2}$ & $\mathbf{3}$ & $\mathbf{4}$ & $\mathbf{5}$ & $\mathbf{6}$ & $\mathbf{7}$ & $\mathbf{8}$ & $\mathbf{9}$ & $\mathbf{1 0}$ & $\mathbf{1 1}$ & $\mathbf{1 2}$ \\
\hline $\mathbf{1}$ & - & $93.2(15)$ & $84.25(8)$ & $85.87(20)$ & $80.32(17)$ & $85.87(7)$ & $86.80(18)$ & $87.9(15)$ & $80.7(8)$ & $91.20(14)$ & $87.0(10)$ & $94.90(20)$ \\
$\mathbf{2}$ & $93.2(15)$ & - & $92.12(16)$ & $93.05(20)$ & $93 .(20)$ & $90.74(20)$ & $91.43(19)$ & $95.37(20)$ & $90.50(20)$ & $95.83(20)$ & $96.06(20)$ & $96.99(20)$ \\
$\mathbf{3}$ & $84.25(8)$ & $92.12(16)$ & - & $86.34(13)$ & $71.75(7)$ & $80.32(13)$ & $75.69(6)$ & $87.9(11)$ & $76.62(10)$ & $90.50(12)$ & $87.73(9)$ & $93 .(18)$ \\
$\mathbf{4}$ & $85.87(20)$ & $93.05(20)$ & $86.34(13)$ & - & $69.44(9)$ & $83.79(17)$ & $86.57(16)$ & $81.94(15)$ & $79.86(19)$ & $84.95(12)$ & $73.14(10)$ & $93.98(20)$ \\
$\mathbf{5}$ & $80.32(17)$ & $93 .(20)$ & $71.75(7)$ & $69.44(9)$ & - & $76.15(11)$ & $75.4(8)$ & $77.08(9)$ & $71.99(10)$ & $71.29(8)$ & $76.38(13)$ & $94.2(20)$ \\
$\mathbf{6}$ & $85.87(7)$ & $90.74(20)$ & $80.32(13)$ & $83.79(17)$ & $76.15(11)$ & - & $79.62(15)$ & $85.18(12)$ & $81.94(10)$ & $89.12(14)$ & $83.56(7)$ & $92.36(20)$ \\
$\mathbf{7}$ & $86.80(18)$ & $91.43(19)$ & $75.69(6)$ & $86.57(16)$ & $75.4(8)$ & $79.62(15)$ & - & $86.80(12)$ & $80.7(12)$ & $91.43(13)$ & $84.49(9)$ & $93 .(19)$ \\
$\mathbf{8}$ & $87.9(15)$ & $95.37(20)$ & $87.9(11)$ & $81.94(15)$ & $77.08(9)$ & $85.18(12)$ & $86.80(12)$ & - & $84.95(14)$ & $89.35(14)$ & $84.49(8)$ & $95.37(20)$ \\
$\mathbf{9}$ & $80.7(8)$ & $90.50(20)$ & $76.62(10)$ & $79.86(19)$ & $71.99(10)$ & $81.94(10)$ & $80.7(12)$ & $84.95(14)$ & - & $84.25(14)$ & $84.49(8)$ & $93.2(20)$ \\
$\mathbf{1 0}$ & $91.20(14)$ & $95.83(20)$ & $90.50(12)$ & $84.95(12)$ & $71.29(8)$ & $89.12(14)$ & $91.43(13)$ & $89.35(14)$ & $84.25(14)$ & - & $85.64(12)$ & $96.29(20)$ \\
$\mathbf{1 1}$ & $87.0(10)$ & $96.06(20)$ & $87.73(9)$ & $73.14(10)$ & $76.38(13)$ & $83.56(7)$ & $84.49(9)$ & $84.49(8)$ & $84.49(8)$ & $85.64(12)$ & - & $93.2(11)$ \\
$\mathbf{1 2}$ & $94.90(20)$ & $96.99(20)$ & $93 .(18)$ & $93.98(20)$ & $94.2(20)$ & $92.36(20)$ & $93 .(19)$ & $95.37(20)$ & $93.2(20)$ & $96.29(20)$ & $93.2(11)$ & - \\
\hline
\end{tabular}

destacam, sendo seguidos pelas matrizes de co-ocorrência e Gabor-wavelets. Estes resultados refletem a eficiência de métodos estado-da-arte ou já consagrados e que possuem sua eficácia já bem conhecida na literatura da área.

Tabela 7.54 - Taxa de acerto para os métodos da literatura na base de Vistex, classificados por SVM.

\begin{tabular}{lccccc}
\hline Método & ND & TA $(\%)$ & $\kappa$ & E1 & E2 \\
\hline Fourier & 20 & 84.49 & 0.84 & 0.16 & 0.14 \\
GLCM & 17 & 90.05 & 0.90 & 0.10 & 0.09 \\
GLDM & 17 & 57.64 & 0.57 & 0.42 & 0.41 \\
Gabor & 19 & 90.51 & 0.90 & 0.09 & 0.08 \\
LBP & 20 & 92.59 & 0.92 & 0.07 & 0.07 \\
Laws & 14 & 81.94 & 0.82 & 0.18 & 0.16 \\
Multifractal 1 & 9 & 44.21 & 0.44 & 0.56 & 0.55 \\
Multifractal 2 & 12 & 92.13 & 0.92 & 0.08 & 0.07 \\
Multifractal 3 & 4 & 13.89 & 0.14 & 0.86 & 0.85 \\
\hline
\end{tabular}

\subsubsection{Resumo dos Resultados}

A Tabela 7.55 exibe um sumário dos resultados obtidos por todas as abordagens comparadas.

Mais uma vez, os descritores fractais obtiveram melhores taxas de acerto usando a transformação tempo-escala ou mesmo os descritores individuais. Entretanto, há que se observar que na maioria dos casos o ganho pela transformação é pequeno e, sobretudo quando questões de custo computacional estão envolvidas, pode ser interessante o uso direto dos descritores originais. Os métodos com maior acerto foram, pela ordem, Wavelike, Bouligand-Minkowski e Fourier. Este resultado confirma o obtido pelo classificador KNN e realça o poder de classificação do método Wavelike, que apresentou sensível vantagem em relação ao método de Bouligand-Minkowski, que lhe dá origem. Já o método de Probabilidade que tinha sido eficiente na base de Brodatz dá lugar a Fourier, que se sobressai com sua análise espectral nesta base com informação de cor e variações de luminosidade.

Já no caso dos descritores fractais combinados, o resultado também confirma aquele obtido por KNN, sendo que todas as melhores combinações foram obtidas usando-se descritores 
individuais, sem qualquer tipo de transformação. Desta forma, a informação extraída por cada método é usada em todo o seu potencial, sem qualquer influência de transformadas que alterem a visão dada da imagem. Os melhores acertos se aproximaram de 100\%, comprovando a eficácia destas combinações, superando com larga vantagem métodos de grande aceitação como LBP.

Tabela 7.55 - Resumo das taxas de acerto obtidas para a base de Vistex, classificada por SVM.

\begin{tabular}{lccccc}
\hline Método & ND & TA $(\%)$ & $\kappa$ & E1 & E2 \\
\hline LBP & 20 & 92.59 & 0.92 & 0.07 & 0.07 \\
Multifractal 2 & 12 & 92.13 & 0.92 & 0.08 & 0.07 \\
Gabor & 19 & 90.51 & 0.90 & 0.09 & 0.08 \\
GLCM & 17 & 90.05 & 0.90 & 0.10 & 0.09 \\
Fourier & 20 & 84.49 & 0.84 & 0.16 & 0.14 \\
Laws & 14 & 81.94 & 0.82 & 0.18 & 0.16 \\
GLDM & 17 & 57.64 & 0.57 & 0.42 & 0.41 \\
Multifractal 1 & 9 & 44.21 & 0.44 & 0.56 & 0.55 \\
Multifractal 3 & 4 & 13.89 & 0.14 & 0.86 & 0.85 \\
\hline \hline Wavelike & 14 & 95.37 & 0.95 & 0.05 & 0.04 \\
Bouligand-Minkowski + TE & 16 & 90.97 & 0.91 & 0.09 & 0.08 \\
Fourier & 13 & 85.88 & 0.86 & 0.14 & 0.13 \\
Wavelets + EE & 17 & 81.02 & 0.81 & 0.19 & 0.20 \\
Triangular + TF & 16 & 80.09 & 0.80 & 0.20 & 0.20 \\
Blanket + TE & 13 & 76.16 & 0.76 & 0.24 & 0.23 \\
Variograma + TE & 6 & 73.15 & 0.73 & 0.27 & 0.25 \\
Lacunaridade + TE & 8 & 70.60 & 0.70 & 0.29 & 0.27 \\
Probabilidade & 10 & 67.36 & 0.67 & 0.33 & 0.31 \\
Box-counting + FDA & 8 & 65.51 & 0.65 & 0.34 & 0.35 \\
Variação + TF & 18 & 64.58 & 0.64 & 0.35 & 0.35 \\
Browniano + TE & 10 & 54.63 & 0.54 & 0.45 & 0.39 \\
\hline \hline Fourier+Wavelike & 18 & 99.54 & 1.00 & 0.00 & 0.00 \\
Blanket+Wavelike & 13 & 98.61 & 0.99 & 0.01 & 0.01 \\
Variograma+Wavelike & 20 & 98.15 & 0.98 & 0.02 & 0.02 \\
Bouligand-Minkowski+Wavelike & 12 & 97.45 & 0.97 & 0.03 & 0.02 \\
Probabilidade+Wavelike & 20 & 97.45 & 0.97 & 0.03 & 0.02 \\
Triangular+Wavelike & 20 & 97.45 & 0.97 & 0.03 & 0.02 \\
Variação+Wavelike & 19 & 96.99 & 0.97 & 0.03 & 0.03 \\
Box-counting+Wavelike & 20 & 96.76 & 0.97 & 0.03 & 0.03 \\
Lacunaridade+Wavelike & 19 & 96.30 & 0.96 & 0.04 & 0.03 \\
Browniano+Wavelike & 11 & 95.60 & 0.96 & 0.04 & 0.04 \\
\hline
\end{tabular}

Por sua vez, a Figura 7.10 mostra as taxas de acerto em função do número de descritores para cada um dos melhores três métodos por categoria. O aspecto geral de cada curva se assemelha ao obtido na classificação por KNN, sendo que a combinação Fourier+Wavelike propiciou o melhor nível de corretude com poucos descritores. Estas são abordagens que separadamente apresentam diferentes paradigmas de análise de complexidade (espectral e espacial), mas quando juntas fornecem descritores completos e precisos. Já o método de LBP, embora tenha se saído melhor entre as opções da literatura, teve o aumento mais lento nos primeiros descritores, exigindo um número maior de atributos para alcançar um resultado razoável. Este número maior pode constituir uma deficiência tanto em relação ao custo computacional que pode ser proibitivo em determinadas aplicações, quanto em relação à confiabilidade, podendo levar a aberrações como o chamado "mal da dimensionalidade" (113). 


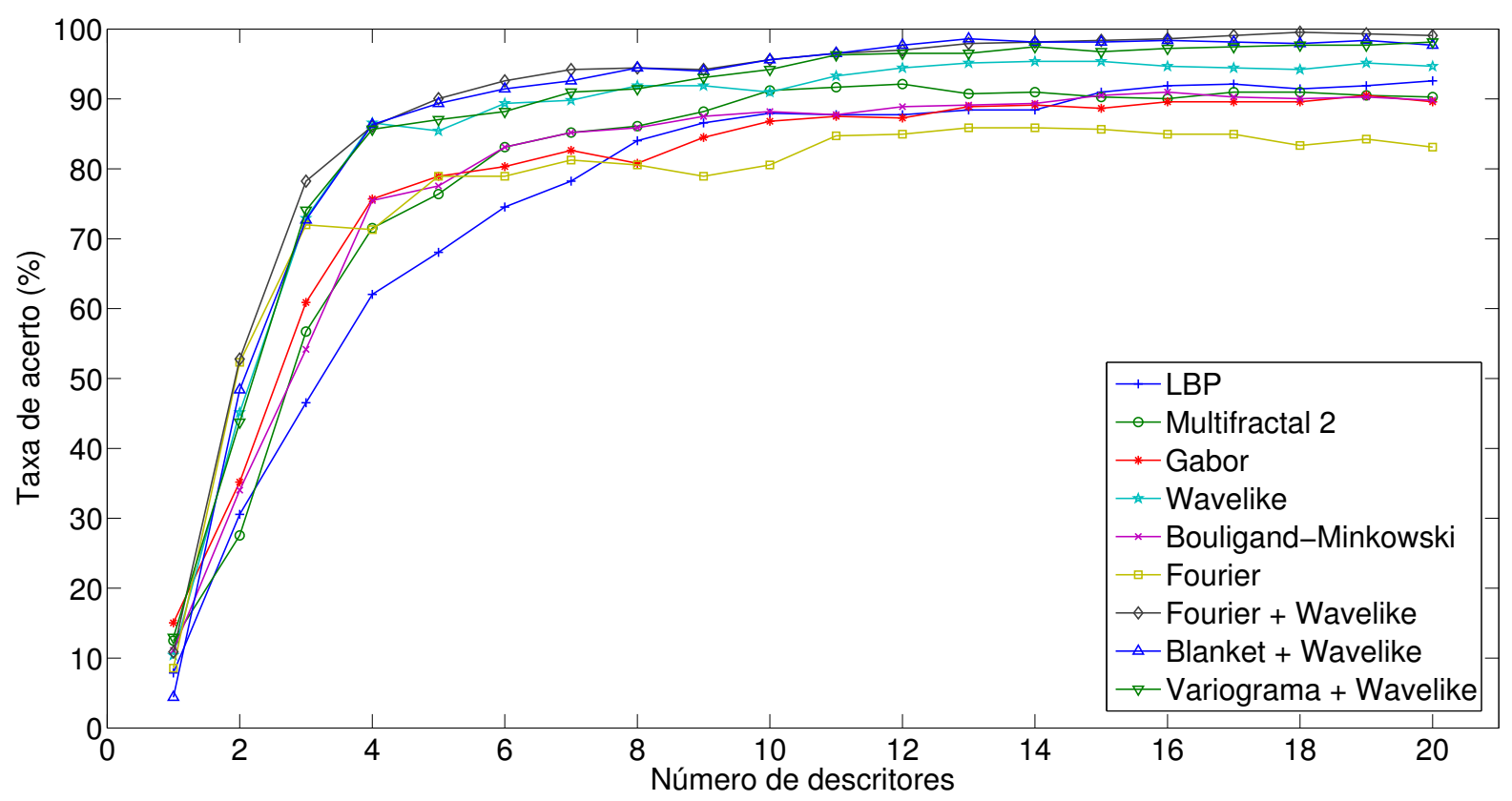

Figura 7.10 - Taxas de acerto em função do número de descritores para a base de Vistex, com classificação por SVM.

Finalmente, as Figuras 7.11 e 7.12 traçam em mapas de intensidade as matrizes de confusão dos métodos representados na Figura 7.10, para o número de descritores que levou ao maior acerto. As matrizes são similares às obtidas por KNN apresentando novamente pontos de confusão em classes como a 33/34, embora esta deficiência seja levemente atenuada pelo classificador mais robusto. Os descritores combinados geraram as matrizes de melhor aspecto, com diagonais contínuas e com pontos mais escuros fora da diagonal. Esta matriz permite ainda que se observe que as combinações Blanket+Wavelike e Variograma+Wavelike apresentam padrões um pouco diferentes. Enquanto a primeira apresentou um erro um maior erro do tipo 1, quando o método atribuiu imagens a outras classes, o segundo apresenta um erro mais espalhado. A classe 1 possui de fato uma variação forte de padrões, dificultando a função de métodos morfológicos como Wavelike e Blanket.

\subsection{Vistex Cores}

A seguir, passa-se à análise dos descritores fractais desenvolvidos durante este projeto com o intuito de descrever imagens coloridas levando em conta a informação de cor. É importante frisar que novamente a base de Vistex é analisada, entretanto agora sob outra perspectiva e comparando-se o resultado com outros métodos encontrados na literatura e apresentados como específicos para análise de texturas coloridas. 


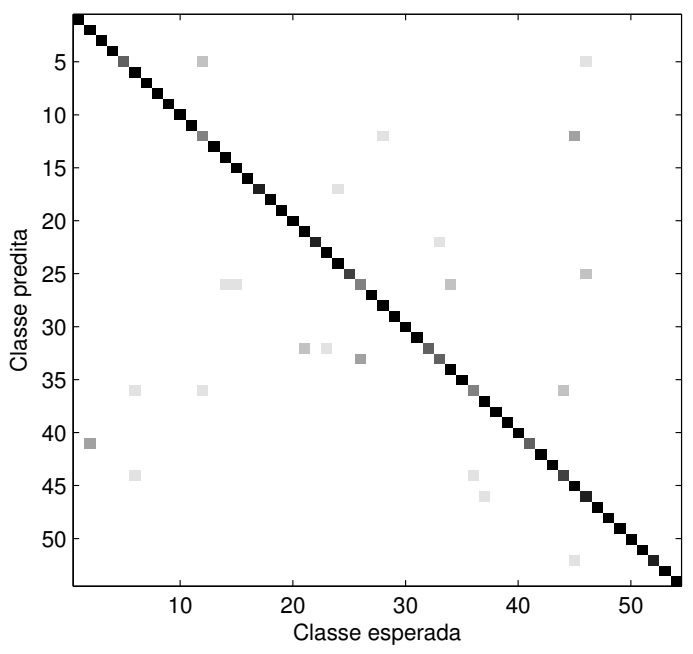

(a)

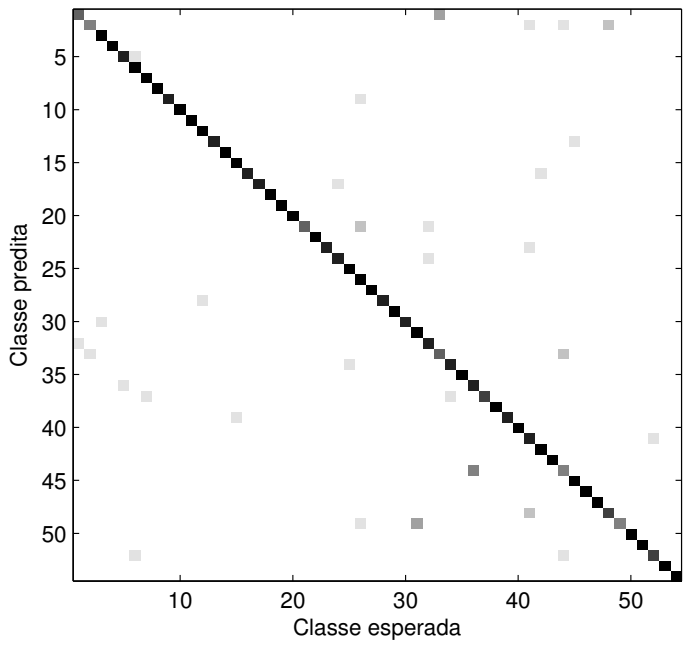

(c)

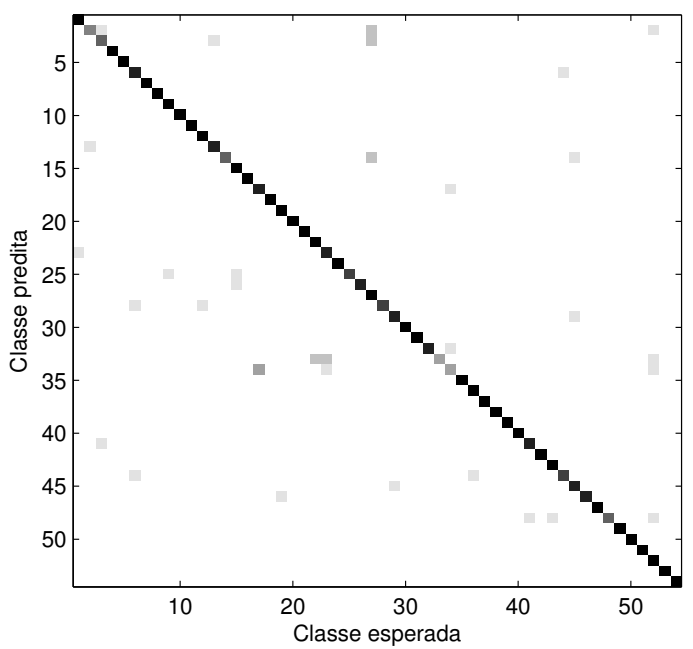

(e)

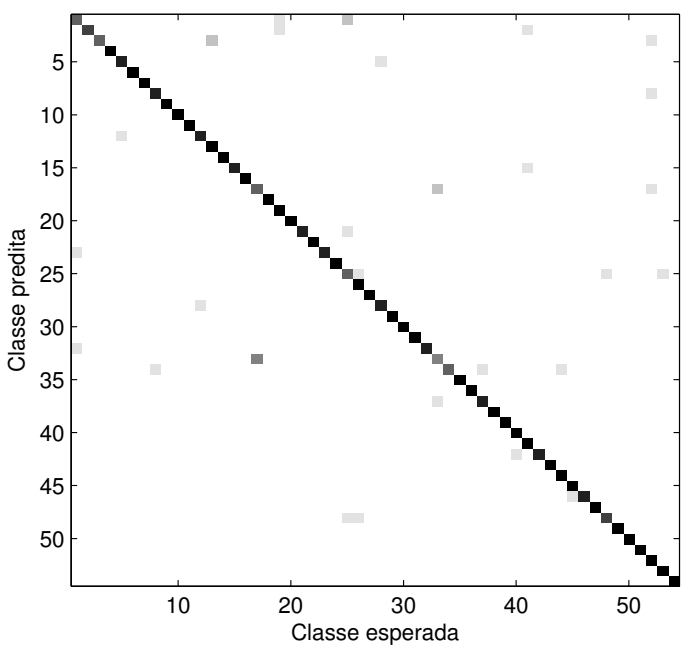

(b)
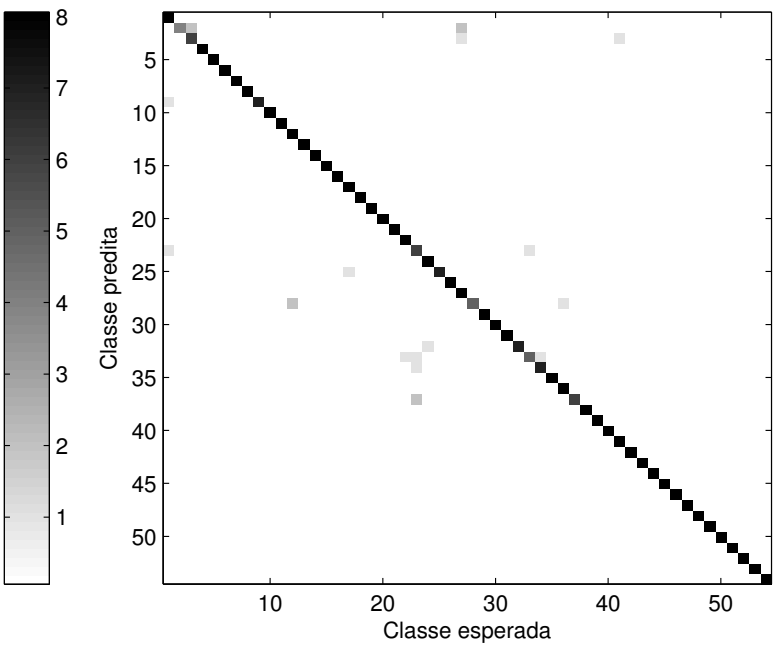

(d)
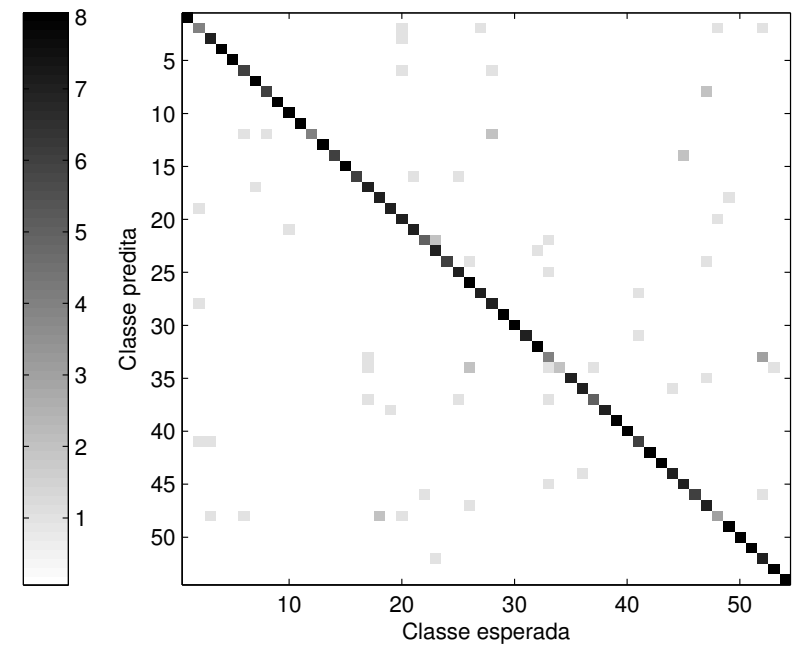

(f)

Figura 7.11 - Matrizes de confusão (parte 1) para os métodos comparados sobre a base de Vistex, usando classificador SVM. (a) LBP. (b) Multifractal 2. (c) Gabor. (d) Wavelike. (e) Bouligand-Minkowski. (f) Fourier. 


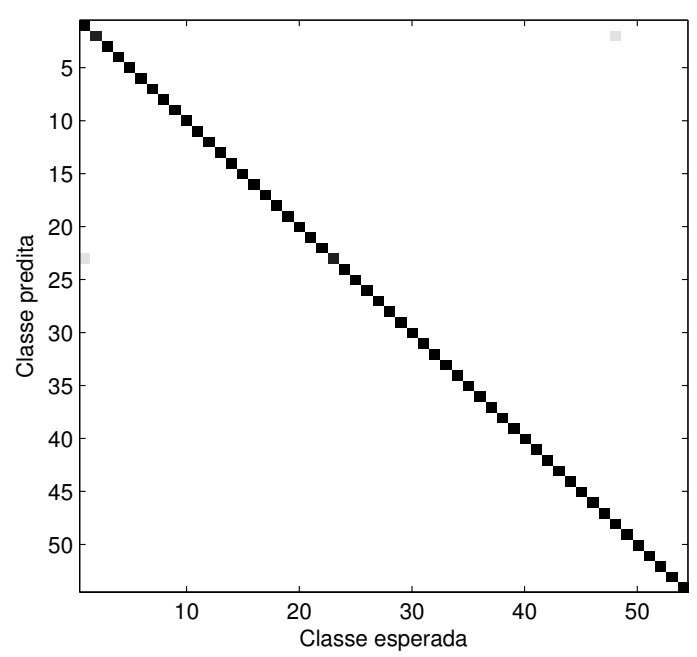

(a)
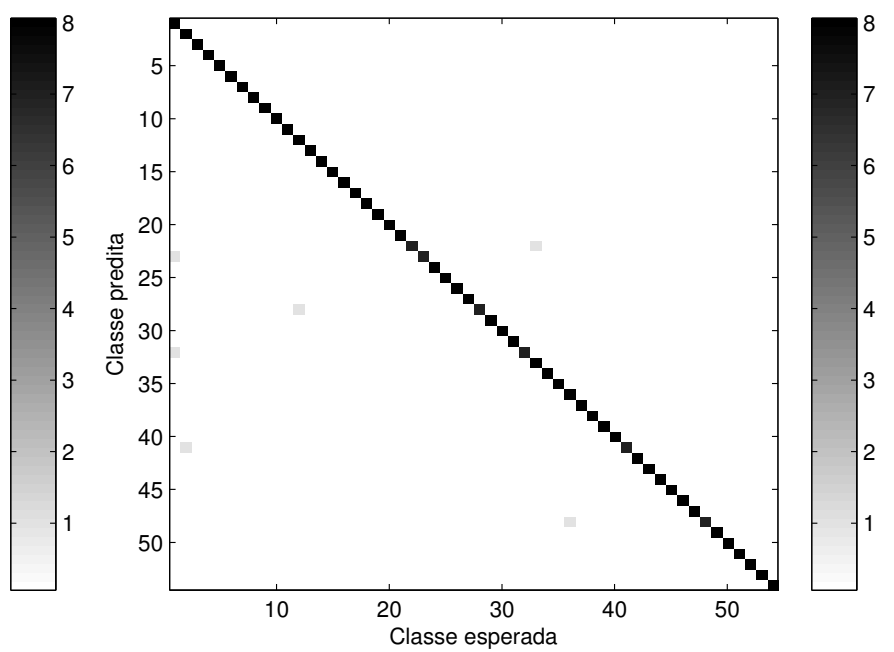

(b)

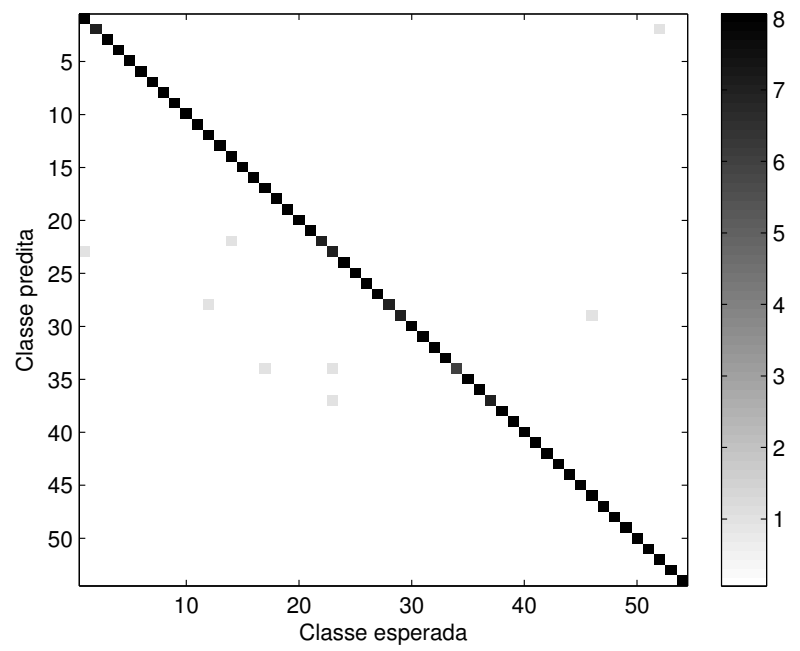

(c)

Figura 7.12 - Matrizes de confusão (parte 2) para os métodos comparados sobre a base de Vistex, usando classificador SVM. (a) Fourier + Wavelike. (b) Blanket + Wavelike. (c) Variograma + Wavelike. 


\subsubsection{KNN}

Nesta seção, a classificação propriamente é executada pelo método KNN, com intuito de verificar a capacidade direta de cada método na discriminação das texturas, uma vez que este classificador baseia-se no uso direto de distâncias simples.

A Tabela 7.56 exibe os resultados obtidos para o uso direto dos descritores fractais e de outras abordagens na literatura. O método de Fourier EEE obteve o melhor resultado nesta base, com o classificador KNN. O descritor fractal de Fourier permite, por meio de sua análise de frequências, que os atributos extraídos sobre cada canal de cor forneçam uma informação que se complemente com a dos demais canais, em razão do caráter menos correlacionado deste tipo de análise, em oposição aos métodos de Bouligand-Minkowski, para os quais uma grande parte dos dados de cada canal são correlacionados. Esta situação é menos grave no caso do método $3 \mathrm{D}$, em que as superfícies dos canais evoluem ao mesmo tempo.

Tabela 7.56 - Taxa de acerto para os descritores fractais em cores em uso direto e outras medidas na base de Vistex, com classificador KNN.

\begin{tabular}{cccccc}
\hline Método & ND & TA $(\%)$ & $\kappa$ & E1 & E2 \\
\hline Gabor cores & 57 & 90.87 & 0.91 & 0.09 & 0.09 \\
Momentos cromáticos & 20 & 40.15 & 0.40 & 0.59 & 0.60 \\
Razão de histogramas & 79 & 76.05 & 0.76 & 0.24 & 0.24 \\
\hline \hline Bouligand-Minkowski 3D + TF & 77 & 91.66 & 0.92 & 0.08 & 0.08 \\
Bouligand-Minkowski EEE + EE & 49 & 79.87 & 0.80 & 0.19 & 0.20 \\
Fourier EEE + TF & 124 & 98.15 & 0.98 & 0.02 & 0.02 \\
\hline
\end{tabular}

A Tabela 7.57 exibe as taxas de acerto, números de elementos e outras medidas para o uso dos descritores fractais em cores empregados em sua forma nativa, sem uso de qualquer transformada, após uma operação de redução de dimensionalidade por CCA. A grande vantagem foi do método Fourier EEE. À primeira vista, este resultado pode surpreender, uma vez que na análise em tons de cinza o método de Fourier não foi tão eficiente se comparado à abordagem de Bouligand-Minkowski/Wavelike. Entretanto, no caso das texturas coloridas e em particular quando o classificador é mais simplista, a análise de frequências é uma ferramenta de grande importância, uma vez que as variações de intensidade dentro dos canais apresentam um forte caráter periódico, com faixas variáveis de frequências. Já as abordagens de Bouligand-Minkowski não alcançaram um resultado razoável nesta classificação. Em particular, o método 3D, que produz resultados excelentes para classificadores mais complexos, não correspondeu a essa expectativa com o método de K-vizinhos. Isso mostra que, embora este descritor expresse informações ricas, esta riqueza não pode ser representada diretamente pelas distâncias entre os vetores, mas sim por relações mais complexas entre as variáveis. 
Tabela 7.57 - Taxa de acerto para os descritores fractais individuais na base de Vistex, classificados por KNN.

\begin{tabular}{lccccc}
\hline Método & ND & TA $(\%)$ & $\kappa$ & E1 & E2 \\
\hline Bouligand-Minkowski 3D & 10 & 77.78 & 0.77 & 0.21 & 0.22 \\
Bouligand-Minkowski EEE & 8 & 68.29 & 0.68 & 0.30 & 0.32 \\
Fourier EEE & 15 & 95.60 & 0.96 & 0.04 & 0.04 \\
\hline
\end{tabular}

Por sua vez, a Tabela 7.58 mostra os resultados para as combinações dois a dois possíveis. As combinações envolvendo Fourier EEE obtiveram altas taxas de acerto para esta base, sendo maior o ganho com Bouligand-Minkowski 3D. Este resultado apenas reafirma o potencial deste tipo de combinação na análise fractal, também no caso de texturas coloridas. Novamente, as melhores combinações usaram soluções de paradigmas distintos (espacial-espectral), enquanto as combinações envolvendo as duas soluções baseadas em Bouligand-Minkowski, embora tenham melhorado os resultados individuais, não foram capazes de superar métodos mais clássicos da literatura.

Tabela 7.58 - Taxa de acerto para os descritores fractais individuais combinados na base de Vistex, classificados por KNN.

\begin{tabular}{lccccc}
\hline Método & ND & TA $(\%)$ & $\kappa$ & E1 & E2 \\
\hline Bouligand-Minkowski 3D+Bouligand-Minkowski EEE & 17 & 87.73 & 0.88 & 0.11 & 0.12 \\
Bouligand-Minkowski 3D+Fourier EEE & 13 & 97.92 & 0.98 & 0.02 & 0.02 \\
Bouligand-Minkowski EEE+Fourier EEE & 13 & 96.76 & 0.97 & 0.03 & 0.03 \\
\hline
\end{tabular}

Já a Tabela 7.59 ilustra as taxas de acerto alcançadas pelos descritores fractais de cores transformados por FDA. Embora a taxa de acerto para Fourier EEE tenha caído, o desempenho das abordagens de Bouligand-Minkowski melhorou ligeiramente. No geral, o uso de FDA é interessante para estes descritores, uma vez que o processo de concatenação dos canais gera um número alto de valores, havendo elevado índice de redundâncias acumuladas no processo de dilatação, que podem ser atenuadas pela representação de menos coeficientes funcionais. Além disso, o aspecto mais suave dos descritores de Bouligand-Minkowski individuais faz com que a transformação FDA não elimine ou camufle detalhes importantes nos descritores, diferentemente do que ocorre com Fourier.

Tabela 7.59 - Taxa de acerto para os descritores fractais FDA na base de Vistex, classificados por KNN.

\begin{tabular}{lccccc}
\hline Método & ND & TA $(\%)$ & $\kappa$ & E1 & E2 \\
\hline Bouligand-Minkowski 3D & 20 & 82.18 & 0.82 & 0.17 & 0.18 \\
Bouligand-Minkowski EEE & 9 & 69.44 & 0.69 & 0.29 & 0.31 \\
Fourier EEE & 12 & 90.51 & 0.90 & 0.08 & 0.09 \\
\hline
\end{tabular}

Por sua vez, a Tabela 7.60 exibe os resultados para os descritores combinados dois a dois. Nota-se que o único ganho obtido ocorreu com a combinação de descritores de BouligandMinkowski. Neste caso, o ganho é consequência da melhor representação destes descritores 
por FDA, embora não seja ainda suficiente para um resultado mais preciso, em função das redundâncias entre os dois métodos, que impedem que a combinação apresente uma informação mais significativa.

Tabela 7.60 - Taxa de acerto para os descritores fractais FDA combinados na base de Vistex, classificados por KNN.

\begin{tabular}{lccccc}
\hline Método & ND & TA (\%) & $\kappa$ & E1 & E2 \\
\hline Bouligand-Minkowski 3D+Bouligand-Minkowski EEE & 17 & 88.66 & 0.88 & 0.10 & 0.11 \\
Bouligand-Minkowski 3D+Fourier EEE & 12 & 96.06 & 0.96 & 0.03 & 0.04 \\
Bouligand-Minkowski EEE+Fourier EEE & 19 & 95.14 & 0.95 & 0.04 & 0.05 \\
\hline
\end{tabular}

A Tabela 7.61 mostra os resultados para o uso da transformada multiescala, na categoria espaço-escala. Observa-se um ganho substancial nos descritores de Bouligand-Minkowski em antagonia a uma queda drástica da taxa de acerto para o método de Fourier. Este último não apresenta bons resultados pela aplicação da derivada, como ocorreu em outras situações durante estes experimentos. Isto ocorre em função da presença de flutuações de alta frequência que, quando associadas à informação global, são importantes para a classificação por distâncias, mas são danificadas pela aplicação de diferenças finitas, o que leva a uma perda de relevância do conjunto detalhe (microescala) + aproximação (macroescala). Já no caso dos volumes de dilatação, a informação está mais auto-correlacionada internamente nos descritores e os padrões de variação são mais interessantes para o método baseado em vizinhanças.

Tabela 7.61 - Taxa de acerto para os descritores fractais espaço-escala na base de Vistex, classificados por KNN.

\begin{tabular}{lccccc}
\hline Método & ND & TA $(\%)$ & $\kappa$ & E1 & E2 \\
\hline Bouligand-Minkowski 3D & 13 & 86.34 & 0.86 & 0.12 & 0.14 \\
Bouligand-Minkowski EEE & 8 & 78.94 & 0.79 & 0.19 & 0.21 \\
Fourier EEE & 16 & 55.09 & 0.55 & 0.42 & 0.45 \\
\hline
\end{tabular}

De sua parte, a Tabela 7.62 ilustra o desempenho das combinações entre os descritores fractais comparados. As taxas de acerto foram fortemente prejudicadas pelo baixo acerto de Fourier. O melhor resultado foi alcançado pela combinação dos volumes de dilatação obtidos por canais individuais e contabilizando as interferências mútuas. Ainda assim, esta combinação atingiu uma taxa de acerto mais baixa do que pelo uso de outras transformações, mostrando que o uso de derivadas não é recomendado na análise multiescala destes descritores, em função da perda de informação útil e acréscimo de artefatos da derivada, além da camuflagem imposta pela suavização Gaussiana.

A Figura 7.63 já ilustra as taxas de acerto e outros parâmetros de desempenho para os descritores fractais transformados por tempo-frequência. Aqui, as alterações mais relevantes nas taxas ocorreram nas abordagens de Bouligand-Minkowski e de maneira diferente em cada 
Tabela 7.62 - Taxa de acerto para os descritores fractais espaço-escala combinados na base de Vistex, classificados por KNN.

\begin{tabular}{lccccc}
\hline Método & ND & TA (\%) & $\kappa$ & E1 & E2 \\
\hline Bouligand-Minkowski 3D+Bouligand-Minkowski EEE & 14 & 90.97 & 0.91 & 0.08 & 0.09 \\
Bouligand-Minkowski 3D+Fourier EEE & 13 & 55.32 & 0.55 & 0.42 & 0.45 \\
Bouligand-Minkowski EEE+Fourier EEE & 12 & 54.86 & 0.55 & 0.42 & 0.45 \\
\hline
\end{tabular}

abordagem. No método 3D ocorreu uma forte queda, enquanto o EEE teve um ganho de mais de $20 \%$. Esta diferença é explicada pelo mecanismo de dilatação empregado em cada método. Enquanto no método 3D, o crescimento conjunto dos raios de dilatação gera descritores mais homogêneos e com menos variação significativa entre padrões de frequência, a abordagem EEE trabalha com transformações que realçam as diferenças entre os canais cromáticos e geram descritores com maior influência dos micro e macropadrões de frequências expressos nas janelas deslizantes do método de Gabor.

Tabela 7.63 - Taxa de acerto para os descritores fractais tempo-frequência na base de Vistex, classificados por KNN.

\begin{tabular}{lccccc}
\hline Método & ND & TA $(\%)$ & $\kappa$ & E1 & E2 \\
\hline Bouligand-Minkowski 3D & 19 & 86.11 & 0.86 & 0.13 & 0.14 \\
Bouligand-Minkowski EEE & 7 & 57.64 & 0.57 & 0.40 & 0.42 \\
Fourier EEE & 14 & 95.37 & 0.95 & 0.04 & 0.05 \\
\hline
\end{tabular}

Já a Tabela 7.64 mostra as taxas de acerto obtidas para cada combinação de descritor de tempo-frequência. As combinações com Fourier EEE se sobressaíram novamente em relação à concatenação de Bouligand-Minkowski. Nota-se, porém, que a transformada influiu negativamente em todos os resultados, fazendo com que as taxas de acerto caíssem em relação às combinações de descritores individuais. O método de Bouligand-Minkowski também fez com que as combinações envolvendo Fourier tivessem uma taxa no máximo igual ao uso apenas do descritor de Fourier.

Tabela 7.64 - Taxa de acerto para os descritores fractais tempo-frequência combinados na base de Vistex, classificados por KNN.

\begin{tabular}{lccccc}
\hline Método & ND & TA (\%) & $\kappa$ & E1 & E2 \\
\hline Bouligand-Minkowski 3D+Bouligand-Minkowski EEE & 14 & 86.34 & 0.86 & 0.13 & 0.14 \\
Bouligand-Minkowski 3D+Fourier EEE & 12 & 95.37 & 0.95 & 0.04 & 0.05 \\
Bouligand-Minkowski EEE+Fourier EEE & 14 & 93.75 & 0.94 & 0.06 & 0.06 \\
\hline
\end{tabular}

A Tabela 7.65 exibe as taxas de acerto para os descritores fractais transformados por tempo-escala e classificados por KNN. Chama atenção a queda experimentada pelos descritores de Fourier EEE, fenômeno que também ocorria nos descritores de tons de cinza. Da mesma forma que naquele caso, o resultado é consequência da variação na resolução de frequências que ocorre na transformada wavelets (bandas mais largas para baixas frequências e mais estreitas para altas). Ocorre que nos descritores de Fourier, a informação relevante de complexidade 
está distribuída por todo espectro e as variações de alta e baixa frequência se complementam com igual peso.

Tabela 7.65 - Taxa de acerto para os descritores fractais tempo-escala na base de Vistex, classificados por KNN.

\begin{tabular}{lccccc}
\hline Método & ND & TA $(\%)$ & $\kappa$ & E1 & E2 \\
\hline Bouligand-Minkowski 3D & 10 & 75.46 & 0.75 & 0.26 & 0.25 \\
Bouligand-Minkowski EEE & 14 & 79.86 & 0.80 & 0.19 & 0.20 \\
Fourier EEE & 20 & 23.61 & 0.23 & 0.73 & 0.76 \\
\hline
\end{tabular}

Por fim, a Tabela 7.66 mostra as taxas de acerto obtidas pelos descritores transformados por tempo-escala e combinados dois a dois. Dado que o método de Fourier apresentava o maior índice de sucesso na classificação e teve seu desempenho fortemente prejudicado pela transformada multiescala empregada, como esperado, as combinações não alcançaram resultados sequer próximos do razoável para a classificação desta base.

Tabela 7.66 - Taxa de acerto para os descritores fractais tempo-escala combinados na base de Vistex, classificados por KNN.

\begin{tabular}{lccccc}
\hline Método & ND & TA (\%) & $\kappa$ & E1 & E2 \\
\hline Bouligand-Minkowski 3D+Bouligand-Minkowski EEE & 14 & 77.55 & 0.77 & 0.23 & 0.22 \\
Bouligand-Minkowski 3D+Fourier EEE & 14 & 76.16 & 0.76 & 0.24 & 0.24 \\
Bouligand-Minkowski EEE+Fourier EEE & 20 & 34.95 & 0.35 & 0.62 & 0.65 \\
\hline
\end{tabular}

\subsubsection{Outros Métodos}

A Tabela 7.67 ilustra os resultados obtidos por outras soluções encontradas na literatura para a análise de texturas coloridas. O método de Gabor é mais recente e se apresenta como o mais preciso neste processo, dada sua flexibilidade de análise de frequências levando em conta informações de escala e anisotropismo da textura. Já os outros dois são mais antigos e vão apresentar alguma utilidade em poucas situações, aparecendo aqui mais a caráter de ilustração das diferentes estratégias usadas para a análise de cores na literatura.

Tabela 7.67 - Taxa de acerto para os métodos da literatura na base de Vistex, classificados por KNN.

\begin{tabular}{lccccc}
\hline Método & ND & TA $(\%)$ & $\kappa$ & E1 & E2 \\
\hline Gabor cores & 16 & 89.81 & 0.90 & 0.09 & 0.10 \\
Momentos cromáticos & 6 & 47.45 & 0.47 & 0.50 & 0.53 \\
Razão de histogramas & 14 & 68.52 & 0.68 & 0.31 & 0.31 \\
\hline
\end{tabular}

\subsubsection{Resumo dos Resultados}

A Tabela 7.68 resume os melhores resultados alcançados em cada categoria, para aquelas transformações que levaram a uma maior taxa de acerto. 
Entre os descritores fractais propostos neste trabalho, os descritores de Fourier EEE apresentam o melhor resultado, superando a metodologia estado-da-arte de Gabor. Este método, embora simples em sua essência, combina duas transformadas, EEE e Fourier, que enfatizam informações relacionadas ao significado físico das cores expressas nestas texturas, seja por meio de um filtro deduzido de teorias de Física, seja pelo espectro de energias de Fourier. Este tipo de representação é sobremaneira vantajoso quando se envolve análise de cores e ainda mais sob influência de fortes variações de luminosidade, como ocorre nesta base de Vistex.

Já entre as combinações propostas, as taxas de acerto superaram o método de Gabor em todos os casos, ilustrando a força deste tipo de solução em que diferentes medidas de complexidade se ajudam mutuamente para compor um conjunto de atributos que, embora pequeno, seja capaz de discriminar texturas com tamanha complexidade de padrões de morfologia e/ou ambiente de captura. Assim, esta opção se confirma como de grande potencial de aplicação em problemas práticos, com condições mais severas, e que exigem uma taxa de acerto aceitável com baixo número de descritores.

Tabela 7.68 - Resumo das taxas de acerto obtidas para a base de Vistex, classificada por KNN.

\begin{tabular}{|c|c|c|c|c|c|}
\hline Método & ND & TA $(\%)$ & $\kappa$ & E1 & E2 \\
\hline Gabor cores & 16 & 89.81 & 0.90 & 0.09 & 0.10 \\
\hline Razão de histogramas & 14 & 68.52 & 0.68 & 0.31 & 0.31 \\
\hline Momentos cromáticos & 6 & 47.45 & 0.47 & 0.50 & 0.53 \\
\hline Fourier EEE & 15 & 95.60 & 0.96 & 0.04 & 0.04 \\
\hline Bouligand-Minkowski 3D + EE & 13 & 86.34 & 0.86 & 0.12 & 0.14 \\
\hline Bouligand-Minkowski EEE + TE & 14 & 79.86 & 0.80 & 0.19 & 0.20 \\
\hline Bouligand-Minkowski 3D+Fourier EEE & 13 & 97.92 & 0.98 & 0.02 & 0.02 \\
\hline Bouligand-Minkowski EEE+Fourier EEE & 13 & 96.76 & 0.97 & 0.03 & 0.03 \\
\hline Bouligand-Minkowski 3D+Bouligand-Minkowski EEE + EE & 14 & 90.97 & 0.91 & 0.08 & 0.09 \\
\hline
\end{tabular}

A Figura 7.13 mostra então uma representação da variação das taxas de acerto para os métodos comparados em relação ao número de descritores utilizados. Os gráficos seguem o padrão esperado de descritores bem comportados que vão adicionando informação homogeneamente ao classificador, levando a um grande aumento inicial na taxa de acerto seguido por um comportamento próximo do constante. Um aspecto importante é o desempenho de Fourier EEE, que leva vantagem até mesmo sobre as duas abordagens de Bouligand-Minkowski combinadas. De fato, o método baseado em análise espectral demonstra apresentar sua informação mais relevante de forma direta, permitindo a alta taxa de acerto, ainda que se use um classificador tão simples quanto KNN.

Finalmente, as Figuras 7.14 e 7.15 exibem as matrizes de confusão de cada método, seja descritor fractal simples ou combinado ou outra abordagem da literatura. De início, já se nota que a maioria dos métodos apresentou grandes deficiências nas classes 33/34. A alta variação interna destas classes faz com que até mesmo a classificação humana possa falhar. Assim, uma 


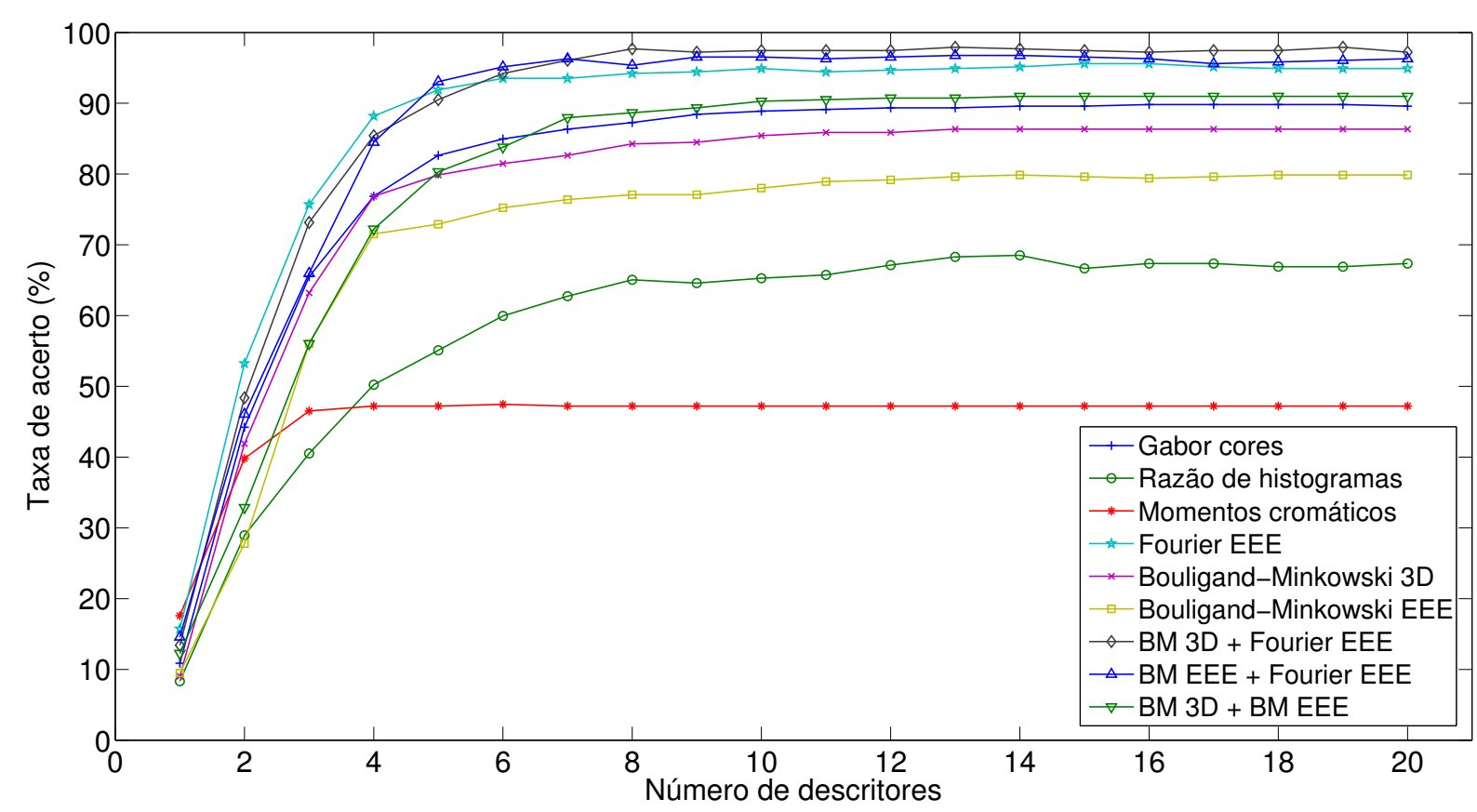

Figura 7.13 - Taxas de acerto em função do número de descritores para a base de Vistex, com classificador KNN.

vez detectado este tipo de classe em uma base de texturas, pode ser útil o desenvolvimento de um tratamento especial. Aí reside a importância da análise das matrizes de confusão envolvidas no processo de classificação.

\subsubsection{SVM}

A seguir, apresentam-se os resultados para a base de Vistex classificada por descritores fractais de cores empregados no método de SVM, abordagem mais eficiente e robusta, que tende a aumentar as taxas de acerto para cada descritor testado.

A Tabela 7.69 exibe os resultados atingidos por cada descritor em seu uso direto, sem qualquer redução de dimensionalidade por PCA ou CCA. Esta tabela mostra um ganho substancial dos métodos de Bouligand-Minkowski em relação ao resultado obtido por KNN. O aumento no acerto é particularmente relevante no método 3D. Este ganho se dá pela natureza do classificador, que a partir de um aprendizado mais robusto é capaz de atenuar o efeito da correlação entre os canais, realçando a análise conjunta da distribuição de cores e intensidades no espaço propiciada pelo volume de dilatação.

A Tabela 7.70 exibe as taxas de acerto e medidas relacionadas na classificação usando-se os descritores fractais individuais, com redução de dimensionalidade. Nota-se que houve uma 


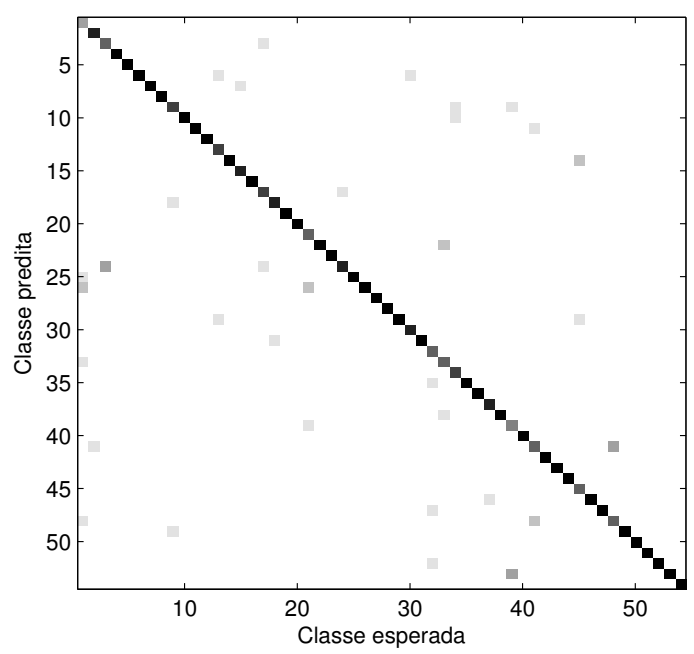

(a)

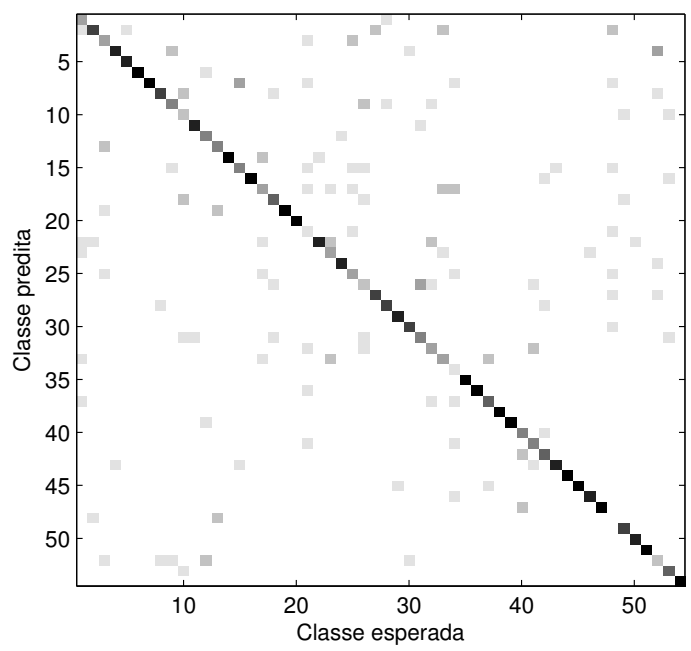

(c)

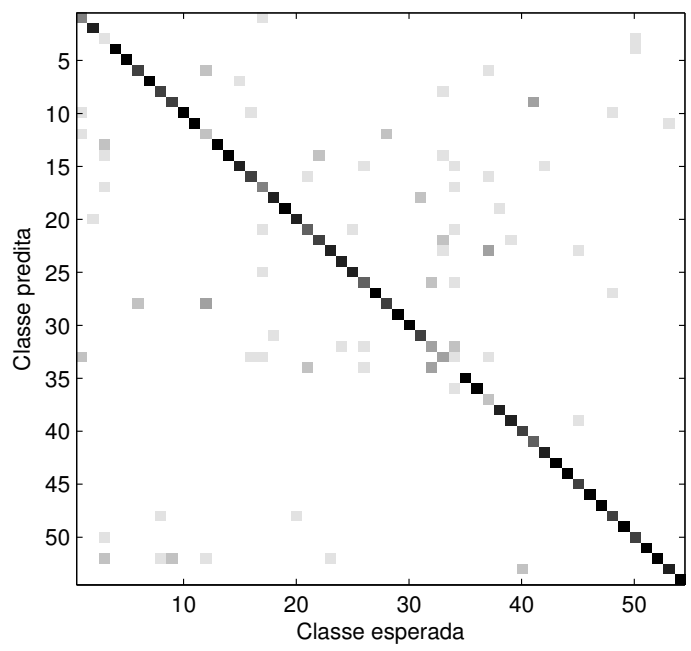

(e)
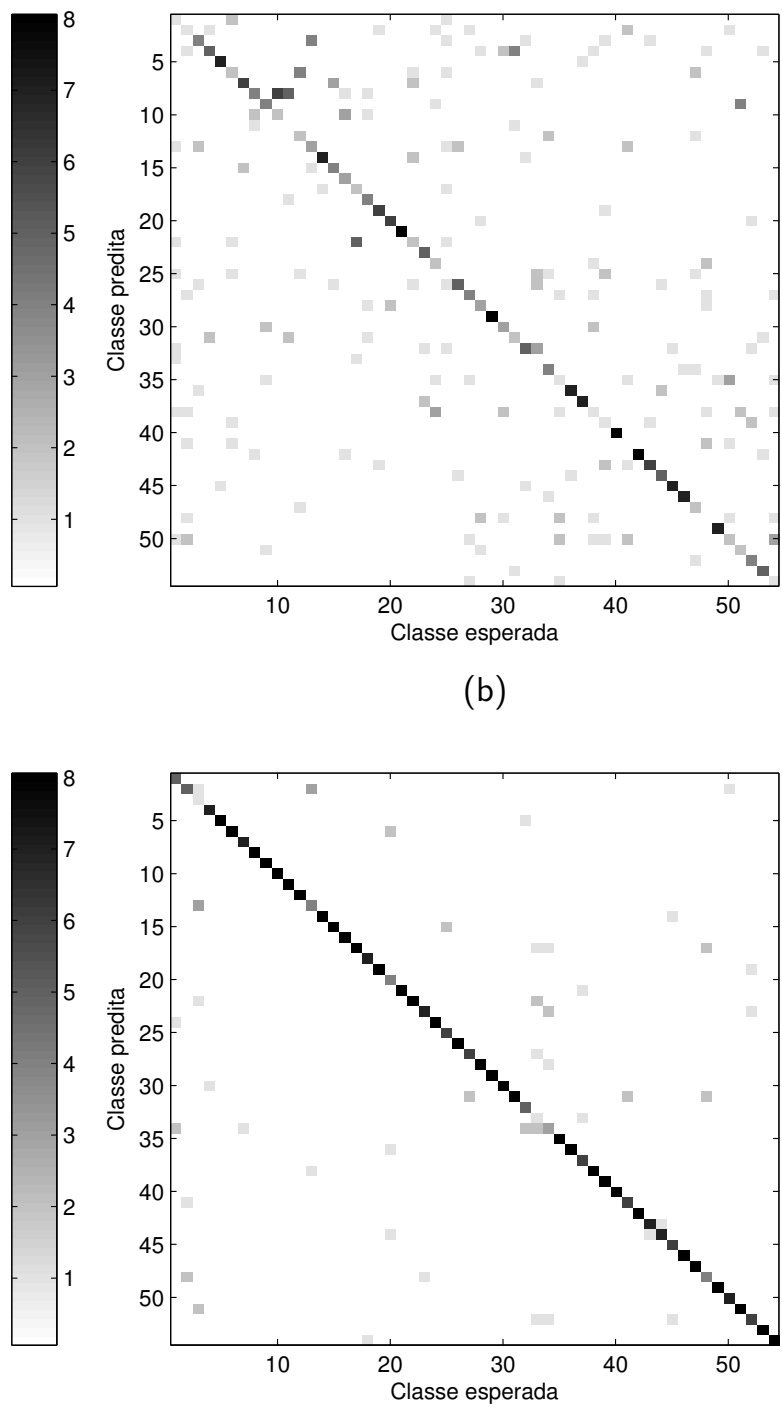

(d)
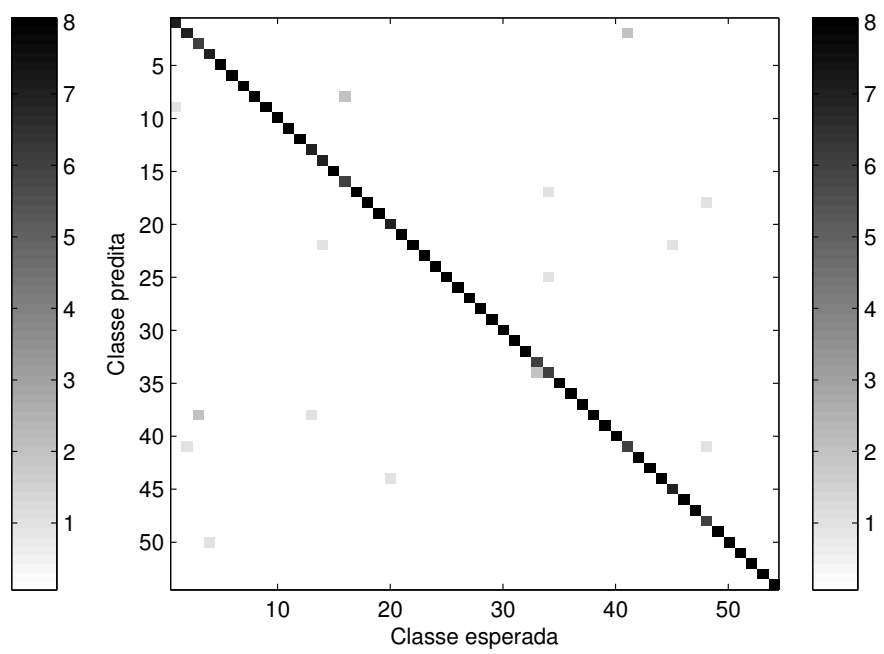

(f)

Figura 7.14 - Matrizes de confusão (parte 1) para os métodos comparados sobre a base de Vistex, usando classificador SVM. (a) Gabor cores. (b) Momentos cromáticos. (c) Razão de histogramas. (d) Bouligand-Minkowski 3D. (e) Bouligand-Minkowski EEE. (f) Fourier EEE. 


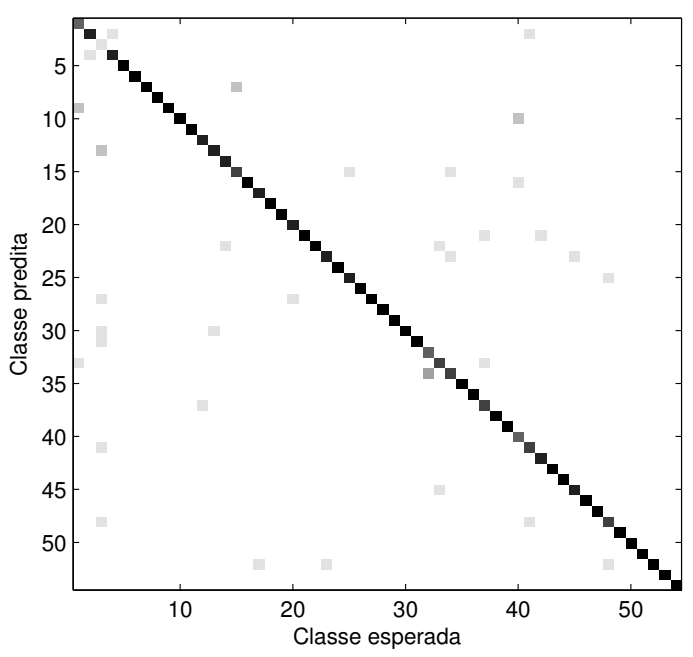

(a)

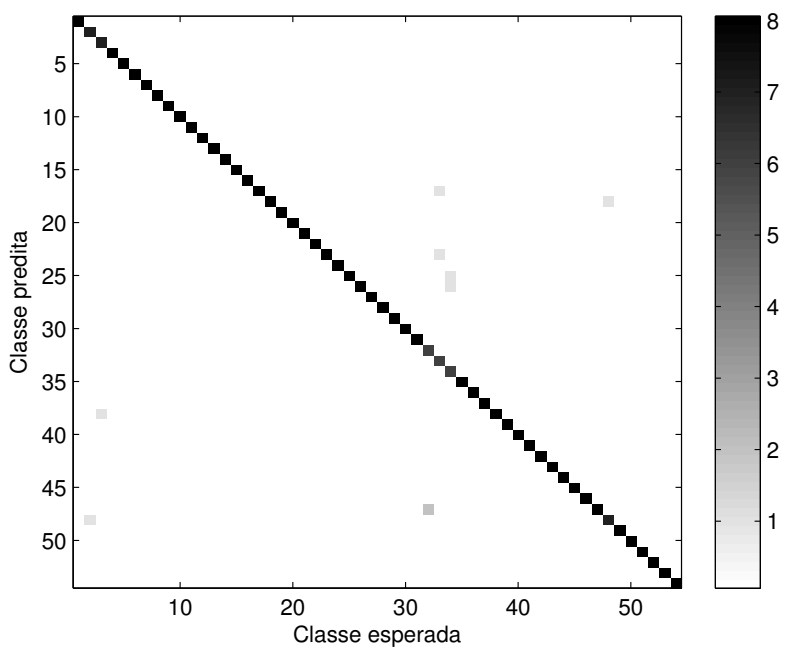

(b)

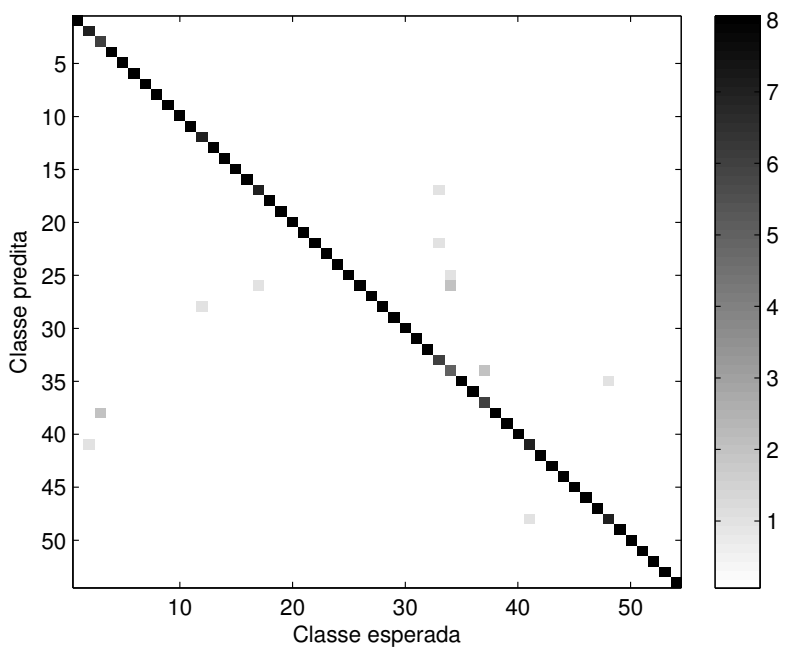

(c)

Figura 7.15 - Matrizes de confusão (parte 2) para os métodos comparados sobre a base de Vistex, usando classificador SVM. (a) Bouligand-Minkowski 3D + Bouligand-Minkowski EEE. (b) Bouligand-Minkowski 3D + Fourier EEE. (c) Bouligand-Minkowski EEE + Fourier EEE.

Tabela 7.69 - Taxa de acerto para os descritores fractais em cores, sem redução de dimensionalidade, e outras medidas para a base de Vistex com SVM.

\begin{tabular}{cccccc}
\hline Método & ND & TA $(\%)$ & $\kappa$ & E1 & E2 \\
\hline Gabor cores & 57 & 90.87 & 0.91 & 0.09 & 0.09 \\
Momentos cromáticos & 20 & 40.15 & 0.40 & 0.59 & 0.60 \\
Razão de histogramas & 79 & 76.05 & 0.76 & 0.24 & 0.24 \\
\hline \hline Bouligand-Minkowski 3D + TE & 62 & 98.84 & 0.96 & 0.04 & 0.03 \\
Bouligand-Minkowski EEE + TE & 42 & 91.86 & 0.89 & 0.11 & 0.10 \\
Fourier EEE + FDA & 50 & 97.67 & 0.94 & 0.06 & 0.05 \\
\hline
\end{tabular}


inversão de papéis em relação às taxas de acerto, havendo pequena queda nos descritores de Fourier e grande aumento nos de Bouligand-Minkowski. Este resultado exibe um cenário em que os descritores de Fourier mostram-se ideais para classificação por KNN, enquanto as abordagens de Bouligand-Minkowski são mais bem aproveitadas no classificador SVM. Esta diferença é explicada pela natureza de cada método. Enquanto os descritores de Fourier apresentam a informação de forma mais direta, tornando viável a análise por distâncias simples, o método de Bouligand-Minkowski mede a morfologia de cada superfície cromática e a informação extraída não é passível de uma análise tão simplista.

Tabela 7.70 - Taxa de acerto para os descritores fractais individuais na base de Vistex, classificados por SVM.

\begin{tabular}{lccccc}
\hline Método & ND & TA $(\%)$ & $\kappa$ & E1 & E2 \\
\hline Bouligand-Minkowski 3D & 12 & 95.60 & 0.96 & 0.04 & 0.04 \\
Bouligand-Minkowski EEE & 16 & 90.97 & 0.91 & 0.09 & 0.07 \\
Fourier EEE & 8 & 92.59 & 0.92 & 0.07 & 0.07 \\
\hline
\end{tabular}

Por sua vez, a Tabela 7.71 exibe as taxas de acerto para as combinações de descritores fractais. Da mesma maneira que com os descritores individuais, as combinações apresentaram melhor desempenho com Bouligand-Minkowski e menor acerto com Fourier EEE. Novamente, existe um melhor aproveitamento de determinado descritor para um classificador específico, o que se justifica pelos diferentes paradigmas empregados em ambas as técnicas.

Tabela 7.71 - Taxa de acerto para os descritores fractais individuais combinados na base de Vistex, classificados por SVM.

\begin{tabular}{lccr}
\hline & Bouligand-Minkowski 3D.mat & Bouligand-Minkowski EEE.mat & Fourier EEE.mat \\
\hline Bouligand-Minkowski 3D.mat & - & $96.52(16)$ & $96.52(12)$ \\
Bouligand-Minkowski EEE.mat & $96.52(16)$ & - & $93.98(11)$ \\
Fourier EEE.mat & $96.52(12)$ & $93.98(11)$ & - \\
\hline
\end{tabular}

Já a Tabela 7.72 exibe as taxas de acerto para os descritores após aplicação da transformação de FDA. Nota-se que neste caso a análise funcional possibilitou um ganho na taxa de acerto para as abordagens de Bouligand-Minkowski, permitindo taxas ainda mais altas para esta base e superando os métodos conhecidos na literatura. Aqui, o classificador mais eficiente foi capaz de utilizar, de forma mais útil, os descritores transformados por FDA e as características analíticas extraídas das curvas originais. Já o método de Fourier sofreu mais o processo de suavização intrínseco à análise funcional e que acabou eliminando flutuações importantes no processo de discriminação das texturas.

A Tabela 7.73 ilustra os resultados para os descritores fractais transformados por FDA e combinados em pares. Os números mostram que houve ganho nas combinações dos métodos de Bouligand-Minkowski e perda nas demais situações. Este fenômeno se dá também pela natureza mais suave e de maior regularidade analítica dos descritores de volumes de dilatação, 
Tabela 7.72 - Taxa de acerto para os descritores fractais FDA na base de Vistex, classificados por SVM.

\begin{tabular}{lccccc}
\hline Método & ND & TA $(\%)$ & $\kappa$ & E1 & E2 \\
\hline Bouligand-Minkowski 3D & 13 & 96.30 & 0.96 & 0.04 & 0.03 \\
Bouligand-Minkowski EEE & 20 & 91.67 & 0.92 & 0.08 & 0.05 \\
Fourier EEE & 9 & 86.34 & 0.86 & 0.14 & 0.12 \\
\hline
\end{tabular}

fazendo com que a síntese realizada pelos coeficientes FDA acrescente informação relevante ao processo de discriminação.

Tabela 7.73 - Taxa de acerto para os descritores fractais FDA combinados na base de Vistex, classificados por SVM.

\begin{tabular}{lccc}
\hline & Bouligand-Minkowski 3D.mat & Bouligand-Minkowski EEE.mat & Fourier EEE.mat \\
\hline Bouligand-Minkowski 3D.mat & - & $96.99(17)$ & $94.2(11)$ \\
Bouligand-Minkowski EEE.mat & $96.99(17)$ & - & $89.81(7)$ \\
Fourier EEE.mat & $94.2(11)$ & $89.81(7)$ & - \\
\hline
\end{tabular}

A Tabela 7.74 exibe os resultados obtidos pelos descritores fractais quando estes são transformados por espaço-escala. Apenas o método de Bouligand-Minkowski EEE apresentou melhora na taxa de acerto e ainda assim em pequena escala, podendo também ser associada a variações inerentes ao processo empírico. O uso de derivada numérica sobre estes dados acaba acrescentando artefatos, ou seja, padrões de descritores que não são indicativos das dissimilaridades entre amostras de classes diferentes. Estes artefatos podem apresentar um resultado contraditório com os demais descritores ou no mínimo atenuar o efeito dos descritores mais relevantes.

Tabela 7.74 - Taxa de acerto para os descritores fractais espaço-escala na base de Vistex, classificados por SVM.

\begin{tabular}{lccccc}
\hline Método & ND & TA $(\%)$ & $\kappa$ & E1 & E2 \\
\hline Bouligand-Minkowski 3D & 17 & 92.36 & 0.92 & 0.08 & 0.06 \\
Bouligand-Minkowski EEE & 16 & 91.90 & 0.92 & 0.08 & 0.06 \\
Fourier EEE & 8 & 76.85 & 0.77 & 0.23 & 0.23 \\
\hline
\end{tabular}

A Tabela 7.75 explicita as taxas de acerto fornecidas pelas combinações de descritores fractais transformados por espaço-escala. Os resultados são similares aos obtidos pela transformada FDA no caso dos métodos de Bouligand-Minkowski e há uma queda de desempenho para o método de Fourier EEE. Esta queda está mais uma vez associada à baixa eficácia da transformada espaço-escala em relação a descritores extraídos do espectro de potência. Enquanto, no caso espacial, a derivada captura pequenos detalhes de transição entre múltiplas escalas, a derivada do espectro de Fourier altera o sentido de variações já presentes nos descritores individuais e que são usadas como elemento de enriquecimento para o classificador.

Por sua vez, a Tabela 7.76 ilustra as taxas de acerto e outras medidas correlatas para a 
Tabela 7.75 - Taxa de acerto para os descritores fractais espaço-escala combinados na base de Vistex, classificados por SVM.

\begin{tabular}{lccc}
\hline & Bouligand-Minkowski 3D.mat & Bouligand-Minkowski EEE.mat & Fourier EEE.mat \\
\hline Bouligand-Minkowski 3D.mat & - & $96.75(15)$ & $78.24(8)$ \\
Bouligand-Minkowski EEE.mat & $96.75(15)$ & - & $78.00(8)$ \\
Fourier EEE.mat & $78.24(8)$ & $78.00(8)$ & - \\
\hline
\end{tabular}

base de Vistex, quando são usados descritores fractais transformados por tempo-frequência. $\mathrm{O}$ método de Fourier se manteve exatamente com o mesmo desempenho do descritor sem transformação. Já no caso de Bouligand-Minkowski, houve aumento na taxa de acerto do método 3D e diminuição na abordagem EEE. Importante também observar-se que este comportamento é inverso àquele verificado no caso do classificador KNN. Esta diferença de comportamento se deve ao mecanismo usado por cada classificador, uma vez que as frequências no método 3D exibem perfil mais complexo, dada a sobreposição de padrões ocasionados pelo crescimento conjunto dos raios de dilatação.

Tabela 7.76 - Taxa de acerto para os descritores fractais tempo-frequência na base de Vistex, classificados por SVM.

\begin{tabular}{lccccc}
\hline Método & ND & TA $(\%)$ & $\kappa$ & E1 & E2 \\
\hline Bouligand-Minkowski 3D & 15 & 96.30 & 0.96 & 0.04 & 0.03 \\
Bouligand-Minkowski EEE & 11 & 84.95 & 0.85 & 0.15 & 0.14 \\
Fourier EEE & 8 & 92.59 & 0.92 & 0.07 & 0.07 \\
\hline
\end{tabular}

A Figura 7.77 mostra a capacidade de discriminação dos descritores fractais transformados por tempo-frequência e combinados dois a dois. Em uma visão geral, vê-se que as combinações com tempo-frequência apresentaram taxas de acerto maiores do que as com descritores individuais. Aqui, a transformada tempo-frequência mostrou-se interessante, sobretudo pela possibilidade de combinações que geram taxas de classificação que superam com vantagem relevante as demais soluções da literatura comparadas. A análise de frequências locais permite que se explicitem características que não se expressam nos simples valores dos descritores, características estas que são realçadas nas combinações.

Tabela 7.77 - Taxa de acerto para os descritores fractais tempo-frequência combinados na base de Vistex, classificados por SVM.

\begin{tabular}{lccc}
\hline & Bouligand-Minkowski 3D.mat & Bouligand-Minkowski EEE.mat & Fourier EEE.mat \\
\hline Bouligand-Minkowski 3D.mat & - & $95.83(16)$ & $97.22(12)$ \\
Bouligand-Minkowski EEE.mat & $95.83(16)$ & - & $95.13(14)$ \\
Fourier EEE.mat & $97.22(12)$ & $95.13(14)$ & - \\
\hline
\end{tabular}

Finalizando as transformações, a Tabela 7.78 exibe as taxas de acerto obtidas pela transformação tempo-escala. Neste caso, assim como na classificação por KNN, a mudança mais significativa ocorre com os descritores de Fourier EEE que apresentam forte queda na taxa de acerto, tendo seu uso inviabilizado nesta situação específica. Esta queda tão marcante já 
foi explicada anteriormente como sendo consequência da perda de frequências importantes durante a sucessão dessas duas modalidades de análise (espectro de potência + transformada wavelets).

Tabela 7.78 - Taxa de acerto para os descritores fractais tempo-escala na base de Vistex, classificados por SVM.

\begin{tabular}{lccccc}
\hline Método & ND & TA $(\%)$ & $\kappa$ & E1 & E2 \\
\hline Bouligand-Minkowski 3D & 20 & 94.68 & 0.95 & 0.05 & 0.04 \\
Bouligand-Minkowski EEE & 14 & 93.06 & 0.93 & 0.07 & 0.06 \\
Fourier EEE & 10 & 24.77 & 0.25 & 0.75 & 0.72 \\
\hline
\end{tabular}

Já a Tabela 7.79 ilustra as taxas de acerto com número de atributos para os descritores tempo-escala combinados entre si. Os resultados indicam que a única combinação viável é a que junta os dois métodos de Bouligand-Minkowski. O resultado ainda é similar ao uso dos descritores individuais, mostrando que a contribuição da transformada não foi suficiente para efetivamente melhorar o resultado da classificação. Este desempenho insatisfatório confirma o peso simétrico que as altas e baixas frequências apresentam nos descritores. Ocorre que as medidas espectrais no caso medem complexidade e não possuem o mesmo comportamento dos descritores clássicos de Fourier em que as frequências são usadas diretamente.

Tabela 7.79 - Taxa de acerto para os descritores fractais tempo-escala combinados na base de Vistex, classificados por SVM.

\begin{tabular}{lccc}
\hline & Bouligand-Minkowski 3D.mat & Bouligand-Minkowski EEE.mat & Fourier EEE.mat \\
\hline Bouligand-Minkowski 3D.mat & - & $96.99(15)$ & $77.54(11)$ \\
Bouligand-Minkowski EEE.mat & $96.99(15)$ & - & $34.95(10)$ \\
Fourier EEE.mat & $77.54(11)$ & $34.95(10)$ & - \\
\hline
\end{tabular}

\subsubsection{Outros Métodos}

A Tabela 7.80 mostra os resultados obtidos pelas abordagens não-fractais da literatura e comparados com os novos descritores aqui propostos. Como esperado, o classificador mais poderoso levou a um aumento nas taxas de acerto para os descritores. O método de Gabor mais uma vez obteve larga vantagem em relação às demais abordagens, usando um número baixo de descritores.

Tabela 7.80 - Taxa de acerto para os métodos da literatura na base de Vistex, classificados por SVM.

\begin{tabular}{lccccc}
\hline Método & ND & TA $(\%)$ & $\kappa$ & E1 & E2 \\
\hline Gabor cores & 10 & 94.91 & 0.95 & 0.05 & 0.05 \\
Momentos cromáticos & 12 & 68.06 & 0.68 & 0.32 & 0.28 \\
Razão de histogramas & 20 & 69.91 & 0.70 & 0.30 & 0.27 \\
\hline
\end{tabular}




\subsubsection{Resumo dos Resultados}

A Tabela 7.81 sumariza os resultados obtidos em cada categoria de descritores de texturas coloridas. Assim como nos demais experimentos, esta tabela mostra os descritores fractais com suas transformações que geraram os melhores resultados. As taxas de acerto aumentaram na maioria dos casos, como esperado do melhor classificador.

Entre os descritores fractais, o método de Bouligand-Minkowski 3D obteve a maior taxa de acerto neste processo de classificação, empregando 13 descritores para isto. O resultado expressa o potencial discriminatório desta técnica, que não havia sido explorado na classificação por KNN. A informação fornecida por esses descritores possui uma interpretação mais difícil, uma vez que são expressas tanto informações de morfologia espacial quanto de relações entre vizinhanças espaciais e cromáticas, sendo então necessário um algoritmo de treinamento mais avançado para aproveitar todo o potencial do método.

Já no caso das combinações, a concatenação Bouligand-Minkowski 3D+Fourier EEE foi a mais eficiente. Estes são também métodos com paradigmas distintos, um tratando canais de forma independente, outro como sendo uma estrutura única entrelaçada. A associação entre ambas as estratégias possibilita que os novos descritores expressem tanto as relações entre vizinhanças cromáticas e espaciais quanto dados do espectro de potência de canais individuais.

Tabela 7.81 - Resumo das taxas de acerto obtidas para a base de Vistex, classificada por SVM.

\begin{tabular}{|c|c|c|c|c|c|}
\hline Método & ND & TA ( $\%)$ & $\kappa$ & E1 & E2 \\
\hline Gabor cores & 10 & 94.91 & 0.95 & 0.05 & 0.05 \\
\hline Momentos cromáticos & 12 & 68.06 & 0.68 & 0.32 & 0.28 \\
\hline Razão de histogramas & 20 & 69.91 & 0.70 & 0.30 & 0.27 \\
\hline Bouligand-Minkowski 3D + FDA & 13 & 96.30 & 0.96 & 0.04 & 0.03 \\
\hline Bouligand-Minkowski EEE + TE & 14 & 93.06 & 0.93 & 0.07 & 0.06 \\
\hline Fourier EEE + TF & 8 & 92.59 & 0.92 & 0.07 & 0.07 \\
\hline Bouligand-Minkowski 3D+Bouligand-Minkowski EEE + TE & 15 & 96.99 & 0.97 & 0.03 & 0.03 \\
\hline Bouligand-Minkowski 3D+Fourier EEE + TF & 12 & 97.22 & 0.97 & 0.03 & 0.02 \\
\hline Bouligand-Minkowski EEE+Fourier EEE + TF & 14 & 95.14 & 0.95 & 0.05 & 0.04 \\
\hline
\end{tabular}

Por sua vez, a Figura 7.16 ilustra o comportamento das taxas de acerto em função do número de descritores usados na base de Vistex, usando-se classificação por SVM. No aspecto geral, as curvas apresentam maior flutuação do que no uso do classificador KNN. Isto é reflexo do processamento não linear de SVM, que faz com que algumas medidas de alta variância influenciem negativamente na taxa de acerto. Esta característica é bem visível no método de Fourier, que mostra que os eixos PCA com menor variância podem comprometer o desempenho geral do classificador. No mais, a combinação Bouligand-Minkowski 3D + Fourier EEE proporcionou altas taxas de acerto, próximas a 90\%, com apenas 5 descritores, 
mostrando sua alta capacidade de discriminação em bases com classificação mais difícil.

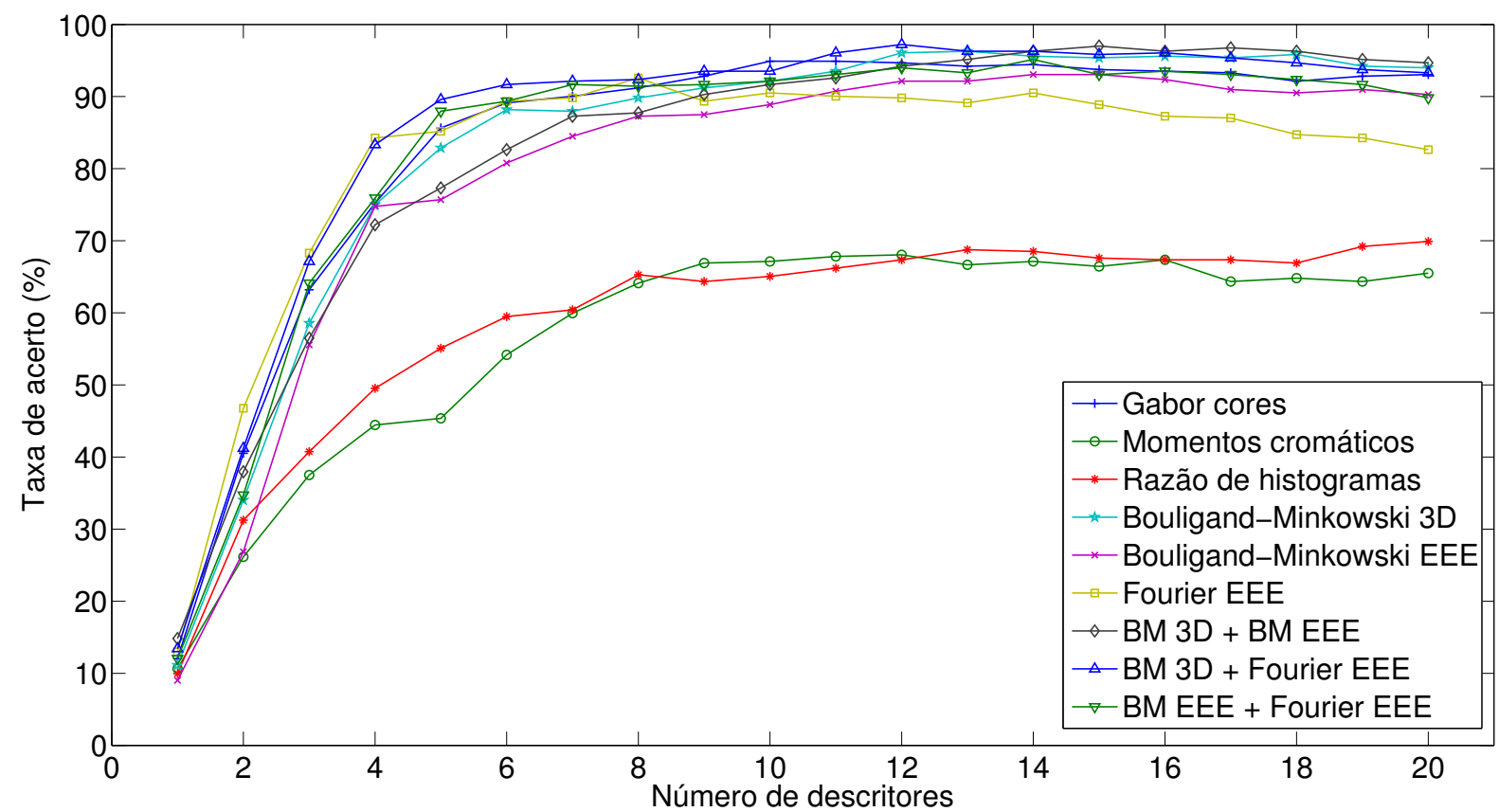

Figura 7.16 - Taxas de acerto em função do número de descritores.

Por fim, as Figuras 7.17 e 7.18 exibem as matrizes de confusão para os métodos de análise de textura comparados. Nota-se nestas matrizes que o problema nas classes 33/34 foi reduzido substancialmente neste classificador. Esta melhora é uma consequência direta do uso de um classificador com maior capacidade de extrair informações que estão explícitas não nos valores dos descritores em si, mas sim nas correlações entre variáveis e em propriedades estatísticas destes mesmos atributos.

\subsection{Outex Cores}

As tabelas e figuras a seguir mostram os resultados alcançados pela base de Outex. Esta possui nível de dificuldade compatível com Vistex, entretanto, apresenta número maior de imagens e de classes, levando a taxas de acerto ligeiramente mais baixas. 


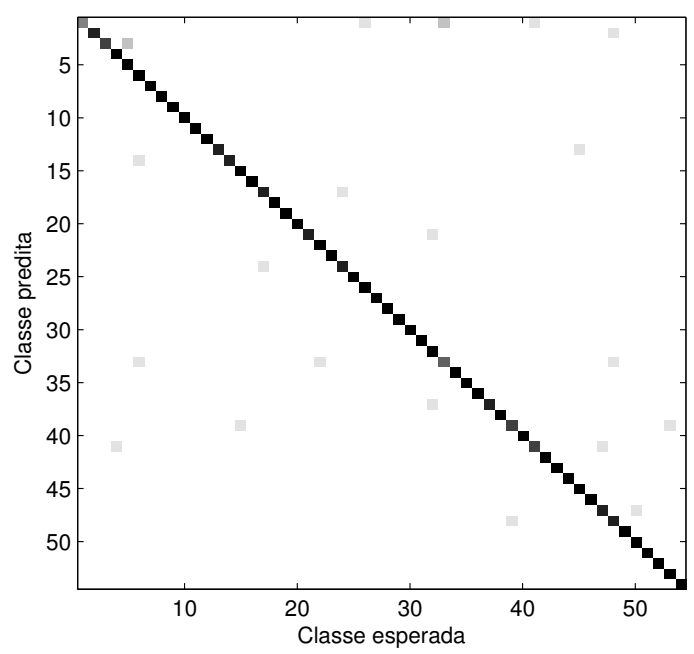

(a)

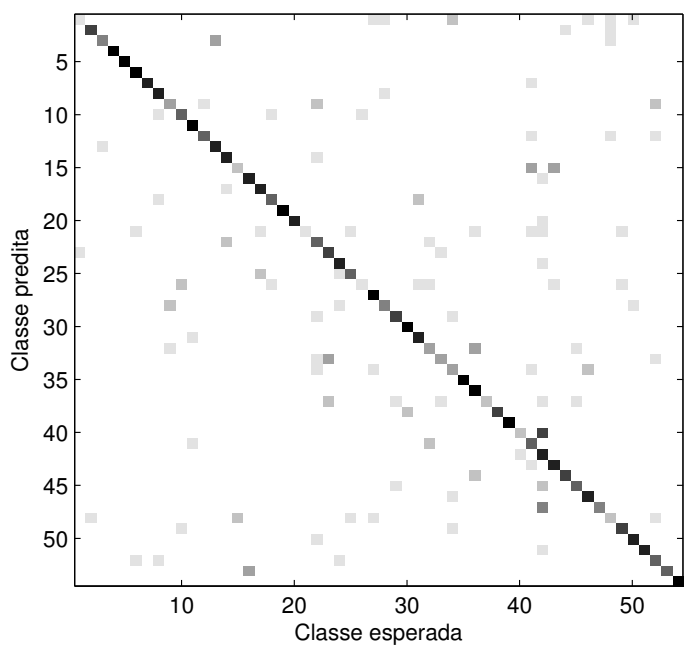

(c)

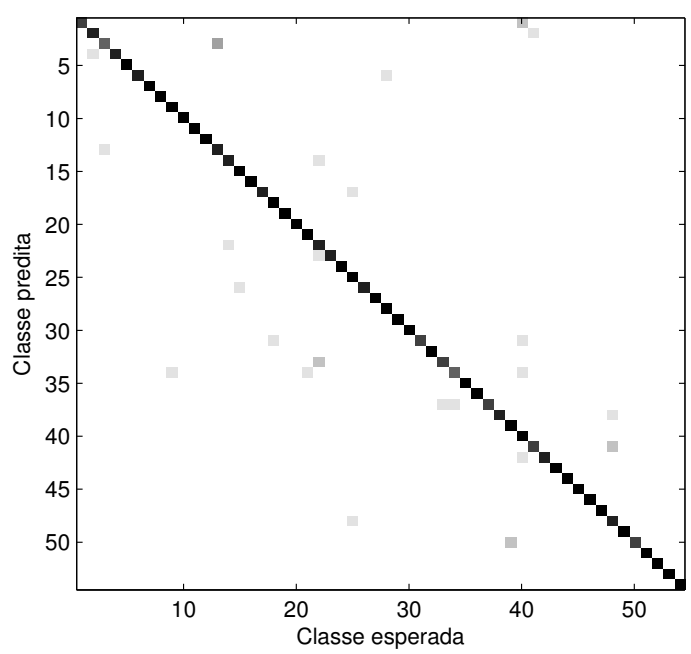

(e)
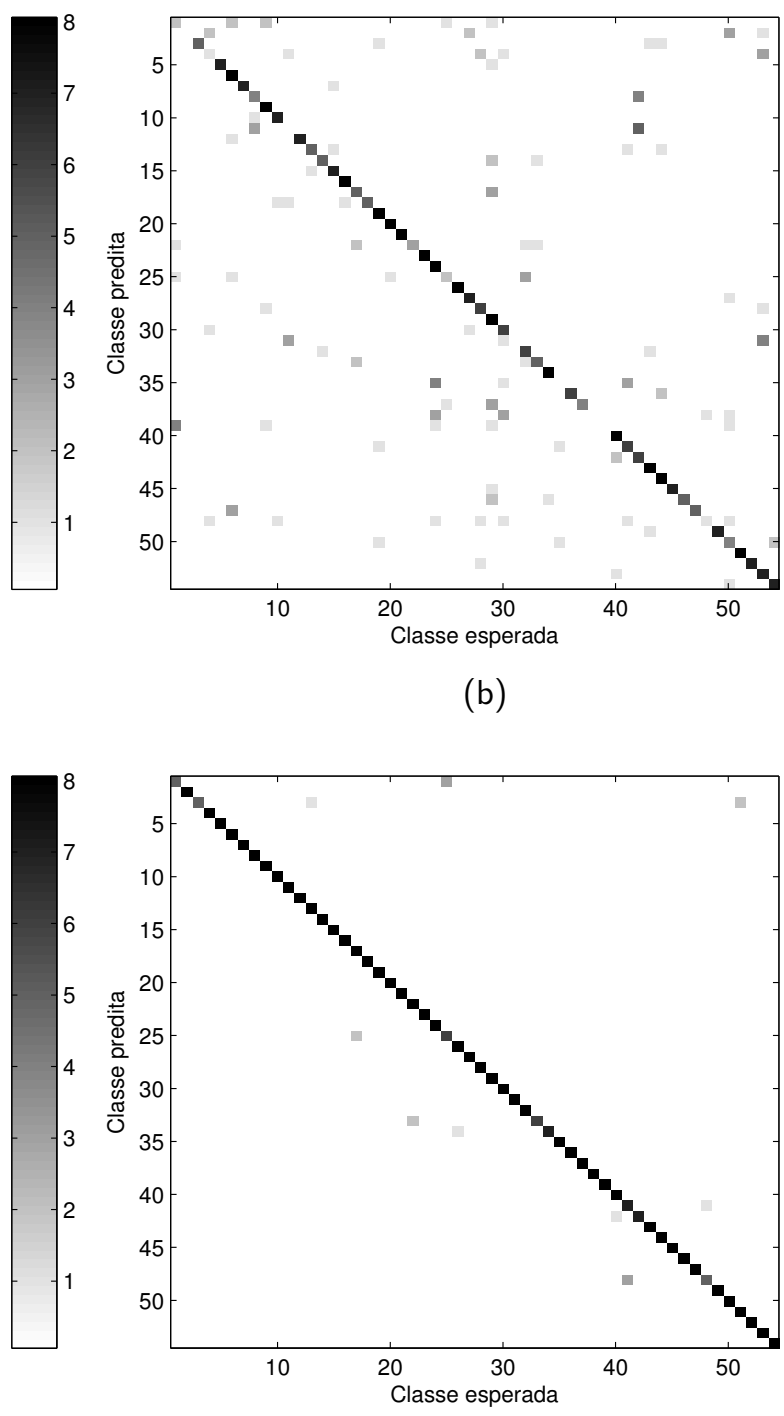

(d)
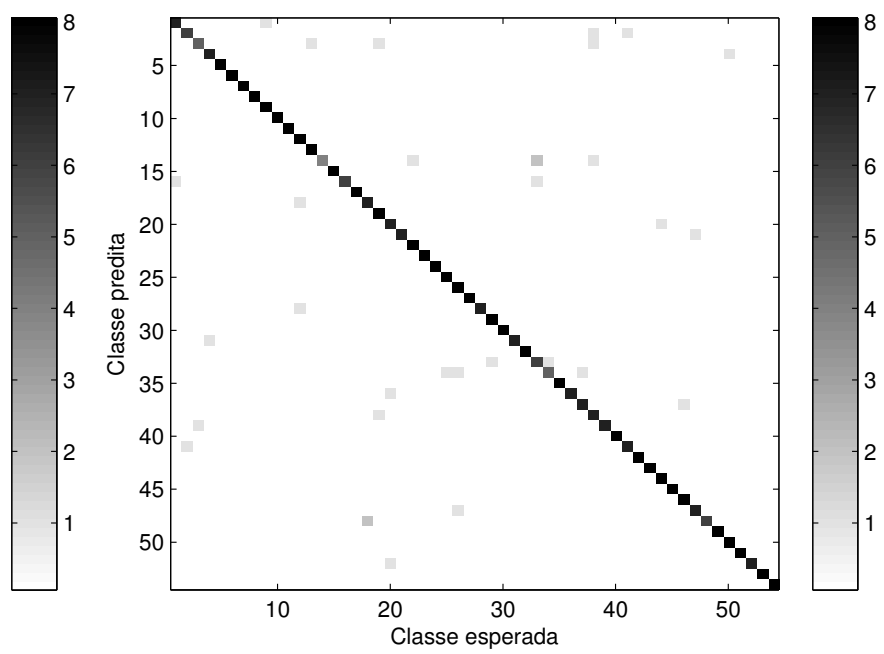

(f)

Figura 7.17 - Matrizes de confusão (parte 1) para os métodos comparados sobre a base de Vistex, usando classificador SVM. (a) Gabor cores. (b) Momentos cromáticos. (c) Razão de histogramas. (d) Bouligand-Minkowski 3D. (e) Bouligand-Minkowski EEE. (f) Fourier EEE. 


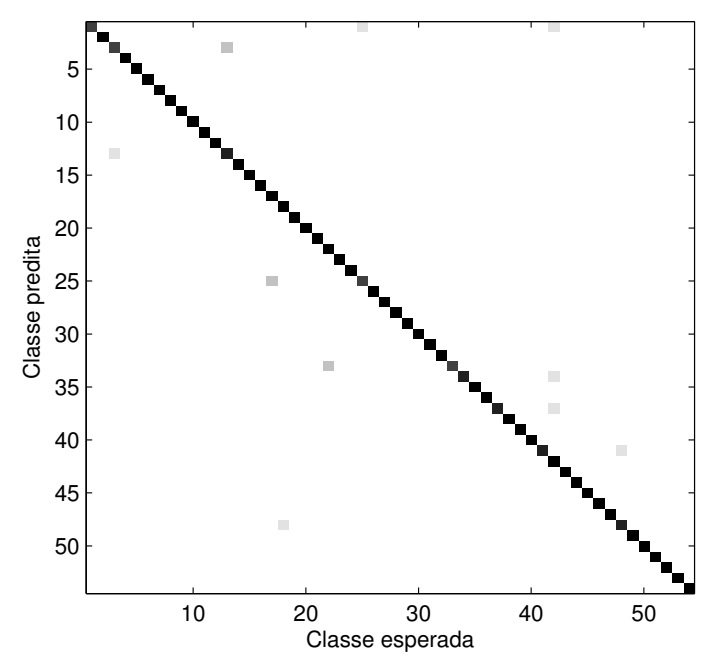

(a)
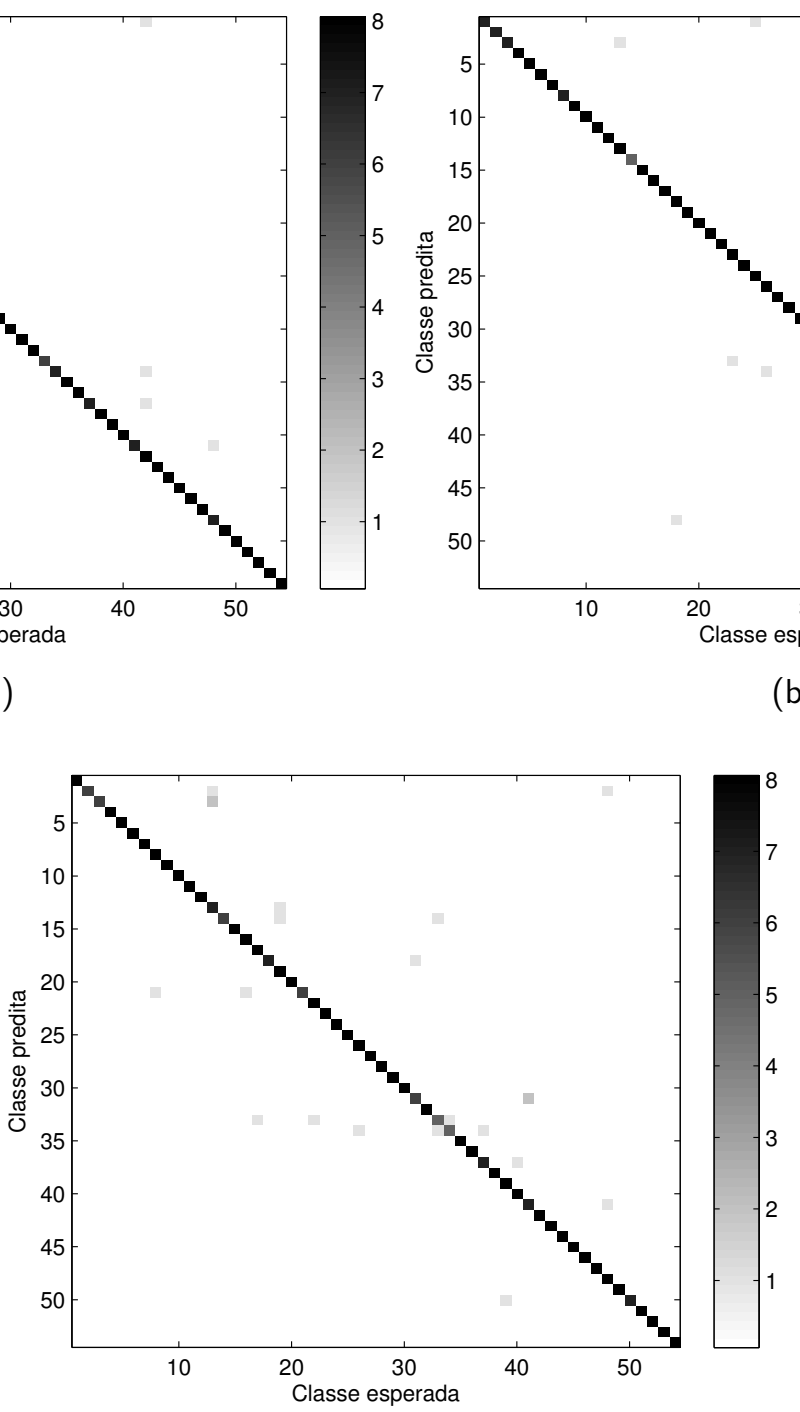

(c)

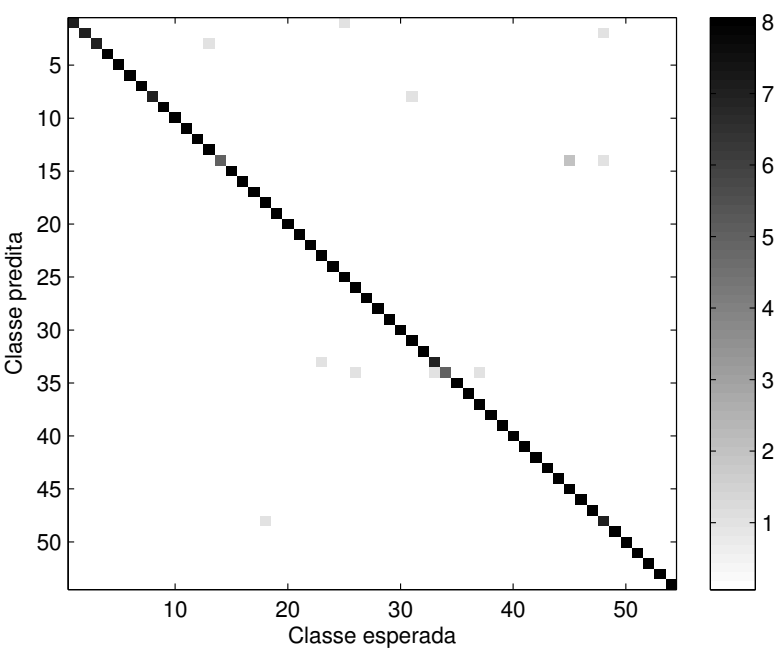

(b)

Figura 7.18 - Matrizes de confusão (parte 2) para os métodos comparados sobre a base de Vistex, usando classificador SVM. (a) Bouligand-Minkowski 3D + Bouligand-Minkowski EEE. (b) Bouligand-Minkowski 3D + Fourier EEE. (c) Bouligand-Minkowski EEE + Fourier EEE. 


\subsubsection{KNN}

Neste primeiro experimento na base, as texturas são classificadas por KNN, tendo como entrada os descritores fractais em suas versões originais e com transformações.

A Tabela 7.82 mostra os resultados alcançados pelos descritores da literatura e fractais, no uso sem redução de dimensionalidade. Embora com imagens mais homogêneas, esta base mostra-se um grande desafio para os descritores, em função do grande número de classes e do alto nível de similaridade entre as imagens de várias classes distintas. O melhor resultado para este classificador foi obtido por Bouligand-Minkowski 3D. Este é um caso em que a informação só pode ser mais significativa quando representa a morfologia dos arranjos de pixels em conjunto com as cores destes mesmos pixels. O método 3D é o que melhor captura essa informação conjunta da imagem.

Tabela 7.82 - Taxa de acerto para os descritores fractais em cores usados de forma direta e outras medidas na base de Outex, com KNN.

\begin{tabular}{cccccc}
\hline Método & ND & TA $(\%)$ & $\kappa$ & E1 & E2 \\
\hline Gabor cores & 60 & 86.69 & 0.87 & 0.13 & 0.13 \\
Momentos cromáticos & 34 & 37.50 & 0.37 & 0.60 & 0.62 \\
Razão de histogramas & 49 & 61.91 & 0.62 & 0.38 & 0.38 \\
\hline \hline Bouligand-Minkowski 3D + TF & 122 & 88.16 & 0.88 & 0.11 & 0.12 \\
Bouligand-Minkowski EEE + TE & 20 & 59.41 & 0.59 & 0.40 & 0.41 \\
Fourier EEE + TF & 139 & 83.01 & 0.83 & 0.17 & 0.17 \\
\hline
\end{tabular}

A Tabela 7.83 exibe os resultados para os descritores fractais individuais com redução de dimensionalidade por CCA. Como esperado, as taxas são menores em relação às obtidas na base de Vistex. Entretanto, aqui, mesmo com o classificador KNN, o método de BouligandMinkowski 3D apresentou o melhor resultado nesta base. Esse fenômeno ocorre em função do aspecto geral das imagens de textura, que são mais regulares do que no caso de Vistex. Esta regularidade faz com que abordagens que analisam a imagem de forma mais global, sem a independência de canais das abordagens EEE, forneçam uma informação mais confiável.

Tabela 7.83 - Taxa de acerto para os descritores fractais individuais na base de Outex, classificados por KNN.

\begin{tabular}{lccccc}
\hline Método & ND & TA (\%) & $\kappa$ & E1 & E2 \\
\hline Bouligand-Minkowski 3D & 17 & 91.76 & 0.92 & 0.08 & 0.08 \\
Bouligand-Minkowski EEE & 19 & 78.24 & 0.78 & 0.20 & 0.22 \\
Fourier EEE & 19 & 85.74 & 0.86 & 0.14 & 0.14 \\
\hline
\end{tabular}

A Tabela 7.84 exibe as taxas de acerto para as combinações entre os descritores fractais propostos. As combinações, com exceção da última, apresentaram melhor resultado do que os descritores aplicados separadamente, além de usar menos descritores. O método de Fourier 
EEE apresenta maior contribuição à combinação com Fourier, dada sua natureza diferente de análise, baseada em padrões de frequências.

Tabela 7.84 - Taxa de acerto para os descritores fractais individuais combinados na base de Outex, classificados por KNN.

\begin{tabular}{lccccc}
\hline Método & ND & TA (\%) & $\kappa$ & E1 & E2 \\
\hline Bouligand-Minkowski 3D+Bouligand-Minkowski EEE & 14 & 92.79 & 0.93 & 0.07 & 0.07 \\
Bouligand-Minkowski 3D+Fourier EEE & 18 & 93.97 & 0.94 & 0.06 & 0.06 \\
Bouligand-Minkowski EEE+Fourier EEE & 12 & 86.76 & 0.87 & 0.13 & 0.13 \\
\hline
\end{tabular}

A Tabela 7.85 exibe as taxas de acerto para os descritores fractais transformados por FDA. A transformação permitiu um incremento na taxa de acerto do método de BouligandMinkowski 3D. Neste caso, os descritores orignais apresentam maior regularidade e a análise funcional expressa as informações mais importantes em um número reduzido de descritores transformados, sem perder variações relevantes no processo de suavização. Nos demais casos, em que os canais foram analisados separadamente, cada canal fornece valores mais heterogêneos, havendo variações bruscas, sobretudo nos pontos de concatenação, variações estas que são importantes no processo de classificação.

Tabela 7.85 - Taxa de acerto para os descritores fractais FDA na base de Outex, classificados por KNN.

\begin{tabular}{lccccc}
\hline Método & ND & TA $(\%)$ & $\kappa$ & E1 & E2 \\
\hline Bouligand-Minkowski 3D & 14 & 92.06 & 0.92 & 0.08 & 0.08 \\
Bouligand-Minkowski EEE & 13 & 76.47 & 0.76 & 0.22 & 0.24 \\
Fourier EEE & 10 & 83.68 & 0.83 & 0.16 & 0.16 \\
\hline
\end{tabular}

Já a Tabela 7.86 mostra os índices de sucesso na classificação de Outex pelos descritores fractais transformados por FDA. Também neste caso, a maior taxa de acerto foi provida pela combinação envolvendo descritores com visões mais distintas da mesma imagem, no caso, Bouligand-Minkowski 3D e Fourier EEE. Note-se que no caso da terceira combinação, embora as duas abordagens EEE apresentem focos distintos (espacial e espectral), o uso em comum da transformada EEE e de canais separados faz com que haja redundâncias como a interpretação física (ondas de frequências específicas) das cores.

Tabela 7.86 - Taxa de acerto para os descritores fractais FDA combinados na base de Outex, classificados por KNN.

\begin{tabular}{lccccc}
\hline Método & ND & TA $(\%)$ & $\kappa$ & E1 & E2 \\
\hline Bouligand-Minkowski 3D+Bouligand-Minkowski EEE & 19 & 92.06 & 0.92 & 0.08 & 0.08 \\
Bouligand-Minkowski 3D+Fourier EEE & 19 & 92.94 & 0.93 & 0.07 & 0.07 \\
Bouligand-Minkowski EEE+Fourier EEE & 14 & 86.03 & 0.86 & 0.13 & 0.14 \\
\hline
\end{tabular}

A Tabela 7.87 mostra as taxas de acerto alcançadas pelos descritores transformados por espaço-escala. Neste caso, todas as soluções testadas apresentaram queda de rendimento, 
inclusive as soluções de Bouligand-Minkowski, que anteriormente tinham apresentado precisão com a associação entre os volumes de dilatação e as derivadas suavizadas. Entretanto, no caso presente, em que os descritores originais já possuem boa capacidade de classificação em função da regularidade da base, a presença da derivada apenas enfatiza variações que constituem de fato ruídos de captura e representação e que não são úteis para o processo de classificação.

Tabela 7.87 - Taxa de acerto para os descritores fractais espaço-escala na base de Outex, classificados por KNN.

\begin{tabular}{lccccc}
\hline Método & ND & TA $(\%)$ & $\kappa$ & E1 & E2 \\
\hline Bouligand-Minkowski 3D & 17 & 82.50 & 0.82 & 0.16 & 0.18 \\
Bouligand-Minkowski EEE & 20 & 48.82 & 0.49 & 0.50 & 0.51 \\
Fourier EEE & 11 & 70.59 & 0.70 & 0.28 & 0.29 \\
\hline
\end{tabular}

Já a Tabela 7.88 explicita as taxas de acerto para cada combinação entre os descritores transformados. As taxas de acerto foram insuficientes para um uso prático em todos os casos, sendo que a combinação Bouligand-Minkowski 3D+Fourier EEE apresentou taxa de acerto menor do que ambos usados separadamente. Este resultado indica que os atributos de cada método apresentam informações conflitantes. Por exemplo, enquanto um apresenta um padrão específico crescente de correlação entre as variáveis no treinamento e teste, o outro não apresenta um padrão definido satisfatoriamente.

Tabela 7.88 - Taxa de acerto para os descritores fractais espaço-escala combinados na base de Outex, classificados por KNN.

\begin{tabular}{lccccc}
\hline Método & ND & TA (\%) & $\kappa$ & E1 & E2 \\
\hline Bouligand-Minkowski 3D+Bouligand-Minkowski EEE & 18 & 69.85 & 0.70 & 0.29 & 0.30 \\
Bouligand-Minkowski 3D+Fourier EEE & 20 & 58.82 & 0.59 & 0.41 & 0.41 \\
Bouligand-Minkowski EEE+Fourier EEE & 20 & 55.29 & 0.55 & 0.43 & 0.45 \\
\hline
\end{tabular}

Já a Tabela 7.89 exibe os acertos para os descritores transformados por tempo-frequência. A análise de frequência na transformação de Garbor gerou índices de acerto significativamente piores do que os obtidos pelo uso dos descritores individuais. Este comportamento deficiente da transformada de frequência se deve à homogeneidade da base, que leva a descritores mais suaves e nos quais os padrões de baixas e altas frequências não são significativos.

Tabela 7.89 - Taxa de acerto para os descritores fractais tempo-frequência na base de Outex, classificados por KNN.

\begin{tabular}{lccccc}
\hline Método & ND & TA (\%) & $\kappa$ & E1 & E2 \\
\hline Bouligand-Minkowski 3D & 8 & 64.71 & 0.64 & 0.34 & 0.35 \\
Bouligand-Minkowski EEE & 19 & 57.94 & 0.58 & 0.41 & 0.42 \\
Fourier EEE & 3 & 55.00 & 0.55 & 0.44 & 0.45 \\
\hline
\end{tabular}

As combinações dos descritores transformados são ilustradas na Tabela 7.90. Também essas combinações não foram capazes de obter taxas de acerto aceitáveis como uma solução 
prática. Mais uma vez, observa-se um caso em que a combinação gerou uma taxa de acerto menor do que os descritores separados. No caso das duas abordagens de Bouligand-Minkowski, surgem perfis opostos de descritores entre aqueles extraídos considerando a interação entre os canais e aqueles obtidos independentemente.

Tabela 7.90 - Taxa de acerto para os descritores fractais tempo-frequência combinados na base de Outex, classificados por KNN.

\begin{tabular}{lccccc}
\hline Método & ND & TA (\%) & $\kappa$ & E1 & E2 \\
\hline Bouligand-Minkowski 3D+Bouligand-Minkowski EEE & 17 & 52.35 & 0.52 & 0.45 & 0.48 \\
Bouligand-Minkowski 3D+Fourier EEE & 5 & 79.12 & 0.79 & 0.20 & 0.21 \\
Bouligand-Minkowski EEE+Fourier EEE & 11 & 57.06 & 0.57 & 0.42 & 0.43 \\
\hline
\end{tabular}

Por fim, a Tabela 7.91 ilustra o desempenho dos descritores fractais transformados por tempo-escala. Embora menor, ainda existe uma queda em relação aos índices de sucesso alcançados pelos descritores individuais. A melhora no resultado se deve à maior flexibilidade da transformada tempo-escala, baseada na transformada wavelets, que por sua vez, usa bandas de comprimento diferente para diferentes faixas de frequências, levando a uma resolução mais precisa nos descritores transformados.

Tabela 7.91 - Taxa de acerto para os descritores fractais tempo-escala na base de Outex, classificados por KNN.

\begin{tabular}{lccccc}
\hline Método & ND & TA $(\%)$ & $\kappa$ & E1 & E2 \\
\hline Bouligand-Minkowski 3D & 19 & 88.82 & 0.89 & 0.11 & 0.11 \\
Bouligand-Minkowski EEE & 13 & 67.35 & 0.67 & 0.32 & 0.33 \\
Fourier EEE & 4 & 70.00 & 0.70 & 0.30 & 0.30 \\
\hline
\end{tabular}

Já a Tabela 7.92 ilustra as taxas de acerto para cada combinação possível de descritores transformados por tempo-escala. Embora tenha melhorado em relação às combinações de tempo-frequência, as taxas de acerto ainda são bem mais baixas do que as obtidas pelas combinações de descritores individuais. Na prática, a análise de frequências não se mostra interessante nesta base de dados para o classificador KNN.

Tabela 7.92 - Taxa de acerto para os descritores fractais tempo-escala combinados na base de Outex, classificados por KNN.

\begin{tabular}{lccccc}
\hline Método & ND & TA $(\%)$ & $\kappa$ & E1 & E2 \\
\hline Bouligand-Minkowski 3D+Bouligand-Minkowski EEE & 19 & 89.26 & 0.89 & 0.10 & 0.11 \\
Bouligand-Minkowski 3D+Fourier EEE & 19 & 90.29 & 0.90 & 0.10 & 0.10 \\
Bouligand-Minkowski EEE+Fourier EEE & 17 & 78.97 & 0.79 & 0.20 & 0.21 \\
\hline
\end{tabular}

\subsubsection{Outros Métodos}

A Tabela 7.93 exibe as taxas de acerto para outras abordagens propostas na literatura e comparadas aqui para verificar a precisão dos descritores fractais propostos. O método 
de Gabor permanece apresentando a maior taxa de acerto, embora menor do que na base de Vistex. No geral, a ordem de precisão se mantém com os métodos de Gabor, Razão de histogramas e Momentos cromáticos nesta ordem de taxa decrescente de acerto.

Tabela 7.93 - Taxa de acerto para os métodos da literatura na base de Outex, classificados por KNN.

\begin{tabular}{lccccc}
\hline Método & ND & TA (\%) & $\kappa$ & E1 & E2 \\
\hline Gabor cores & 19 & 90.44 & 0.90 & 0.09 & 0.10 \\
Momentos cromáticos & 18 & 33.82 & 0.34 & 0.63 & 0.66 \\
Razão de histogramas & 14 & 54.26 & 0.54 & 0.44 & 0.46 \\
\hline
\end{tabular}

\subsubsection{Resumo dos Resultados}

A Tabela 7.94 resume todos os resultados obtidos para as respectivas categorias comparadas de descritores de texturas coloridas.

Entre os descritores fractais simples, o método de Bouligand-Minkowski 3D obteve a maior taxa de acerto, superando o método de Gabor em cores. Neste caso, a transformada FDA colaborou para um aumento na taxa de acerto destes descritores obtidos dos volumes de dilatação e com crescimento suave da curva de fractalidade. Nos demais casos, os descritores individuais obtiveram resultados mais precisos do que pelo uso de transformações, confirmando que o perfil mais homogêneo das imagens dentro de cada classe leva a uma importância maior da curva de fractalidade tomada em sua versão original.

As melhores combinações também foram alcançadas pelos descritores individuais. Particularmente, as duas primeiras combinações alcançaram resultados melhores do que Gabor e uma taxa razoável para uma base com tantas imagens e classes, além de um classificador simplista. A combinação de métodos EEE foi prejudicada pela análise individual de canais. Este tipo de metodologia não é suficiente para discriminar bases tão ricas quanto a Outex, quando a influência entre os canais deve se somar à informação individual de cada cor para compor um método robusto e preciso de descrição.

Tabela 7.94 - Resumo das taxas de acerto obtidas para a base de Outex, classificada por KNN.

\begin{tabular}{lccccc}
\hline Método & ND & TA (\%) & $\kappa$ & E1 & E2 \\
\hline Gabor cores & 19 & 90.44 & 0.90 & 0.09 & 0.10 \\
Razão de histogramas & 14 & 54.26 & 0.54 & 0.44 & 0.46 \\
Momentos cromáticos & 18 & 33.82 & 0.34 & 0.63 & 0.66 \\
\hline \hline Bouligand-Minkowski 3D + FDA & 14 & 92.06 & 0.92 & 0.08 & 0.08 \\
Fourier EEE & 19 & 85.74 & 0.86 & 0.14 & 0.14 \\
Bouligand-Minkowski EEE & 19 & 78.24 & 0.78 & 0.20 & 0.22 \\
\hline \hline Bouligand-Minkowski 3D+Fourier EEE & 18 & 93.97 & 0.94 & 0.06 & 0.06 \\
Bouligand-Minkowski 3D+Bouligand-Minkowski EEE & 14 & 92.79 & 0.93 & 0.07 & 0.07 \\
Bouligand-Minkowski EEE+Fourier EEE & 12 & 86.76 & 0.87 & 0.13 & 0.13 \\
\hline
\end{tabular}

A Figura 7.19 exibe o gráfico da taxa de acerto em função do número de descritores 
para os métodos apresentados na Tabela 7.94. Nota-se que com exceção das abordagens de Momentos e Razão de histogramas, os demais métodos apresentam comportamento regular dentro do esperado da aplicação de métodos de redução de dimensionalidade. No caso daquelas abordagens mais clássicas, a flutuação no gráfico se deve à falta de homogeneidade nos descritores originais. Os métodos obtidos por combinações de descritores fractais em geral alcançaram altas taxas de acerto com poucos descritores.

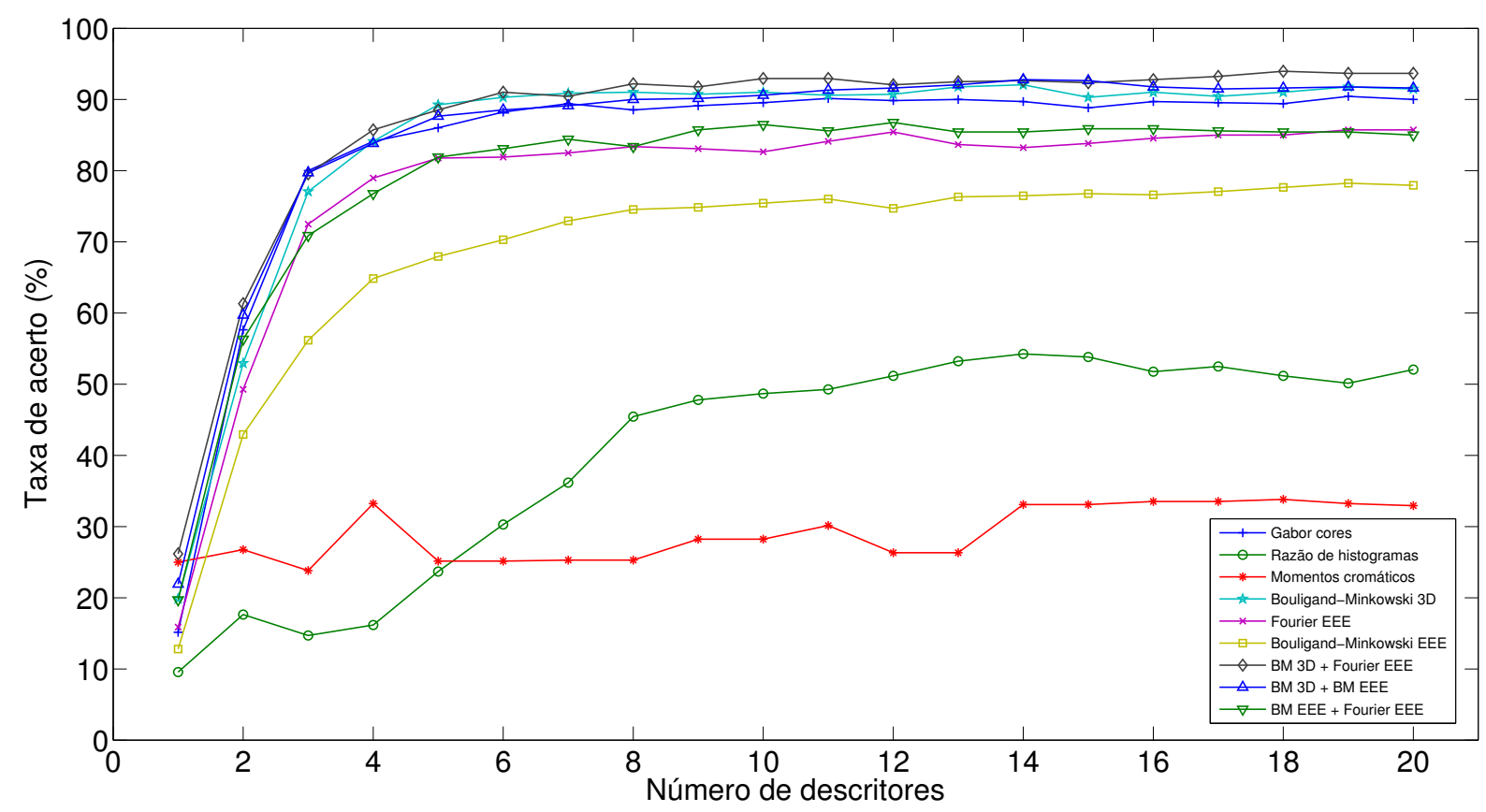

Figura 7.19 - Taxas de acerto em função do número de descritores.

Por fim, as Figuras 7.20 e 7.21 ilustram as matrizes de confusão para os métodos expostos no gráfico da Figura 7.19, no número de descritores que propiciou a maior taxa de acerto. As matrizes mostram sérios problemas para o classificador nas últimas classes da base, onde existe um forte índice de confusão expresso pelos pontos cinza espalhados ao redor da diagonal. Estas classes apresentam imagens de cereais com morfologias semelhantes, como arroz, feijão, café, entre outros, e em condições de iluminação que dificultam a identificação por cores. Nota-se que estas classes apresentaram significativa contribuição para o menor acerto em relação a Vistex, pois mesmo os descritores combinados apresentaram problemas nesta região das matrizes. 


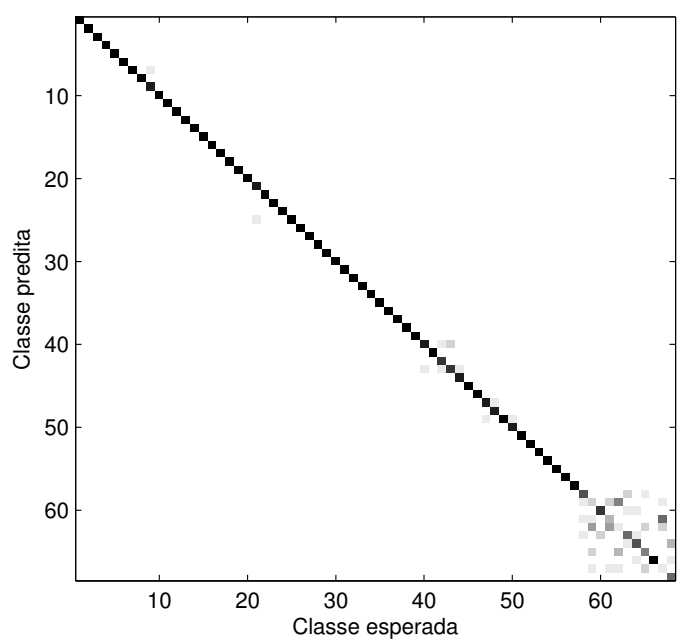

(a)

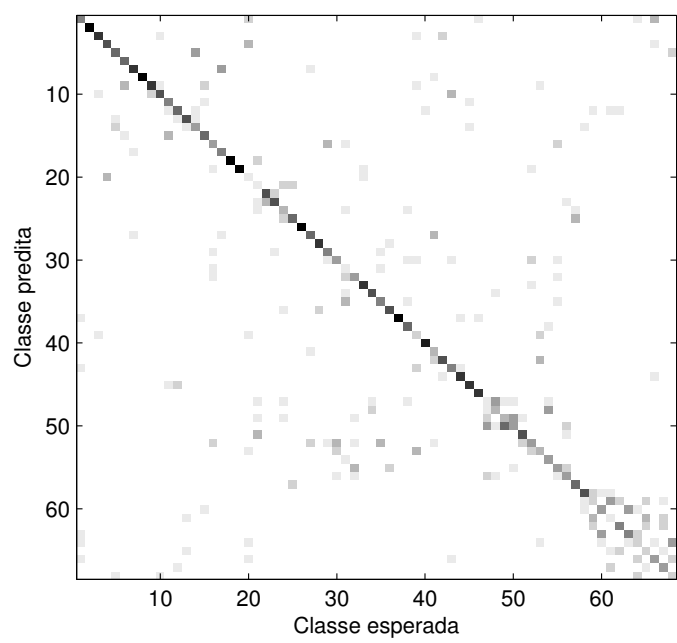

(c)

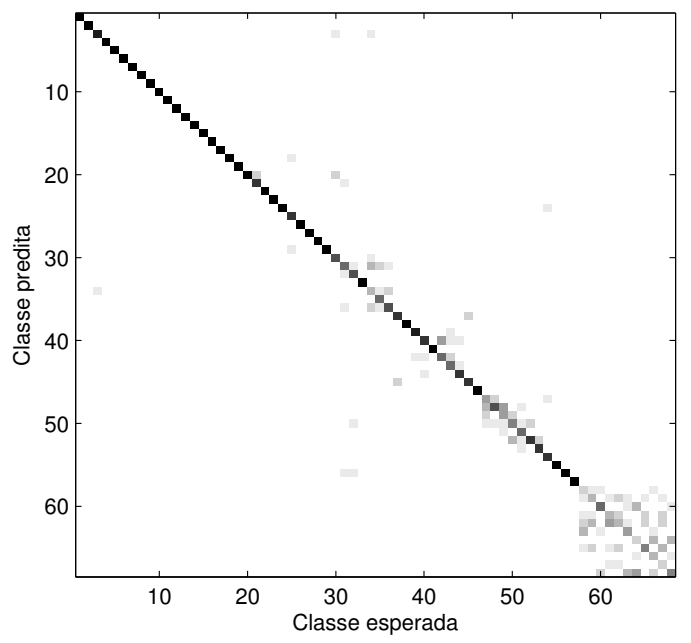

(e)
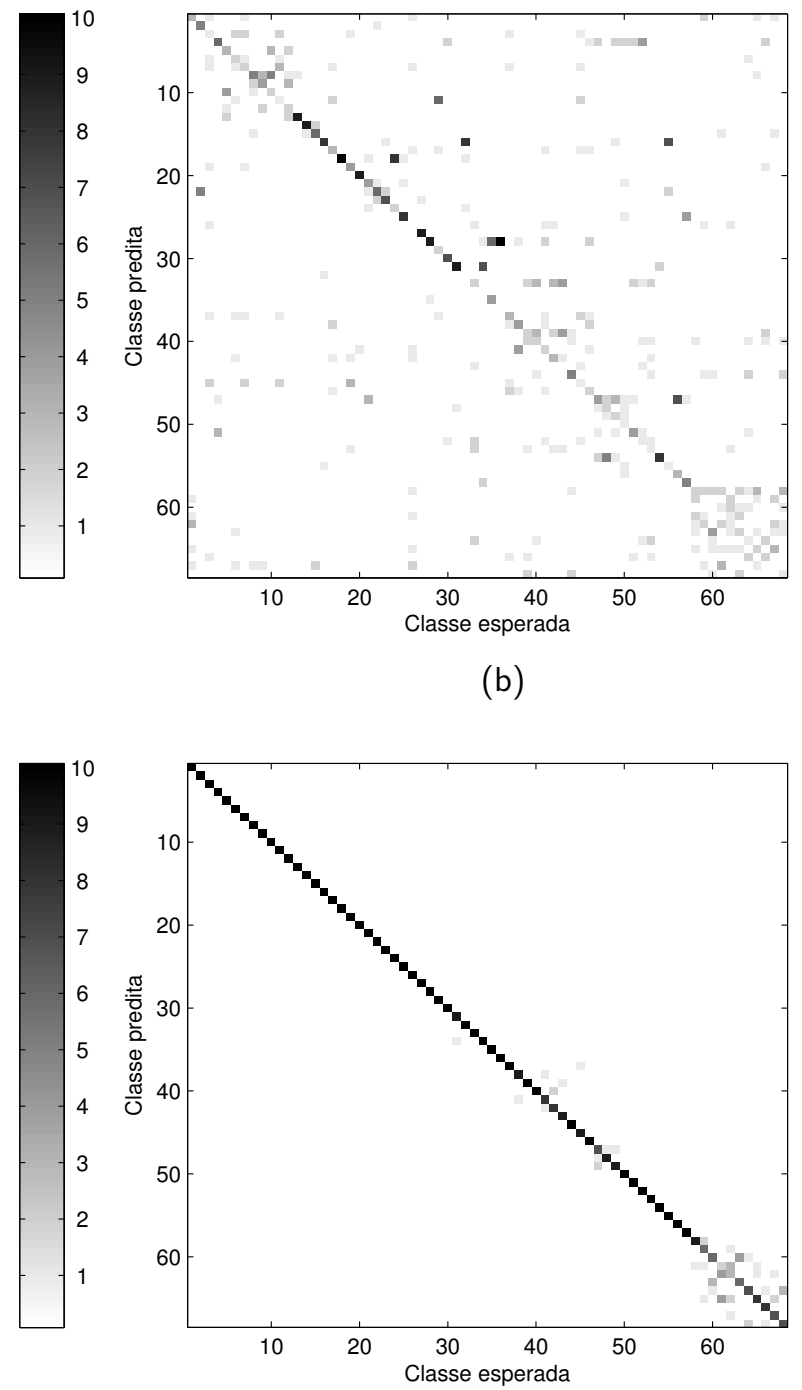

(d)
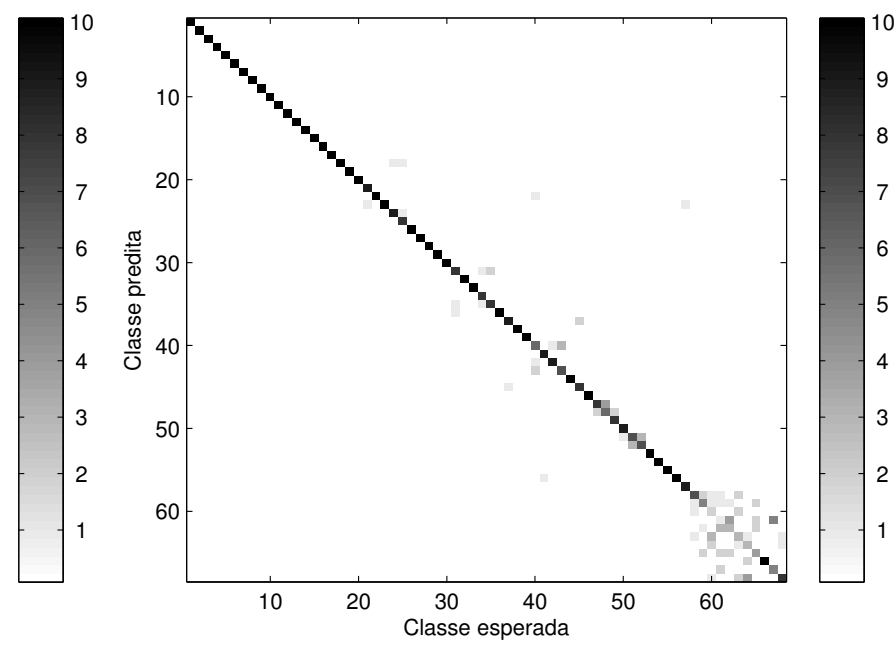

(f)

Figura 7.20 - Matrizes de confusão (parte 1) para os métodos comparados sobre a base de Outex, usando classificador KNN. (a) Gabor cores. (b) Momentos cromáticos. (c) Razão de histogramas. (d) Bouligand-Minkowski 3D. (e) Bouligand-Minkowski EEE. (f) Fourier EEE. 


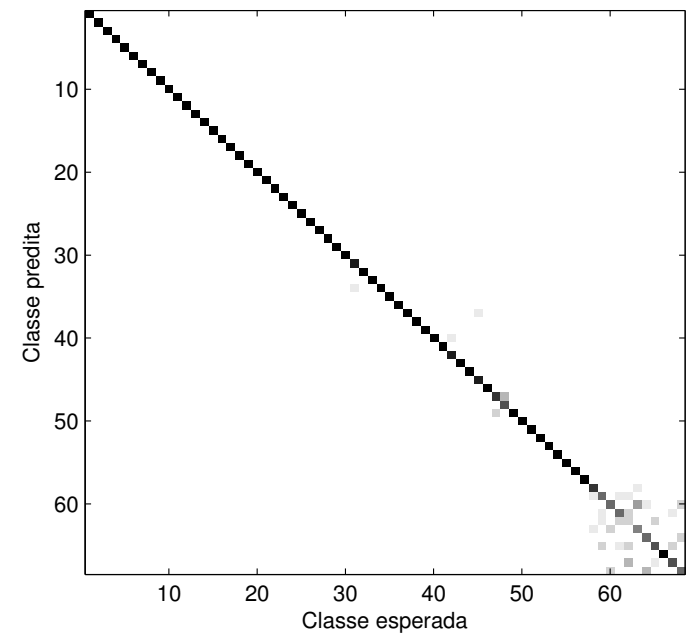

(a)
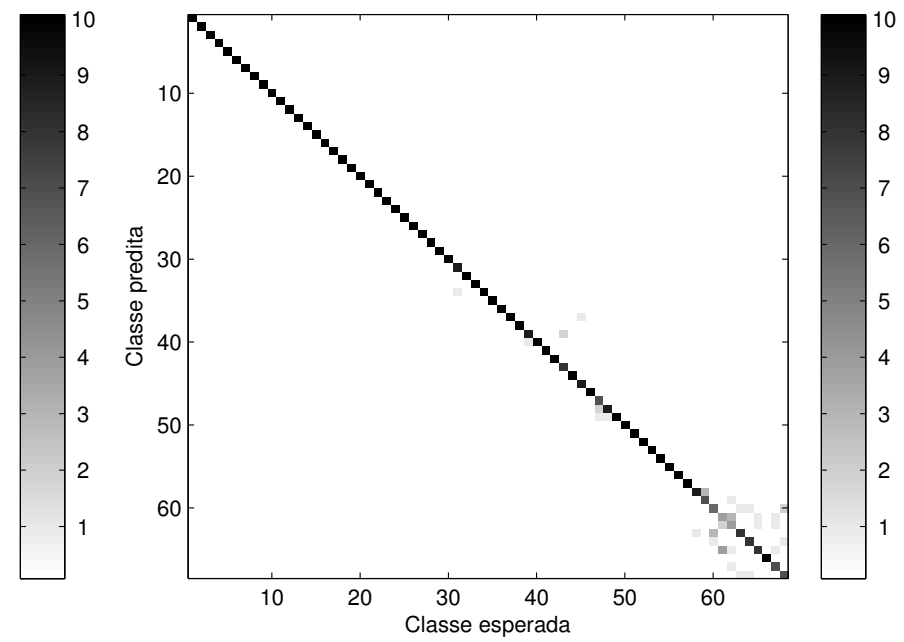

(b)

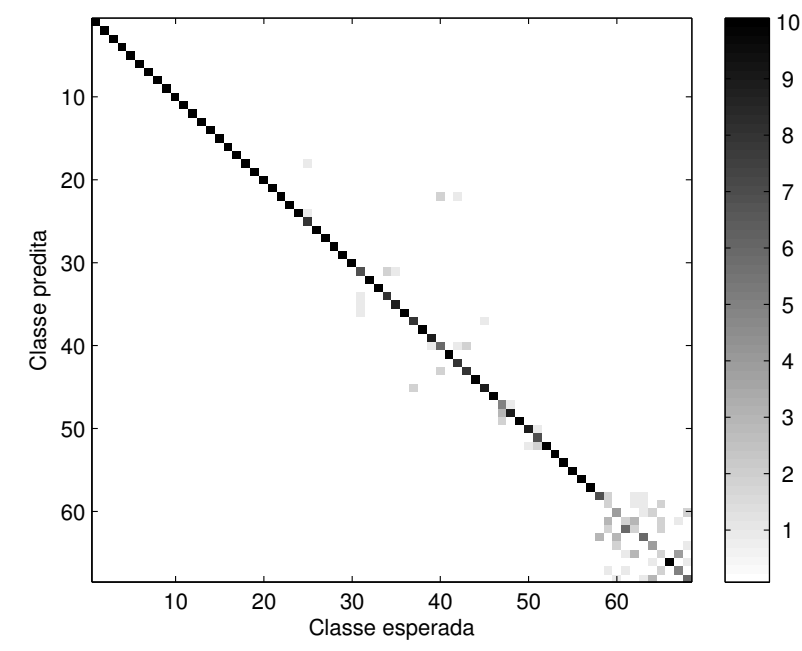

(c)

Figura 7.21 - Matrizes de confusão (parte 2) para os métodos comparados sobre a base de Outex, usando classificador KNN. (a) Bouligand-Minkowski 3D + Bouligand-Minkowski EEE. (b) Bouligand-Minkowski 3D + Fourier EEE. (c) Bouligand-Minkowski EEE + Fourier EEE. 


\subsubsection{SVM}

A seguir são exibidos os resultados para a classificação da base de Outex. Como ocorrido na base de Vistex, espera-se um ligeiro aumento nas taxas de acerto em função da maior robustez do classificador.

A Tabela 7.95 exibe os resultados obtidos por cada descritor em seu uso direto na base de Outex, com classificador SVM. Novamente, o método de Bouligand-Minkowski 3D se sobressai, desta vez, com taxa de acerto maior em razão da técnica de classificação mais rebuscada. O método de Fourier EEE, com sua informação de frequência e baixa correlação entre os descritores, apresenta um resultado satisfatório em relação a outras soluções na literatura.

Tabela 7.95 - Taxa de acerto para os descritores fractais em cores usados no modo direto e outras medidas na base de Outex, com classificador SVM.

\begin{tabular}{cccccc}
\hline Método & ND & TA $(\%)$ & $\kappa$ & E1 & E2 \\
\hline Gabor cores & 41 & 89.71 & 0.87 & 0.13 & 0.12 \\
Momentos cromáticos & 46 & 34.56 & 0.34 & 0.65 & 0.69 \\
Razão de histogramas & 55 & 56.62 & 0.57 & 0.42 & 0.42 \\
\hline \hline Bouligand-Minkowski 3D + TE & 87 & 94.85 & 0.94 & 0.06 & 0.06 \\
Bouligand-Minkowski EEE + TF & 30 & 69.12 & 0.66 & 0.33 & 0.33 \\
Fourier EEE & 91 & 84.56 & 0.82 & 0.18 & 0.18 \\
\hline
\end{tabular}

A Tabela 7.96 exibe as taxas de acerto para os descritores fractais classificados por SVM. Em relação ao resultado obtido por KNN, apenas o método de Bouligand-Minkowski 3D apresentou ligeiro aumento na taxa de acerto. Este resultado mais favorável a um método de classificação simples como KNN é consequência do perfil da base de texturas, que não possui imagens de padrões morfológicos complexos, mas sim um número alto de imagens e classes, além de classes com alta similaridade no aspecto de suas imagens, como as últimas da base.

Tabela 7.96 - Taxa de acerto para os descritores fractais individuais na base de Outex, classificados por SVM.

\begin{tabular}{lccccc}
\hline Método & ND & TA $(\%)$ & $\kappa$ & E1 & E2 \\
\hline Bouligand-Minkowski 3D & 18 & 92.50 & 0.92 & 0.07 & 0.07 \\
Bouligand-Minkowski EEE & 20 & 65.74 & 0.65 & 0.34 & 0.30 \\
Fourier EEE & 6 & 77.65 & 0.77 & 0.22 & 0.21 \\
\hline
\end{tabular}

As combinações de descritores são exibidas na Tabela 7.97. Estas apresentaram taxas de acerto mais baixas do que o método de Bouligand-Minkowski 3D apenas. Apenas a combinação de Fourier EEE com Bouligand-Minkowski EEE apresentou resultado melhor do que os descritores individuais, mas ainda bem abaixo do obtido por Gabor. Como ocorrido com o classificador KNN, o uso de combinação não se mostrou interessante devido às informações com baixa complementaridade presentes nos diferentes descritores. 
Tabela 7.97 - Taxa de acerto para os descritores fractais individuais combinados na base de Outex, classificados por SVM.

\begin{tabular}{lccc}
\hline & Bouligand-Minkowski 3D.mat & Bouligand-Minkowski EEE.mat & Fourier EEE.mat \\
\hline Bouligand-Minkowski 3D.mat & - & $87(20)$ & $90.88(9)$ \\
Bouligand-Minkowski EEE.mat & $87(20)$ & - & $79.26(7)$ \\
Fourier EEE.mat & $90.88(9)$ & $79.26(7)$ & - \\
\hline
\end{tabular}

A Tabela 7.98 mostra as taxas de acerto, número de descritores e medidas de precisão efetiva $(\kappa)$ e erro para os descritores transformados por FDA. A aplicação da análise funcional permitiu um aumento na taxa de acerto para as abordagens de Bouligand-Minkowski, tanto EEE quanto 3D. Este ganho ocorre em função do aspecto suave dos descritores originais. O mecanismo de dilatação faz com que cada volume para um raio de dilatação específico contenha em si o volume de raios menores. Isso faz com que as variáveis se correlacionem fortemente e como consequência produzam descritores com transições mais suaves, ideais para a síntese FDA com suas funções diferenciáveis.

Tabela 7.98 - Taxa de acerto para os descritores fractais FDA na base de Outex, classificados por SVM.

\begin{tabular}{lccccc}
\hline Método & ND & TA $(\%)$ & $\kappa$ & E1 & E2 \\
\hline Bouligand-Minkowski 3D & 16 & 93.38 & 0.93 & 0.07 & 0.07 \\
Bouligand-Minkowski EEE & 17 & 66.18 & 0.66 & 0.34 & 0.31 \\
Fourier EEE & 5 & 65.44 & 0.65 & 0.35 & 0.33 \\
\hline
\end{tabular}

A Tabela 7.99 exibe as taxas de acerto alcançadas pelos descritores FDA concatenados. Apesar da melhora no acerto dos descritores individuais, os resultados para os pares apresenta uma sensível queda na taxa de acerto em relação às combinações de descritores individuais. Esta queda mostra que a transformada FDA adiciona elementos redundantes aos diferentes descritores transformados, fazendo com que as combinações não sejam tão eficientes quanto o esperado.

Tabela 7.99 - Taxa de acerto para os descritores fractais FDA combinados na base de Outex, classificados por SVM.

\begin{tabular}{lccc}
\hline & Bouligand-Minkowski 3D.mat & Bouligand-Minkowski EEE.mat & Fourier EEE.mat \\
\hline Bouligand-Minkowski 3D.mat & - & $86.91(19)$ & $84.85(7)$ \\
Bouligand-Minkowski EEE.mat & $86.91(19)$ & - & $66.32(7)$ \\
Fourier EEE.mat & $84.85(7)$ & $66.32(7)$ & - \\
\hline
\end{tabular}

Já a Tabela 7.100 ilustra as taxas de acerto para os descritores transformados por espaçoescala. O desempenho para cada método apresenta diferenças substanciais. Enquanto o método de Bouligand-Minkowski 3D não apresentou alteração, os descritores de BouligandMinkowski EEE apresentaram aumento na taxa de acerto e o método de Fourier EEE apresentou queda relevante no sucesso da classificação. A diferença se deve à natureza de cada descritor original. Assim, o método de Bouligand-Minkowski contém informação de interesse 
em sua derivada, enquanto o espectro de potência não é formado por acumulação como o volume de dilatação e assim a informação de variação não corresponde com precisão à fractalidade local como ocorria com o método de Bouligand-Minkowski.

Tabela 7.100 - Taxa de acerto para os descritores fractais espaço-escala na base de Outex, classificados por SVM.

\begin{tabular}{lccccc}
\hline Método & ND & TA $(\%)$ & $\kappa$ & E1 & E2 \\
\hline Bouligand-Minkowski 3D & 20 & 92.50 & 0.92 & 0.08 & 0.07 \\
Bouligand-Minkowski EEE & 9 & 68.68 & 0.68 & 0.31 & 0.32 \\
Fourier EEE & 10 & 64.85 & 0.65 & 0.35 & 0.34 \\
\hline
\end{tabular}

Por sua vez, a Tabela 7.101 ilustra as taxas de acero alcançadas pelas combinações dos descritores transformados por espaço-escala. Também neste caso os descritores combinados não atingiram o desempenho do método de Bouligand-Minkowski 3D simples. Novamente, a homogeneidade da base não se relacionou bem com a operação de derivada que enfatiza variações que constituem uma informação ruidosa e desnecessária para o classificador.

Tabela 7.101 - Taxa de acerto para os descritores fractais espaço-escala combinados na base de Outex, classificados por SVM.

\begin{tabular}{lccc}
\hline & Bouligand-Minkowski 3D.mat & Bouligand-Minkowski EEE.mat & Fourier EEE.mat \\
\hline Bouligand-Minkowski 3D.mat & - & $91.02(19)$ & $75.73(9)$ \\
Bouligand-Minkowski EEE.mat & $91.02(19)$ & - & $64.70(11)$ \\
Fourier EEE.mat & $75.73(9)$ & $64.70(11)$ & - \\
\hline
\end{tabular}

A Tabela 7.102 mostra os resultados com a aplicação da operação multiescala de tempofrequência, derivada da transformação de Gabor unidimensional. Os resultados mantiveram-se similares à aplicação dos descritores individuais, com pequena vantagem obtida no método de Bouligand-Minkowski 3D e pequena queda na taxa de acerto das outras duas abordagens. O bom resultado para o método 3D é consequência dos padrões periódicos de diferentes frequências presentes nos volumes das superfícies dilatadas em conjunto e que são realçadas neste tipo de multiescala.

Tabela 7.102 - Taxa de acerto para os descritores fractais tempo-frequência na base de Outex, classificados por SVM.

\begin{tabular}{lccccc}
\hline Método & ND & TA (\%) & $\kappa$ & E1 & E2 \\
\hline Bouligand-Minkowski 3D & 20 & 93.82 & 0.94 & 0.06 & 0.05 \\
Bouligand-Minkowski EEE & 11 & 64.85 & 0.65 & 0.35 & 0.34 \\
Fourier EEE & 6 & 76.76 & 0.77 & 0.23 & 0.21 \\
\hline
\end{tabular}

Já a Tabela 7.103 combina os descritores fractais tempo-frequência e exibe os resultados obtidos em termos de taxas de acerto e número de descritores. Novamente os ganhos mais significativos e resultados mais robustos são obtidos a partir dos descritores de BouligandMinkowski combinados nas modalidades EEE e 3D. Estes métodos beneficiam-se da riqueza da informação de frequência sobre os volumes de dilatação. 
Tabela 7.103 - Taxa de acerto para os descritores fractais tempo-frequência combinados na base de Outex, classificados por SVM.

\begin{tabular}{lccc}
\hline & Bouligand-Minkowski 3D.mat & Bouligand-Minkowski EEE.mat & Fourier EEE.mat \\
\hline Bouligand-Minkowski 3D.mat & - & $91.76(13)$ & $89.70(9)$ \\
Bouligand-Minkowski EEE.mat & $91.76(13)$ & - & $82.05(12)$ \\
Fourier EEE.mat & $89.70(9)$ & $82.05(12)$ & - \\
\hline
\end{tabular}

Finalmente, a Tabela 7.104 exibe as taxas de acerto obtidas pelos descritores transformados por tempo-escala. Todos os métodos apresentaram queda na taxa de acerto, entretanto, o método de Fourier caiu de $77.65 \%$ para $23.68 \%$. Este fenômeno ocorre devido à forma como esses descritores são definidos e o tipo de análise executado pela transformação tempo-escala. Os descritores fractais de Fourier são extraídos da relação entre o espectro de potência e a frequência, enquanto a transformada tempo-escala realiza uma transformação de wavelets sobre a curva de descritores. Deste modo, sobretudo as altas frequências são comprometidas pelo uso de bandas mais estreitas, enquanto essas mesmas frequências desempenham papel tão importante quanto as baixas na determinação do padrão de complexidade.

Tabela 7.104 - Taxa de acerto para os descritores fractais tempo-escala na base de Outex, classificados por SVM.

\begin{tabular}{lccccc}
\hline Método & ND & TA $(\%)$ & $\kappa$ & E1 & E2 \\
\hline Bouligand-Minkowski 3D & 16 & 91.91 & 0.92 & 0.08 & 0.07 \\
Bouligand-Minkowski EEE & 8 & 63.82 & 0.64 & 0.36 & 0.34 \\
Fourier EEE & 14 & 23.68 & 0.23 & 0.76 & 0.79 \\
\hline
\end{tabular}

A Tabela 7.105 exibe os resultados para os descritores fractais transformados por tempoescala e combinados dois a dois para servirem de entrada ao classificador SVM. A combinação dos métodos de Bouligand-Minkowski apresentou a maior taxa de acerto, embora ainda menor do que o descritor de Bouligand-Minkowski 3D separadamente. De um modo geral, a transformada tempo-escala não constitui uma ferramente útil para a análise dos descritores fractais sobre esta base de texturas.

Tabela 7.105 - Taxa de acerto para os descritores fractais tempo-escala combinados na base de Outex, classificados por SVM.

\begin{tabular}{lccc}
\hline & Bouligand-Minkowski 3D.mat & Bouligand-Minkowski EEE.mat & Fourier EEE.mat \\
\hline Bouligand-Minkowski 3D.mat & - & $91.17(18)$ & $(14)$ \\
Bouligand-Minkowski EEE.mat & $91.17(18)$ & - & $35.44(11)$ \\
Fourier EEE.mat & $(14)$ & $35.44(11)$ & - \\
\hline
\end{tabular}

\subsubsection{Outros Métodos}

A Tabela 7.106 mostra as taxas de acerto alcançadas pelos demais métodos de análise de texturas coloridas disseminados na literatura e tomados como base de comparação com os descritores propostos. O método de Gabor apresenta novamente ampla vantagem, embora a 
taxa de acerto seja menor do que no classificador SVM. O fato de SVM não ter se sobressaído nesta base de texturas se justifica pelo aspecto de cada textura, com padrões homogêneos e bem definidos, além de classes mais severas em que o uso de classificadores mais rebuscados não é capaz de obter melhora sensível nos resultados propriamente ditos.

Tabela 7.106 - Taxa de acerto para os métodos da literatura na base de Outex, classificados por SVM.

\begin{tabular}{lccccc}
\hline Método & ND & TA (\%) & $\kappa$ & E1 & E2 \\
\hline Gabor cores & 6 & 88.97 & 0.89 & 0.11 & 0.09 \\
Momentos cromáticos & 8 & 51.03 & 0.51 & 0.49 & 0.44 \\
Razão de histogramas & 20 & 52.94 & 0.53 & 0.47 & 0.45 \\
\hline
\end{tabular}

\subsubsection{Resumo dos Resultados}

A Tabela 7.107 ilustra as taxas de acerto obtidas por cada descritor, fractal ou não, sobre a base de Outex, classificados por SVM.

Novamente, o método de Bouligand-Minkowski 3D superou o método estado-da-arte de Gabor-wavelets em imagens coloridas. Este também foi superado por duas abordagens de descritores combinados, ou seja, Bouligand-Minkowski 3D+Fourier EEE e Bouligand-Minkowski EEE+Fourier EEE.

Este resultado ilustra o potencial dos descritores fractais na análise de imagens de texturas coloridas, mesmo em bases com grande número de imagens e classes, bem como com classes de difícil discriminação como as imagens de cereais apresentadas nesta base. Neste sentido, a base de Outex constitui um importante padrão para se verificar a aplicabilidade dos descritores fractais sobre conjuntos de texturas que surgem em aplicações do mundo real. E os descritores propostos demonstraram assim sua robustez e precisão nestas situações mais severas comuns em problemas práticos.

Tabela 7.107 - Resumo das taxas de acerto obtidas para a base de Outex, classificada por SVM.

\begin{tabular}{|c|c|c|c|c|c|}
\hline Método & ND & TA $(\%)$ & $\kappa$ & E1 & E2 \\
\hline Gabor cores & 6 & 88.97 & 0.89 & 0.11 & 0.09 \\
\hline Momentos cromáticos & 8 & 51.03 & 0.51 & 0.49 & 0.44 \\
\hline Razão de histogramas & 20 & 52.94 & 0.53 & 0.47 & 0.45 \\
\hline Bouligand-Minkowski 3D + TF & 20 & 93.82 & 0.94 & 0.06 & 0.05 \\
\hline Bouligand-Minkowski EEE + EE & 9 & 68.68 & 0.68 & 0.31 & 0.32 \\
\hline Fourier EEE & 6 & 77.65 & 0.77 & 0.22 & 0.21 \\
\hline Bouligand-Minkowski 3D+Bouligand-Minkowski EEE + TF & 13 & 91.76 & 0.92 & 0.08 & 0.07 \\
\hline Bouligand-Minkowski 3D+Fourier EEE & 9 & 90.88 & 0.91 & 0.09 & 0.09 \\
\hline Bouligand-Minkowski EEE+Fourier EEE + TF & 12 & 82.06 & 0.82 & 0.18 & 0.17 \\
\hline
\end{tabular}

A Figura 7.22 exibe os gráficos das taxas de acerto para os métodos de análise de texturas comparados. Três métodos se destacam ao atingir altas taxas de acerto com poucos 
descritores, sendo eles Gabor, Bouligand-Minkowski 3D e a combinação das duas abordagens de Bouligand-Minkowski. Ainda vale ressaltar que o método de Fourier EEE apresentou queda acentuada no índice de sucesso após um determinado número (pequeno) de descritores. Este fato corrobora uma propriedade importante deste método que é a presença de uma grande porcentagem de variância nos componentes iniciais, o que por sua vez indica o alto nível de correlação dentro do espectro de potência. Este fato compromete o uso deste tipo de descritor em uma base mais homogênea como Outex.

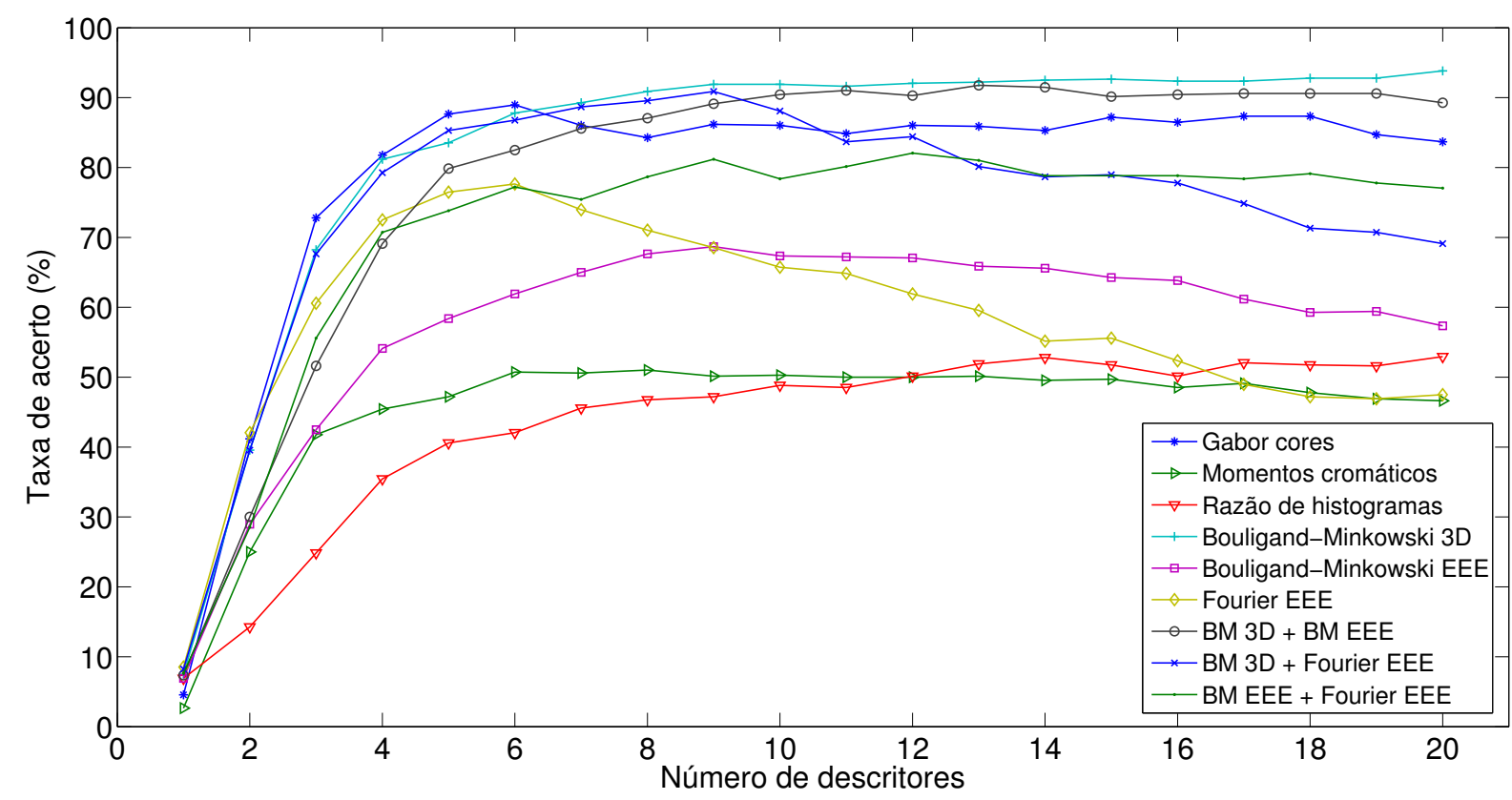

Figura 7.22 - Taxas de acerto em função do número de descritores na base de Outex, com classificador SVM.

Já as Figuras 7.23 e 7.24 mostram as matrizes de confusão relativas a cada melhor taxa de acerto obtida e exibida na Figura 7.22. Mais uma vez, as figuras mostram a dificuldade na classificação de várias das últimas classes da base de texturas. Como citado anteriormente, estas imagens são obtidas de agrupamentos de cereais com formato parecido e cores mais neutras em função do padrão de iluminação utilizado. Na prática, essas imagens levam a padrões de arranjos de pixels similares entre diferentes classes e comprometem severamente 0 desempenho de qualquer descritor de textura aplicado. 


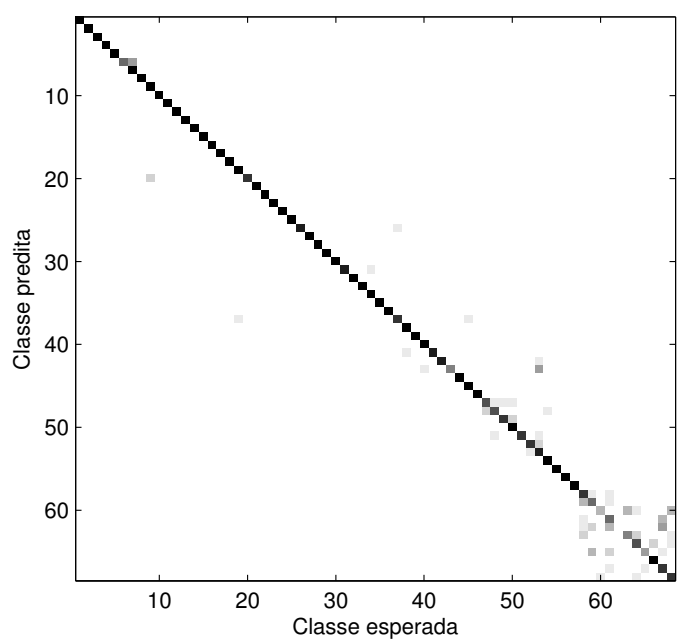

(a)

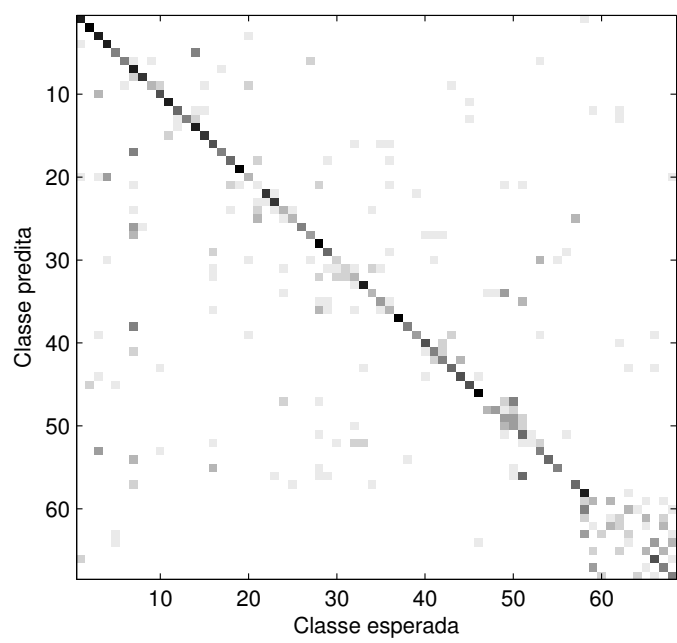

(c)

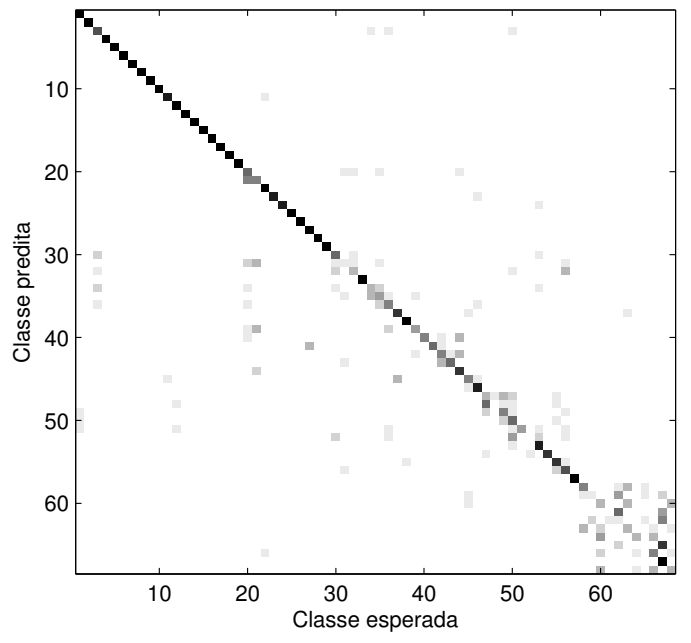

(e)

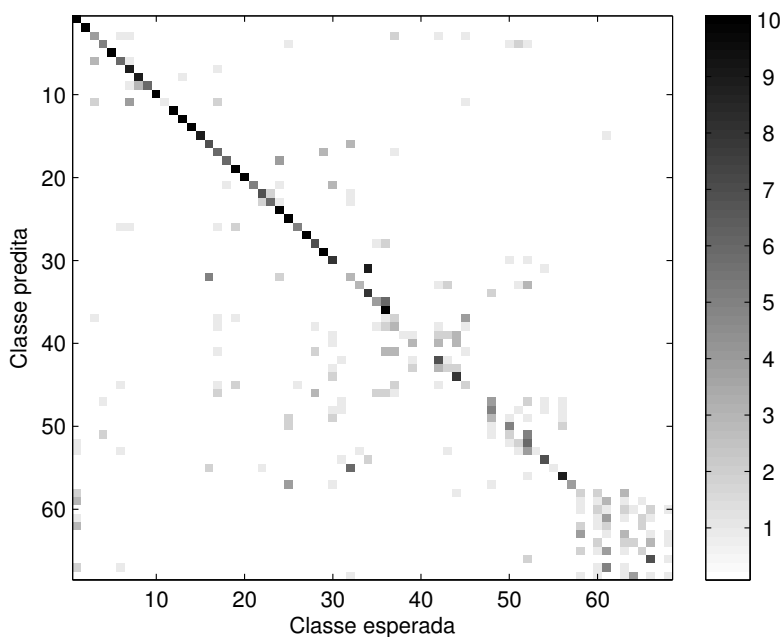

(b)

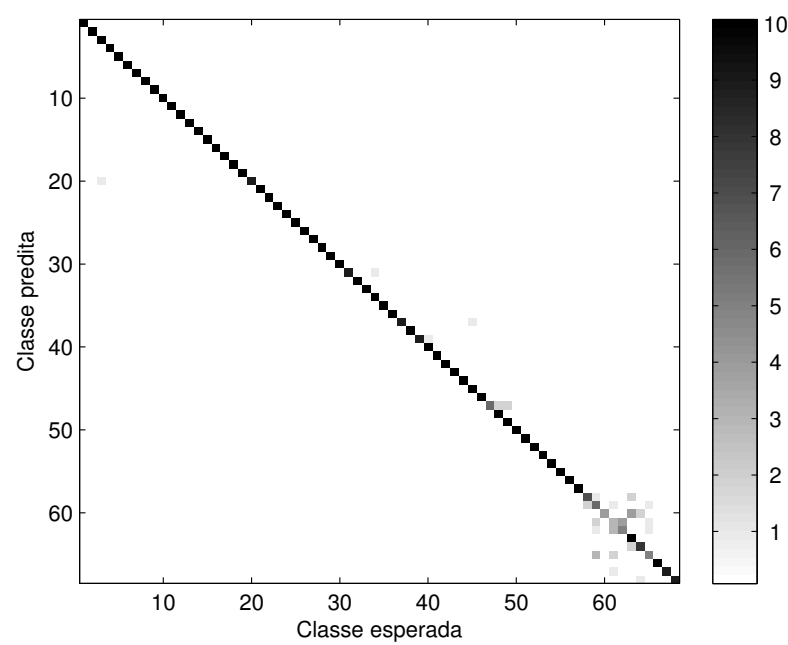

(d)
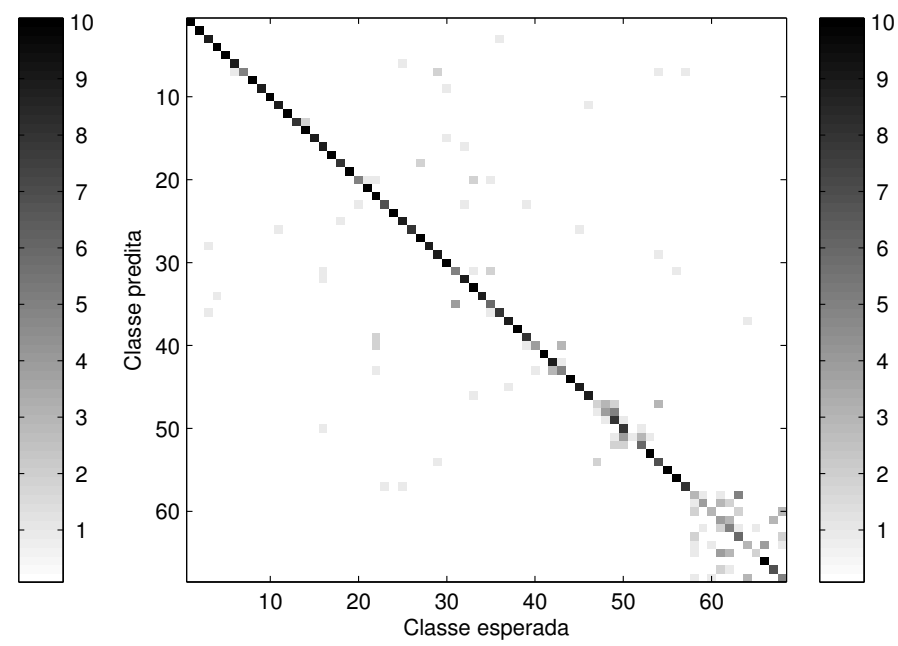

(f)

Figura 7.23 - Matrizes de confusão (parte 1) para os métodos comparados sobre a base de Outex, usando classificador SVM. (a) Gabor cores. (b) Momentos cromáticos. (c) Razão de histogramas. (d) Bouligand-Minkowski 3D. (e) Bouligand-Minkowski EEE. (f) Fourier EEE. 


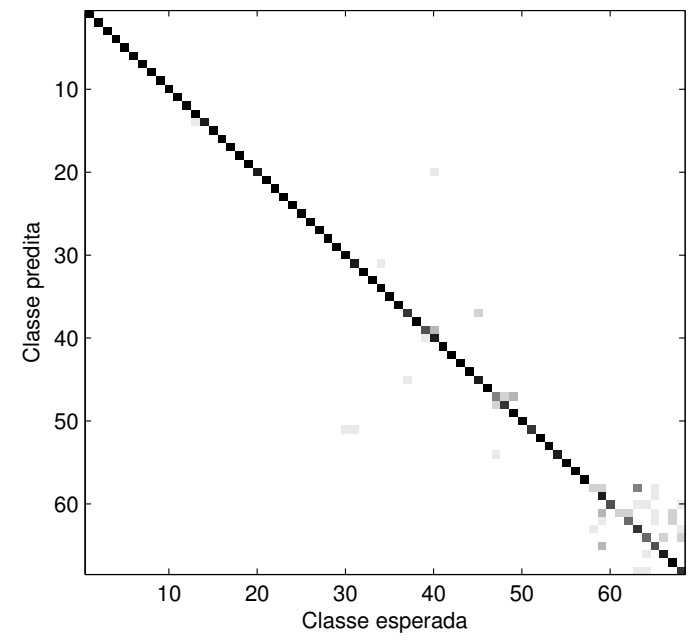

(a)
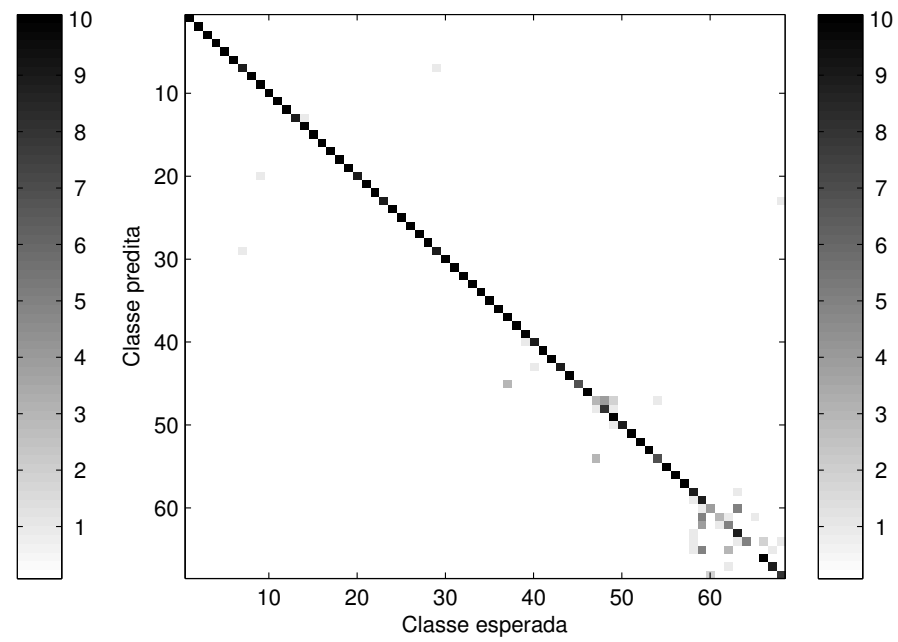

(b)

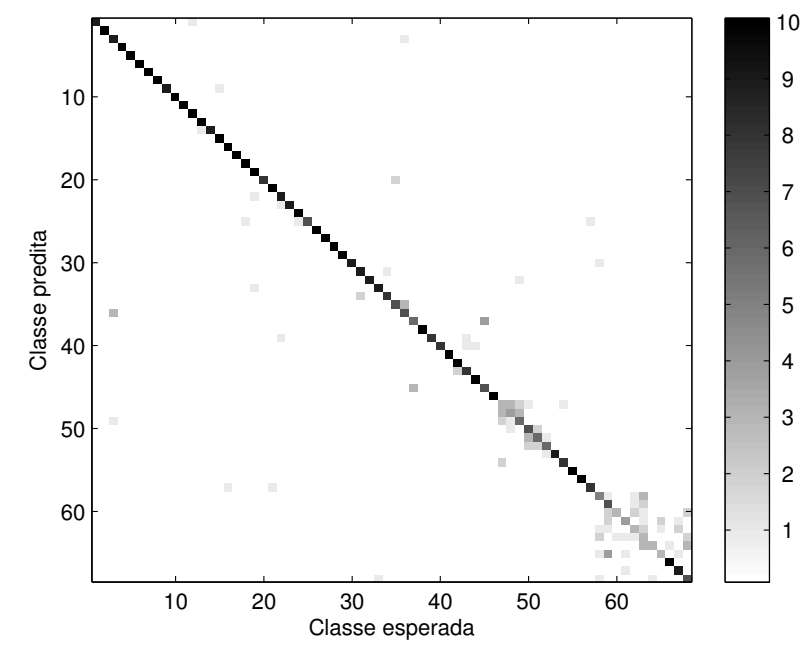

(c)

Figura 7.24 - Matrizes de confusão (parte 2) para os métodos comparados sobre a base de Outex, usando classificador SVM. (a) Bouligand-Minkowski 3D + Bouligand-Minkowski EEE. (b) Bouligand-Minkowski 3D + Fourier EEE. (c) Bouligand-Minkowski EEE + Fourier EEE. 


\subsection{Tolerância a Ruídos}

As Tabelas 7.108 e 7.109 mostram os resultados obtidos pelos descritores fractais e da literatura que obtiveram melhor desempenho nos experimentos anteriores, após a aplicação de ruído Gaussiano e "sal-e-pimenta", respectivamente, sobre as imagens de texturas na base de Brodatz com classificador SVM. A Tabela 7.110 exibe a porcentagem de perda na taxa de acerto que cada tipo de ruído propiciou para cada método de análise.

Em relação aos descritores fractais, o método de Bouligand-Minkowski apresentou a menor variação decorrente de ruído, tendo se mantido com a maior taxa de acerto no experimento com erro do tipo "sal-e-pimenta". Já no caso da aplicação de ruído Gaussiano, os descritores fractais foram superados por métodos mais antigos, embora o método de Bouligand-Minkowski ainda tenha superado LBP. De um modo geral, todos os descritores apresentaram uma queda mais drástica na taxa de acerto com o ruído Gaussiano. Tal fenômeno se explica pelo fato deste tipo de ruído agir sobre todos os pixels. Os métodos fractais usados neste experimento são extraídos da superfície que mapeia a textura e são altamente sensíveis a mudanças nas intensidades de cinza, sobretudo quando estas afetam todos os pixels, como no caso Gaussiano. O método GLCM apresentou uma "queda negativa", ou seja, a taxa de acerto aumentou com a introdução de ruído "sal-e-pimenta". Na prática, isto indica que esse método foi robusto a esse tipo de ruído, já que o pequeno aumento é fruto do erro inerente ao experimento. A robustez de métodos baseados em vizinhança como GLCM e LBP para o ruído "sal-e-pimenta" se explica pelo fato deste ruído afetar um número baixo de pixels em cada vizinhança. O inverso ocorre no caso do ruído Gaussiano.

Em resumo, os descritores fractais não se mostraram suficientemente robustos a ruído, em função da propagação que estes métodos fazem de qualquer distorção na morfologia da textura analisada. Mesmo assim, o método de Bouligand-Minkowski ainda supera, nos dois experimentos, o forte método de LBP.

Tabela 7.108 - Resultado para as texturas de Brodatz afetadas por ruído Gaussiano.

\begin{tabular}{lccccc}
\hline Método & ND & TA $(\%)$ & $\kappa$ & E1 & E2 \\
\hline Fourier clássico & 8 & 83.24 & 0.83 & 0.17 & 0.13 \\
GLCM & 16 & 80.18 & 0.80 & 0.20 & 0.18 \\
LBP & 11 & 76.58 & 0.76 & 0.23 & 0.21 \\
Bouligand-Minkowski & 10 & 81.08 & 0.81 & 0.19 & 0.16 \\
Probabilidade & 7 & 61.98 & 0.62 & 0.38 & 0.34 \\
Lacunaridade & 11 & 54.59 & 0.54 & 0.45 & 0.43 \\
\hline
\end{tabular}


Tabela 7.109 - Resultado para as texturas de Brodatz afetadas por ruído "sal-e-pimenta".

\begin{tabular}{lccccc}
\hline Método & ND & TA $(\%)$ & $\kappa$ & E1 & E2 \\
\hline LBP & 16 & 91.53 & 0.91 & 0.08 & 0.08 \\
GLCM & 17 & 90.09 & 0.90 & 0.10 & 0.08 \\
Fourier clássico & 9 & 78.74 & 0.79 & 0.21 & 0.17 \\
Bouligand-Minkowski & 20 & 92.61 & 0.93 & 0.07 & 0.05 \\
Probabilidade & 9 & 81.98 & 0.82 & 0.18 & 0.15 \\
Lacunaridade & 9 & 80.54 & 0.80 & 0.19 & 0.17 \\
\hline
\end{tabular}

Tabela 7.110 - Porcentagem da queda nas taxas de acerto para cada tipo de ruído.

\begin{tabular}{lcc}
\hline Método & Ruído Gaussiano & Ruído "sal-e-pimenta" \\
\hline LBP & 18.95 & 1.93 \\
GLCM & 10.82 & -0.20 \\
Fourier clássico & 5.53 & 10.63 \\
Bouligand-Minkowski & 15.41 & 3.39 \\
Probabilidade & 31.61 & 9.54 \\
Lacunaridade & 35.67 & 5.09 \\
\hline
\end{tabular}

\subsection{Custo Computacional}

A Tabela 7.111 exibe o tempo médio de processamento para a obtenção dos descritores, bem como dos métodos da literatura, na base de Vistex e usando um computador pessoal, com processador Intel ${ }^{\complement}$ Core i5-2410M, $2.30 \mathrm{GHz}, 4 \mathrm{~GB}$ de memória RAM, sistema operacional Windows $7^{\circledR}, 64$ bits e Matlab ${ }^{\circledR}$ R2009b, 64 bits.

Em relação aos descritores de imagens em tons de cinza, os métodos fractais apresentaram um custo computacional maior do que os já conhecidos na literatura. Já entre os descritores de cores, a melhor abordagem clássica da literatura, Gabor, apresentou o pior desempenho no uso dos recursos computacionais. Há que se ressaltar contudo que essa diferença de tempo não é tão relevante, levando-se em conta que, à exceção dos descritores de Bouligand-Minkowski, os demais métodos não foram otimizados com o objetivo de garantir maior eficiência computacional. Ademais, o ambiente de programação usado, Matlab ${ }^{\circledR}$, é voltado para a facilidade na manipulação de matrizes e não na eficiência de processamento. Para aplicações reais, que demandem desempenho, várias soluções podem ser empregadas, a começar pelo uso de linguagens de programação, como $C$, além de otimizações nos algoritmos em si e do desenvolvimento de soluções que possam ser executadas em sistemas paralelizados, como clusters ou placas de vídeo. 
Tabela 7.111 - Resumo do tempo computacional consumido para os diferentes métodos de análise de texturas, na geração dos descritores para cada imagem.

\begin{tabular}{lc}
\hline Método & Tempo (s) \\
\hline Multifractal 3 & 2.3771 \\
Multifractal 1 & 1.0152 \\
Multifractal 2 & 0.1915 \\
GLCM & 0.1484 \\
GLDM & 0.0736 \\
Gabor & 0.0658 \\
LBP & 0.0643 \\
Laws & 0.0319 \\
Fourier & 0.0096 \\
\hline Wavelike & 14.7809 \\
Wavelets & 3.6459 \\
Blanket & 1.8595 \\
Lacunaridade & 1.7876 \\
Probabilidade & 1.7763 \\
Box-counting & 1.6239 \\
Variograma & 0.5102 \\
Variação & 0.4267 \\
Bouligand-Minkowski & 0.4137 \\
Fourier & 0.1216 \\
Triangular & 0.0650 \\
Browniano & 0.0402 \\
\hline \hline Gabor cores & 10.5668 \\
Momentos cromáticos & 0.3377 \\
Razão de histogramas & 0.0082 \\
\hline Bouligand-Minkowski 3D & 1.2566 \\
Bouligand-Minkowski EEE & 0.9505 \\
Fourier EEE & 0.3327 \\
\hline
\end{tabular}

\subsection{Dimensão Fractal}

As tabelas a seguir ilustram os resultados obtidos pelo novo método de estimativa de dimensão fractal proposto em (27). Os valores obtidos para a dimensão de alguns objetos fractais clássicos são comparados com outras técnicas conhecidas na literatura e ao valor esperado da dimensão de Hausdorff-Besicovitch, calculada analiticamente. As dimensões estimadas também são comparadas em situações em que os objetos são submetidos a transformações geométricas, bem como afetados por ruídos aleatórios.

$\mathrm{Na}$ Tabela 7.112 são mostrados os resultados para os fractais em seu aspecto original, sem qualquer transformação. Nota-se que a abordagem proposta obteve o melhor desempenho, aproximando-se mais do valor esperado em 6 dos 10 objetos analisados. 0 resultado é relevante, uma vez que um método simples e de baixo custo computacional permite uma aproximação razoável ao valor analítico, que, além de apresentar um cálculo significativamente mais custoso, ainda não pode ser executado em muitas situações em que a lei de formação do fractal não é inteiramente conhecida, caso, por exemplo, de fractais gerados estatisticamente.

Já a Tabela 7.113 mostra os valores obtidos para a dimensão fractal quando os objetos 
Tabela 7.112 - Dimensão dos objetos fractais comparados calculada por diferentes métodos e comparada à dimensão teórica de Hausdorff-Besicovitch. Os valores sublinhados correspondem às melhores aproximações.

\begin{tabular}{cccccc}
\hline Fractal & Box-counting & Minkowski & Fourier & Proposto & Hausdorff \\
\hline Dragon & 1.4414 & 1.4524 & 1.3689 & $\underline{1.5760}$ & 1.5236 \\
Fibonacci & 1.3044 & 1.3453 & 1.2669 & $\underline{1.2499}$ & 1.2465 \\
Gosper & $\underline{1.1284}$ & 1.1217 & 1.0685 & 1.1213 & 1.1292 \\
Julia1 & $\underline{1.0905}$ & 1.0538 & 1.1283 & 1.1485 & 1.0812 \\
Julia2 & 1.1465 & 1.1972 & 1.2146 & $\underline{1.2509}$ & 1.2683 \\
Julia 3 & 0.9677 & 1.0166 & 1.0680 & $\underline{1.0076}$ & 1.0043 \\
Koch & 1.2479 & 1.2497 & 1.1080 & $\underline{1.2722}$ & 1.2619 \\
Rabbit & 1.2724 & $\underline{1.3643}$ & 1.2197 & $\underline{1.3586}$ & 1.3934 \\
Terdragon & 1.1871 & 1.0949 & 1.1162 & $\underline{1.2313}$ & 1.2619 \\
Vicsek & 1.3757 & $\underline{1.4356}$ & 1.3308 & 1.5436 & 1.4650 \\
\hline
\end{tabular}

são rotacionados por um ângulo de $45^{\circ}$. A observação do comportamento de métricas de estimativa fractal diante de transformações deste tipo é importante, dado que em situações nas quais se deseja automatizar o processo deste tipo de medida, a robustez a transformações é fundamental uma vez que o sistema computacional não pode, a priori, ter um controle de como esses objetos serão apresentados na entrada do sistema que calcula a dimensão fractal. O mais importante a se observar nesta tabela não são os valores em si, mas a variação destes valores em relação aos estimados para o fractal original. No caso, observa-se que o método proposto apresentou a máxima robustez, preservando os mesmos valores da dimensão em todos os casos. Tal fato é uma consequência direta do uso de operações de ponto flutuante na transformada de Fourier, enquanto Box-counting e Bouligand-Minkowski são geométricos e baseados em um espaço discretizado. Por sua vez, o método de Fourier em imagem é suscetível à rotação e outras transformações, uma vez que, para cada nova imagem, um novo espectro e, consequentemente, um novo valor de dimensão será obtido.

Tabela 7.113 - Dimensão dos fractais rotacionados de 45 graus.

\begin{tabular}{cccccc}
\hline Fractal & Box-counting & Minkowski & Fourier & Proposto & Hausdorff \\
\hline Dragon & 1.4339 & 1.4535 & 1.3839 & 1.5760 & 1.5236 \\
Fibonacci & 1.2525 & 1.3479 & 1.1742 & 1.2499 & 1.2465 \\
Gosper & 1.1389 & 1.1240 & 1.0627 & 1.1213 & 1.1292 \\
Julia1 & 1.1140 & 1.0566 & 0.8218 & 1.1485 & 1.0812 \\
Julia2 & 1.1997 & 1.1992 & 0.9498 & 1.2509 & 1.2683 \\
Julia 3 & 1.0959 & 1.0189 & 0.9748 & 1.0076 & 1.0043 \\
Koch & 1.2176 & 1.2526 & 1.1712 & 1.2722 & 1.2619 \\
Rabbit & 1.2783 & 1.3657 & 1.1106 & 1.3586 & 1.3934 \\
Terdragon & 1.2275 & 1.0960 & 0.9882 & 1.2313 & 1.2619 \\
Vicsek & 1.5059 & 1.4368 & 1.0311 & 1.5436 & 1.4650 \\
\hline
\end{tabular}

A Tabela 7.114 mostra os resultados também para os fractais rotacionados, mas neste caso de $90^{\circ}$. Novamente, o método proposto se mantém incólume ao efeito da rotação. No caso, os métodos que sofreram uma influência mais drástica da transformação foram Boxcounting e Fourier. Como dito, a dimensão por Fourier em imagem sofre com o fato de um objeto transformado ser analisado como se fosse uma imagem totalmente distinta, o que influi no resultado final da dimensão estimada. Já o Box-counting sofre com a maior rigidez 
do processo de divisão da imagem em áreas retangulares, enquanto o uso de círculos no Bouligand-Minkowski atenua essa variação, que neste último caso é devida em maior parte ao fato dos cálculos serem baseados em valores arredondados.

Tabela 7.114 - Dimensão dos fractais rotacionados de 90 graus.

\begin{tabular}{cccccc}
\hline Fractal & Box-counting & Minkowski & Fourier & Proposto & Hausdorff \\
\hline Dragon & 1.4832 & 1.4524 & 1.4855 & 1.5760 & 1.5236 \\
Fibonacci & 1.3029 & 1.3453 & 1.2710 & 1.2499 & 1.2465 \\
Gosper & 1.1428 & 1.1217 & 1.1224 & 1.1213 & 1.1292 \\
Julia1 & 1.0940 & 1.0538 & 1.1612 & 1.1485 & 1.0812 \\
Julia2 & 1.1468 & 1.1972 & 1.1226 & 1.2509 & 1.2683 \\
Julia 3 & 1.0913 & 1.0166 & 1.2325 & 1.0076 & 1.0043 \\
Koch & 1.2487 & 1.2497 & 1.2141 & 1.2722 & 1.2619 \\
Rabbit & 1.3538 & 1.3643 & 1.2573 & 1.3586 & 1.3934 \\
Terdragon & 1.2410 & 1.0949 & 1.1132 & 1.2313 & 1.2619 \\
Vicsek & 1.4974 & 1.4356 & 1.3512 & 1.5436 & 1.4650 \\
\hline
\end{tabular}

Já a Tabela 7.115 ilustra o comportamento dos métodos comparados na estimativa da dimensão de objetos escalados por fator 0.5 , ou seja, reduzidos à metade. Mais uma vez, a abordagem proposta manteve os mesmos valores estimados originalmente. Em relação às demais técnicas, nota-se que na maioria dos casos o valor da dimensão fractal obtida foi menor que o valor inicial. Tal ponto é explicado pelo fato de que contornos menores geram imagens menores que, por sua vez, perdem alguns detalhes neste processo de redução. Assim, as técnicas clássicas acabam capturando esta menor complexidade na estrutura do objeto por meio de um menor valor, enquanto a abordagem proposta por trabalhar diretamente com as coordenadas do contorno acaba sendo imune a esta redução.

Tabela 7.115 - Dimensão dos fractais reduzidos horizontal e verticalmente por um fator 0.5.

\begin{tabular}{cccccc}
\hline Fractal & Box-counting & Minkowski & Fourier & Proposto & Hausdorff \\
\hline Dragon & 1.3439 & 1.5337 & 1.2109 & 1.5760 & 1.5236 \\
Fibonacci & 1.2267 & 1.2895 & 1.1491 & 1.2499 & 1.2465 \\
Gosper & 1.0669 & 1.1078 & 0.9326 & 1.1213 & 1.1292 \\
Julia1 & 1.0305 & 1.0445 & 1.0192 & 1.1485 & 1.0812 \\
Julia2 & 1.0946 & 1.1760 & 1.0957 & 1.2509 & 1.2683 \\
Julia 3 & 0.9157 & 1.0133 & 1.0706 & 1.0076 & 1.0043 \\
Koch & 1.1760 & 1.2279 & 1.0777 & 1.2722 & 1.2619 \\
Rabbit & 1.2057 & 1.3776 & 1.0768 & 1.3586 & 1.3934 \\
Terdragon & 1.1455 & 1.2571 & 0.8698 & 1.2313 & 1.2619 \\
Vicsek & 1.3349 & 1.4803 & 1.1157 & 1.5436 & 1.4650 \\
\hline
\end{tabular}

Por sua vez, na Tabela 7.116, são exibidos os resultados para os objetos fractais com seus contornos aumentados em 2 vezes. Novamente, como apontado na tabela anterior, a dimensão reflete o grau de complexidade (nível de detalhes) na imagem digital que representa o contorno analisado. Mais uma vez, o método proposto garantiu a maior robustez à operação aplicada.

$\mathrm{Na}$ Tabela 7.117, são mostrados os resultados obtidos por cada método de dimensão fractal quando os objetos são transladados em relação ao original por uma diferença de 10 
Tabela 7.116 - Dimensão dos fractais aumentados horizontal e verticalmente por um fator 2.0.

\begin{tabular}{cccccc}
\hline Fractal & Box-counting & Minkowski & Fourier & Proposto & Hausdorff \\
\hline Dragon & 1.4948 & 1.2672 & 1.5031 & 1.5760 & 1.5236 \\
Fibonacci & 1.3586 & 1.3354 & 1.3830 & 1.2499 & 1.2465 \\
Gosper & 1.1608 & 1.1318 & 1.1538 & 1.1213 & 1.1292 \\
Julia1 & 1.1218 & 1.0711 & 1.0345 & 1.1485 & 1.0812 \\
Julia2 & 1.1701 & 1.2126 & 1.1882 & 1.2509 & 1.2683 \\
Julia 3 & 1.0017 & 0.9677 & 1.0492 & 1.0076 & 1.0043 \\
Koch & 1.2880 & 1.2542 & 1.0354 & 1.2722 & 1.2619 \\
Rabbit & 1.3042 & 1.2495 & 1.2831 & 1.3586 & 1.3934 \\
Terdragon & 1.2340 & 0.8577 & 1.3865 & 1.2313 & 1.2619 \\
Vicsek & 1.4046 & 1.3318 & 1.5783 & 1.5436 & 1.4650 \\
\hline
\end{tabular}

pixels. Aqui, além da metodologia proposta, o método de Bouligand-Minkowski também se manteve invariante à transformação. Tal aspecto é justificado pelo fato de que a dilatação sempre parte do contorno do objeto independentemente da posição espacial em que este se encontra. Então, como não existe variação de escala, a expansão e as frentes de onda também são preservadas, levando ao mesmo valor de dimensão fractal. Já o método de Boxcounting sofreu uma variação, embora menor que no caso da rotação. Essa variação se deve ao reposicionamento das caixas que cobrem o objeto quando este é transladado.

Tabela 7.117 - Dimensão dos fractais transladados horizontal e verticalmente por 10 pixels.

\begin{tabular}{cccccc}
\hline Fractal & Box-counting & Minkowski & Fourier & Proposto & Hausdorff \\
\hline Dragon & 1.4396 & 1.4524 & 1.4137 & 1.5760 & 1.5236 \\
Fibonacci & 1.3045 & 1.3453 & 1.2832 & 1.2499 & 1.2465 \\
Gosper & 1.1260 & 1.1217 & 1.1029 & 1.1213 & 1.1292 \\
Julia1 & 1.0861 & 1.0538 & 1.0868 & 1.1485 & 1.0812 \\
Julia2 & 1.1446 & 1.1972 & 1.1635 & 1.2509 & 1.2683 \\
Julia 3 & 0.9820 & 1.0166 & 1.0952 & 1.0076 & 1.0043 \\
Koch & 1.2477 & 1.2497 & 1.0556 & 1.2722 & 1.2619 \\
Rabbit & 1.2723 & 1.3643 & 1.2078 & 1.3586 & 1.3934 \\
Terdragon & 1.1889 & 1.0949 & 1.0732 & 1.2313 & 1.2619 \\
Vicsek & 1.3767 & 1.4356 & 1.3319 & 1.5436 & 1.4650 \\
\hline
\end{tabular}

Já a Tabela 7.118 mostra a influência de uma translação de 20 pixels no contorno original. O comportamento dos métodos em geral é semelhante à translação de 10 pixels. Novamente, Bouligand-Minkowski e a abordagem proposta apresentaram maior robustez à operação aplicada.

Tabela 7.118 - Dimensão dos fractais transladados horizontal e verticalmente por 20 pixels.

\begin{tabular}{cccccc}
\hline Fractal & Box-counting & Minkowski & Fourier & Proposto & Hausdorff \\
\hline Dragon & 1.4412 & 1.4524 & 1.4267 & 1.5760 & 1.5236 \\
Fibonacci & 1.3022 & 1.3453 & 1.2843 & 1.2499 & 1.2465 \\
Gosper & 1.1297 & 1.1217 & 1.1158 & 1.1213 & 1.1292 \\
Julia1 & 1.0849 & 1.0538 & 1.0656 & 1.1485 & 1.0812 \\
Julia2 & 1.1457 & 1.1972 & 1.0821 & 1.2509 & 1.2683 \\
Julia 3 & 1.0025 & 1.0166 & 1.1686 & 1.0076 & 1.0043 \\
Koch & 1.2425 & 1.2497 & 1.1116 & 1.2722 & 1.2619 \\
Rabbit & 1.2722 & 1.3643 & 1.2115 & 1.3586 & 1.3934 \\
Terdragon & 1.1882 & 1.0949 & 1.0503 & 1.2313 & 1.2619 \\
Vicsek & 1.3688 & 1.4356 & 1.3679 & 1.5436 & 1.4650 \\
\hline
\end{tabular}

A Tabela 7.119 resume os resultados nas tabelas anteriores mostrando o erro médio apre- 
sentado por cada método em caso de transformações geométricas. A tabela mostra que a metodologia proposta apresenta um erro $44 \%$ menor que o segundo melhor método, no caso, Bouligand-Minkowski. No caso do método de Fourier, esta instabilidade no resultado era esperada, dado que este método trata o fractal como sendo a imagem digital de um objeto qualquer. Assim, qualquer alteração geométrica, por mais simples que seja, gera um objeto que é interpretado como sendo outra imagem e com outra distribuição de espectro/frequência. Este método, entretanto, ainda vale ser citado como uma opção em situações em que o custo computacional tem maior significância que a precisão em si. Já no caso dos métodos geométricos de Bouligand-Minkowski e Box-counting, os resultados foram afetados severamente pelas transformações, sobretudo no segundo caso, em que um deslocamento, por menor que seja, na posição original interfere na distribuição de caixas que vão cobrir o objeto de interesse em cada nível de escala. Por fim, o método proposto une a análise baseada diretamente nas coordenadas do contorno do objeto com cálculos exatos em ponto flutuante para produzir uma ferramenta precisa na obtenção dos valores da dimensão fractal e robusta a qualquer tipo de transformação geométrica linear.

Tabela 7.119 - Erro médio na estimativa da dimensão fractal pelos métodos comparados em objetos fractais submetidos a transformações geométricas.

\begin{tabular}{cc}
\hline Método & Erro Médio Quadrático \\
\hline Box-counting & 0.2340 \\
Bouligand-Minkowski & 0.2249 \\
Fourier & 0.3610 \\
Proposto & $\underline{0.1269}$ \\
\hline
\end{tabular}

$\mathrm{Na}$ Tabela 7.120 , são exibidos os valores estimados para a dimensão fractal dos objetos, quando estes são submetidos a um ruído pontual, ou seja, variação aleatória de um pixel em qualquer direção em cada ponto do contorno. Neste caso, o método desenvolvido também foi afetado, tendo uma baixa em sua acurácia, embora ainda se mantenha mais preciso que os demais. É importante que se note que aqui não foi aplicado nenhum tipo de pré-processamento visando atenuar o ruído inserido. Assim, a queda de desempenho do método de estimativa é natural uma vez que, de certa forma, o objeto ruidoso é diferente do objeto original, possuindo um padrão de complexidade distinto e levando a valores diversos para a dimensão.

A Tabela 7.121 mostra a tabela anterior sobre uma outra perspectiva, a dos erros associados a cada abordagem na presença de ruído. Nota-se que o desempenho da opção proposta caiu ligeiramente, enquanto o erro dos demais métodos se manteve em patamares semelhantes. Ainda assim, o método desenvolvido manteve o menor índice de erro, demonstrando sua capacidade de análise global, inerente à transformada de Fourier empregada, garantindo maior imunidade a ruídos localizados no objeto. 
Tabela 7.120 - Dimensão fractal de objetos afetados por ruído pontual.

\begin{tabular}{cccccc}
\hline Fractal & Box-counting & Bouligand-Minkowski & Fourier & Proposto & Valor Esperado \\
\hline Dragon & 1.4461 & 1.4623 & 1.3712 & $\underline{1.5404}$ & 1.5236 \\
Fibonacci & 1.3070 & 1.3512 & 1.2580 & $\underline{1.2494}$ & 1.2465 \\
Gosper & 1.1408 & 1.1357 & 1.1737 & $\underline{1.1275}$ & 1.1292 \\
Julia 1 & $\underline{1.0965}$ & 1.0591 & 1.1375 & 1.1560 & 1.0812 \\
Julia 2 & 1.1529 & 1.1997 & 1.2146 & $\underline{1.2395}$ & 1.2683 \\
Julia 3 & 1.0494 & $\underline{1.0315}$ & 1.1498 & 1.1924 & 1.0043 \\
Koch & 1.2503 & $\underline{1.2542}$ & 1.1289 & 1.2384 & 1.2619 \\
Rabbit & 1.2737 & $\underline{1.3642}$ & 1.2359 & 1.3598 & 1.3934 \\
Terdragon & 1.1871 & 1.0949 & 1.1162 & $\underline{1.2313}$ & 1.2619 \\
Vicsek & 1.3767 & $\underline{1.4358}$ & 1.3302 & 1.5351 & 1.465 \\
\hline
\end{tabular}

Tabela 7.121 - Erro médio na estimativa da dimensão de objetos fractais afetados por ruído.

\begin{tabular}{cc}
\hline Método & Erro Médio Quadrático \\
\hline Box-counting & 0.2307 \\
Bouligand-Minkowski & 0.2244 \\
Fourier & 0.3667 \\
Proposto & $\underline{0.2228}$ \\
\hline
\end{tabular}

Por fim, mas igualmente importante, o tempo computacional de cada método para cada objeto fractal foi calculado e é exibido na Tabela 7.122. Mais uma vez, os números são altamente favoráveis à metodologia proposta, que se mostrou quase 10 vezes mais rápida que o segundo melhor método neste quesito. Esse desempenho é reflexo do uso de FFT (sigla em Inglês para transformada rápida de Fourier) para obter o espectro de Fourier, enquanto os demais métodos espaciais se baseiam em operações geométricas custosas e o método de Fourier em imagem analisa todos os pixels da região retangular que contém o contorno e não apenas o objeto propriamente. Some-se a isto ainda a simplicidade do método proposto que basicamente apenas extrai o espectro de potência do sinal (contorno) e o analisa em relação à distribuição de frequências. Essas operações são diretas e rápidas, influindo diretamente na rapidez da proposta.

Tabela 7.122 - Tempo computacional médio de cada método para cada objeto fractal.

\begin{tabular}{cc}
\hline Método & Tempo Computacional (s) \\
\hline Box-counting & 3.0394 \\
Bouligand-Minkowski & 4.2518 \\
Fourier & 4.2482 \\
Proposto & $\underline{0.4318}$ \\
\hline
\end{tabular}

De um modo geral, esta nova abordagem para a estimativa do valor aproximado da dimensão fractal, desenvolvida neste projeto e descrita em detalhes em (27), apresentou-se rápida, de simples implementação, precisa e robusta a transformações geométricas e mesmo a ruídos pontuais no objeto. Assim, como os demais métodos comparados, a nova técnica também pode ser extrapolada para a estimativa de dimensão de objetos que não sejam necessariamente fractais, mas que igualmente careçam de uma medida descritiva de complexidade de sua estrutura espacial. Desta forma, o método de Fourier em sinal acaba tendo um grande potencial para este tipo de aplicação, uma vez que permite que essa medida seja extraída 
sem grande custo computacional, mesmo quando o número de objetos analisados é alto ou quando esses objetos são apresentados em diferentes posições, formas e mesmo afetados por ruídos, situação que é usual na prática. A técnica apresentada também pode ser generalizada para a obtenção de descritores fractais, como na seção anterior, ou para a análise multifractal, permitindo a geração de espectros multifractais de forma direta. Por fim, a metodologia se apresenta como uma útil ferramenta de apoio ao matemático que analisa novos objetos fractais buscando encontrar suas propriedades analíticas, sendo que o método de estimativa pode servir como um direcionador e até mesmo verificador para os métodos analíticos.

\subsection{Segmentação}

Esta seção apresenta os resultados para a aplicação dos descritores fractais à tarefa de segmentação de imagens de textura (em tons de cinza, no caso). A análise é feita em imagens de satélite obtidas pelo programa de computador Google Earth ${ }^{\complement}$ e tomadas sob diferentes níveis de escalas de observação (zoom). O classificador utilizado foi K-means (não-supervisionado) (12) e as janelas escolhidas tinham tamanho de 10, 20 e 30 pixels. A verificação da validade do método proposto é feita por meio da comparação pixel a pixel com a imagem segmentada por um especialista (arquiteto). O resultado é comparado com outras estratégias de análise de texturas, também seguindo a mesma ideia de se extraírem descritores de cada janela.

A Tabela 7.123 mostra a precisão da segmentação de imagens de três regiões do mundo: Buenos Aires, Nova York e São Paulo. Cada cidade forneceu duas imagens de satélite. A taxa de acerto mostrada corresponde à porcentagem de pixels que foram atribuídos à mesma categoria (urbana ou rural) tanto na imagem segmentada quanto na solução apresentada pelo especialista. Vê-se então que o método proposto apresentou os melhores resultados em todos os casos analisados, com diferentes tamanhos de janela. No caso, esse tamanho estabelece um compromisso entre uma segmentação mais fina (janelas pequenas que permitem a categorização de regiões menores) e um processo de segmentação mais global, no qual se perde precisão em detalhes, mas se ganha na riqueza dos descritores gerados. No caso do método fractal, nota-se que a diferença no uso de tamanhos variáveis não foi tão discrepante, correspondendo ao comportamento inerentemente multiescala da análise fractal.

Em um contexto geral, o bom desempenho dos descritores fractais é explicado pela flexibilidade que estes apresentam na captura da complexidade e, sobretudo do nível de autosimilaridade dos objetos. Essa auto-similaridade está fortemente presente em estruturas da 
natureza tão comuns às zonas rurais assim como na distribuição arquitetônica das cidades, quando estas são observadas de uma visão mais global. A dimensão fractal e sua extrapolação nos descritores fractais permitem que estes padrões de ocupação e distribuição no espaço sejam precisamente mensurados, tornando possível uma análise rica e intuitiva da caracterização das regiões físicas estudadas.

Tabela 7.123 - Comparação entre as taxas de acerto do método de segmentação proposto e outros métodos clássicos. Os melhores resultados estão sublinhados.

\begin{tabular}{ccccc}
\hline Imagem & Método & Janela $10 \times 10$ & Janela $30 \times 30$ & Janela $50 \times 50$ \\
\hline Buenos Aires 1 & Histograma & 83.1406 & 83.4005 & 82.8326 \\
& Co-ocorrência & 57.1438 & 69.5005 & 55.1322 \\
& Gabor & 74.4000 & 84.2860 & 84.9862 \\
& Bouligand-Minkowski & 87.6097 & 89.4383 & 89.6674 \\
\hline Buenos Aires 2 & Histograma & 83.7408 & 84.9030 & 72.8831 \\
& Co-ocorrência & 68.2347 & 79.3150 & 81.1566 \\
& Gabor & 81.4440 & 86.4464 & 86.4402 \\
& Bouligand-Minkowski & 88.1395 & $\underline{89.3878}$ & 88.8622 \\
\hline Sao Paulo 1 & Histograma & 51.0829 & 85.9608 & 85.7014 \\
& Co-ocorrência & 55.1818 & 54.8157 & 57.8361 \\
& Gabor & 58.4539 & 60.4285 & 62.1554 \\
& Bouligand-Minkowski & 86.8019 & 88.1858 & 88.3899 \\
\hline Sao Paulo 2 & Histograma & 74.0825 & 73.6898 & 77.7402 \\
& Co-ocorrência & 54.0472 & 53.6719 & 53.1275 \\
& Gabor & 65.1786 & 65.6421 & 63.1337 \\
& Bouligand-Minkowski & 84.0419 & 81.4744 & 80.3716 \\
\hline Nova York 1 & Histograma & 73.3506 & 59.4071 & 66.1774 \\
& Co-ocorrência & 69.4935 & 77.9449 & 77.3584 \\
& Gabor & 80.5984 & 86.8179 & 82.2267 \\
& Bouligand-Minkowski & 84.6537 & 88.8919 & 85.9715 \\
\hline Nova York 2 & Histograma & 79.8295 & 80.8639 & 73.9733 \\
& Co-ocorrência & 74.2889 & 79.0794 & 82.2714 \\
& Gabor & 84.1780 & 91.2903 & 91.8569 \\
& Bouligand-Minkowski & 89.1449 & $\underline{92.5966}$ & 91.7489 \\
\hline
\end{tabular}

A Tabela 7.124 ilustra o desempenho da segmentação de cada método quando uma mesma região é avaliada sob diferentes níveis de aproximação. Mais uma vez, os descritores fractais se destacam como as melhores abordagens.

Tabela 7.124 - Comparação entre as taxas de acerto do método de segmentação proposto e outros métodos clássicos para mapas de Buenos Aires sob diferentes níveis de aproximação. Os melhores resultados estão sublinhados.

\begin{tabular}{lcccc}
\hline Imagem & Método & Janela $10 \times 10$ & Janela $30 \times 30$ & Janela $50 \times 50$ \\
\hline Altura 1 & Histograma & 75.3591 & 77.4348 & 51.0788 \\
& Co-ocorrência & 52.9513 & 55.1190 & 58.5404 \\
& Gabor & 67.9342 & 81.5338 & 82.6699 \\
& Bouligand-Minkowski & 84.2680 & $\underline{86.0663}$ & 84.9301 \\
\hline Altura 2 & Histograma & 79.5779 & 82.8708 & 81.8006 \\
& Co-ocorrência & 64.2025 & 74.4019 & 77.7403 \\
& Gabor & 74.2620 & 87.2550 & 87.2261 \\
& Bouligand-Minkowski & 88.2039 & $\underline{90.3729}$ & 89.3287 \\
\hline Altura 3 & Histograma & 82.1259 & 85.5208 & 87.8649 \\
& Co-ocorrência & 56.7547 & 57.6659 & 55.1969 \\
& Gabor & 57.2369 & 73.6820 & 82.3037 \\
& Bouligand-Minkowski & 81.7246 & 89.1525 & $\underline{89.4821}$ \\
\hline
\end{tabular}

As Figuras 7.25 e 7.26 mostram as imagens em si segmentadas por cada método comparado. Aqui também se nota visualmente que a metodologia proposta aproximou melhor 0 
resultado fornecido pelo especialista.
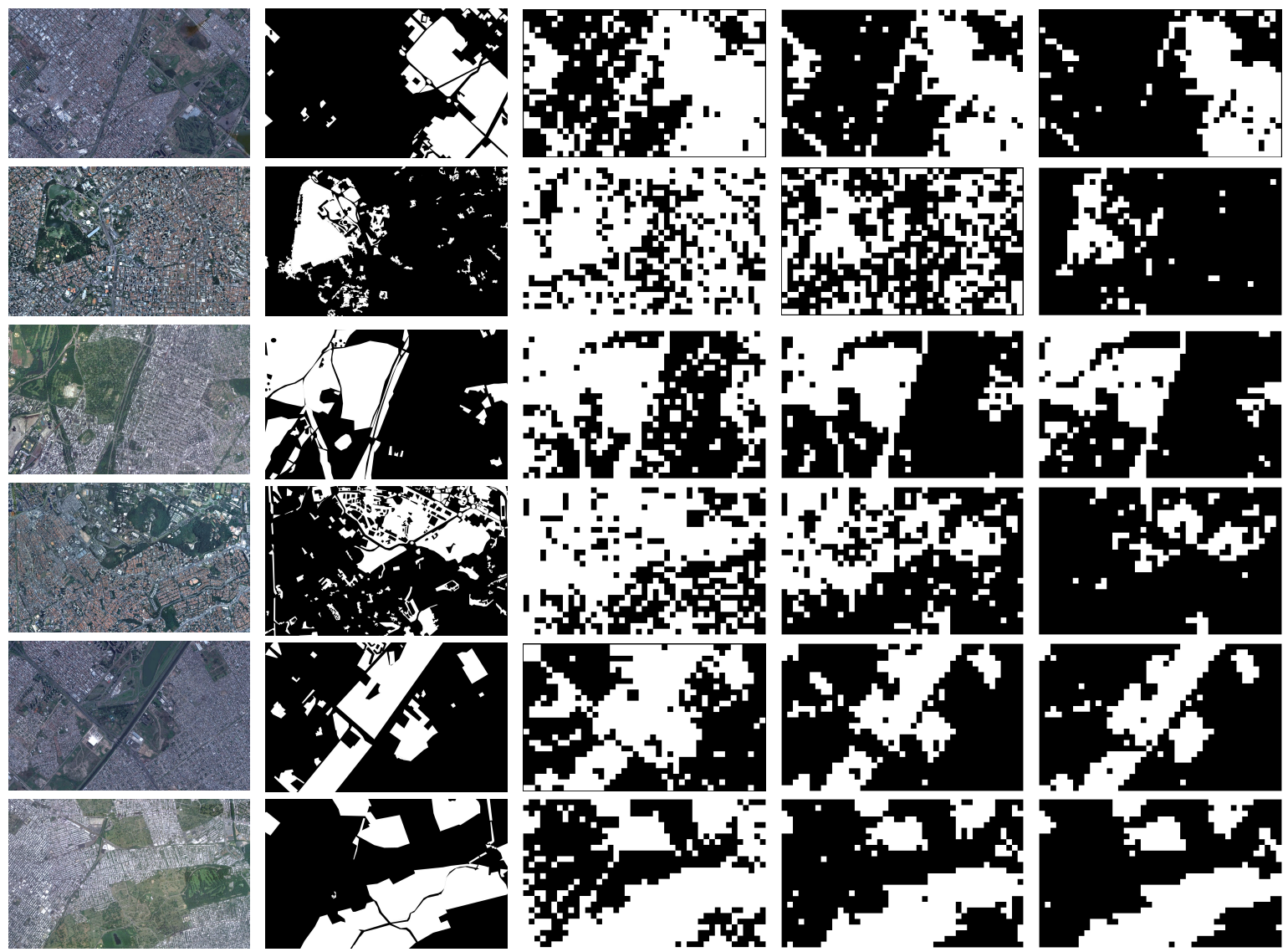

Figura 7.25 - Imagens segmentadas pelos métodos comparados e resultados esperados. Da primeira à sexta linha, imagens de Buenos Aires 1, Buenos Aires 2, Sao Paulo 1, Sao Paulo 2, Nova York 1 e Nova York 2. Na primeira coluna, as imagens originais, na segunda, as imagens segmentadas por um especialista, na terceira, imagens segmentadas por matriz de co-ocorrência, na quarta, por Gabor e na quinta coluna, imagens segmentadas pelo método proposto.

Em resumo, constata-se que os descritores fractais apresentam potencial para este tipo de aplicação, tendo em vista que a habilidade de discriminar padrões de texturas se torna um forte aliado neste tipo de tarefa. Isso é ainda mais notável na segmentação de padrões naturais ou que tendam, em uma visão mais global, a um aspecto auto-similar. 

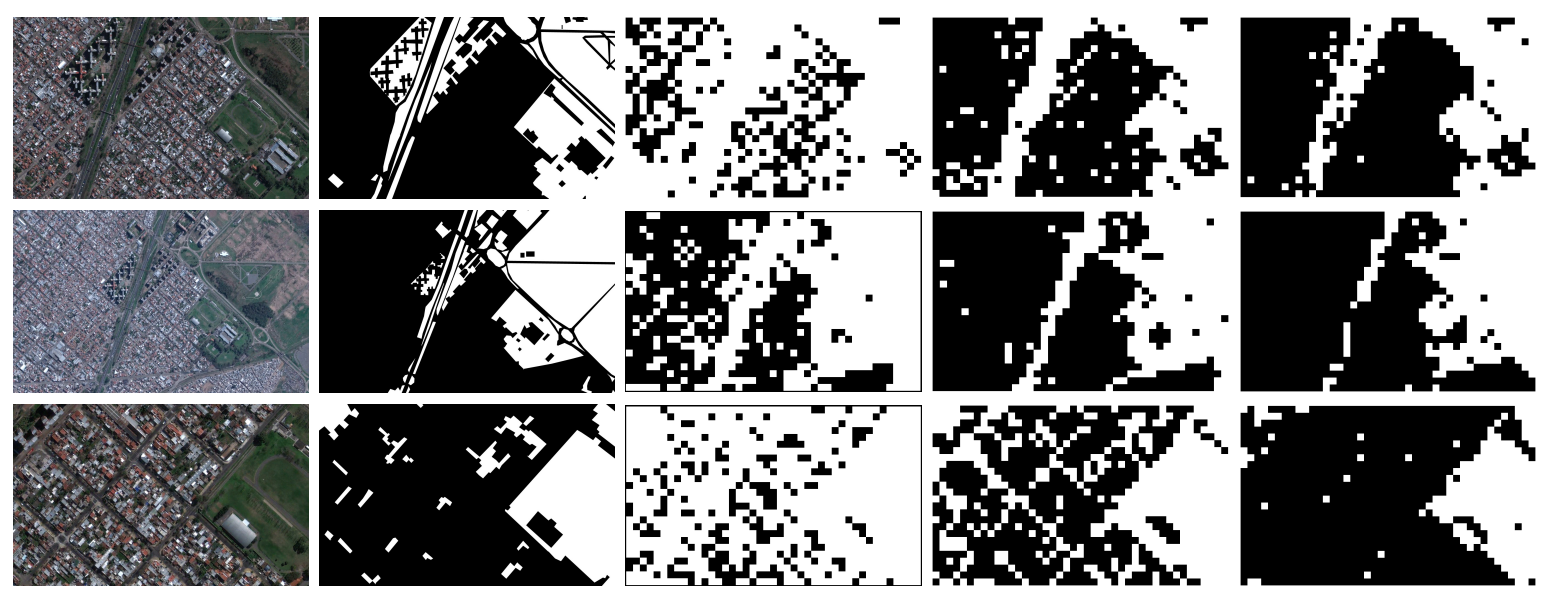

Figura 7.26 - Imagens de Buenos Aires, observadas sob três diferentes alturas (níveis de zoom) segmentadas pelos métodos comparados e respectivos resultados esperados. Na primeira coluna, são mostradas as imagens originais, na segunda, as imagens segmentadas por um especialista, na terceira, imagens segmentadas por matriz de co-ocorrência, na quarta, por Gabor e na quinta coluna, imagens segmentadas pelo método proposto.

\subsection{Análise de Imagens em Nanoescala}

\subsubsection{Descritores Globais}

Neste experimento, foram aplicados os descritores fractais de Bouligand-Minkowski multiescala para a discriminação de um conjunto de imagens de óxido de titânio em escala nanométrica.

A morfologia estrutural é um atributo importante em Ciência de Materiais, uma vez que permite que se determine a usabilidade de certa amostra em determinadas aplicações. Particularmente, um material para o qual este tipo de análise tem se mostrado eficiente é o óxido de titânio. Assim, demonstra-se, por exemplo, que esses materiais podem ir de estruturas compostas por poros auto-organizados (117-119) até amostras totalmente aporosas (120, 121). Em (120, 122, 123), são mostrados usos desta propriedade em que amostras de óxido de titânio preparadas por anodização galvanostática são analisadas por ferramentas de análise de imagens, com objetivo de identificar o grau de fotoatividade.

Nos trabalhos apresentados em (124, 125), verifica-se que a dimensão fractal é uma ferramenta poderosa na discriminação de amostras de óxido de titânio sob diferentes atividades fotoativas. Entretanto, a eficiência desta metodologia fica limitada a conjuntos de amostras cuja morfologia é bem comportada, apresentando falhas quando este conjunto é menos restrito. 
Deste modo, torna-se necessária uma pesquisa por ferramentas fractais mais avançadas, que não façam uso apenas do valor único da dimensão, mas sim de um conjunto de medidas de complexidade da amostra. Neste contexto, os descritores fractais se apresentam como uma solução que pode ser amplamente explorada.

Após alguns testes, também com descritores de Fourier e Wavelets, optou-se pelos de Bouligand-Minkowski, que apresentaram melhor discriminação entre as amostras sob diferentes condições experimentais. Essas amostras foram preparadas sobre uma folha de titânio (Alfa Aesar, 99.99\%, $0.25 \mathrm{~mm}$ de espessura) com uma área de exposição de $1 \mathrm{~cm}^{2}$ e duas folhas de platina usadas como eletrodos contadores. As duas amostras investigadas inicialmente foram preparadas em uma solução de ácido oxálico (amostra 1 com concentração 0.05 mol $\mathrm{L}^{-1}$ e amostra $2 \mathrm{em} 0.5 \mathrm{~mol} \mathrm{~L}^{-1}$ ), usando-se uma densidade de corrente de $10 \mathrm{mAcm}^{-2}$ e 20 $\mathrm{mAcm}^{-2}$, respectivamente, no eletrodo funcional. A temperatura no processo de anodização foi preservada constante e em $10{ }^{\circ} \mathrm{C}$ em ambas as amostras.

A Figura 7.27 exibe as curvas associadas a cada conjunto de descritores extraídos das amostras. Linhas sólidas correspondem à amostra 1 e linhas pontilhadas, à amostra 2. Observa-se claramente a distinção entre as duas classes (condições experimentais). A figura mostra que não existe nenhum tipo de entrelaçamento entre as curvas de diferentes condições em nenhum ponto. O resultado confirma a eficácia dos descritores fractais devida à propriedade destes em representar ricamente o arranjo de pixels presente em cada imagem e, consequentemente, a distribuição no espaço ou morfologia do material que deu origem à imagem.

Por sua vez, a Figura 7.28 exibe um gráfico de componentes PCA e CCA. Neste caso, a discriminação é mapeada na distribuição de pontos, que formam aglomerados bem definidos em cada conjunto. No caso, foram usados os dois primeiros componentes, que mostram os atributos transformados mais relevantes (menos correlacionados com os demais) dos descritores. Nota-se então que mesmo o uso de apenas dois atributos no espaço dos componentes já foi suficiente para uma boa discriminação. Este resultado também ilustra o alto índice de correlação entre os descritores de Bouligand-Minkowski, como atestado por seu melhor desempenho em classificadores após a extração de componentes CCA.

\subsubsection{Descritores por Janelas}

Neste experimento, foram usados óxido de titânio (Oxálico) e óxido de zircônio (Zirconia), dopado por cálcio e nióbio. Os descritores usados foram os de Bouligand-Minkowski e o 


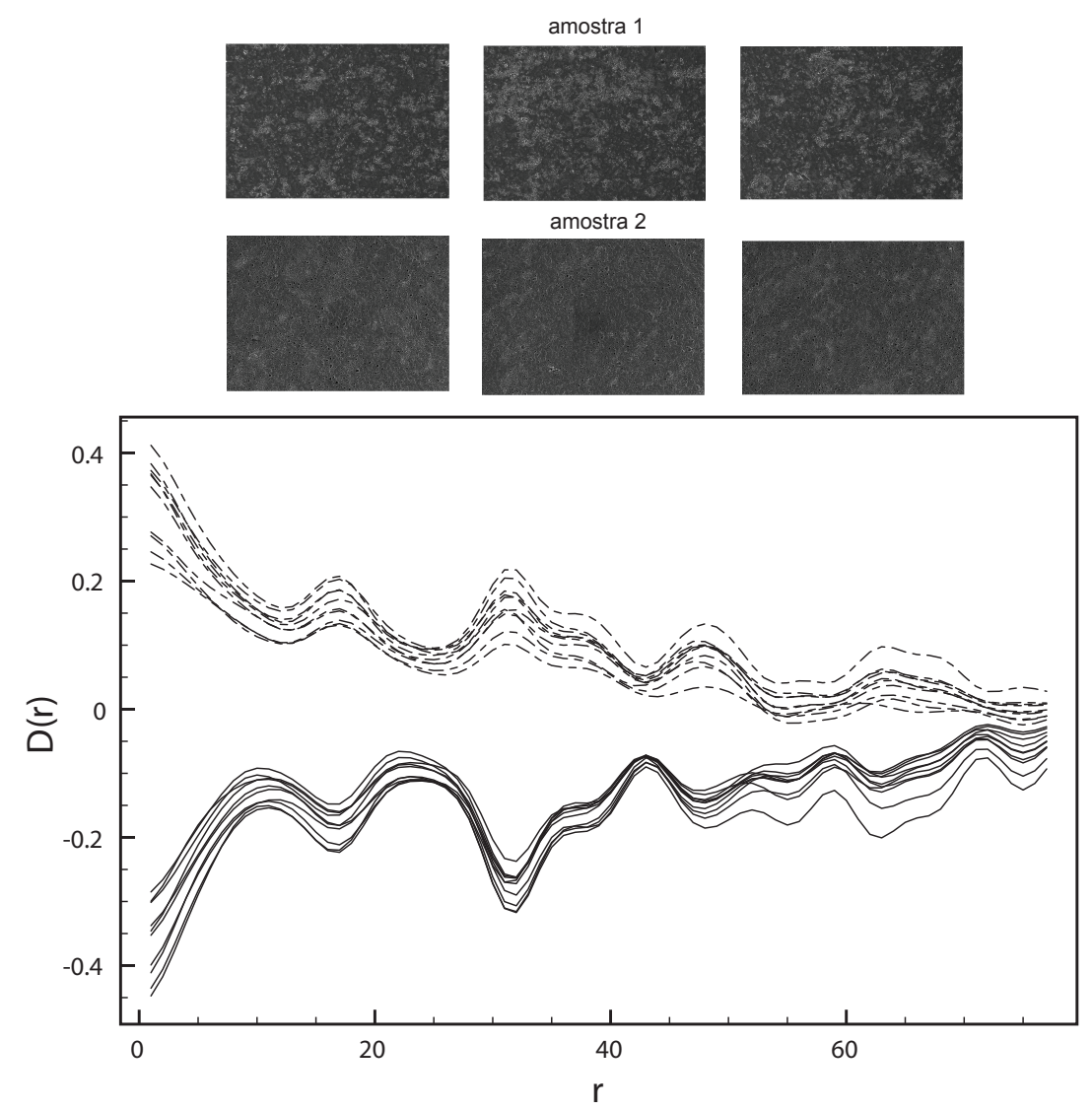

Figura 7.27 - Curvas de descritores fractais para as amostras analisadas. Linhas sólidas correspondem à amostra 1 e linhas pontilhadas, à amostra 2.

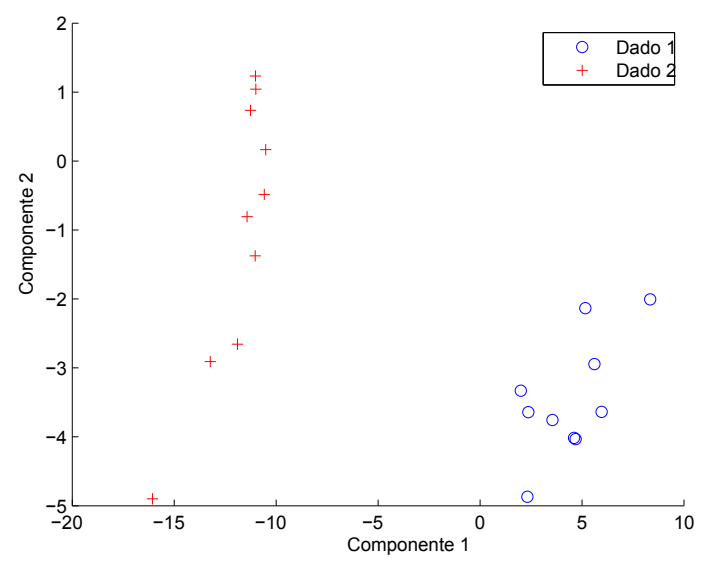

(a)

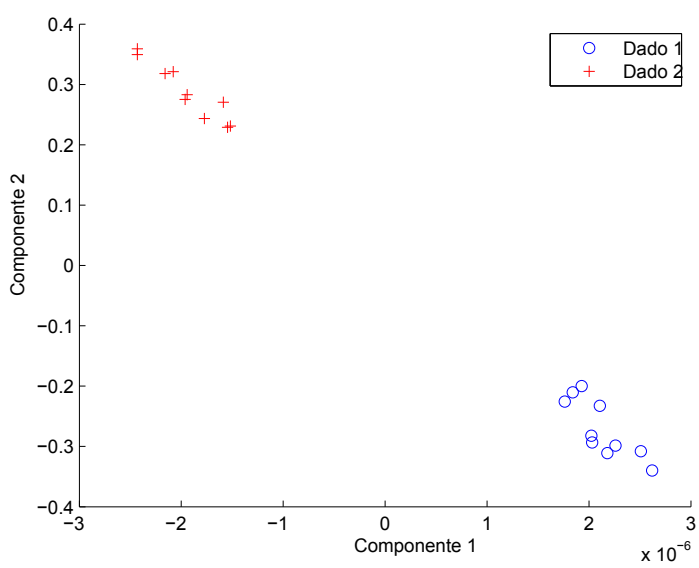

(b)

Figura 7.28 - Gráfico dos componentes PCA (esquerda) e CCA (direita) dos descritores. Nota-se a clara formação de duas nuvens de pontos representando cada condição de experimento. 
classificador foi o KNN. Neste último caso, ainda foram usadas imagens de microscopia com resolução 3000x e 8000x. As Figuras 7.29, 7.30, 7.31 e 7.32 mostram as taxas de acerto obtidas em função do número de pares de janelas usados.

A Figura 7.29 mostra uma curva com grande nível de irregularidade e com valores da taxa de acerto concentrados em um pequeno intervalo, refletindo a ampla variabilidade das janelas e a eficiência desta metodologia em atingir bons índices de precisão apesar das dificuldades inerentes. Como esperado, a curva também demonstra que o uso de um maior número de janelas deteriora o acerto, uma vez que as semelhanças entre as bases de treinamento e teste vão sendo diluídas. Por fim, é importante ressaltar o papel do tamanho das janelas. Janelas maiores apresentam maior variabilidade interna e levam a descritores menos precisos.

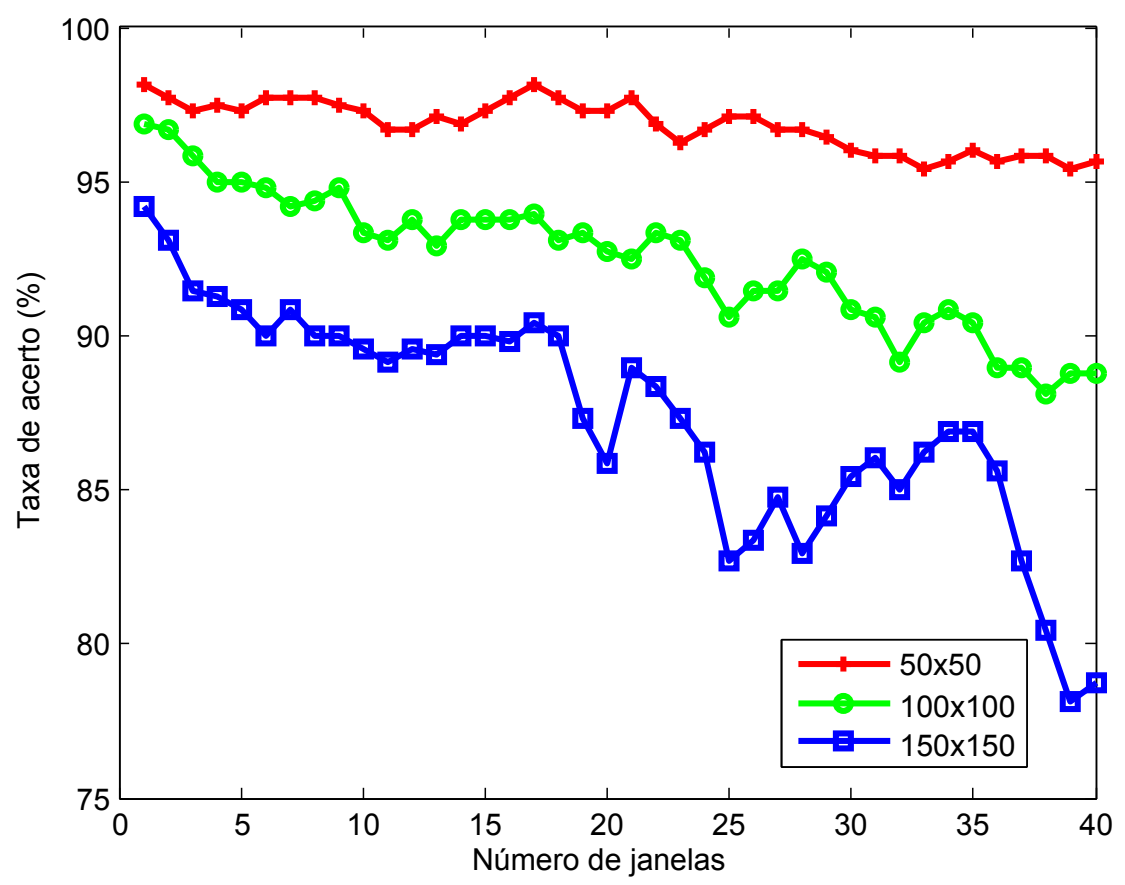

Figura 7.29 - Taxa acerto em função do número de pares de janelas para o óxido de titânio.

No caso dos experimentos com Zirconia, dois fatos interessantes são observados. O primeiro é que a variação na taxa de acerto em função do número de janelas é maior do que no caso do Oxálico, confirmando o caráter mais heterogêneo das amostras que levam a descritores fractais com aspecto distinto mesmo para janelas da mesma imagem. Outro ponto importante é que os descritores se mostraram robustos à variação de resolução, uma vez que os resultados foram mais afetados pelo material usado no processo de dopagem do que pelo zoom considerado.

Resumindo, esta nova metodologia para a obtenção de descritores fractais foi capaz de obter altas taxas de acerto mesmo em um problema de significativo grau de dificuldade como 


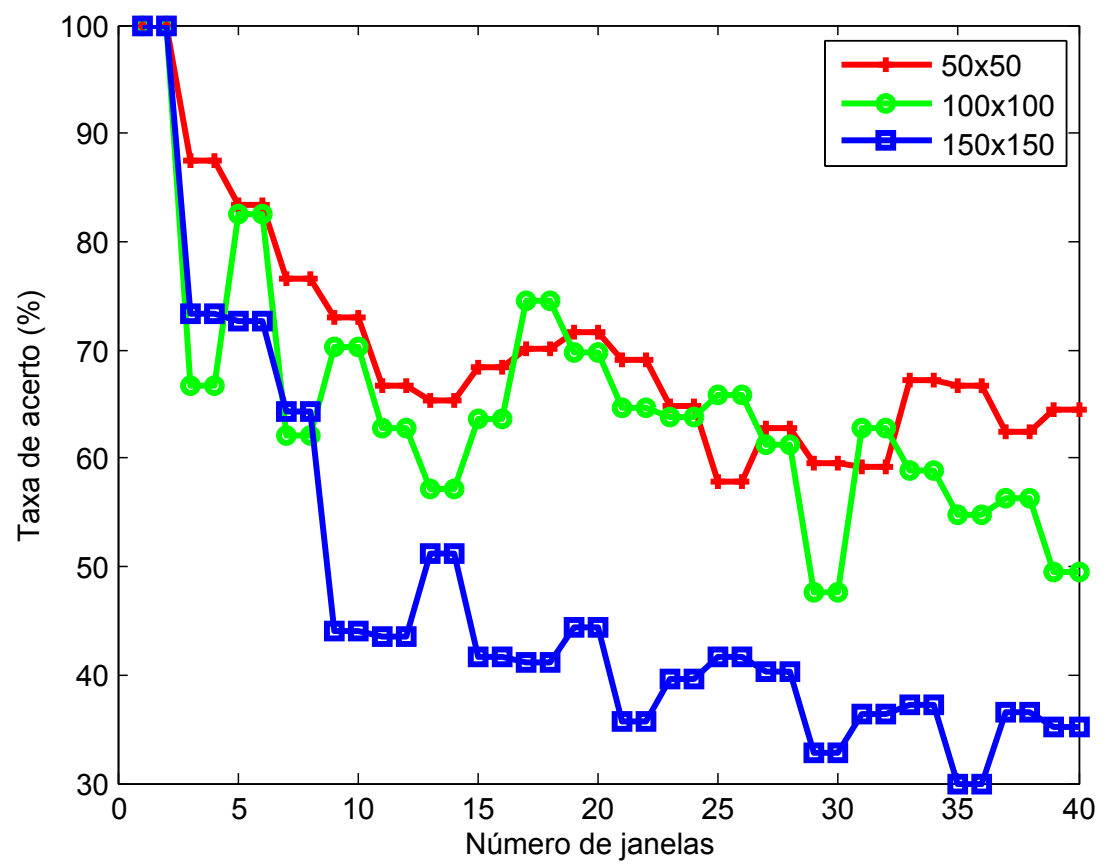

Figura 7.30 - Taxa acerto em função do número de pares de janelas para o óxido de zircônio dopado por cálcio.

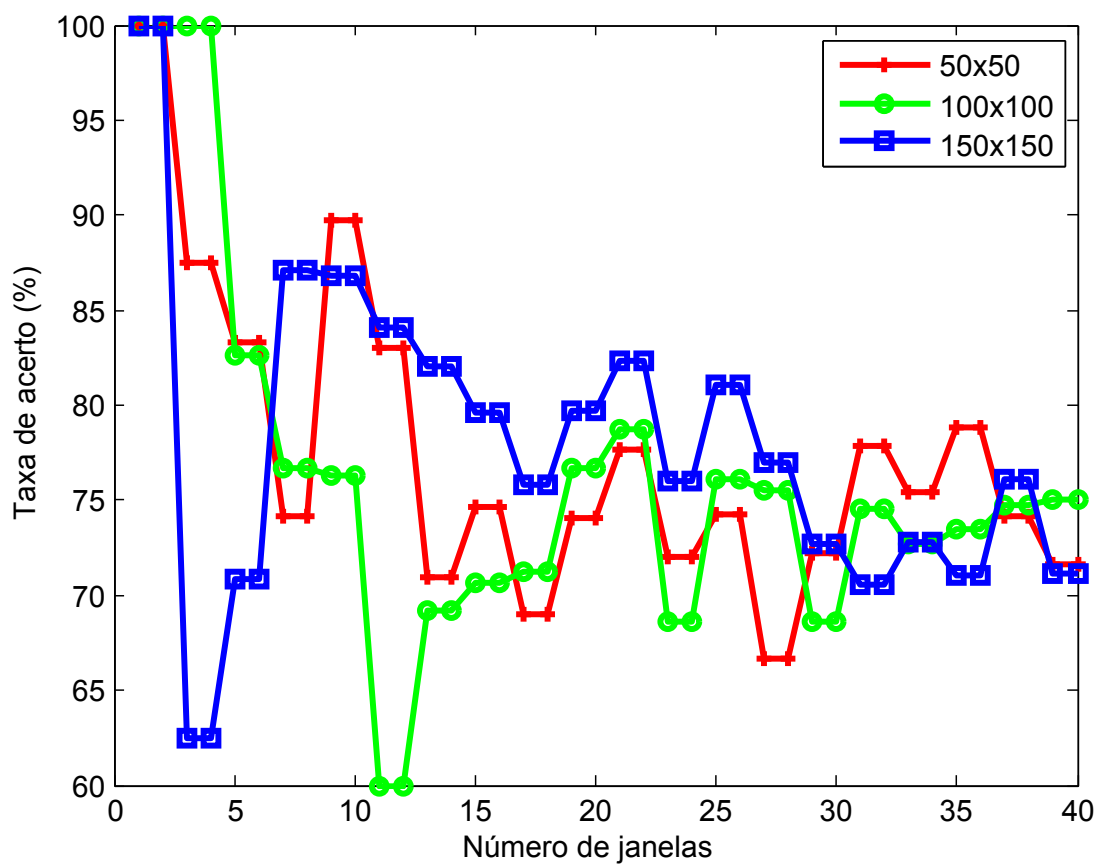

Figura 7.31 - Taxa acerto em função do número de pares de janelas para o óxido de zircônio dopado por nióbio, aumentado 3000x. 


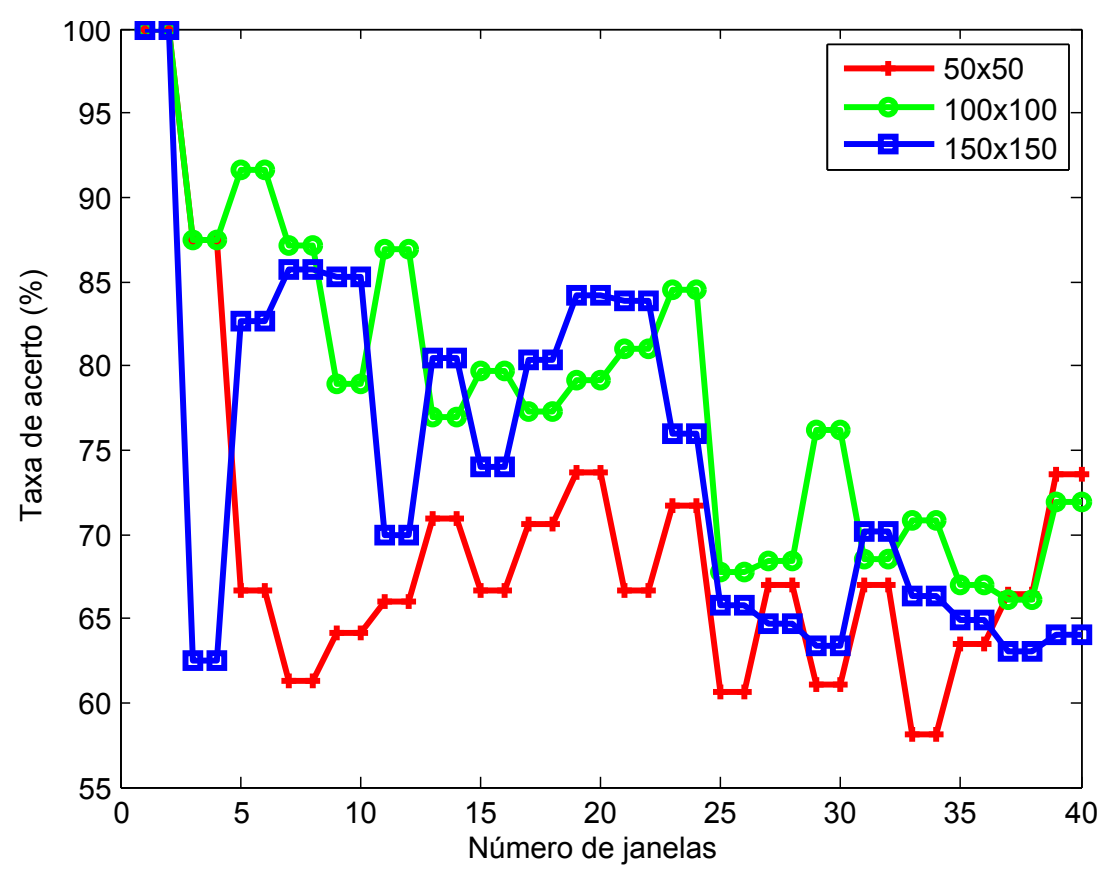

Figura 7.32 - Taxa acerto em função do número de pares de janelas para o óxido de zircônio dopado por nióbio, aumentado $8000 x$.

a discriminação destas imagens de materiais sob diferentes condições experimentais. O bom desempenho dos descritores se explica pela capacidade destes em expressar a complexidade do material sob diferentes escalas. Esta complexidade é capaz de descrever com precisão importantes atributos físicos da amostra como rugosidade, porosidade, topografia, etc. O uso de janelas possibilitou a resolução de um problema frequente na análise deste tipo de imagem, que é a forte dissimilaridade entre os conjuntos de treinamento e teste. Assim, os descritores fractais por janelas constituem um método que permite uma análise precisa e robusta e ainda consumindo poucos recursos computacionais e financeiros, tornando-se assim uma ferramenta de grande potencial para aplicações práticas em diversos problemas na Ciência dos Materiais e áreas afins. 


\section{CAPÍTULO 8}

\section{Conclusões}

\subsection{Considerações Finais}

Este projeto de doutorado propôs, aplicou e analisou o desempenho dos descritores fractais em diferentes bases de texturas coloridas e em tons de cinza. Ademais, foram apresentadas aplicações da metodologia desenvolvida em análise de imagens de satélites (segmentação), bem como na análise de materiais representados em imagens expressas em nanoescala. $O$ projeto ainda desenvolveu um novo método para estimativa de dimensão fractal.

Os resultados obtidos demonstraram um grande potencial destes descritores em análise de imagens, tarefa esta que surge em muitas situações práticas, em problemas de áreas que vão desde Medicina e Botânica até Física e Engenharia.

Em um primeiro momento, foram estudados vários métodos apresentados na literatura para a estimativa da dimensão fractal de objetos do mundo real. Em seguida, para cada uma dessas dimensões foram propostos descritores fractais a partir da curva de fractalidade. Em seguida, estes descritores foram incrementados pelo uso de transformações do tipo multiescala (espaço-escala, tempo-frequência e tempo-escala) e FDA.

Os descritores obtidos foram empregados em um primeiro experimento no qual duas bases de texturas eram classificadas levando-se em conta as intensidades de cinza (Brodatz e Vistex) e duas usando a informação de cor (Vistex e Outex). Os resultados foram comparados em termos das taxas de acerto, número de descritores e medidas de erro com outras abordagens clássicas e estado-da-arte encontradas na literatura de análise de texturas. Os descritores fractais também foram combinados para compor métodos ainda mais robustos em cada tipo de aplicação.

Os resultados demonstraram a vantagem de métodos como os descritores fractais de Bouligand-Minkowski, Wavelike e Probabilidade para as texturas cinzas, bem como de Bouligand- 
Minkowski 3D e Fourier EEE para texturas coloridas, quando comparados aos métodos da literatura. Já as combinações de descritores geraram taxas de acerto excelentes e com vantagem substancial em relação a métodos consagrados na literatura, como LBP, e isso usando um número baixo de descritores.

Os descritores propostos também foram aplicados a um problema de identificação de regiões urbanas e rurais em imagens de satélite. As imagens foram divididas em janelas e para cada uma delas os descritores foram extraídos, seguindo-se então um processo de classificação não-supervisionado para identificação das regiões. Os descritores apresentaram vantagem sobre outras abordagens deste tipo, como Gabor e GLCM.

Ainda uma segunda aplicação foi realizada no reconhecimento de imagens de materiais sob diferentes condições experimentais. Em uma primeira etapa, a separação foi feita apenas usando-se os componentes principais dos descritores extraídos da imagem inteira. Em um segundo momento, foi desenvolvida uma solução baseada na divisão das imagens em janelas e representação usando-se os descritores das janelas mais próximas por algum critério de distância. Este método obteve taxas de acerto em torno de 100\%, mesmo em uma base de imagens com padrões texturais tão complexos.

Por fim, este projeto ainda levou ao desenvolvimento de um novo método de estimativa de dimensão fractal de formas, baseado no espectro de Fourier de funções complexas. A técnica se mostrou precisa e altamente robusta a transformações geométricas e ruídos. $\mathrm{O}$ método ainda demonstrou apresentar um custo computacional significativamente mais baixo que outras abordagens usadas para este fim.

De uma maneira geral, os resultados aqui obtidos apontam o grande poder de discriminação que estes descritores apresentam dada a natureza prática que a análise de complexidade realizada por estas abordagens carrega, uma vez que a complexidade mede o nível de detalhes sob diferentes escalas da estrutura de pixels da imagem e essa distribuição de detalhes representa atributos físicos fundamentais do material gerador e, por consequência, da imagem analisada. Ainda, em particular, as combinações de descritores mostraram um nível louvável de precisão, ao juntar diferentes perspectivas da complexidade de uma mesma imagem e compor assim uma informação tão rica em poucos atributos.

\subsection{Atividades Realizadas e Contribuições Geradas}

Em essência, as atividades e contribuições podem ser divididas em três etapas. 
Na primeira, foi feita uma revisão bibliográfica de todos os conceitos teóricos e práticos relacionados à geometria fractal e análise de texturas como um todo. Neste contexto foi estudada a definição de fractal e dimensão fractal, o método analítico e os métodos numéricos para o cálculo desta dimensão, bem como as medidas fractais como multifractais, dimensão multiescala e descritores fractais, aplicados na análise de imagens. Foram estudadas também diferentes metodologias em análise de imagens, como transformadas multiescala, análise de dados funcionais, além de métodos de classificação e redução de dimensionalidade.

Na segunda fase, são propostos novos métodos em análise de imagens. Estes métodos se dividem em uma nova técnica para estimar a dimensão fractal numericamente e várias abordagens para a extração de descritores fractais de texturas, seja de forma direta a partir de vários métodos diferentes de dimensão fractal, por transformações multiescala e de análise funcional, ou ainda por meio de uma abordagem multiníveis de janelas recursivas. Outra proposta que gera excelentes resultados é a combinação entre abordagens diferentes de descritores.

Por fim, toda a metodologia desenvolvida é aplicada em problemas do mundo real, no caso, na segmentação de imagens extraídas por satélite, na identificação de regiões rurais e urbanas, e na discriminação de materiais analisados em nanoescala, com o objetivo de identificar as condições que deram origem àquele material.

A Tabela 8.1 resume as principais contribuições e atividades deste trabalho de doutorado.

Tabela 8.1 - Atividades realizadas e contribuições geradas por este trabalho de doutorado.

\begin{tabular}{|c|c|}
\hline Contribuição & Descrição \\
\hline Revisão Bibliográfica & $\begin{array}{l}\text { Ampla pesquisa por diferentes métodos de dimensão fractal, ferramentas de transformação } \\
\text { de dados e de reconhecimento de padrões em geral }\end{array}$ \\
\hline Dimensão Fractal & $\begin{array}{l}\text { Proposta de novo método numérico de dimensão fractal de formas, com maior robustez a } \\
\text { transformações geométricas e ruídos, além de menor custo computacional }\end{array}$ \\
\hline Descritores Fractais & $\begin{array}{l}\text { Desenvolvimento de novas metodologias de descritores fractais com maior poder de discriminação } \\
\text { de texturas }\end{array}$ \\
\hline Descritores Combinados & $\begin{array}{l}\text { Proposta de combinação de descritores fractais, levando a excelentes resultados mesmo nas bases } \\
\text { de texturas mais complexas }\end{array}$ \\
\hline Segmentação & $\begin{array}{l}\text { Método de segmentação de imagens de texturas a partir da extração de descritores fractais de } \\
\text { janelas da imagem }\end{array}$ \\
\hline Similaridade de Janelas & $\begin{array}{l}\text { Nova técnica para a clasificação de amostras com validação externa, em que os descritores mais } \\
\text { similares são selecionados a partir de janelas da imagem }\end{array}$ \\
\hline Comparação & $\begin{array}{l}\text { Comparação entre os descritores fractais propostos e métodos da literatura em diversas bases públicas, } \\
\text { evidenciando as melhores soluções para cada situação }\end{array}$ \\
\hline Nanotecnologia & $\begin{array}{l}\text { Aplicação a problemas complexos de nanotecnologia, oferecendo uma solução robusta e precisa para } \\
\text { problemas fundamentais da Ciência dos Materiais }\end{array}$ \\
\hline Imagens de Satélie & $\begin{array}{l}\text { Identificação de áreas urbanas e rurais em imagens de satélite, dando uma descrição importante } \\
\text { para vários profissionais, como arquitetos, engenheiros civis, etc. }\end{array}$ \\
\hline Publicações & $\begin{array}{l}\text { Este trabalho gerou nove publicações em periódicos relevantes no cenário internacional, divulgando } \\
\text { as novas propostas para a comunidade científica }\end{array}$ \\
\hline
\end{tabular}




\subsection{Trabalhos Futuros}

Os resultados alcançados pelos descritores fractais demonstraram o potencial desta técnica para análise de texturas, com possibilidade de aplicações em inúmeras áreas da ciência. Entretanto, ainda existem vários tópicos a serem explorados tanto do ponto de vista teórico quanto da aplicação a problemas do mundo real. A lista a seguir resume os itens que ficam como possíveis sugestões para trabalhos futuros.

- Estudo do comportamento dos descritores fractais na análise de texturas afetadas por transformações geométricas;

- Verificação da possibilidade de aplicação de descritores fractais a bases de imagens de texturas com dimensões variadas. Estudar novas abordagens que possam ser usadas com eficiência nestes casos;

- Aprofundar o estudo da aplicação em imagens de materiais;

- Estudar novas propostas para aplicação de descritores fractais em segmentação de imagens, possivelmente baseadas no conceito de descritores fractais locais (ver item seguinte);

- Desenvolver e verificar a aplicabilidade de uma técnica que faz a estimativa de uma medida de complexidade em cada pixel da imagem, com base em sua vizinhança. Tal abordagem se encontra na fronteira entre as técnicas de descritores fractais e aquelas baseadas em multifractais e permitirá, por exemplo, a extensão de métodos eficazes baseados em vizinhanças locais como a técnica de padrões locais binários (mais conhecida pela sigla em inglês LBP) (105).

- Estudar novas estratégias para se combinarem descritores fractais com redes complexas, uma vez que são abordagens que têm obtido bom desempenho e que poderiam ter suas melhores características somadas para a extração de descritores ainda mais precisos e confiáveis.

\subsection{Publicações Geradas}

Este projeto já gerou até o momento publicações em importantes periódicos e conferências internacionais, em diferentes áreas do conhecimento, como Ciência da Computação, Física, 
Engenharia e áreas correlatas. Segue uma lista dos trabalhos publicados, aceitos, submetidos e em redação.

\subsubsection{Publicados}

- FLORINDO, J. B.; BACKES, A. R.; CASTRO, M.; BRUNO, O. M. A comparative study on multiscale fractal dimension descriptors. Pattern Recognition Letters, v. 33, n. 6, p. 798-806, 2012.

- FLORINDO, J. B.; BRUNO, O. M. Closed contour fractal dimension estimation by the Fourier transform. Chaos, Solitons and Fractals, v. 44, n. 10, p. 851-861, 2011.

- FLORINDO, J. B.; BRUNO, O. M. Fractal descriptors in the Fourier domain applied to color texture analysis. Chaos, v. 21, n. 4, p. 1-10, 2011.

- Florindo, J. B.; SIKORA, M.; PEREIRA, E.; BRUNO, O. M. Multiscale fractal descriptors applied to nanoscale images. Journal of Superconductivity and Novel Magnetism, 6p., 2012. DOI:10.1007/s10948-012-1449-9.

- FLORINDO, J. B.; CASTRO, M.; BRUNO, O. M. Enhancing multiscale fractal descriptors using functional data analysis. International Journal of Bifurcationa and Chaos, v. 20, n. 11, p. 3443-3460, 2010.

- Florindo, J. B.; CASTRO, M.; BRUNO, O. M. Enhancing volumetric BouligandMinkowski fractal descriptors by using functional data analysis. International Journal of Modern Physics C, v. 22, n. 9, p. 929-952, 2011.

- FLORINDO, J. B.; BRUNO, O. M. Fractal descriptors based on fourier spectrum applied to texture analysis. Physica A, v. 391, n. 20, p. 4909-4922, 2012.

- BACKES, A. R.; FLORINDO, J. B.; BRUNO, O. M. Shape analysis using fractal dimension: a curvature based approach. Chaos, v. 22, n. 4, p. 043103, 2012.

- BACKeS, A. R.; Florindo, J. B.; BRUNO, O. M. A Novel Approach to Estimate Fractal Dimension from Closed Curves. In: COMPUTER ANALYSIS OF IMAGES AND PATTERNS, 13., 2009, Munster, Germany. Proceedings .... Berlin: Springer-Verlag, c2009 (Lecture Notes in Computer Science, v. 5702), p. 253-260. 
- FLORINDO, J. B.; BRUNO, O. M. Fourier fractal descriptors for colored texture analysis. In: ADVANCES CONCEPTS FOR INTELLIGENT VISION SYSTEMS, 13., 2011, Ghent, Belgium. Proceedings.... Berlin: Springer, c2011 ( Lecture Notes in Computer Science, v. 6915). p. 284-292.

- Florindo, J. B.; BACKES, A. R.; BRUNO, O. M. Leaves Shape Classification Using Curvature and Fractal Dimension. In: INTERNATIONAL CONFERENCE ON IMAGE AND SIGNAL PROCESSING, 4., 2010, Trois Rivieres, Canada. Proceedings .... Berlin: Springer-Verlag, c2010 ( Lecture Notes in Computer Science, v. 6134). p. 456-462.

- FLORINDO, J. B.; BRUNO, O. M. Texture classification based on lacunarity descriptors. In: IMAGE AND SIGNAL PROCESSING, 5., 2012, Agadir, Morocco, Proceedings .... Berlin: Springer-Verlag, c2012 (Lecture Notes in Computer Science, v. 7340). p. 513520.

\subsubsection{Aceitos}

- FLORINDO, J. B.; BRUNO, O. M. Texture analysis by fractal descriptors of wavelet domain. Expert Systems with Applications.

\subsubsection{Submetidos}

- FLORINDO, J. B.; BRUNO, O. M. Texture analysis using wavelet fractal descriptors. Expert Systems with Applications.

\subsubsection{Em redação}

- FLORINDO, J. B.; BRUNO, O. M. Probability fractal descriptors.

- FLORINDO, J. B.; BRUNO, O. M. Triangular prism fractal descriptors. 


\subsection{Distinções Obtidas}

Primeiro lugar no ImageCLEF 2011, competição acadêmica internacional de métodos de Visão Computacional, na tarefa de identificação de imagens de plantas. Trabalho publicado em:

- CASANOVA, D.; FLORINDO, J. B.; BRUNO, O. M. IFSC/USP at ImageCLEF 2011: plant identication task. In: CONFERENCE ON MULTILINGUAL AND MULTIMODAL INFORMATION ACCESS EVALUATION, 9., 2011, Padua, Italy. Proceedings... Berlin: Springer, c2011 (CLEF (Notebook Papers/Labs/Workshop)). 


\section{REFERÊNCIAS}

1 MANDELBROT, B. B. The fractal geometry of nature. New York: Freeman, 1968.

2 CHAPPARD, D.; DEGASNE, I.; HURE, G.; LEGRAND, E.; AUDRAN, M.; BASLE, M. Image analysis measurements of roughness by texture and fractal analysis correlate with contact profilometry. Biomaterials, v. 24, n. 8, p. 1399-1407, 2003.

3 CALZETTI, D.; GIAVALISCO, M. Fractal structures and the angular correlation function of galaxies. Vistas in Astronomy, v. 33, n. 3/4, p. 295-304, 1990.

4 FLORINDO, J. B.; SIKORA, M.; PEREIRA, E.; BRUNO, O. Multiscale fractal descriptors applied to nanoscale images. Journal of Superconductivity and Novel Magnetism, 6p., 2012. DOI:10.1007/s10948-012-1449-9.

5 CHAUDHURI, B. B.; SARKAR, N. Texture segmentation using fractal dimension. IEEE Transactions on Pattern Analysis and Machine Intelligence, v. 17, n. 1, p. 72-77, 1995.

6 PAIK, K. Simulation of landscape evolution using a global flow path search method. Environmental Modelling \& Software, v. 33, p. 35-47, 2012. DOI:10.1016/j.envsoft.2012.01.005.

7 FLORINDO, J. B.; BRUNO, O. M. Fourier fractal descriptors for colored texture analysis. In: ADVANCES CONCEPTS FOR INTELLIGENT VISION SYSTEMS, 13., 2011, Ghent, Belgium. Proceedings.... Berlin: Springer, c2011 ( Lecture Notes in Computer Science, v. 6915). p. 284-292.

8 JONES, C. L.; JELINEK, H. F. Wavelet packet fractal analysis of neuronal morphology. Methods, v. 24, n. 4, p. 347-358, 2001.

9 RASOULI, G.; RASOULI, M.; LENZ, F. A.; VERHAGEN, L.; BORRETT, D. S.; KWAN, H. C. Fractal characteristics of human parkinsonian neuronal spike trains. Neuroscience, v. 139, n. 3, p. 1153-1158, 2006.

10 TIAN-GANG, L.; WANG, S.; ZHAO, N. Fractal research of pathological tissue images. Computerized Medical Imaging and Graphics, v. 31, n. 8, p. 665-671, 2007. 
11 KAPLAN, L. Extended fractal analysis for texture classification and segmentation. IEEE Transactions on Image Processing, v. 8, n. 11, p. 1572-1585, 1999.

12 GONZALEZ, R. C.; WOODS, R. E. Digital image processing. 2nd ed. Upper Saddle River: Prentice Hall, 2002.

13 MATERKA, A.; STRZELECKI, M.; ANALYSIS, T.; REVIEW, M. A.; MATERKA, A.; STRZELECKI, M. Texture analysis methods - a review. Poland: Institute of Electronics, Technical University of Lodz, 1998. Technical report.

14 JAIN, A. K.; DUIN, R. P. W.; MAO, J. Statistical pattern recognition: A review. IEEE Transactions on Pattern Analysis and Machine Intelligence, v. 22, n. 1, p. 4-37, 2000.

15 OHANIAN, P.; DUBES, R. Performance evaluation for 4 classes of textural features. Pattern Recognition, v. 25, n. 8, p. 819-833, 1992.

16 SCOTT, R.; UNGAR, P.; BERGSTROM, T.; BROWN, C.; GRINE, F.; TEAFORD, M.; WALKER, A. Dental microwear texture analysis shows within-species diet variability in fossil hominins. Nature, v. 436, n. 7051, p. 693-695, 2005.

17 CHRISTODOULOU, C.; PATTICHIS, C.; PANTZIARIS, M.; NICOLAIDES, A. Texturebased classification of atherosclerotic carotid plaques. IEEE Transactions on Medical Imaging, v. 22, n. 7, p. 902-912, 2003.

18 HARTE, D. Multifractals: theory and applications. Boca Raton: Chapman and Hall/CRC, 2001.

19 MANOEL, E. T. M.; DA FONTOURA COSTA, L.; STREICHER, J.; MüLLER, G. B. Multiscale fractal characterization of three-dimensional gene expression data. In: BRAZILIAN SYMPOSIUM ON COMPUTER GRAPHICS AND IMAGE PROCESSING, 15., 2002, Fortaleza,Brazil. Proceedings .... Washington,DC: IEEE Computer Society, c2002. p. 269-274.

20 BRUNO, O. M.; DE OLIVEIRA PLOTZE, R.; FALVO, M.; DE CASTRO, M. Fractal dimension applied to plant identification. Information Sciences, v. 178, n. 12, p. 2722-2733, 2008.

21 PlotZE, R. O.; PADUA, J. G.; FALVO, M.; VIEIRA, M. L. C.; OlIVEIRA, G. C. X.; BRUNO, O. M. Leaf shape analysis by the multiscale minkowski fractal dimension, a new morphometric method: a study in passiflora I. (passifloraceae). Canadian Journal of BotanyRevue Canadienne de Botanique, v. 83, n. 3, p. 287-301, 2005.

22 FLORINDO, J. B.; BRUNO, O. M. Fractal descriptors based on fourier spectrum applied to texture analysis. Physica A, Amsterdam, 2012. In press. 
23 BACKES, A. R.; FLORINDO, J. B.; BRUNO, O. M. A novel approach to estimate fractal dimension from closed curves. In: COMPUTER ANALYSIS OF IMAGES AND PATTERNS, 13., 2009, Muster,Germany. Proceedings .... Berlin: Springer-Verlag, c2009 ( Lecture Notes in Computer Science, v. 5702). p. 253-260.

24 FLORINDO, J. B.; BACKES, A. R.; BRUNO, O. M. Leaves shape classification using curvature and fractal dimension. In: INTERNATIONAL CONFERENCE ON IMAGE AND SIGNAL PROCESSING, 4., 2010, Trois Rivieres, Canada. Proceedings .... Berlin: SpringerVerlag, c2010 ( Lecture Notes in Computer Science, v. 6134). p. 456-462.

25 FLORINDO, J. B.; DE CASTRO, M.; BRUNO, O. M. Enhancing multiscale fractal descriptors using functional data analysis. International Journal of Bifurcation and Chaos, v. 20, n. 11, p. 3443-3460, 2010.

26 FLORINDO, J. B.; DE CASTRO, M.; BRUNO, O. M. Enhancing volumetric bouligandminkowski fractal descriptors by using functional data analysis. International Journal of Modern Physics C, v. 22, n. 9, p. 929-952, 2011.

27 FLORINDO, J. B.; BRUNO, O. M. Closed contour fractal dimension estimation by the fourier transform. Chaos Solitons \& Fractals, v. 44, n. 10, p. 851-861, 2011.

28 FLORINDO, J. B.; BRUNO, O. M. Fractal descriptors in the fourier domain applied to color texture analysis. Chaos, v. 21, n. 4, p. 1-10, 2011.

29 FLORINDO, J. B.; BACKES, A. R.; DE CASTRO, M.; BRUNO, O. M. A comparative study on multiscale fractal dimension descriptors. Pattern Recognition Letters, v. 33, n. 6, p. 798-806, 2012.

30 PEITGEN, H.; RICHTER, P. The beauty of fractals: Images of complex dynamical systems. Berlin: Springer, 1986.

31 PESIN, Y.; CLIMENHAGA, V. Lectures on fractal geometry and dynamical systems. New York: American Mathematical Society, 2009.

32 CARLIN, M. Measuring the complexity of non-fractal shapes by a fractal method. Pattern Recognition Letters, v. 21, n. 11, p. 1013-1017, 2000.

33 ADDISON, P. Fractals and chaos: an illustrated course. London: Institute of Physics Publishing, 1997.

34 FALCONER, K. Fractal geometry: mathematical foundations and applications. Chichester,UK: Wiley, 2003. 
35 TAYLOR, C. G. "Fleshing Out" Artificial Life II. In: LANGTON, C. G.; TAYLOR, C.; FARMER, J. D.; RASMUSSEN, S. (Eds.) Artificial Life II. Cambridge: Addison Wesley, 1992. p. 26-38.

36 LINDENMAYER, A. Mathematical models for cellular interaction in development: Parts I and II. Journal of Theoretical Biology, v. 18, n. 3, 1968.

37 CHOMSKY, N. Three models for the description of language. IRE Transactions on Information Theory, v. 2, n. 3, p. 113-124, 1956.

38 MISHRA, J.; MISHRA, S. L-system fractals. Amsterdam: Elsevier Science, 2007.

39 BARNSLEY, M. F. Fractals everywhere. 2nd ed. New York: Academic Press, 1993.

40 PERUGGIA, M. Discrete iterated function systems. Wellesley, MA, USA: A.K. Peters, 1993.

41 WELSTEAD, S. Fractal and wavelet image compression techniques. Bellingham, USA: SPIE-International Society for Optical Engine, 1999.

42 PEITGEN, H.; JÜRGENS, H.; SAUPE, D. Chaos and fractals: new frontiers of science. New York: Springer, 2004.

43 BARNSLEY, M.; HURD, L. Fractal image compression. Wellesley, MA, USA: AK Peters, 1993.

44 MANDELBROT, B. How long is the coast of britain? statistical self-similarity and fractional dimension. Science, Washington, v. 156, n. 3775, p. 636-638, 1967.

45 JULESZ, B. Experiments in the visual perception of texture. Scientific American, v. 232, n. 4 , p. $34-43,1975$.

$46 \mathrm{KUBE}, \mathrm{P}$.; PENTLAND, A. On the imaging of fractal surfaces. IEEE Transactions on Pattern Analysis and Machine Intelligence, v. 10, n. 5, p. 704-707, 1988.

47 PENTLAND, A. P. Fractal-based description of natural scenes. IEEE Transactions on Pattern Analysis and Machine Intelligence, v. 6, n. 6, p. 661-674, 1984.

48 PELEG, S.; NAOR, J.; HARTLEY, R.; AVNIR, D. Multiple resolution texture analysis and classification. Maryland: University of Maryland, 1983.

49 TRICOT, C. Curves and fractal dimension. Berlin: Springer-Verlag, 1995. 
50 PEITGEN, H.-O.; BARNSLEY, M. F.; SAUPE, D. The science of fractal images. Berlin: Springer-Verlag, 1988.

51 FALCONER, K. J. The geometry of fractal sets. New York: Cambridge University Press, 1986.

52 RUSS, J. C. Fractal surfaces. New York: Plenum Press, 1994.

53 LOPES, R.; BETROUNI, N. Fractal and multifractal analysis: A review. Medical Image Analysis, v. 13, n. 4, p. 634-649, 2009.

54 SERRA, J. Image analysis and mathematical morphology. Orlando, FL, USA: Academic Press, Inc., 1983.

55 FABBRI, R.; COSTA, L. D. F.; TORELLI, J. C.; BRUNO, O. M. 2d Euclidean distance transform algorithms: a comparative survey. ACM Computer Surveys, v. 40, n. 1, p. 1-44, 2008.

56 SCHROEDER, M. Fractals, chaos, power laws: minutes from an infinite paradise. New York: W.H. Freeman, 1991.

57 JENSEN, A. A.; La Cour-Harbo, A. A. Ripples in mathematics: the discrete wavelet transform. New York: Springer-Verlag, 2001.

58 RUSKAI, M. B.; BEYLKIN, G.; COIFMAN, R.; DAUBECHIES, I.; MALLAT, S.; MEYER, Y.; RAPHAEL, L. (Eds.). Wavelets and their applications. Boston: Jones and Bartlett, 1992.

59 SHANNON, C. E. Prediction and entropy of printed english. Bell System Technical Journal, v. 27, n. 1, p. 379-423, 1951.

60 VOSS, R. F. Characterization and measurement of random fractals. Physica Scripta, Stockholm, v. 1986, n. T13, p. 27, 1986.

61 CLARKE, K. C. Computation of the fractal dimension of topographic surfaces using the triangular prism surface area method. Computers and Geosciences, v. 12, n. 5, p. 713-722, 1985.

62 GOODCHILD, M. F. Fractals and the accuracy of geographical measures. Mathematical Geology, v. 12, n. 2, p. 85-98, 1980.

63 DUBUC, B.; QUINIOU, J. F.; CARMES, C. R.; TRICOT, C.; ZUCKER, S. W. Evaluating the fractal dimension of profiles. Physical Review A, Woodbury, v. 39, n. 3, p. 1500-1512, 1989. 
64 GEFEN, Y.; MEIR, Y.; MANDELBROT, B. B.; AHARONY, A. Geometric implementation of hypercubic lattices with noninteger dimensionality by use of low lacunarity fractal lattices. Physical Review Letters, New York, v. 50, n. 3, p. 145+, 1983.

65 PRESS, W. H.; TEUKOLSKY, S. A.; VETTERLING, W. T.; FLANNERY, B. P. Numerical recipes: the art of scientific computing. 3rd ed. New York: Cambridge University Press, 2007.

66 SOILLE, P.; RIVEST, J.-F. On the validity of fractal dimension measurements in image analysis. Journal of Visual Communication and Image Representation, v. 7, n. 3, p. 217 229, 1996.

67 SCARLAT, E. I.; MIHAILESCU, M.; SOBETKII, A. Spatial frequency and fractal complexity in single-to-triple beam holograms. Journal of Optoelectronics and Advanced Materials, v. 12, n. 1, p. 105-109, 2010.

68 CHEN, W. Y.; CHANG, S. J.; WENG, M. H.; HUNG, C. Y. Design of the fractalbased dual-mode bandpass filter on ultra thin liquid-crystal-polymer substrate. Journal of Electromagnetic Waves and Applications, v. 24, n. 2-3, p. 391-399, 2010.

69 WANG, H.; SIOPONGCO, J.; WADE, L. J.; YAMAUCHI, A. Fractal analysis on root systems of rice plants in response to drought stress. Environmental and Experimental Botany, v. 65, n. 2-3, p. 338-344, 2009.

70 BIRD, N.; DIAZ, M.; SAA, A.; TARQUIS, A. Fractal and multifractal analysis of pore-scale images of soil. Journal of Hydrology, v. 322, n. 1-4, p. 211-219, 2006.

71 HAN, D.; WANG, M.; ZHOU, J. Fractal analysis of self-mixing speckle signal in velocity sensing. Optics Express, v. 16, n. 5, p. 3204-3211, 2008.

72 DAS, I.; AGRAWAL, N. R.; GUPTA, S. K.; GUPTA, S. K.; RASTOGI, R. P. Fractal growth kinetics and electric potential oscillations during electropolymerization of pyrrole. Journal of Physical Chemistry A, v. 113, n. 18, p. 5296-5301, 2009.

73 VINOY, K.; ABRAHAM, J.; VARADAN, V. On the relationship between fractal dimension and the performance of multi-resonant dipole antennas using koch curves. IEEE Transactions on Antennas and Propagation, v. 51, n. 9, p. 2296-2303, 2003.

74 CHEN, Y.; BI, G. On texture classification using fractal dimension. International Journal of Pattern Recognition and Artificial Intelligence, v. 13, n. 6, p. 929-943, 1999.

75 LASHERMES, B.; ROUX, S. G.; ABRY, P.; JAFFARD, S. Comprehensive multifractal analysis of turbulent velocity using the wavelet leaders. European Physical Journal B, v. 61, n. 2, p. 201-215, 2008. 
76 LOVEJOY, S.; GARRIDO, P.; SCHERTZER, D. Multifractal absolute galactic luminosity distributions and the multifractal hubble 3/2 law. Physica A-Statistical Mechanics and its Applications, v. 287, n. 1-2, p. 49-82, 2000.

77 XU, Y.; YANG, X.; LING, H.; JI, H. A new texture descriptor using multifractal analysis in multi-orientation wavelet pyramid. Computer Vision and Pattern Recognition, IEEE Computer Society Conference on, v. 0, p. 161-168, 2010. DOI:10.1109/CVPR.2010.5540217.

$78 \mathrm{XU}, \mathrm{Y}$.; JI, H.; FERMÜLLER, C. Viewpoint invariant texture description using fractal analysis. International Journal of Computer Vision, v. 83, n. 1, p. 85-100, 2009.

79 EMERSON, C.; LAM, N.; QUATTROCHI, D. Multi-scale fractal analysis of image texture and patterns. Photogrammetric Enginnering \& Remote Sensing, v. 65, n.1, p.51-62, 1999.

80 COSTA, L. F.; CESAR JUNIOR, R. M. Shape analysis and classification: theory and practice. Boca Raton: CRC Press, 2000.

81 BRIGHAM, E. O. The fast Fourier transform and its applications. Englewood Cliffs, New Jersey: Prentice-Hall, 1988.

82 BACKES, A. Estudos de métodos de análise de complexidade em imagens. 2010. 180p. Tese (Doutorado em Ciência da Computação) - Instituto de Ciências Matemáticas e de Computação, Universidade de São Paulo, São Carlos, 2010.

83 BACKES, A. R.; CASANOVA, D.; BRUNO, O. M. Plant leaf identification based on volumetric fractal dimension. International Journal of Pattern Recognition and Artificial Intelligence (IJPRAI), v. 23, n. 6, p. 1145-1160, 2009.

84 SENGÜR, A.; TÜRKOGLU, I.; INCE, M. C. Wavelet packet neural networks for texture classification. Expert Systems with Applications, v. 32, n. 2, p. 527-533, 2007.

85 GEUSEBROEK, J.-M.; VAN DEN BOOMGAARD, R.; SMEULDERS, A. W. M.; DEV, A. Color and scale: The spatial structure of color images. In: EUROPEAN CONFERENCE ON COMPUTER VISION, ECCV, 6., 2000, Dublin, Ireland. Proceedings .... Berlin: SpringerVerlag, c2000. p. 331-341.

86 RAMSAY, J. O.; SILVERMAN, B. W. Applied functional data analysis: methods and case studies. New York: Springer-Verlag, 2002.

87 RAMSAY, J. O.; SILVERMAN, B. W. Functional data analysis. New York: SpringerVerlag, 2005.

88 ROSSI, F.; DELANNAY, N.; CONAN-GUEZ, B.; VERLEYSEN, M. Representation of functional data in neural networks. Neurocomputing, v. 64, n. 1, p. 183-210, 2005. 
89 STRANG, G. Linear algebra and its applications. New York: Brooks Cole, 1988.

90 WITKIN, A. P. Scale space filtering: a new approach to multi-scale descriptions. In: IEEE INTERNATIONAL CONFERENCE ON ACOUSTICS, SPEECH, AND SIGNAL PROCESSING, ICASSP, 15., 1984, San Diego. Proceedings .... Saint Martin d'Hères, France: GRETSI, c2003. p. $79-95$.

91 KOENDERINK, J. J.; VAN DOORN, A. J. Generic neighborhood operators. IEEE Transactions on Pattern Analysis and Machine Intelligence, v. 14, n. 6, p. 597-605, 1992.

92 FLANDRIN, P. Time-frequency/time-scale analysis. San Diego: Academic Press, 1999.

93 GABOR, D. Theory of communication. Journal of IEE, v. 93, n. 26, p. 429-457, 1946.

94 COHEN, L. D. On active contour models and balloons. CVGIP: Image Understanding, v. 53, n. 2, p. 211-218, 1991.

95 DAUGMAN, J. G. Complete discrete 2-D Gabor transforms by neural networks for image analysis and compression. Acoustics, Speech and Signal Processing, IEEE Transactions on, v. 36, n. 7, p. 1169-1179, 2002.

96 HLAWATSCH, F.; BOUDREAUX-BARTELS, G. F. Linear and quadratic time-frequency signal representations. IEEE Signal Processing Magazine, v. 9, n. 2, p. 21-67, 1992.

97 GROSSMANN, A.; MORLET, J. Decomposition of hardy functions into square integrable wavelets of constant shape. SIAM Journal on Mathematical Analysis, v. 15, n. 4, p. 723-736, 1984.

98 PARRINELLO, T.; VAUGHAN, R. A. Multifractal analysis and feature extraction in satellite imagery. International Journal of Remote Sensing, v. 23, n. 9, p. 1799-1825, 2002.

99 BRODATZ, P. Textures: a photographic album for artists and designers. New York: Dover Publications, 1966.

100 VISION texture database. 2009. Disponível em: <http://vismod.media.mit.edu/ vismod/imagery/VisionTexture/>. Acesso em: 14-01-2013.

101 OJALA, T.; MAENPAA, T.; PIETIKAINEN, M.; VIERTOLA, J.; KYLLONEN, J.; HUOVINEN, S. Outex - new framework for empirical evaluation of texture analysis algorithms. In: INTERNATIONAL CONFERENCE ON PATTERN RECOGNITION, ICPR, 16., 2002, Quebec, Canada. Proceedings .... Los Alamitos, USA: IEEE Computer Society, c2002. p. 701-706.

102 VAPNIK, V. The nature of statistical learning theory: information science and statistics. 2nd. ed. New York: Springer, 1999. 
103 SHAKHNAROVICH, G.; DARRELL, T.; INDYK, P. Nearest-neighbor methods in learning and vision: theory and practice (neural information processing). Massachussets: The MIT Press, 2006.

104 ANDERSON, T. W.; ANDERSON, T. W. An introduction to multivariate statistical analysis. 2nd ed. California: Wiley, 1984.

105 PIETIKÄINEN, M.; HADID, A.; ZHAO, G.; AHONEN, T. Computer vision using local binary patterns. Berlin: Springer-Verlag, 2011. (Computer imaging and vision, v.40).

106 MANJUNATH, B.; MA, W. Texture features for browsing and retrieval of image data. IEEE Transactions on Pattern Analysis and Machine Intelligence, v. 18, n. 8, p. 837-842, 1996.

107 HARALICK, R. M. Statistical and structural approaches to texture. Proceedings of the IEEE, v. 67, n. 5, p. 786-804, 1979.

108 WESZKA, J.; DYER, C.; ROSENFELD, A. A comparative study of texture measures for terrain classification. IEEE Transactions on Systems, Man and Cybernetics, v. 6, n. 4, p. 269-286, 1976.

109 LAWS, K. I. Goal-directed textured-image segmentation: Technical note 334. Disponível em: <http://www.dtic.mil/cgi-bin/GetTRDoc?AD=ADA461738\&Location= U2\&doc=GetTRDoc $\cdot$ pdf $>$ Acesso em: 14-01-2013.

110 PASCHOS, G.; PETROU, M. Histogram ratio features for color texture classification. Pattern Recognition Letters, v. 24, n. 1-3, p. $309-314,2003$.

111 PASCHOS, G. Chromatic correlation features for texture recognition. Pattern Recognition Letters, v. 19, n. 8, p. $643-650,1998$.

112 HOANG, M. A.; GEUSEBROEK, J.-M.; SMEULDERS, A. W. Color texture measurement and segmentation. Signal Processing, v. 85, n. 2, p. $265-$ 275, 2005.

113 DUDA, R. O.; HART, P. E. Pattern classification and scene analysis. New York: Wiley, 1973.

114 EVERITT, B.; DUNN, G. Applied multivariate data analysis. New Jersey: John Wiley \& Sons, 2009.

115 HOTELLING, H. Relations between two sets of variants. Biometrika, v. 28, n. 1, p. 321-377, 1936.

116 TREFETHEN, L. N.; BAU, D. Numerical linear algebra. Philadelphia: SIAM/Society for Industrial and Applied Mathematics, 1997. 
117 GHICOV, A.; TSUCHIYA, H.; MACAK, J. M.; SCHMUKI, P. Titanium oxide nanotubes prepared in phosphate electrolytes. Electrochemistry Communications, v. 7, n. 5, p. 505-509, 2005.

118 TSUCHIYA, H.; MACAK, J. M.; TAVEIRA, L.; BALAUR, E.; GHICOV, A.; SIROTNA, K.; SCHMUKI, P. Self-organized tio2 nanotubes prepared in ammonium fluoride containing acetic acid electrolytes. Electrochemistry Communications, v. 7, n. 6, p. 576-580, 2005.

119 ZLAMAL, M.; MACAK, J. M.; SCHMUKI, P.; KRýSA, J. Electrochemically assisted photocatalysis on self-organized tio2 nanotubes. Electrochemistry Communications, v. 9, n. 12, p. 2822-2826, 2007.

120 BRUNELLA, M.; DIAMANTI, M.; PEDEFERRI, M.; FONZO, F. D.; CASARI, C.; BASSI, A. L. Photocatalytic behavior of different titanium dioxide layers. Thin Solid Films, Amsterdam, v. 515, n. 16 , p. 6309-6313, 2007.

121 CAI, Q.; YANG, L.; YU, Y. Investigations on the self-organized growth of tio2 nanotube arrays by anodic oxidization. Thin Solid Films, Amsterdam, v. 515, n. 4, p. 1802-1806, 2006.

122 MACÁK, J. M.; TSUCHIYA, H.; GHICOV, A.; SCHMUKI, P. Dye-sensitized anodic tio2 nanotubes. Electrochemistry Communications, v. 7, n. 11, p. 1133-1137, 2005.

123 SIKORA, M. D. S.; ROSARIO, A. V.; PEREIRA, E. C.; PAIVA-SANTOS, C. O. Influence of the morphology and microstructure on the photocatalytic properties of titanium oxide films obtained by sparking anodization in h3po4. Electrochimica Acta, v. 56, n. 9, p. 3122-3127, 2011.

124 XAGAS, A. P.; ANDROULAKI, E.; HISKIA, A.; FALARAS, P. Preparation, fractal surface morphology and photocatalytic properties of tio2 films. Thin Solid Films, v. 357, n. 2, p. $173-178,1999$.

125 PROVATA, A.; FALARAS, P.; XAGAS, A. Fractal features of titanium oxide surfaces. Chemical Physics Letters, v. 297, n. 5-6, p. 484-490, 1998.

126 RICHARDSON, L. F. The problem of contiguity: An appendix to Statistic of Deadly Quarrels. General systems: Yearbook of the Society for the Advancement of General Systems Theory., v. 6, n. 139, p. 139-187, 1961.

127 AVNIR, D.; BIHAM, O.; LIDAR, D.; MALCAI, O. Is the Geometry of Nature Fractal?. Science., v. 279 , n. 5347 , p. 39-40, 1998.

128 MANDELBROT, M. Is Nature Fractal? (letters). Science., v. 279, n. 5352, p. 783-783, 1998. 